\title{
Updated Generation IV Reactors Integrated Materials Technology Program Plan Revision 2
}

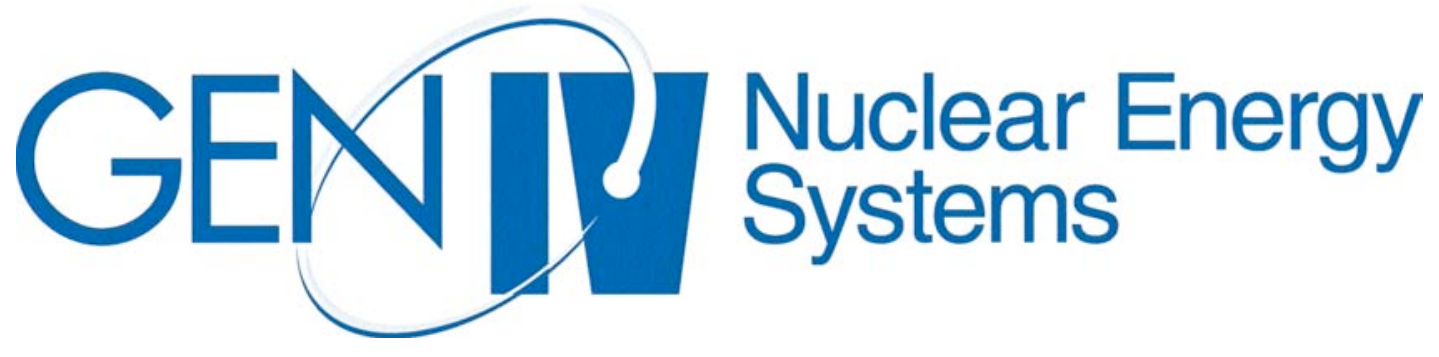

William R. Corwin, ORNL

Timothy D. Burchell, ORNL

William G. Halsey, LLNL

George O. Hayner, INL

Yutai Katoh, ORNL James W. Klett, ORNL

Timothy E. McGreevy, ORNL

Randy K. Nanstad, ORNL

Weiju Ren, ORNL

Lance L. Snead, ORNL

Roger E. Stoller, ORNL

Dane F. Wilson, ORNL 


\title{
Updated Generation IV Reactors Integrated Materials Program Plan
} Revision 2

\author{
William R. Corwin \\ Timothy D. Burchell \\ William G. Halsey \\ George O. Hayner \\ Yutai Katoh \\ James W. Klett \\ Timothy E. McGreevy \\ Randy K. Nanstad \\ Weiju Ren \\ Lance L. Snead \\ Roger E. Stoller \\ Dane F. Wilson
}

Date Submitted - December 31, 2005

\author{
Compiled by \\ P. J. Hadley \\ Prepared for \\ Office of Nuclear Science and Technology \\ AF3410000 \\ Prepared by \\ OAK RIDGE NATIONAL LABORATORY \\ Oak Ridge, Tennessee 37831-6285 \\ managed by \\ UT-BATTELLE, LLC \\ for the \\ U.S. DEPARTMENT OF ENERGY \\ Under contract DE-AC05-00OR22725
}




\section{Table of Contents}

Table of Contents

Figures .

Tables.

Acronyms

Acknowledgements .

Executive Summary.

1.0 Introduction .

1.1 Integrated Materials R\&D Program

2.0 Reactor Concepts Materials Requirements

2.1 Materials Requirements for NGNP

2.1.1 NGNP Component Description and Operation Condition

2.1.1.1 Core Internals and Pressure Vessels

2.1.1.2 Intermediate Heat Exchanger

2.2 Materials Requirements for the SCWR

2.2.1 SCWR Component Description and Operation Conditions

2.2.1.1 SCWR Pressure Vessel .

2.2.1.2 SCWR Core and Fuel Assembly Design .

2.2.1.3 SCWR Pressure Vessel Internals

2.2.1.4 SCWR Power Conversion System

2.3 Materials Requirements for the LFR .

2.3.1 LFR Component Description and Operation Conditions . . . . . . . . . . . . . 24

2.3.1.1 LFR Reactor Vessel.

2.3.1.2 LFR Vessel Internal Components

2.3.1.3 LFR Fuel and Cladding .

2.3.1.4 LFR Heat Exchanges/Steam Generators.

2.3.1.5 LFR Energy Conversion.

2.4 Materials Requirements for the GFR.

2.4.1.1 Operating Conditions for Nonmetallic Core Components and Reactor Internals . . . 33

2.4.1.2 Operating Conditions for Metallic Core Components and Reactor Internals . . . . . $\quad$. 33

2.4.1.3 Operating Conditions for Reactor Pressure Vessel . . . . . . . . . . . . . . . . $\quad .34$

2.4.1.4 Operating Conditions for High Temperature Metallic Components. . . . . . . . $\quad 36$

2.4.1.5 Operating Conditions for Power Conversion Components. . . . . . . . . . . . . 36

2.4.1.6 General Materials Compatibility Considerations in GFR Environments . . . . . 36

2.4.1.7 High-Temperature Design Methodology Considerations . . . . . . . . . $\quad 38$

$2.5 \quad$ Materials Requirements for Nuclear Hydrogen Generation Systems . . . . . . $\quad 39$

2.5.1 Nuclear Hydrogen Generation System Descriptions . . . . . . . . . . . 40

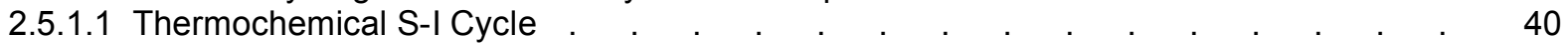

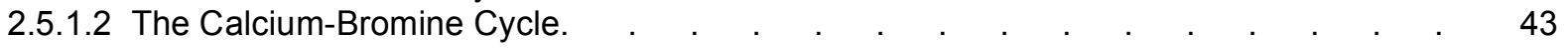

2.5.1.3 High-Temperature Electrolysis . . . . . . . . . . . . . . . . . . . . . . . . . . . . . $\quad . \quad 45$

3.0 Potential Candidate Materials Selections and Research Plans for Gen IV Reactors . $\quad .47$

3.1 Potential Candidate Materials Selections and Research Plans for NGNP . . . . . $\quad 48$

3.1.1 General Considerations for NGNP Materials Research . . . . . . . . . . . 48

3.1.1.1 Irradiation . . . . . . . . . . . . . . . . . . . . . . . . . . . . . . . . . . . 48

3.1.1.2 High-Temperature Exposure . . . . . . . . . . . . . . . . . . . . . . . . 49

3.1.1.3 Helium Gas Cooled Reactor Environment .......... . 50

3.1.2 NGNP High-Temperature Metallic Components . . . . . . . . . . . . . . 51

3.1.2.1 Reactor Pressure Vessel System Materials Selection and Issues . . . . . . . . . $\quad 51$

3.1.2.2 Metallic Reactor Internals Material Selection and Issues . . . . . . . . . . . . $\quad . \quad 58$

3.1.2.3 Intermediate Heat Exchanger Materials Selection and Issues . . . . . . . . . . 63

3.1.2.4 Recuperator, Piping, and Valve Materials Selection and Issues . . . . . . . . . 65

3.1.2.5 Power Conversion System Materials Selection and Issues ...... . 66

3.1.2.6 High-Temperature Structural Design Technology . . . . . . . . . . . . . . . . . . 69

3.1.3 NGNP High-Temperature Non-Metallic Components . . . . . . . . . . . . 86 


\section{Table of Contents (con't)}

3.1.3.1 Materials Selection and Issues for Reactor Core Graphite, Reflector, and Supports $\quad$. $\quad 86$

3.1.3.2 Ceramic Materials Selection and Issues for Thermal Insulation . . . . . . . . . . . 94

3.1.3.3 Reactor Structural Composites Materials Selection and Issues ～. . . . . . . . . $\quad 97$

3.2 Potential Candidate Materials Selections and Research Plans for SCWR . . . . . 106

3.2.1 General Considerations for SCWR Materials Research . . . . . . . . . 106

3.2.1.1 Water Chemistry and Corrosion Issues in SCWRs . . . . . . . . . . . . . . . 106

3.2.2 Reactor Pressure Vessel Materials Selection and Issues . . . . . . . . . . . . . $\quad 109$

3.2.2.1 Expected Research, Testing, and Qualification Needs for SCWR RPV Materials . . 111

3.2.2.2 Experimental RPV R\&D Plans . . . . . . . . . . . . . . . . . . . . . . $\quad$.

3.2.3 RPV Internals Materials Selection and Issues _ . . . . . . . . . . . . . . $\quad . \quad 113$

3.2.3.1 Expected Research, Testing, and Qualification Needs for SCWR RPV Internals Materials 117

3.2.3.2 Experimental Reactor Internals Materials R\&D Plans . . . . . . . . . . . . . $\quad$. 120

3.2.4 Pump, Piping, and Valve Materials Selection and Issues . . . . . . . . . . . . 121

3.2.4.1 Expected Research, Testing, and Qualification Needs for Pump, Piping, Value Materials . . . . . . . . . . . . . . . . . . . . . . . . . 123

3.2.4.2 Experimental R\&D Plans for Pump, Piping, and Valve Materials . . . . . . . . $\quad 123$

3.2.5 Power Conversion System Materials Selection and Issues _ . . . . . . . . . 124

3.2.5.1 Turbines . . . . . . . . . . . . . . . . . . . . . . . . . . . . . . . . . . . 124

3.2.5.2 Condensers. . . . . . . . . . . . . . . . . . . . . . . . . . . . . 126

3.2.5.3 Expected Research, Testing, and Qualification Needs for PCS Materials . . . . . $\quad 127$

3.2.5.4 Experimental PCS Materials R\&D Plans . . . . . . . . . . . . . . . . . . . $\quad 128$

3.3 Potential Candidate Materials Selections and Research Plans for LFR . . . . $\quad$. 129

3.3.1 General Considerations for LFR Materials Research . . . . . . . . . . . . 129

3.3.1.1 Materials Compatibility and Corrosion with $\mathrm{Pb}$ and Pb-Coolants in LFRs . . . . . $\quad 130$

3.3.1.2 Materials for In-Core Use for the SSTAR LFR Concept . . . . . . . . . . . . 131

3.3.2 Cladding Materials Selection and Issues . . . . . . . . . . . . . . . . . . . . . . $\quad . \quad 131$

3.3.3 Core Internals Materials Selection and Issues $\quad . \quad$. . . . . . . . . . . . . . . . . $\quad . \quad 139$

3.3.4 Reactor Vessel Materials Selection and Issues . . . . . . . . . . . . . . . . . . $\quad . \quad 139$

3.3.5 Heat Exchangers Materials Selection and Issues. . . . . . . . . . . . . . . $\quad . \quad 143$

3.3.6 Balance-of-Plant Materials Selection and Issues . . . . . . . . . . . . . . . . $\quad . \quad 144$

3.3.7 Expected Research, Testing, and Qualification Needs for LFR Materials . . . . . $\quad 144$

3.3.7.1 Survey and Selection of Candidate Cladding, Duct, and Structural Materials-Mechanical and Corrosion Performance . . . . . . . . . . 144

3.3.7.2 Lead/LBE Corrosion Testing of Candidate Cladding, Duct, and Structural Materials $\quad$. 144

3.3.7.3 Irradiation Testing of Candidate Cladding, Duct, and Structural Materials . . . . $\quad$. 145

3.3.7.4 High-Temperature Design Methods . . . . . . . . . . . . . . . . . $\quad . \quad 145$

3.3.7.5 Materials Modeling . . . . . . . . . . . . . . . . . . . . . . . . $\quad . \quad 145$

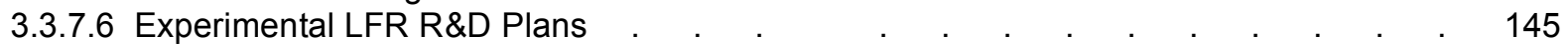

$3.4 \quad$ Potential Candidate Materials Selections and Research Plans for GFR . . . . . $\quad 147$

3.4.1 Nonmetallic GFR Core and Reactor Internals Materials Section and Issues ～. . . . 147

3.4.1.1 Expected Research, Testing, and Qualification Needs for Nonmetallic GFR Core
and Reactor Internals Applications . . . . . . . . . . . . . . . .

3.4.1.2 Experimental Ceramics Core and Internals R\&D Plans . . . . . . . . . . $\quad . \quad 150$

3.4.2 Metallic GFR Core and Reactor Internals Materials Section and Issues . . . . . 150

3.4.2.1 Expected Research, Testing, and Qualification Needs for Metallic GFR Core and Reactor Internals Applications . . . . . . . . . . . . . . . . . 152

3.4.2.2 Experimental Metallic Core and Internals R\&D Plans . . . . . . . . . . . $\quad 153$

3.4.3 RPV Materials Section and Issues . . . . . . . . . . . . . . . . . . . . . $\quad . \quad 154$

3.4.3.1 Expected Research, Testing, and Qualification Needs for GFR RPV . . . . . . . $\quad 154$

3.4.3.2 Experimental Reactor Pressure Vessel Materials R\&D Plans . . . . . . . . . $\quad 155$

3.4.4 High Temperature Metallic Components Materials Selection and Issues . . . . . 156

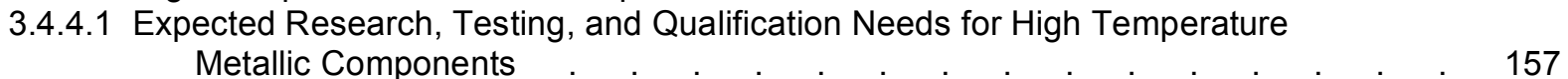

3.4.4.2 Experimental High-Temperature Metallic Materials R\&D Plans ～. . . . . . . 158 


\section{Table of Contents (con't)}

3.4.5 Power Conversion Components Materials Selection and Issues . . . . . . . $\quad 159$

3.4.5.1 Expected Research, Testing, and Qualification Needs for Power Conversion Components . . . . . . . . . . . . . . . . . . 160

3.4.5.2 Experimental Conversion System Materials R\&D Plans _. . . . . . . . . . $\quad$. 160

3.4.6 Materials Compatibility Considerations to Establish Feasibility of GFR ～. . . . . 161

3.4.6.1 Experimental Materials Compatibility R\&D Plans . . . . . . . . . . . . . . $\quad . \quad 162$

3.4.7 Required HTDM Experimental and Analytical Activities for GFR . . . . . . . $\quad 163$

3.4.7.1 Experimental HTDM R\&D Plans . . . . . . . . . . . . . . . . . . . . . . .164

Potential Candidate Materials Sections and Research Plans for Nuclear Hydrogen
Systems

3.5.1 Potential Candidate Materials and Research Needs for SI System Components . . 165

3.5.1.1 Operating Conditions and Candidate Materials for SI System Components . . . $\quad 165$

3.5.1.2 Prioritized Research Needs for SI System Components . . . . . . . . . . . $\quad . \quad 165$

3.5.2 Potential Candidate Materials and Research Needs for Ca-Br System Components . 169

3.5.2.1 Operating Conditions and Candidate Materials for Ca-Br System Components . . 169

3.5.2.2 Prioritized Materials Research Needs for Ca-Br System Components . . . . . . $\quad . \quad 171$

3.5.3 Potential Candidate Materials and Research Needs for HTE System Components $\quad$. 172

3.5.3.1 Operating Conditions and Candidate Materials for HTE System Components . . . 172

3.5.3.2 Prioritized Materials Research Needs for HTE System Components . . . . . . $\quad$. 174

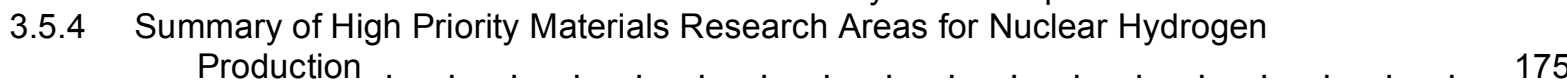

3.5.4.1 High-Priority Materials R\&D for the SI System $\quad$. $\quad . \quad$. . . . . . . . . . . . $\quad$. 176

3.5.4.2 High-Priority Materials R\&D for the Ca-Br System . . . . . . . . . . . . . $\quad . \quad 176$

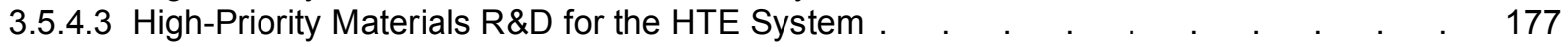

3.5.5 Schedule and Funding Requirements for Nuclear Hydrogen Production Materials . $\quad$. 177

4.0 Crosscutting Materials Research Program . . . . . . . . . . . . . . 181

4.1 Qualification of Materials for Radiation Service . . . . . . . . . . . . . $\quad . \quad 182$

4.2 Qualification of Materials for High-Temperature Service . . . . . . . . . 183

4.3 Microstructural Analysis and Model Development $\quad . \quad$. . . . . . . . . . . $\quad . \quad 185$

4.3.1 Fundamental Materials Issues in the Fission Reactor Environment . . . . . . 186

4.3.2 Accelerting Progress in Materials Research . . . . . . . . . . . . . . . . 187

4.4 Development of Improved High-Temperature Design Methodology ～. . . . . . 187

4.5 System-Specific Materials . . . . . . . . . . . . . . . . . . . . . . . . $\quad . \quad 190$

4.6 National Materials Technology Program Integration . . . . . . . . . . . . 191

4.7 Experimental R\&D Plans for Crosscutting Materials . . . . . . . . . . . . . 192

5.0 Gen IV Materials Funding Requirements . . . . . . . . . . . . . . 199 


\section{Figures}

Figure 1

Figure 2

Figure 3

Figure 4

Figure 5

Figure 6

Figure 7

Figure 8

Figure 9

Figure 10

Figure 11

Figure 12

Figure 13

Figure 14

Figure 15

Figure 16

Figure 17

Figure 18

Figure 19

Figure 20

Figure 21

Figure 22

Figure 23

Figure 24

Figure 25

Figure 26

Figure 27

Figure 28

Figure 29

Figure 30

Figure 31

Figure 32

Figure 33

Figure 34
GT-MHR Core Internals

The graphite core internals of the PBMR

GT-MHR Full Section

GT-MHR Reactor Vessel

GT-MHR Cross Vessel

GT-MHR Power Conversion Vessel

GT-MHR Core Barrel

GT-MHR Control Rod Concept

PBMR Pressure Boundary

PBMR Reactor Unit Vessel Assembly

Representation of the current reactor pressure vessel design

Sketch of the reference SCWR core

The SCWR fuel assembly with metal water rod boxes

Schematic view of SSTAR LFR with natural circulation

Schematic illustration of SSTAR coupled to the $\mathrm{S}-\mathrm{CO}_{2}$ Brayton Cycle showing

normal, shutdown, and emergency heat transfer paths

The gas-cooled fast reactor concept

Main components of the gas-cooled fast reactor concept

The coupled chemical reactions of the SI cycle

Simplified diagram showing principle features of $\mathrm{Ca}-\mathrm{Br}$ water-splitting cycle

Simplified diagram of a high-temperature electrolysis plant

Components of solid oxide cell used for high-temperature electrolysis

Flow chart for visualization of interdependency of tasks within high temperature design methodology project

Dimensions (inches) of several simply notched structures

Dimensions (inches) and cross-section of sphere/nozzle and cylinder/nozzle intersection

Beams, plates, and flathead structures with uniformly distributed loads were investigated (dimensions in inches)

Comparison of predicted creep lives at constant reference stress for notched specimens, pressure vessel components, beams, and plates.

Estimated temperature range of candidate alloys based on mechanical properties and dimensional stability considerations only (no corrosion consideration)

Swelling observed in HT9 and 9Cr-1Mo steels irradiated in FFTF to 208 dpa at $\sim 400^{\circ} \mathrm{C}$

Strain-stress curve for HT9 F/M type steels at high $\mathrm{T} \sim 650^{\circ} \mathrm{C}$ (blue line), Total Thermal Creep Strain Criterion (red line)

Cladding hoop stress decreases with increasing plenum height (black line). Maximum Stress Value of $11 \mathrm{MPa}$ (straight line)

Larson-Miller curve for T91 (mod. 9Cr-1Mo) as compared to other F/M steels

Larson-Miller diagram for the creep-rupture strength of four ODS steels and a conventional ferritic/martensitic steel

Temperature-dependent irradiation creep compliance of MA957 and HT9 during irradiation

Percent increase in yield stress [3.35] reported in AFCI Semi-annual Meeting for HT9 specimens irradiated in FFTF MOTA 2A experiment (cross) as compared to those obtained from previously reported results of HT9 specimens irradiated in Osiris (3.4 dpa) and Sandvik HT9 (12Cr-1MoVW) irradiated in FFTF (7dpa) 


\section{Figures (con't)}

Figure $35 \quad$ Range of temperatures and doses covered by the FFTF LMR tensile database. Note the high dose (up to $200 \mathrm{dpa}$ ) achieved by the FFTF samples irradiated at $400^{\circ} \mathrm{C}$ (triangles)

Figure 36 Ductile-to-brittle transition temperature shift as a function of neutron dose for $12 \mathrm{Cr}-1 \mathrm{MoW}$ (circle) and $9 \mathrm{Cr}-1 \mathrm{MoVNb}$ (triangle) steels. Irradiations carried out at FFTF at $\mathrm{T}_{\text {irr }}=365^{\circ} \mathrm{C}$

Figure 37 Embrittlement decreases as irradiation temperature increases for both HT9 (square) and T91 (circle) steels irradiated to 68 and $110 \mathrm{dpa}$ at Phenix 


\section{Tables}

Table 1

Table 2

Table 3

Table 4

Table 5

Table 6

Table 7

Table 8

Table 9

Table 10

Table 11

Table 12

Table 13

Table 14

Table 15

Table 16

Table 17

Table 18

Table 19

Table 20

Table 21

Table 22

Table 23

Table 24

Table 25

Table 26

Table 27

Table 28

Table 29

Table 30

Table 31

Table 32

Table 33

Table 34

Table 35

Table 36
Comparison of nominal parameters for prismatic and pebble bed design Reference reactor pressure vessel design for the U.S. Generation-IV SCWR Reference fuel assembly design for the U.S. Generation-IV SCWR Reference fuel pin dimensions for the U.S. Generation-IV SCWR SSTAR operating conditions Target design parameters for the GFR system Normal and off-normal conditions for GFR vessel, core, and internals Composition of helium environments (advanced HTGR) used in past tests Reactor pressure vessel system operating conditions affecting candidate material selection for the NGNP

Conditions affecting materials selection for high-temperature metallic NGNP components

Potential candidate materials selection for high-temperature metallic NGNP components

Operating conditions affecting candidate material selection for NGNP higher temperature PCS components and potential candidate materials

Current subsection $\mathrm{NH}$ materials and maximum allowable times and temperatures

Candidate graphites for the core components of the NGNP

Conditions affecting materials selection for reactor internals thermal insulation and potential candidate NGNP materials

Conditions affecting materials selection for structural composites and potential candidate NGNP materials

Relative strengths of ceramic composite materials for NGNP applications

HFIR irradiation matrix

Typical primary water chemistry of supercritical fossil plants and LWRs

Operating conditions and candidate materials for the in-core reactor components of the SCWR. All components listed are part of replaceable fuel assembly Operating conditions and candidate materials for the core structural support reactor components of the SCWR

Summary of alloy candidates for steam turbines

Summary of alloy candidates for condenser circuit

Evolution of Ferritic/Martensitic steels for power-generation industry

Candidate Alloys for LFR cladding

Recent tensile test results of FFTF specimens

Maturity of ceramics for GFR applications

Schedule and summary costs for GFR core and internals ceramics research

Schedule for GFR metallic internals research

Schedule for GFR RPV research

Primary potential candidate materials for high-temperature metallic GFR components

Secondary potential candidate materials for high-temperature metallic GFR components

Testing temperatures and environments for GFR potential candidate hightemperature alloys

Schedule for GFR high-temperature metallic components research

Power conversion system materials compatibility test matrix for alternate GFR designs

Schedule for GFR power conversion materials research 


\section{Tables (con't)}

Table $37 \quad$ Environmental materials test matrix

Table $38 \quad$ Schedule for GFR materials compatibility research

Table 39 Schedule for GFR high-temperature design methodology research

Table $40 \quad$ Operating conditions and materials candidates for major sections of an SI nuclear hydrogen generation plant $(a, b$, and $c)$

Table $41 \quad$ Operating conditions and materials candidates in a $\mathrm{Ca}-\mathrm{Br}$ plant

Table $42 \quad$ Operating conditions and materials candidates in a HTE plant

Table 43 Summary of high priority materials research issues for the $\mathrm{NHI}$ program

Table $44 \quad$ Generation IV reactor concepts, coolant temperatures, and representative candidate structural materials

Table $45 \quad$ FY06 funding for Gen IV Reactor materials R\&D (K\$) 


\section{Acronyms}

\begin{tabular}{|c|c|}
\hline $\begin{array}{l}\text { ACRS } \\
\text { ADS }\end{array}$ & $\begin{array}{l}\text { Advisory Committee on Reactor Safeguards } \\
\text { accelerator driven systems }\end{array}$ \\
\hline $\begin{array}{l}\text { AFCl } \\
\text { AGCNR }\end{array}$ & $\begin{array}{l}\text { advanced fuel cycle initiative } \\
\text { advanced gas cooled nuclear reactor }\end{array}$ \\
\hline AGR & advanced gas-cooled reactor \\
\hline ASME & American Society for Mechanical Engineers \\
\hline ASTM & American Society for Testing and Materials \\
\hline ATR & advanced test reactor \\
\hline AVR & Albeitsgemeinshaft Versuchsreakton \\
\hline AVT & all-volatile treatment \\
\hline BNCS & Board of Nuclear Codes and Standards \\
\hline BWR & boiling water reactor \\
\hline $\mathrm{C}_{f} / \mathrm{C}$ & carbon/carbon \\
\hline CEN & Comit Europen de Normalization \\
\hline CERT & controlled extension rate tests \\
\hline CMCs & ceramic matrix composites \\
\hline CRBRP & Clinch River Breeder Reactor Plant \\
\hline CV & cross vessel \\
\hline DBTT & ductile-brittle transition temperature \\
\hline DLOF & decompression loss of flow \\
\hline DOE & The Department of Energy \\
\hline DOE-FE & DOE's Office of Fossil Energy \\
\hline dpa & displacement per atom \\
\hline EAC & environmentally assisted cracking \\
\hline EBR-II & Experimental Breeder Reactor No. 2 \\
\hline ECP & electro chemical potential \\
\hline FBR & Fast Breeder Reactor \\
\hline F/M & ferritic/martensitic \\
\hline FAC & flow-assisted corrosion \\
\hline FFTF & fast flux test facility \\
\hline GA & General Atomics \\
\hline GFR & gas-cooled fast reactor \\
\hline $\begin{array}{l}\text { GIF } \\
\text { GT-MHR }\end{array}$ & $\begin{array}{l}\text { Generation IV International Forum } \\
\text { gas turbine-modular high-temperature gas-cooled reactor }\end{array}$ \\
\hline $\begin{array}{l}\text { HFIR } \\
\text { HHT }\end{array}$ & $\begin{array}{l}\text { High Flux Isotope Reactor } \\
\text { high-temperature helium turbine systems }\end{array}$ \\
\hline HPC & high-pressure compressor \\
\hline HTDM & high-temperature design methodology \\
\hline HTE & high-temperature electrolysis \\
\hline HTGR & high temperature gas cooled reactor \\
\hline HTR & high temperature reactor \\
\hline HTSD & high temperature structural design \\
\hline $\begin{array}{l}\text { HTTR } \\
\text { HX }\end{array}$ & high temperature test reactor \\
\hline IAEA & International Atomic Energy Agency \\
\hline IASCC & irradiation-assisted stress corrosion cracking \\
\hline IGSCC & intergranular stress corrosion cracking \\
\hline IGRDM & International Group on Radiation Damage Mechanisms \\
\hline
\end{tabular}




\section{Acronyms (con't)}

$\begin{array}{ll}\text { IHX } & \text { intermediate heat exchanger } \\ \text { INERI } & \text { International Nuclear Energy Research Initiative } \\ \text { INL } & \text { Idaho National Laboratory } \\ \text { ISO } & \text { International Organization for Standardization } \\ \text { JAERI } & \text { Japan Atomic Energy Research Institute } \\ \text { LANL } & \text { Los Alamos National Laboratory } \\ \text { LBB } & \text { leak before break } \\ \text { LBE } & \text { lead-bismuth eutectic } \\ \text { LCP } & \text { lower core plate } \\ \text { LFR } & \text { lead-cooled fast reactor } \\ \text { LMFBR } & \text { liquid metal fast breeder reactor } \\ \text { LMR } & \text { liquid-metal reactor } \\ \text { LOFC } & \text { loss of flow condition } \\ \text { LPC } & \text { low-pressure compressor } \\ \text { LWR } & \text { light water reactor } \\ \text { MMM } & \text { multi-scale modeling } \\ \text { METS } & \text { materials elevated temperature swelling } \\ \text { MSR } & \text { molten salt reactor } \\ \text { NDE } & \text { non-destructive evaluation } \\ \text { NGNP } & \text { Next Generation Nuclear Plant } \\ \text { NHI } & \text { nuclear hydrogen initiative } \\ \text { NPH } & \text { nuclear process heat } \\ \text { NRC } & \text { Nuclear Regulatory Commission } \\ \text { NTD } & \text { National Technical Director } \\ \text { OBES } & \text { Office of Basic Energy Science } \\ \text { ODS } & \text { oxide dispersion strengthened } \\ \text { OFES } & \text { Office of Fusion Energy Science } \\ \text { ORNL } & \text { Oak Ridge National Laboratory } \\ \text { OT } & \text { oxygenated treatment } \\ \text { PBMR } & \text { Pebble Bed Modular Reactor } \\ \text { PBR } & \text { Pebble Bed Reactor } \\ \text { PCHEs } & \text { printed circuit heat exchangers } \\ \text { PCS } & \text { power conversion system } \\ \text { PCV } & \text { power conversion vessel } \\ \text { PIE } & \text { post irradiation examination } \\ \text { PM } & \text { program manager } \\ \text { PMR } & \text { Prismatic Modular Reactor } \\ \text { PNNL } & \text { Pacific Northwest National Laboratory } \\ \text { PNP } & \text { prototype nuclear process heat } \\ \text { PSA } & \text { pressure swing absorption } \\ \text { PWR } & \text { pressurized water reactor } \\ \text { QA } & \text { quality assurance } \\ \text { R\&D } & \text { research and development } \\ \text { RPV } & \text { reactor pressure vessel } \\ \text { S-CO } & \text { supercritical carbon dioxide } \\ \text { SCC } & \text { stress corrosion cracking } \\ \text { SCS } & \text { shutdown cooling system } \\ \text { SCW } & \text { supercritical water } \\ & \end{array}$




\section{Acronyms (con't)}

$\begin{array}{ll}\text { SCWR } & \text { supercritical water reactor } \\ \text { SFR } & \text { sodium-cooled fast reactor } \\ \text { SG-ETD } & \text { subgroup on elevated temperature design } \\ \text { SI } & \text { sulfur iodine } \\ \text { SiC }_{f} / \text { SiC } & \text { silicon-carbide/silicon-carbide } \\ \text { SIMs } & \text { system integration managers } \\ \text { SOFC } & \text { solid oxide fuel cells } \\ \text { SS } & \text { stainless steel } \\ \text { SSTAR } & \text { small secure transportable autonomous reactor } \\ \text { THTR } & \text { Thorium Hochtemperature Reaktor } \\ \text { TRISO } & \text { tri-isotopic } \\ \text { UCS } & \text { upper core support plate } \\ \text { UGS } & \text { upper guide support plate } \\ \text { UK } & \text { United Kingdom } \\ \text { VHTR } & \text { very high temperature reactor }\end{array}$




\section{Acknowledgements}

Many people have provided significant input for the preparation of this document. It is based, in large part, upon several basis documents, primarily including materials for radiation service, materials for high-temperature service, materials assessments, surveys and program plans for the different reactor systems and the microstructural analysis and modeling, and hightemperature structural design methodology crosscutting tasks. Text, tables, and figures from these documents have been incorporated into this report. The sheer number of contributors precludes their all being listed as authors, notwithstanding their significant input. To assist in providing appropriate attribution, those non-authors who contributed input from these and related sources are listed, with many thanks, below.

From Argonne National Laboratory

Tom Wei

From Gulf General Atomic

Gottfried Besenbruch

Lloyd Brown

Malcom LaBar

Russ Vollman

Bunsen Wong

From Idaho National Engineering and Environmental Laboratory

Douglas Crawford

Richard Doctor

Jian Gan

Steve Herring

Jim O'Brien

Mark Petri

Robert Bratton

Paul A. Lessin

Thomas Lillo

Ronald E. Mizia

Charles Park

Finis Southworth

Terry C. Totemeier

Kevan D. Weaver

Wil Windes

Richard Wright

From Los Alamos National Laboratory

Ning Li

From Oak Ridge National Laboratory

James M. Corum

Ronald L. Klueh

Louis K. Mansur

Philip L. Rittenhouse

Arthur K. Rowcliffe

Robert W. Swindeman 


\section{Acknowledgements (con't)}

Peter F. Tortorelli

lan G. Wright

Steven J. Zinkle

From Sandia National Laboratory

Fred Gelbard

Paul Pickard

Gary Polansky

From the University of California, Berkeley

Per Peterson

From the Massachusetts Institute of Technology

Ron Ballinger

Jacapo Buongiorno

From the University of Michigan

Gary S. Was

From the University of Nevada, Las Vegas

Tony Hechanova

Ajit Roy

From the University of Wisconsin

Todd R. Allen

The support and guidance provided in the past year as the Gen IV and NHI Materials Programs were being implemented by Tom O'Conner, Rob Versluis, Sue Lesica, Trevor Cook, John Herczeg, and David Henderson at the DOE Office of Nuclear Engineering, Science, and Technology are also gratefully acknowledged.

The valuable comments received from and the time spent by Lou Mansur and Steve Pawel in reviewing this report in preparation for publication are greatly acknowledged.

Lastly, the professional help provided by Pamela Hadley at the Oak Ridge National Laboratory in compiling and polishing the manuscript for this report is very gratefully acknowledged. 


\section{Executive Summary}

An integrated R\&D program is being conducted to study, qualify, and in some cases, develop materials with required properties for the reactor systems being developed as part the U.S. Department of Energy's Generation IV Reactor Program. The goal of the program is to ensure that the materials research and development (R\&D) needed to support Gen IV applications will comprise a comprehensive and integrated effort to identify and provide the materials data and its interpretation needed for the design and construction of the selected advanced reactor concepts.

For the range of service conditions expected in Gen IV systems, including possible accident scenarios, sufficient data must be developed to demonstrate that the candidate materials meet the following design objectives:

- acceptable dimensional stability including void swelling, thermal creep, irradiation creep, stress relaxation, and growth;

- acceptable strength, ductility, and toughness;

- acceptable resistance to creep rupture, fatigue cracking, creep-fatigue interactions, and helium embrittlement; and

- acceptable chemical compatibility and corrosion resistance (including stress corrosion cracking and irradiation-assisted stress corrosion cracking) in the presence of coolants and process fluids.

Additionally, it will be necessary to develop validated models of microstructure-property relationships to enable predictions of long-term materials behavior to be made with confidence and to develop the high-temperature materials design methodology needed for materials use, codification, and regulatory acceptance.

The major materials issues for the four primary systems being considered within the U.S. Gen IV Reactor Program - the Next Generation Nuclear Plant [NGNP (a very high temperature gascooled reactor)], the Supercritical Water Reactor (SCWR), the Gas-Cooled Fast Reactor (GFR), and the Lead-Cooled Fast Reactor (LFR)—are described along with the R\&D currently planned to address them. Additionally, materials issues and associated R\&D plans for the primary candidate systems that may be deployed to utilize the high-temperature process heat from the Gen IV reactors to produce hydrogen are addressed. These systems include both thermochemical systems and high temperature electrolysis.

The majority of materials-related research within the Gen IV program is focused on NGNP, since it is anticipated to be the first system to be deployed. Major research activities include:

- $\quad$ selection and qualification of graphite for core and core support structures;

- selection and qualification of high-temperature metallic materials for use within the primary circuit, with emphasis on the reactor pressure vessel and the intermediate heat exchangers;

- selection and qualification of structural composites for selected reactor internals that must withstand temperatures in excess of current metallic material capabilities;

- examination of the effects of the environment and long-term thermal aging on candidate materials;

- development of the improved high-temperature design methodology for metallic materials and components needed to meet codification and regulatory requirements; 
- support for development and modification of materials and design codes and standards bodies; and

- coordination with and utilization of related materials research activities being conducted by the international Generation IV reactor community.

The other Gen IV reactor systems will take advantage of the materials research being performed for the NGNP where it overlaps their needs, but will also conduct their own more limited and highly targeted research. Initially this research will be primarily focused on highpriority materials questions related to the viability of their concepts. The SCWR materials research will initially address the question of materials capabilities to withstand the particularly challenging effects of coolant corrosion combined with moderately high radiation doses on reactor internals and core support structures. The GFR materials research will initially address the combined challenges of high radiation doses and high temperatures on reactor internals and core support structures that must be constructed from materials other than graphite to minimize excessive moderation of the hard spectrum the concept requires. The LFR system materials research must address the particularly difficult materials challenges resulting from a very aggressive coolant corrosion chemistry combined with extremely high radiation doses on reactor internals and core structures.

While the materials research needed for the nuclear hydrogen production systems will be conducted within a separate, though related, DOE program, the Nuclear Hydrogen Initiative, many of the materials and issues that must be addressed are similar to those within the Gen IV Program, hence, a concerted effort is made to coordinate materials activities in both programs. Hence, the materials challenges and planned research for the hydrogen production systems are also included in this integrated program description. Since it is anticipated that one or more hydrogen production systems will be deployed as part of the NGNP, the selection and qualification of materials for both the nuclear island and the hydrogen plant must be accomplished in the same time frame. While the specifics of the materials issues vary both with the specific hydrogen generation concept and its individual components, the principal challenges all relate to identifying and qualifying materials that can tolerate both the extremely corrosive environments and high temperatures within the systems.

Lastly, it is recognized that there are several areas of materials technology that are common to all the nuclear systems being developed. Hence, crosscutting materials tasks have been established, where appropriate. Principal areas of technology being currently examined for crosscutting applications include high-temperature materials, materials for radiation service, microstructural analysis and modeling, and high-temperature design methodology.

This report is divided into two principal parts. One part is designed to provide an understanding of the different nuclear systems being considered within the Gen IV Program with regard to the challenges they pose to structural materials. The activities comprising the materials R\&D program that is being conducted to address those challenges is the focus of the later portion of the report. Where credible information on materials research funding profiles is available, assumptions are made regarding both the FY06 and future activities within the materials research program. However, the schedules for research activities identified for out-years are highly dependent upon levels of available resources that are largely not known at this time. Updates on these out-year research activities and their schedules will be provided in subsequent editions of this document. 


\subsection{INTRODUCTION}

The Department of Energy's (DOE's) Generation IV Nuclear Energy Systems Program will address the research and development (R\&D) necessary to support next-generation nuclear energy systems. Such R\&D will be guided by the technology roadmap developed for the Generation IV International Forum (GIF) over two years with the participation of over 100 experts from the GIF countries. The roadmap evaluated over 100 future systems proposed by researchers around the world. The scope of the R\&D described in the roadmap covers the six most promising Generation IV systems. The effort ended in December 2002 with the issue of the final Generation IV Technology Roadmap [1.1].

The six most promising systems identified for next generation nuclear energy are described within the roadmap. Two employ a thermal neutron spectrum with coolants and temperatures that enable hydrogen or electricity production with high efficiency (the Supercritical Water Reactor-SCWR and the Very High Temperature Reactor-VHTR). Three employ a fast neutron spectrum to enable more effective management of actinides through recycling of most components in the discharged fuel (the Gas-cooled Fast Reactor-GFR, the Lead-cooled Fast Reactor-LFR, and the Sodium-cooled Fast Reactor-SFR). The Molten Salt Reactor (MSR) employs a circulating liquid fuel mixture that offers considerable flexibility for recycling actinides, and may provide an alternative to accelerator-driven systems.

A few major technologies have been recognized by DOE as necessary to enable the deployment of the next generation of advanced nuclear reactors, including the development and qualification of the structural materials needed to ensure their safe and reliable operation. Accordingly, DOE has identified materials as one of the focus areas for Gen IV technology development.

\subsection{Integrated Materials R\&D Program}

An integrated R\&D program is being conducted to study, quantify, and in some cases, develop materials with required properties for the reactor systems being developed as part DOE's Gen IV Program. The goal of the National Materials Technology Program is to ensure that the materials research and development needed to support Gen IV applications will comprise a comprehensive and integrated effort to identify and provide the materials data and its interpretation needed for the design and construction of the selected advanced reactor concepts.

For the range of service conditions expected in Gen IV systems, including possible accident scenarios, sufficient data must be developed to demonstrate that the candidate materials meet the following design objectives:

- acceptable dimensional stability including void swelling, thermal creep, irradiation creep, stress relaxation, and growth;

- acceptable strength, ductility, and toughness;

- acceptable resistance to creep rupture, fatigue cracking, creep-fatigue interactions, and helium embrittlement; and

- acceptable chemical compatibility and corrosion resistance (including stress corrosion cracking and irradiation-assisted stress corrosion cracking) in the presence of coolants and process fluids. 
Additionally, it will be necessary to develop validated models of microstructure-property relationships to enable predictions of long-term materials behavior to be made with confidence and to develop the high-temperature materials design methodology needed for materials use, codification, and regulatory acceptance.

To make efficient use of program resources, the development of the required databases and methods for their application will incorporate both the extensive results from historic and ongoing programs in the United States and abroad that address related materials needs. These would include, but not be limited to, DOE, Nuclear Regulatory Commission (NRC), and industry programs on liquid-metal-, gas-, and light-water-cooled reactor, fossil-energy, and fusion materials research programs, as well as similar foreign efforts.

Since many of the materials challenges and potential solutions will be shared by more than one reactor concept, it is necessary to work closely with the system integration managers (SIMs) for the individual reactor concepts to examine the range of requirements for their major components to ascertain what the materials challenges and solutions to those will be for the widely varying materials needs within the Gen IV Program. There will be two primary categories for materials research needs:

- Materials needs that crosscut two or more specific reactor concepts and

- Materials needs specific to one reactor concept or energy conversion technology.

Where there are commonly identified materials needs for more than one concept, a crosscutting technology development activity is being established to address those issues. Where a specific reactor concept has unique materials challenges, those activities are being addressed in conjunction with that particular reactor concept's R\&D. Examples of this category of materials needs include reactor-specific materials compatibility issues associated with a particular coolant and materials used within only one reactor concept, such as graphite within the VHTR [now called the Next Generation Nuclear Plant (NGNP) in the U.S. program]. Also included in the reactor-specific materials category are materials issues that might otherwise be considered crosscutting, except that the schedule requirements established by one reactor are much more pressing than schedules for the other reactors. A large portion of the materials R\&D for the NGNP will fall into this category.

The National Materials Technology Program within the overall DOE Gen IV Program has responsibility for establishing, managing, and executing the integrated plan that addresses cross-cutting, reactor-specific, and energy-conversion materials research needs in a coordinated and prioritized manner. In so doing, it will be critical to work with the SIM for each of the Gen IV reactor concepts, the National Technical Directors (NTDs) for fuel and cladding and for energy conversion systems, and the Program Manager (PM) for Nuclear Hydrogen Inititative (NHI) to gain a detailed understanding of their materials challenges as a basis for developing and executing the research needed to provide the information required to select and qualify the materials needed for their design process.

Four interrelated areas of materials R\&D are generally considered crosscutting: (1) qualification of materials for service within the vessel and core of the reactors that must withstand radiationinduced challenges; (2) qualification of materials for service in the rest of plant that must withstand high-temperature challenges; (3) the development of validated models for predicting long-term, physically based microstructure-property relationships for the high-temperatures, extended-operation periods, and high irradiation doses that will exist in Gen IV reactors; and (4) the development of an updated high-temperature materials design methodology to provide a basis for design, use, and codification of materials under combined time-independent and timedependent loadings. Materials research that has been identified for the individual reactor and 
energy-conversion concepts includes materials compatibility with a particular coolant or heattransfer medium, as well as materials expected to used only within a single reactor or energy conversion system, such as graphite, selectively permeable membranes, catalysts, etc. and those materials needs that must be addressed in a time frame that significantly precedes those in the other reactor concepts.

While the current plan addresses materials issues for all the reactors currently being examined within the Gen IV program, the recognition that the VHTR Gen IV reactor concept will be built as a demonstration of the NGNP by the end of the next decade will strongly drive much of the materials research during the next seven to ten years of the program.

\section{References}

[1.1] U.S. Department of Energy, "A Technology Roadmap for Generation IV Nuclear Energy Systems," Generation IV International Forum, GIF-002-00, December 2002

\subsection{REACTOR CONCEPTS MATERIALS REQUIREMENTS}

Currently, there are only four reactor concepts that are being actively addressed within DOE's Gen IV Program. They are the VHTR (henceforth called NGNP), SCWR, LFR, and GFR. At the present time, other GIF partners are addressing the remaining two Gen IV concepts, the SFR and MSR. Consequently, only needs for the four active reactor systems will be included explicitly within the DOE Gen IV National Materials Technology Program. Additionally, the materials needs for $\mathrm{NHI}$ will be included in the overall integrated program to provide close coordination with and minimize duplication of related reactor materials studies.

As a first step to address the crosscutting and reactor-specific materials needs for each active reactor concept, a survey of those needs was conducted in close cooperation with each reactor SIM. Such surveys have been performed for all active reactor concepts as well as for the NHI nuclear hydrogen production systems.

For each system, the SIM (or NHI PM) and his staff developed as comprehensive a set of component descriptions and their operating conditions as the level of design maturity of their individual system concepts would allow. Based on these descriptions, a set of likely, and where possible, bounding materials requirements were developed. These requirements were then used to formulate a list of potential candidate materials that might have the required capabilities and an initial program plan was developed to screen and, where possible, qualify them for service. As the individual system materials-needs surveys become increasingly mature, their results are being combined to update the integrated materials R\&D program described herein. This is an ongoing process and this document provides the second revision of the overall Gen IV Reactor Materials selections and research plans.

To provide a basis for the integrated materials R\&D program that has been developed, a condensed set of system and component descriptions, along with resulting materials requirements, based on the individual system needs studies, follows [2.1-2.6].

\subsection{Materials Requirements for NGNP}

The U.S. DOE has selected the VHTR design for the NGNP Project. The NGNP reference concept is a helium-cooled, graphite-moderated, thermal neutron spectrum reactor with an 
outlet temperature in the range of 850 to $1000^{\circ} \mathrm{C}$ and a 60 -year operating lifetime. The reactor core is currently envisioned to be a prismatic graphite block type core. However, it is feasible to also consider a pebble-bed type of gas-cooled reactor. The final selection of a reference design will be made in the future. The plant size, reactor thermal power, and core configuration will be designed to ensure passive decay heat removal without fuel damage or radioactive material releases during accidents. The initial fuel cycle will be a once-through use of very high burn-up, low-enriched uranium.

The basic technology for the NGNP has been established in former high-temperature gascooled reactor plants (e.g., DRAGON, Peach Bottom, Albeitsgemeinschaft Versuchsreaktor [AVR], Thorium Hochtemperatur Reaktor [THTR], and Fort St. Vrain). These reactor designs represent two design categories: the Pebble Bed Reactor (PBR) and the Prismatic Modular Reactor (PMR). Commercial examples of potential NGNP candidates are the Gas TurbineModular Helium Reactor (GT-MHR) from General Atomics (GA), the High Temperature Reactor concept (ANTARES) from AREVA, and the Pebble Bed Modular Reactor (PBMR) from PBMR consortium. Furthermore, the Japanese High-Temperature Engineering Test Reactor (HTTR) and Chinese High-Temperature Reactor (HTR) are demonstrating the feasibility of the reactor components and materials needed for NGNP. (The HTTR reached a maximum coolant outlet temperature of $950^{\circ} \mathrm{C}$ in April 2004.) Therefore, the NGNP is focused on building a demonstration plant, rather than simply confirming the basic feasibility of the concept.

Demonstration of hydrogen production may use both electricity and process heat from the reactor. A separate program for development of efficient hydrogen production technologies is operating in parallel with the NGNP Materials R\&D Program.

The operating conditions for the NGNP represent a major departure from existing water-cooled reactor technologies. Although a significant assortment of materials and alloys for hightemperature applications are in use in the petrochemical, metals processing, and aerospace industries, a very limited number of these materials have been tested or qualified for use in nuclear reactor-related systems. Today's high-temperature alloys and associated American Society of Mechanical Engineers (ASME) Codes for reactor applications reach about $800^{\circ} \mathrm{C}$. Some primary system components for the NGNP will require use of materials at temperatures above $800^{\circ} \mathrm{C}$. Such use will require further assessment of existing, well-characterized materials or selection of newer materials for which less data exists. Potential postulated accident conditions with associated temperatures above nominal operational temperatures would dictate the use of composite or ceramic materials within the reactor pressure vessel (RPV). The use of structural ceramics or composites in safety-related reactor components represents a completely new challenge to the nuclear industry.

Selection and qualification of materials for successful and long-life application at the hightemperature conditions planned for the NGNP is the major purpose for the NGNP Materials R\&D Program. Few choices exist for metals or metallic alloys for use at NGNP conditions and the design lifetime considerations for the metallic components may restrict the maximum operating temperature.

Selection of the technology and design configuration for the NGNP must consider both the cost and risk profiles to ensure that the demonstration plant establishes a sound foundation for future commercial deployments. The NGNP challenge is to achieve a significant advancement in nuclear technology while at the same time setting the stage for an economically viable deployment of the new technology in the commercial sector soon after 2020.

The following assumptions are used in estimating the scope, cost, and schedule for completing the materials R\&D processes: 
1. The materials R\&D process will be directed and governed by the Energy Policy Act of 2005. The scope of this work will be adjusted to reflect the level of congressional appropriations.

2. The reactor design has not been formally selected. For the purposes of this document, the design is assumed to be a helium-cooled, prismatic, graphite block core design fueled with tri-isotopic (TRISO)-design fuel particles in carbon-based compacts or a pebble-bed reactor design.

3. The NGNP must demonstrate the capability to obtain a NRC operating license. However, the licensing strategy for the NGNP has not been developed to date. In any case, the design, materials, and construction will need to meet appropriate Quality Assurance (QA) methods and criteria and other nationally recognized codes and standards.

4. The NGNP is expected to be a full-sized reactor plant based on the reactor concept selected (400-600 MWt) with a hydrogen demonstration unit sized to use at least ten percent of the plant output process heat and/or electricity.

5. The demonstration plant will be designed to operate for a nominal 60 years.

6. Application for an NRC operating license and fabrication of the NGNP will occur with direct interaction with one or more DOE-sponsored commercial organizations.

The objectives of the NGNP include:

1. Demonstrate a full-scale prototype VHTR by about 2021

2. Demonstrate high-temperature Brayton Cycle electric power production at full scale with a focus on economic performance

3. Demonstrate nuclear-assisted production of hydrogen (with about $10 \%$ of the heat) with a focus on economic performance

4. Demonstrate by test the exceptional safety capabilities of the advanced gas cooled reactors

5. Obtain an NRC License to construct and operate the NGNP and to provide a basis for future performance-based, risk-informed licensing

6. Support the development, testing, and prototyping of hydrogen infrastructures

An extensive description of the NGNP Materials R\&D Plan has been recently prepared [2.1] that documents the details and sources of the anticipated NGNP configuration and component operating requirements. A condensed version of that information is contained within this document.

\subsubsection{NGNP Component Description and Operating Conditions}

Because no pre-conceptual design currently exists for the NGNP, the GT-MHR design and the PBMR design, developed by the GA and the PBMR Company, respectively, have been used to provide the starting point for the NGNP design. GA and AREVA/Framatome are currently proposing PMR designs and the PBMR Company is currently proposing PBR designs. The GTMHR operational requirements were used to estimate operational requirements for the NGNP by adding estimated deltas to the GT-MHR operational requirements. Therefore, only generic temperatures, neutronics, and conditions or features are contained in this program plan.

The environment expected for the NGNP will be very challenging for the structural materials. The sustained operating temperature may reach $1000^{\circ} \mathrm{C}$ or higher in a helium atmosphere with 
a pressure of $7.5 \mathrm{MPa}$ and flow velocities on the order of $40 \mathrm{~m} / \mathrm{s}$. A pure helium atmosphere would not cause environmental degradation of high-temperature materials, but the helium could be contaminated with gaseous impurities such as $\mathrm{CO}, \mathrm{CO}_{2}, \mathrm{CH}_{4}, \mathrm{H}_{2}, \mathrm{H}_{2} \mathrm{O}$, and $\mathrm{O}_{2}$. A reducing atmosphere, for instance, may be quite aggressive for conventional high-temperature alloys since they are typically designed for an oxidizing environment and designed to form a thin protective $\mathrm{Cr}$ or $\mathrm{Al}$ oxide layer to protect the alloy from attack. High-velocity flowing gases may also contain particulates from abrasion of the graphite or other materials in the system. A particulate-laden, high-velocity gas also raises the potential issue of particle erosion in some components.

To select materials for the NGNP reactor and predict their performance for a time period up to 60 years, it is necessary to identify the degradation mechanism(s) for different gas compositions and determine the kinetics of deterioration. An environmental testing program will determine the corrosion and oxidation performance of candidate alloys and the effect of environmental degradation on mechanical properties. While it might be feasible to predict reactions resulting in alteration of surface chemistry for the gas compositions of interest, the influence of high gas velocity and particle erosion are nearly impossible to predict without appropriate high-velocity testing.

The subsequent discussions in the following section provide information based on the PMR and PBR conceptual designs. However, the actual conceptual design selected for the NGNP could be different from the information noted. Therefore, the information provided should be viewed as illustrative for the materials requirements of the NGNP.

\subsubsection{Core Internals and Pressure Vessels}

Graphite Internals.

In the PMR design, the graphite core is a right circular cylinder composed of 102 columns each containing 10 blocks (Figure 1). The cylinder is arranged in eleven circular rings. The inner reflector uses the first five rings; the active core uses rings six, seven and eight; the outer reflector is composed of rings nine and ten; and ring eleven is the permanent outer reflector. On top of the core column is a reflector block then a half height upper plenum block that caps the column. Below the core column is a bottom reflector block then two half-height insulation graphite blocks. Under each column is a graphite pedestal. The pedestals rest on two additional insulation blocks (graphite or ceramic), which in turn sits on the core support floor.

The top and bottom insulator graphite blocks, upper plenum graphite blocks, and core pedestal supports see low to negligible neutron exposure. The normal operating temperature for the upper blocks is $500^{\circ} \mathrm{C}$ and $1000^{\circ} \mathrm{C}$ for the bottom blocks. The off-normal temperatures for the top blocks are $1200^{\circ} \mathrm{C}$ and $600^{\circ} \mathrm{C}$ for the bottom blocks, due to a flow reversal.

Replaceable outer and inner reflector graphite blocks are placed on the inside and outside of the core ring. The inner reflector sees the highest temperatures and fluences. Peak fluences range from 1.8 to $6.7 \mathrm{E} 20 \mathrm{n} / \mathrm{cm}^{2}(\mathrm{E}>0.1 \mathrm{MeV})$ and 0.16 to 0.56 dpa per year. Temperatures in the outer reflector blocks are $750^{\circ} \mathrm{C}$ for normal conditions and $1100^{\circ} \mathrm{C}$ for off-normal conditions. Peak temperatures in the inner blocks during normal operation conditions are $850^{\circ} \mathrm{C}$ and $1200^{\circ} \mathrm{C}$ during off-normal conditions. 


\section{GT-MHR Core Internals}

(Courtesy of General Atomics)
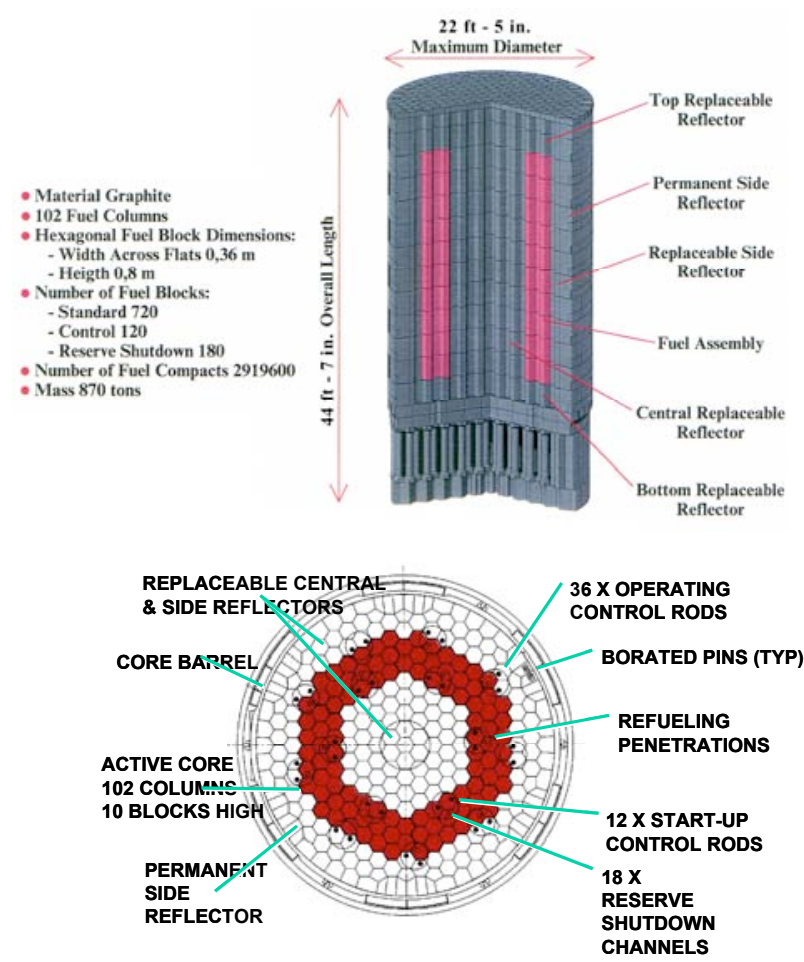

Fig. 1. GT-MHR Core Internals.

The active core fuel blocks see the highest temperatures and fluences of all the graphite components at $9.9 \mathrm{E} 20 \mathrm{n} / \mathrm{cm}^{2}$ or dpa of 0.82 per year. Normal operating temperatures for the fuel blocks are approximately $1250^{\circ} \mathrm{C}$, climbing to approximately $1600^{\circ} \mathrm{C}$ during off-normal conditions.

The graphite internals of the PBMR are illustrated in Figure 2. The annular shaped reactor core, which is composed of a bed of fuel pebbles, is supported by the bottom reflector and is laterally restrained by the central reflector and side reflector. The central and side reflectors are constructed from stacks of large interlocking (keyed) graphite blocks. 


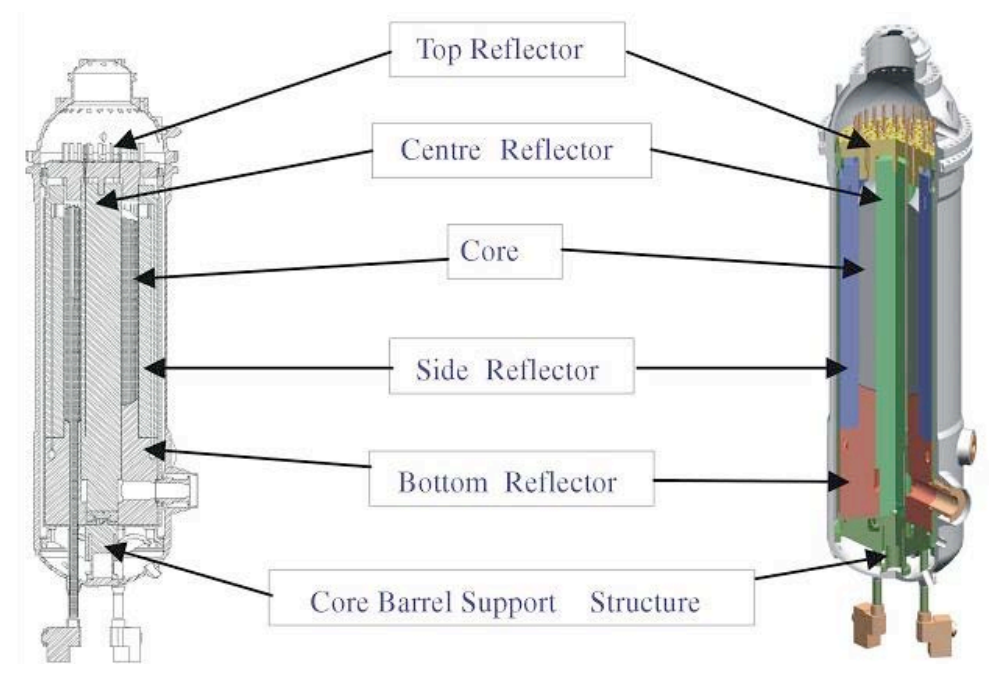

Fig. 2. The graphite core internals of the PBMR.

The currently designated graphite grades for the PBMR core internals are SGL NGB-10 and NGB-12. Both graphites are extruded, pitch coke graphites manufactured at SGL's Chedde facility in France. The pitch coke used is the same as that currently used for the production of the United Kingdom (UK) Advanced Gas Reactor (AGR) graphite fuel sleeves, and thus there is considerable production experience for this coke and graphite. Consideration is also being given to grade NGB-18, a vibrationally molded graphite.

The volume average thermal flux in the core is $7.90 \times 10^{13} \mathrm{n} / \mathrm{cm}^{2} \cdot \mathrm{s}[\mathrm{E}>1.86 \mathrm{eV}]$. The volume average fast flux, which is more relevant since it is fast neutrons that displace carbon atoms and cause the dimensional and property changes, is $3.26 \times 10^{13} \mathrm{n} / \mathrm{cm}^{2} \cdot \mathrm{s}[\mathrm{E}>0.1 \mathrm{MeV}]$. Typical lifetime fast fluences for the PBMR graphite core internals for a 35 effective full power year life are:

- Fuel Pebbles

- Upper reflector edge (maximum)

- Outer reflector side (maximum)

- Inner reflector side (maximum

- Lower reflector edge (maximum)
$2.65 \times 10^{21} \mathrm{n} / \mathrm{cm}^{2}[\mathrm{E}>0.1 \mathrm{MeV}]$

$0.21 \times 10^{22} \mathrm{n} / \mathrm{cm}^{2}[\mathrm{E}>0.1 \mathrm{MeV}]$

$3.85 \times 10^{22} \mathrm{n} / \mathrm{cm}^{2}[\mathrm{E}>0.1 \mathrm{MeV}]$

$4.73 \times 10^{22} \mathrm{n} / \mathrm{cm}^{2}[\mathrm{E}>0.1 \mathrm{MeV}]$

$0.53 \times 10^{22} \mathrm{n} / \mathrm{cm}^{2}[\mathrm{E}>0.1 \mathrm{MeV}]$

The neutron fluence to the central and side reflector is clearly very significant, potentially necessitating their replacement during the life of the reactor. Consequently, the graphite blocks of the central reflector and the inner side reflector are designed to be removable. The average fuel temperature in the PBMR varies axially through the PBMR core. The fuel temperature is $\sim 500^{\circ} \mathrm{C}$ at the top of the core where the coolant gas enters and increases to $\sim 900^{\circ} \mathrm{C}$ at the reactor mid plane.

The peak mean fuel temperature is $\sim 1000^{\circ} \mathrm{C}$ close to the bottom of the core. The PBMR fuel temperature is always less than $1160^{\circ} \mathrm{C}$. The peak graphite temperatures under normal operating conditions are also likely to be $\sim 1000^{\circ} \mathrm{C}$. Consequently, those areas of the core (inner edge of the side reflector and the outer edge of the central reflector column) that experience high temperatures $\left(>600^{\circ} \mathrm{C}\right)$ and high neutron fluence $\left(>3.0 \times 10^{22} \mathrm{n} / \mathrm{cm}^{2}[\mathrm{E}>0.1 \mathrm{MeV}]\right)$ will experience significant distortion due to the irradiation induced shrinkage reversal to growth. 
Temperature and fast neutron fluence gradients will cause differential stresses in the core, which will relax due to irradiation-induced creep of the graphite.

The PBMR core will also utilize carbon-carbon $\left(\mathrm{C}_{f} / \mathrm{C}\right)$ composites. Anticipated applications include the core lateral restraints and the hot gas outlet duct and interface components. Moreover, $\mathrm{C}_{\mathrm{f}} / \mathrm{C}$ composites will be utilized as metal replacements in selected interface components and for thermal expansion compensation of the core. The majority of these applications will be in low neutron fluence areas where the only affected property will be thermal conductivity. However, applications such as control rod cladding (if adopted) would experience greater fluences, and thus undergo dimensional and property changes. The GT-MHR is expected to use $\mathrm{C}_{f} / \mathrm{C}$ composites in a similar manner as the PBMR.

Internals and Pressure Vessels- NGNP Prismatic Design.

The three main vessels in the GT-MHR design, the RPV, cross vessel (CV), and secondary vessel (see Figure 3), represent the pressure boundary of the primary coolant. The GT-MHR uses a closed Brayton cycle to generate electricity where helium coolant flows out of the reactor directly through the main turbine. The helium exiting the main turbine is re-pressurized to the inlet operational conditions and pumped through the reactor. The NGNP PMR design operational inlet helium pressure and temperature for the reactor is less than $490^{\circ} \mathrm{C}$ at a pressure of 7.4 to $8.0 \mathrm{MPa}$. The inlet helium flows between the core barrel and the RPV maintaining the RPV at a cooler temperature than the core. Nominal operating temperature of the RPV wall is $470^{\circ} \mathrm{C}$. The helium exits the reactor core at temperatures less than $1000^{\circ} \mathrm{C}$ at pressures of 7.33 to $7.93 \mathrm{MPa}$. The pressure drop across the core is $\sim 70 \mathrm{kPa}$. Recent system design modifications by GA have been incorporated into their $\mathrm{H} 2-$ Modular Helium Reactor. The prismatic core has an inlet temperature of $590^{\circ} \mathrm{C}$ and an outlet temperature $950^{\circ} \mathrm{C}$ with a primary pressure of $7 \mathrm{MPa}$. By using bypass flow from the high-pressure helium compressor to supplement the inlet flow in reducing the temperature of reactor pressure vessel wall, the vessel wall temperature can be decreased from $480^{\circ} \mathrm{C}$ to $338^{\circ} \mathrm{C}$. 


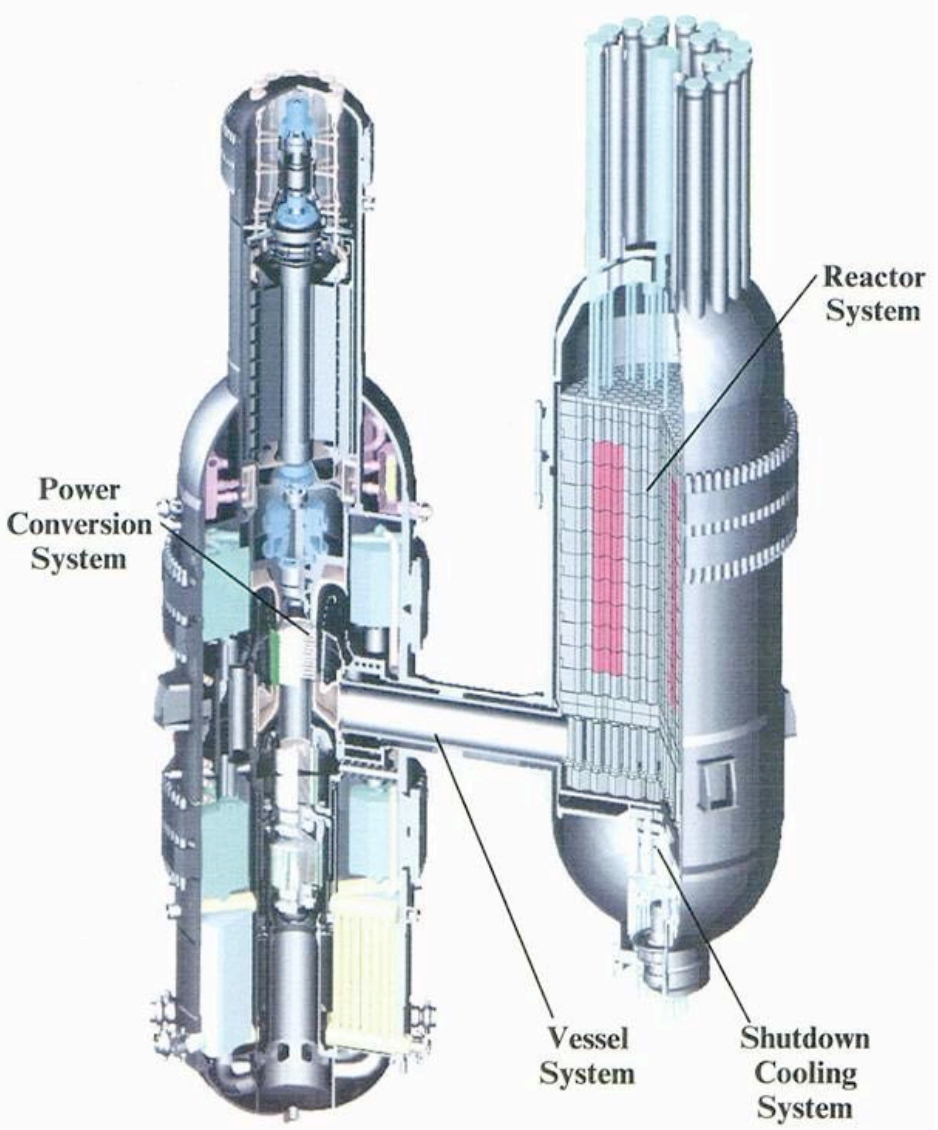

Fig. 3. GT-MHR Full Section.

Figure 3 identifies the components of the RPV. The estimated physical dimension of the RPV is a diameter of less than nine meters with wall thicknesses between $100 \mathrm{~mm}$ and $300 \mathrm{~mm}$. The vessel itself can be made of welded sections of different thicknesses. 


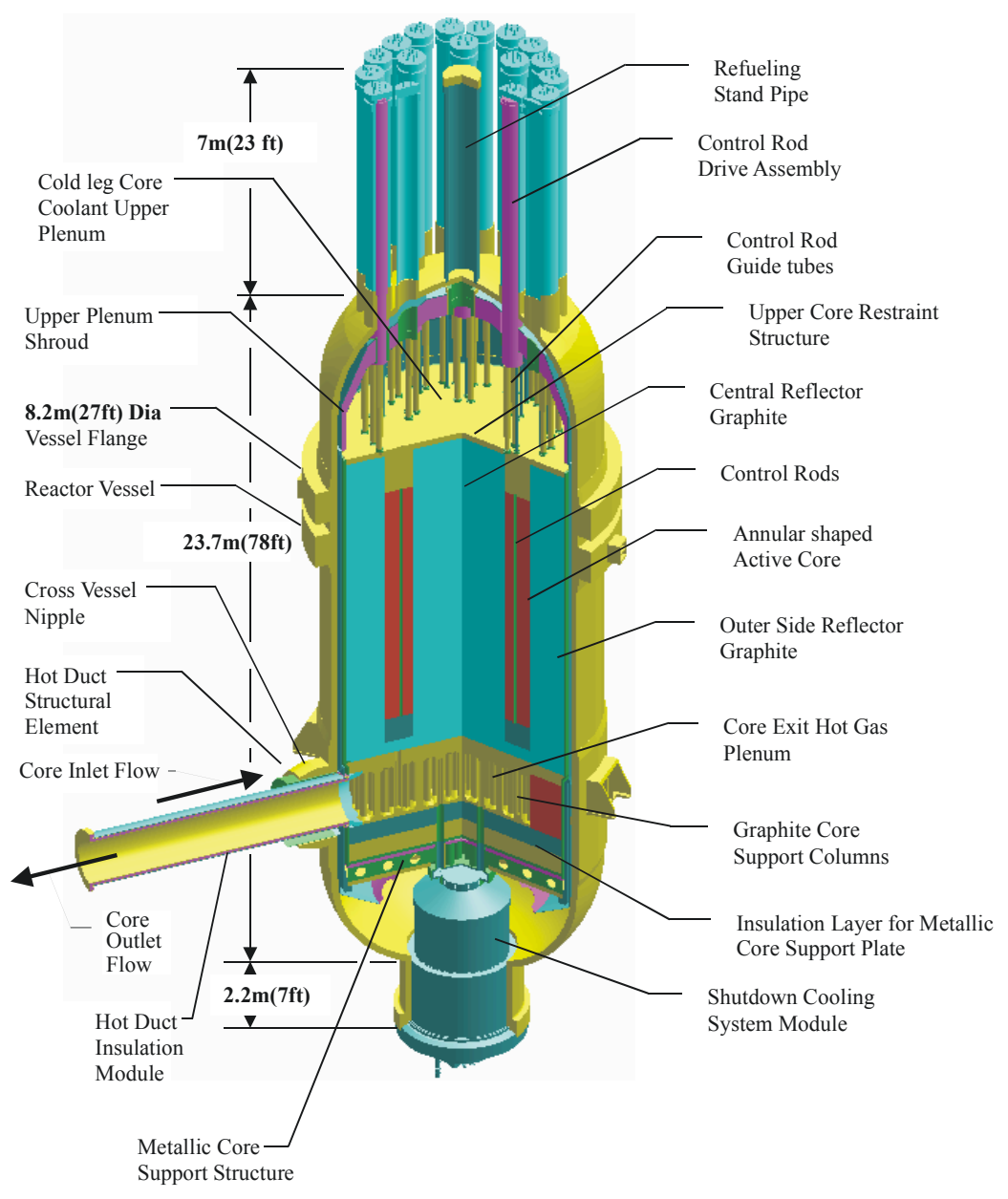

Fig. 4. GT-MHR Reactor Vessel.

The components in the reactor internals system other than graphite that will experience significant radiation exposure are the core barrel, upper plenum shroud, core support floor, upper core restraint, and the shutdown cooling system (SCS; heat exchanger) shell and tubes. The design life of the non-replaceable core internals is 60 years. For some sub-components of those systems where temperatures are excessive, non-metallic materials may be specified. Relative to current light-water reactor (LWR) vessels and internals, the structures in the NGNP will be exposed to relatively low neutron doses. However, because of the significantly higher operating temperatures for the NGNP, the materials for most of the internal structures will not be the same as those for the LWRs for which a vast amount of experience is available. For the NGNP reactor internals, (depending on the specific component) normal operating temperatures may range from 600 to less than $1000^{\circ} \mathrm{C}$. The fluence for the RPV is expected to be $1 \mathrm{E} 19$ $\mathrm{n} / \mathrm{cm}^{2}$ fluence (>0.1 MeV) and the dpa 0.077 for 60 years.

The optimum conditions expected for the RPV for the current commercial reactor designs and their NGNP counterpart are shown in Table 1. Maximum accident RPV temperatures would still reach the Table 1 values for a short time unless active RPV cooling systems are included in the design. 
Table 1. Comparison of Nominal Parameters for Prismatic and Pebble Bed Design [Ref 2.1].

\begin{tabular}{|c|c|c|c|c|c|}
\hline RPV Parameter & GT-MHR & $\begin{array}{c}\text { GA- } \\
\text { Prismatic }\end{array}$ & $\begin{array}{l}\text { Prismatic } \\
\text { NGNP }\end{array}$ & PBMR & NGNP PBR \\
\hline $\begin{array}{l}\text { Nominal Gas Outlet } \\
\text { Temperature }\left({ }^{\circ} \mathrm{C}\right)\end{array}$ & 850 & 950 & 1000 & 900 & 1000 \\
\hline $\begin{array}{l}\text { Nominal Gas Inlet } \\
\text { Temperature }\left({ }^{\circ} \mathrm{C}\right)\end{array}$ & 491 & 590 & 490 & 500 & 490 \\
\hline $\begin{array}{l}\text { RPV Normal Operating } \\
\text { Temperature }\left({ }^{\circ} \mathrm{C}\right)\end{array}$ & 495 & 350 & 470 & 300 & 465 \\
\hline $\begin{array}{l}\text { RPV Worst Case Accident } \\
\text { Temperature }\left({ }^{\circ} \mathrm{C}\right)\end{array}$ & 565 & 530 & 560 & 450 & 560 \\
\hline Inlet Gas Pressure (MPa) & 7.07 & 7.07 & 7.07 & 8.9 & 7 \\
\hline Outlet Gas Pressure (MPa) & 7.02 & 7.02 & 7.02 & 8.6 & $6.5 ?$ \\
\hline $\begin{array}{l}\text { RPV External Diameter } \\
\text { (meters) }\end{array}$ & 8.2 & 8.2 & 8.2 & 7.02 & 7.06 \\
\hline $\begin{array}{l}\text { RPV Nominal Wall } \\
\text { Thickness }(\mathrm{mm})\end{array}$ & $100-300$ & $100-300$ & $100-300$ & $120-220$ & $120-220$ \\
\hline $\begin{array}{l}\text { RPV Nominal Height } \\
\text { (meters) }\end{array}$ & 23.7 & 23.7 & 24 & 27 & 19 \\
\hline $\begin{array}{l}\text { Maximum Radiation Fast } \\
\text { Fluence in the RPV in the } \\
\text { RPV over } 60 \text { years }\left(\mathrm{n} / \mathrm{cm}^{2}\right)\end{array}$ & $3 \times 10^{18}$ & & $1 \times 10^{19}$ & $4.5 \times 10^{19}$ & $3.0 \times 10^{19}$ \\
\hline
\end{tabular}

The cross vessel is the pressure boundary for the exchange of helium between the RPV and power conversion vessel (PCV) (Figure 5). The outside diameter of the vessel is on the order of 2.5 meters with a thickness of less than $100 \mathrm{~mm}$. The cross vessel is welded to the RPV and $\mathrm{PCV}$. To accommodate thermal expansion during operation, the PCV is allowed to slide laterally away from the RPV. The hot helium coolant flows out of the reactor in a structural duct inside the cross vessel and returns from the PCV on the outside of a structural duct, designated the hot duct. The hot duct is insulated from the higher temperature helium by ceramic insulation on the inside surface of the duct. The return helium maintains the cross-vessel wall temperature at $600^{\circ} \mathrm{C}$. The hot duct only sees the pressure differential of the core across its thickness and, protected by the insulation, only slightly higher temperatures than the cross-vessel wall. The hot duct is welded to the core barrel at the lower core plenum outlet and is connected to the PCV by means of a metallic bellows. The hot duct is seal welded to the metallic bellows. The bellows is mechanically connected to the turbine inlet shroud. The fluence and dpa experienced by the cross vessel and hot duct are the same as the RPV and core barrel where the attachment welds are made. The fluence and dpa in the remaining portion of the cross vessel gradually decrease to negligible values at the PCV. 


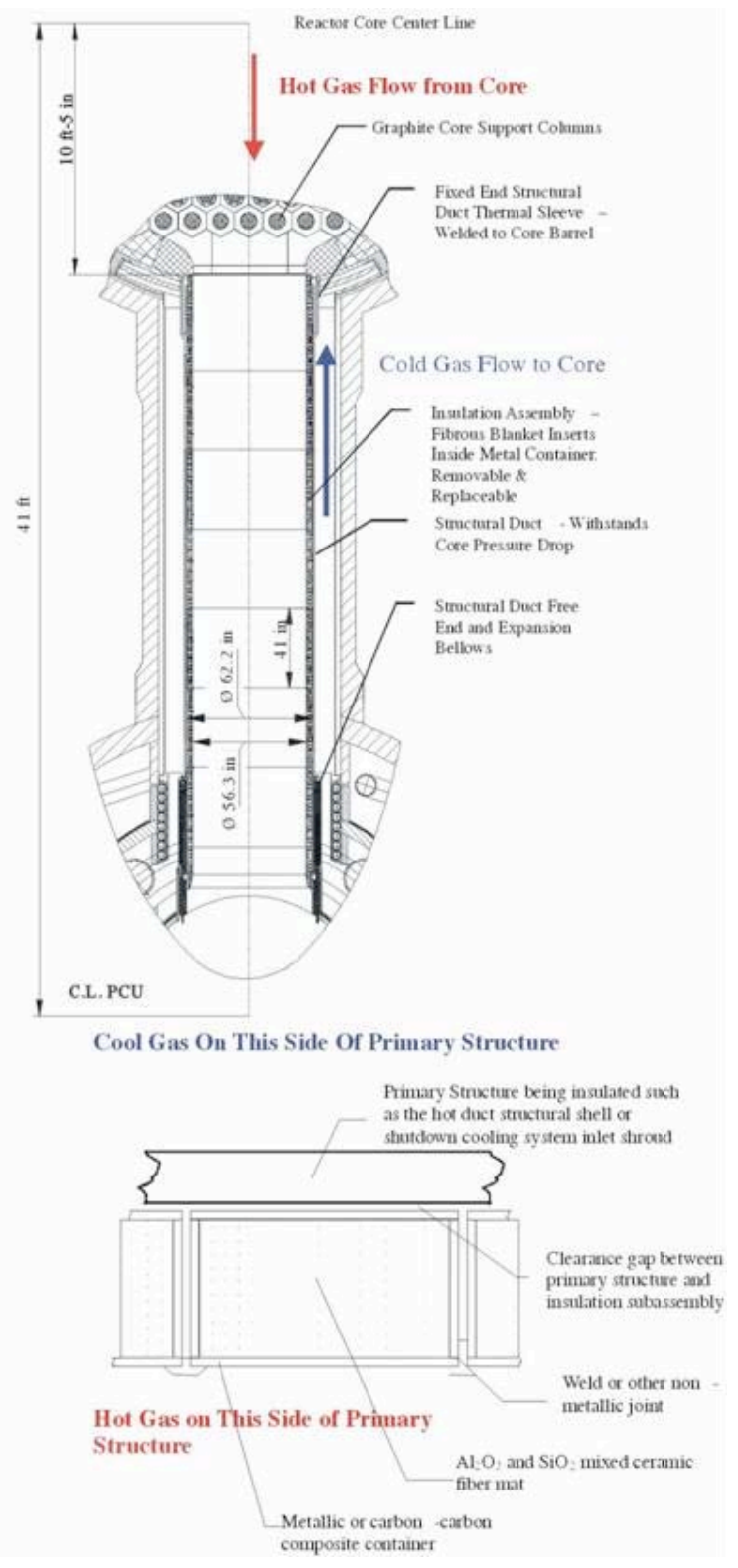

Fig. 5. GT-MHR Cross Vessel.

The power conversion vessel, (Figure 6), houses the main turbine, generator, and associated turbo machinery and heat exchangers. The vessel is on the order of 35 meters tall with outer diameters between 7 and 9 meters. The wall thickness is between 100 and $200 \mathrm{~mm}$. The normal operating temperature for the vessel is $200^{\circ} \mathrm{C}$ with an off-normal temperature of $300^{\circ} \mathrm{C}$ and a design pressure between 5 and $6 \mathrm{MPa}$. The fluence and dpa seen by the PCV is negligible. The only two components that will see the very high temperature reactor outlet helium $\left(<1000^{\circ} \mathrm{C}\right)$ in the PCV are the metallic bellows and a small portion of the turbine inlet shroud. 


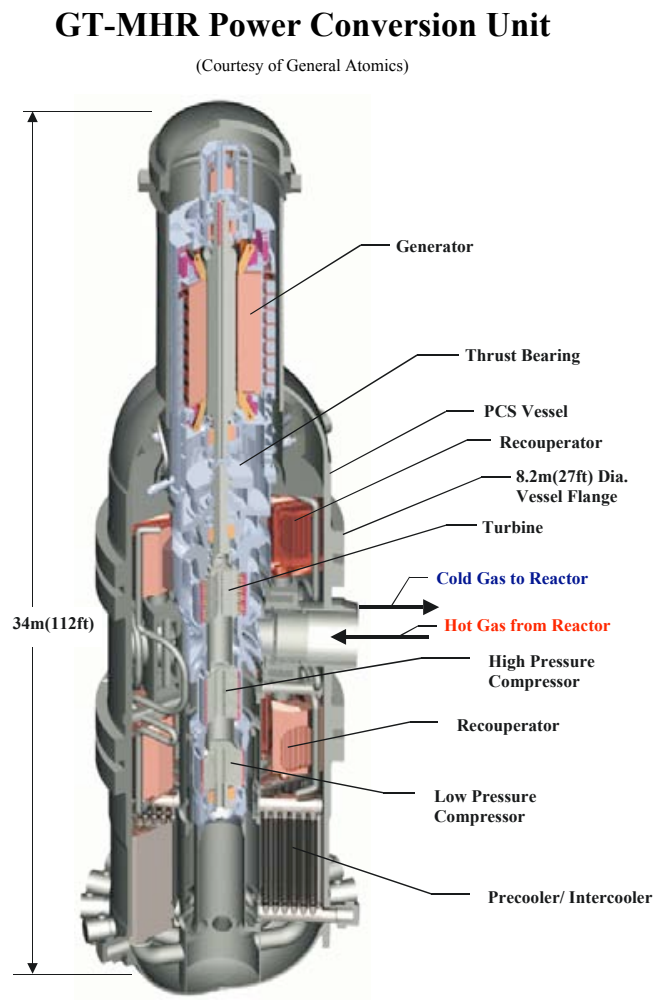

Fig. 6. GT-MHR Power Conversion Vessel.

Core Internals - Prismatic Design.

The core support floor is a structure of concentric rings welded together with radial beams originating from the center ring. The entire structure rests on supports forged into the lower head of the RPV. The floor supports the mass of the graphite core, core barrel, shroud, and upper core restraints. The structure is maintained at inlet helium temperatures and will experience negligible neutron exposure.

The core barrel (Figure 7) is a metallic cylinder with a diameter of 6.8 to 7 meters, a height of $\sim 14$ meters and a thickness of 25 to $50 \mathrm{~mm}$. The cylinder is welded to the core support floor. The core barrel physically restrains the graphite core during earthquakes and from radial thermal expansion during normal operations. The core barrel is centered and restrained in the RPV by keys that fit into corresponding keyways in the reactor pressure vessel. During operation, there is no space between the permanent graphite reflector and the core barrel; the permanent reflector blocks remain in contact with the core barrel. The normal operating temperature of the core barrel is about $\approx 600^{\circ} \mathrm{C}$. Temperature during off-normal conditions could reach as high as $1070^{\circ} \mathrm{C}$ for short periods. 


\section{GT-MHR Core Barrel}

(Courtesy of General Atomics)

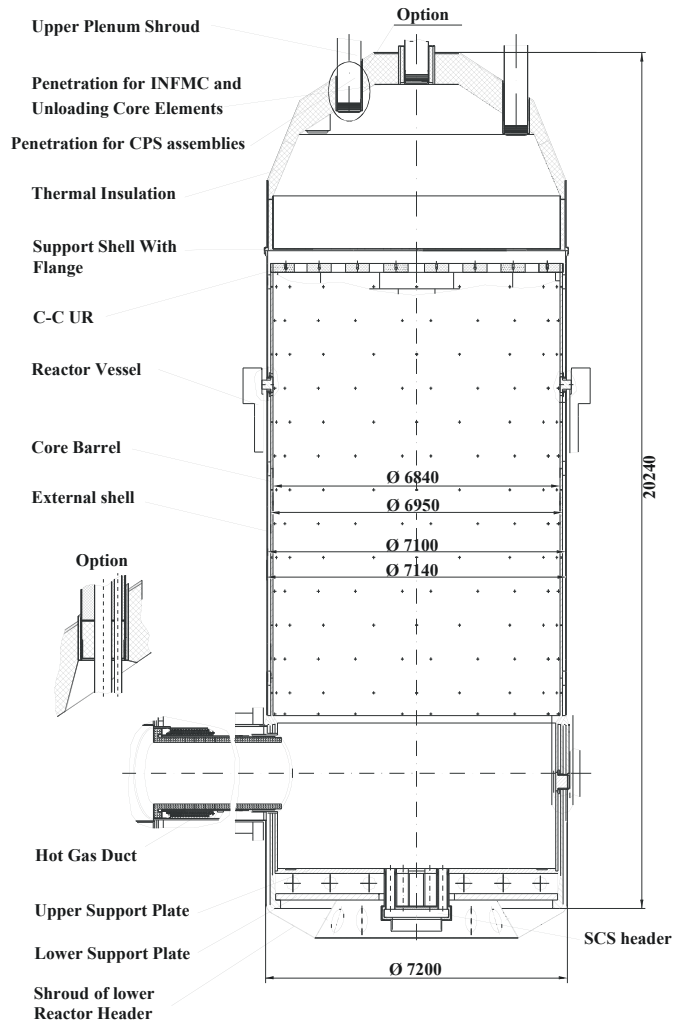

Fig. 7. GT-MHR Core Barrel

The shutdown cooling heat exchanger is located in the bottom of the core and is used primarily for removal of heat during refueling. The system can be used for normal and off-normal heat removal during shutdown. The upper portion is a helical tube heat exchanger in an environment of inlet helium at $600^{\circ} \mathrm{C}$ mixed with the core outlet flow from the lower core plenum. The tubes are between 12 and $19 \mathrm{~mm}$ thick. Water flows at rates necessary to keep the water subcooled and tube wall temperatures modest.

The last internal components are the control rods and their guide tubes. In past prismatic gas reactor core designs, the control rods were metal tubes filled with $\mathrm{B}_{4} \mathrm{C}$ right cylinders with center annuli as shown in Figure 8. The rods must remain straight to enable quick insertion at any time. The control rods that see the highest fluence and temperatures reside on the inside periphery of the core between the inner core and reflector. Normal operating temperatures reach $1050^{\circ} \mathrm{C}$ with off-normal temperatures reaching as high as $1400^{\circ} \mathrm{C}$. Considering the high temperatures of these components, it is unlikely that metallic materials can be used solely and structural composites will likely be needed. These control rods see fluences of $6.7 \mathrm{E} 20 \mathrm{n} / \mathrm{cm}^{2}$ per year with dpa values of about 0.56 per year. These high fluences may limit the lifetime of the control rods to less than 40 years; therefore, the fluence and dpa are given on a per year basis. Since control rods may be changed out, the reactor lifetime ( $\sim 60$ years) is not limited by the life of the control rods. 
Silicon-carbide/silicon-carbide $\left(\mathrm{SiC}_{\mathrm{f}} / \mathrm{SiC}\right)$ composites are being considered as a candidate material for the control rod sheath and guide tubes because metallic materials cannot withstand the level of neutron irradiation and high temperature of $1050^{\circ} \mathrm{C}$ or higher found in the core. In addition, there is evidence that $\mathrm{SiC}_{\mathrm{f}} / \mathrm{SiC}$ composites show superior irradiation performance compared to other thermally stable composites such as $\mathrm{C}_{f} / \mathrm{C}$ composites. Thus, $\mathrm{SiC}_{f} / \mathrm{SiC}$ components have the potential to be lifetime components (no change-out required) within the expected high thermal and radiation environment of the NGNP core.
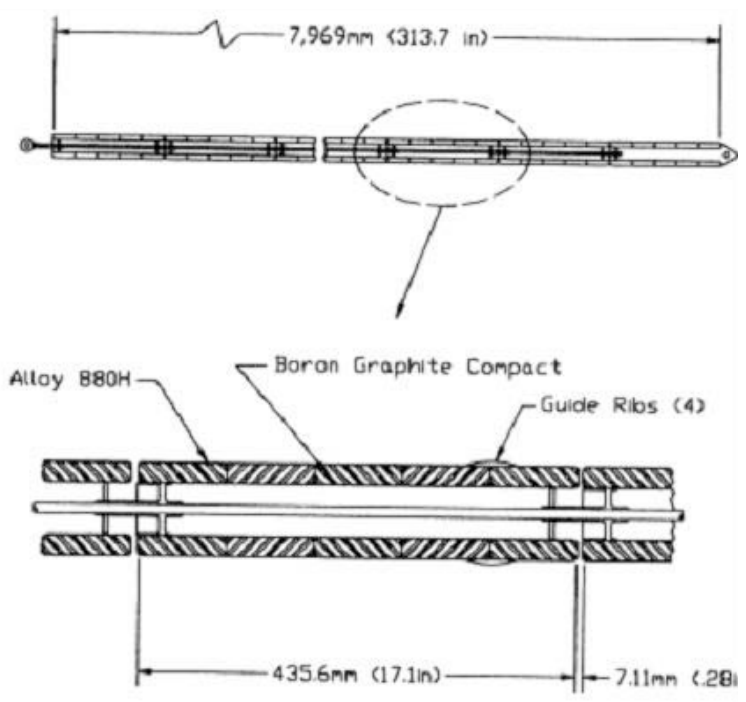

Fig. 8. GT-MHR Control Rod Concept.

Metallic Internals and Pressure Vessels - Pebble Bed Design.

The PBMR is a helium-cooled, graphite-moderated HTR, employing graphite fuel balls or pebbles, $6 \mathrm{~cm}$ in diameter, with TRISO ceramic particle fuel dispersed in the pebble. The ceramic fuel consists of a $\mathrm{UO}_{2}$ kernel, $(0.5 \mathrm{~mm})$ coated with layers of pyrolytic carbon and a silicon carbide layer for a total diameter of $.92 \mathrm{~mm}$. The helium gas from the reactor outlet is directly coupled to a gas turbine driven generator system forming a closed Brayton cycle. Recent design changes have incorporated a single shaft design where the high- and lowpressure compressor, the turbine, and the generator/reduction gear are driven by the same shaft. Figure 9 shows the components inside the PBMR pressure boundary, which include the reactor, the direct cycle power generation turbine, and high and low pressure turbo compressor components. The generator is located outside for maintenance access. 


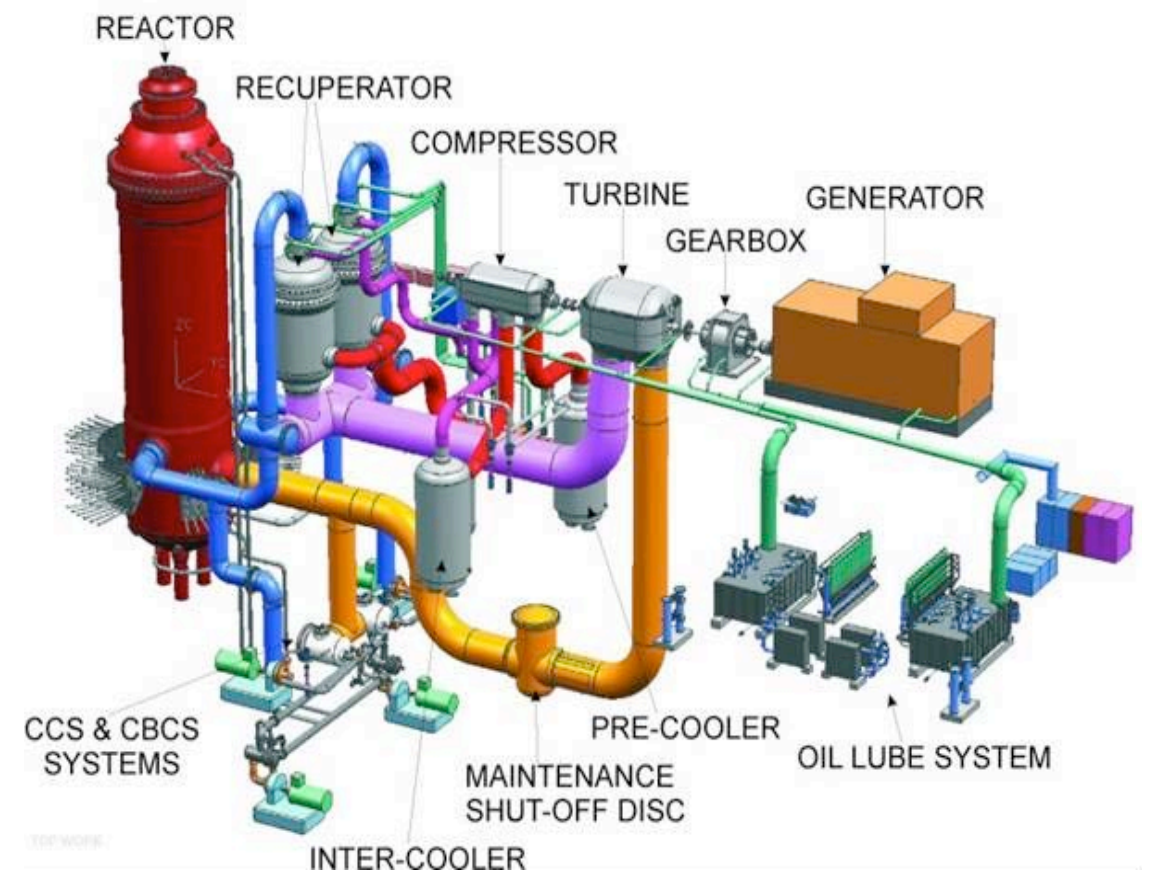

Fig. 9. PBMR Pressure Boundary.

In the PBMR, the helium exits the bottom of the reactor at a temperature of about $900^{\circ} \mathrm{C}$. The helium then expands in the high-pressure turbine that drives the high-pressure compressor (HPC). The helium then flows through the low-pressure turbine that drives the low-pressure compressor (LPC). The helium then expands in the power turbine, which drives the generator. The high-temperature helium then flows through the primary side of the recuperator where it transfers heat to the low temperature gas returning to the reactor. The helium that passed through the primary side of the recuperator is then cooled by means of a pre-cooler. The helium is then compressed by the LPC and cooled in the inter-cooler. The HPC then compresses the helium to 8.5 MPa. The cold, high-pressure helium stream then flows through the recuperator where it is pre-heated after which it returns to the top of the reactor.

The helium enters the PBMR RPV (Figure 10) at a temperature of about $500^{\circ} \mathrm{C}$ through the cold gas inlet at a pressure of about $8.9 \mathrm{MPa}$. The inlet helium flows between the core barrel and the RPV maintaining the RPV at a cooler temperature than the core. Nominal operating temperature of the RPV wall is $380^{\circ} \mathrm{C}$. The vertical steel RPV is $27 \mathrm{~m}$ high with an inside diameter of $6.2 \mathrm{~m}$. The pressure vessel material is ASME SA 508/SA 533. The pressure vessel is lined with a layer of graphite bricks. The core barrel surrounds and supports the graphite reflector. This graphite layer serves as an outer reflector for the neutrons generated by the nuclear reaction and a passive heat transfer medium. The graphite brick lining is drilled with vertical holes to house the control elements. This graphite reflector encloses the core where the nuclear reaction takes place. Helium flows through the pebble bed and removes the heat generated by the nuclear reaction. Total height of core barrel is $22 \mathrm{~m}$ with an outside diameter of $5.85 \mathrm{~m}$.

The core barrel material is 316 stainless steel. The designs of the RPV and core barrel meet ASME Section III, Subsections NB and NG respectively. The Decompression Loss of Flow Accident (DLOF) maximum temperature for the core barrel is $621^{\circ} \mathrm{C}$ and is covered under 
ASME Code Case N-201. The DLOF for the RPV is $450^{\circ} \mathrm{C}$ and is covered under ASME Code Case $\mathrm{N}-499$. The design life of this system is 40 years.

The fluences for the RPV, core barrel and reactor metallic internals are expected to be comparable to those discussed earlier for the GT-MHR.

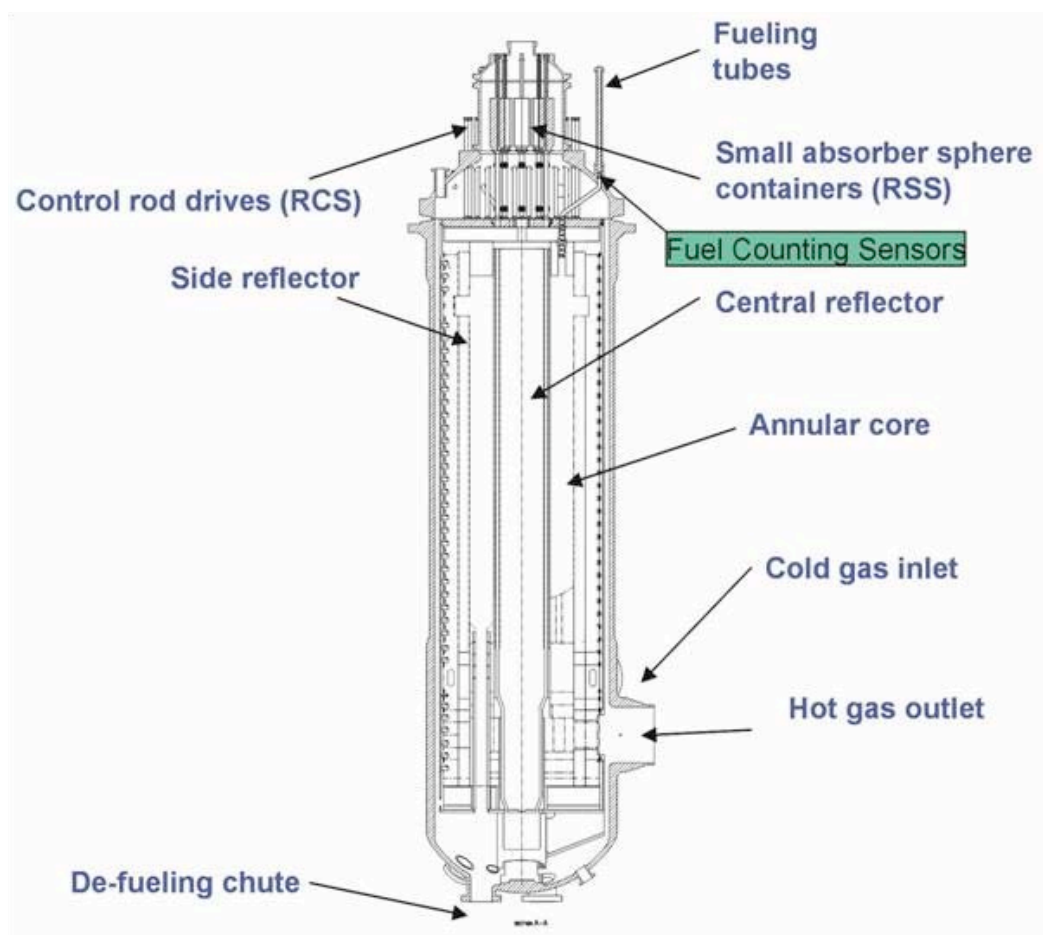

Fig. 10. PBMR Reactor Unit Vessel Assembly.

\subsubsection{Intermediate Heat Exchanger}

A current NGNP requirement states that $10 \%$ of the heat from the primary loop must be able to be diverted to the production of hydrogen. The remaining $90 \%$ will be used to produce electricity. To accommodate this requirement, an intermediate heat exchanger (IHX) within a pressure vessel would be employed to divert heat from the primary side of the reactor to a hydrogen production plant. The heat exchanger needs to isolate hydrogen production plant equipment from the radioactive contaminants in the helium coolant and prevent any backflow of hydrogen or heat transfer fluids from the hydrogen plant back into the primary He loop. The primary circuit IHX may be employed in either a direct or indirect cycle application. The indirect cycle places the IHX and its pressure vessel directly between the reactor core and the power conversion unit (PCU). The direct cycle diverts $10 \%$ of the reactor outlet gases to an IHX as a bypass around the gas turbine.

The IHX must handle the temperatures of the heated gases exiting the reactor core. The operational temperature of $850^{\circ} \mathrm{C}$ (for the GT-MHR) is near the expected regulatory limits for the most heat resistant commercial alloys available at this time. Accident situations may take the $\mathrm{IHX}$ beyond the realm of feasibility for a metallic material. For these reasons, depending on specific NGNP design, intermetallic or ceramic heat exchange components may have to be considered in the future, but current designs include only metallic construction materials. 
Direct Cycle Application-The direct cycle application would require a compact heat exchanger sized for $10 \%$ of the reactor heat load to be placed inside or very close to the secondary vessel. The turbine inlet would have a small leg diverting primary coolant to the heat exchanger. The secondary side of the heat exchanger would contain coolant coming from the hydrogen production plant, probably from a secondary heat exchanger. The outlet of the primary side would re-enter the primary loop downstream of the turbine or in one of the turbine stages.

The operating pressure on both sides of the $\mathrm{IHX}$ is expected to be in the 6.7 to $7.1 \mathrm{MPa}$ range with the secondary pressure exceeding the primary pressure by $0.1 \mathrm{MPa}$ (if pressure is used to prevent primary gas flow into the secondary system). Depressurization of the secondary side while the primary remains hot and at pressure would create significant thermal stress within the $\mathrm{IHX}$. Membrane stresses in the IHX will also be affected, but only as a function of the IHX design and the overall pressure differential. These off-normal stress states may challenge the material properties at operating temperatures. The radiation fluence on the IHX is negligible inside or immediately adjacent to the secondary vessel. A pressurized core conduction cooldown event would push the average primary inlet temperature above $1000^{\circ} \mathrm{C}$ for a short period.

The primary advantages of the direct cycle IHX would be its relatively small size and the potential of incorporating the hardware within the secondary vessel. However, the direct cycle approach almost guarantees that a second heat exchanger will be needed to ensure isolation of primary system contamination and potentially allow change from He to a different operating fluid.

Indirect Cycle-The indirect cycle application would require the IHX to be sized to handle the entire heat load of the reactor. The IHX is placed between the RPV and secondary vessel with structural ducts between the RPV and IHX and between the IHX and the main turbine/generator. The primary side of the IHX would see flow from the reactor and exit to the turbo-machinery pumps, intercoolers, pre-coolers and recuperator for conditioning the gas back to reactor inlet conditions. The IHX secondary side outlet helium would run the main turbine/generator. The secondary balance of plant would return the helium coolant to the secondary IHX inlet conditions using normal turbo machinery. The heat for the hydrogen plant would be drawn from the secondary outlet of the IHX upstream of the turbine. This configuration would isolate both the hydrogen plant and the main turbine/generator from the radioactive contamination in the primary leg. Even though the flow rates, heat loads, and associated component sizes would be significantly greater in this approach, the temperatures and pressures would be comparable to those in the direct cycle configuration.

IHX Types-Three types of heat exchangers have been suggested for the IHX based on efficiency and potential feasibility: the printed circuit, the plate and fin, and intermetallics or ceramic open-cell heat foam. The more traditional, helical coiled tubes in a tube sheet design may also be feasible for the indirect cycle IHX. Printed circuit heat exchangers rely on thermal diffusion welds between plates. The plate and fin type heat exchangers use high-temperature brazing to join the plates and seal the system. Intermetallics or ceramic heat exchangers hold potential for the NGNP, but the required unit would be several times larger than anything currently manufactured. Open cell graphite and intermetallic ceramic foam materials with exceptional thermal conductivities of up to $150 \mathrm{~W} / \mathrm{m} \mathrm{K}$ have been developed recently, though methodologies to use the thermal conductivity while retaining a pressure boundary must still be developed.

Each heat exchanger configuration has advantages and disadvantages to consider. Of the metallic systems, the printed circuit and plate-fin types allow the greatest surface area per unit volume of gas to minimize size. The tube type heat exchangers are more bulky and less 
efficient, but easier to build in a manner that can handle severe thermal transients. The pressure boundary for the printed circuit heat exchanger depends on the diffusion welds between every layer. The plate-fin pressure boundary depends on the high-temperature brazing material and the successful furnace brazing of an entire unit without any defects. In addition, the braze metal must take the stresses resulting from thermal transients. Intermetallic and ceramic heat exchangers may effectively eliminate the concerns of operating at high steady state temperatures but have major issues arising from their inherently brittle nature coupled with the need to handle thermal transients.

\subsection{Materials Requirements for the SCWR}

The currently envisioned SCWR plant design will utilize a direct power generation cycle. Highpressure $(25.0 \mathrm{MPa})$ coolant enters the vessel at $280^{\circ} \mathrm{C}$. The inlet flow splits with about $70 \%$ of the inlet flow going down the space between the core barrel and the reactor pressure vessel (the down-comer) and about $30 \%$ of the inlet flow going to the plenum at the top of the rector pressure vessel to then flow downward through the core in special water rods to the inlet plenum. This strategy is employed to provide good moderation at the top of the core, where supercritical water flowing upward through the core is at very low mass density. The coolant is heated to about $500^{\circ} \mathrm{C}$ and delivered to a power conversion cycle which is similar to that used in supercritical fossil-fired plants: high- intermediate- and low-pressure turbines are employed with two re-heaters. The most significant factors in changing the materials needs in going from the current pressurized- and boiling-water reactor designs to the SCWR are those associated with the increase in outlet coolant temperature from 300 to $500^{\circ} \mathrm{C}$ and the chemical species of the supercritical water.

\subsubsection{SCWR Component Description and Operation Conditions}

\subsubsection{SCWR Pressure Vessel}

A schematic drawing of the current vessel design is shown in Figure 11 and key vessel dimensions are listed in Table 2. The vessel will be exposed to $280^{\circ} \mathrm{C}$ inlet coolant on the inside surfaces. The outlet nozzles will be protected with insulation and/or thermal sleeves against the full outlet temperature. However, they may operate at temperatures somewhat above $280^{\circ} \mathrm{C}$. Peak fluence of the RPV is expected to be no more than $5 \times 10^{19} \mathrm{n} / \mathrm{cm}^{2}(E>0.1 \mathrm{MeV})$. 


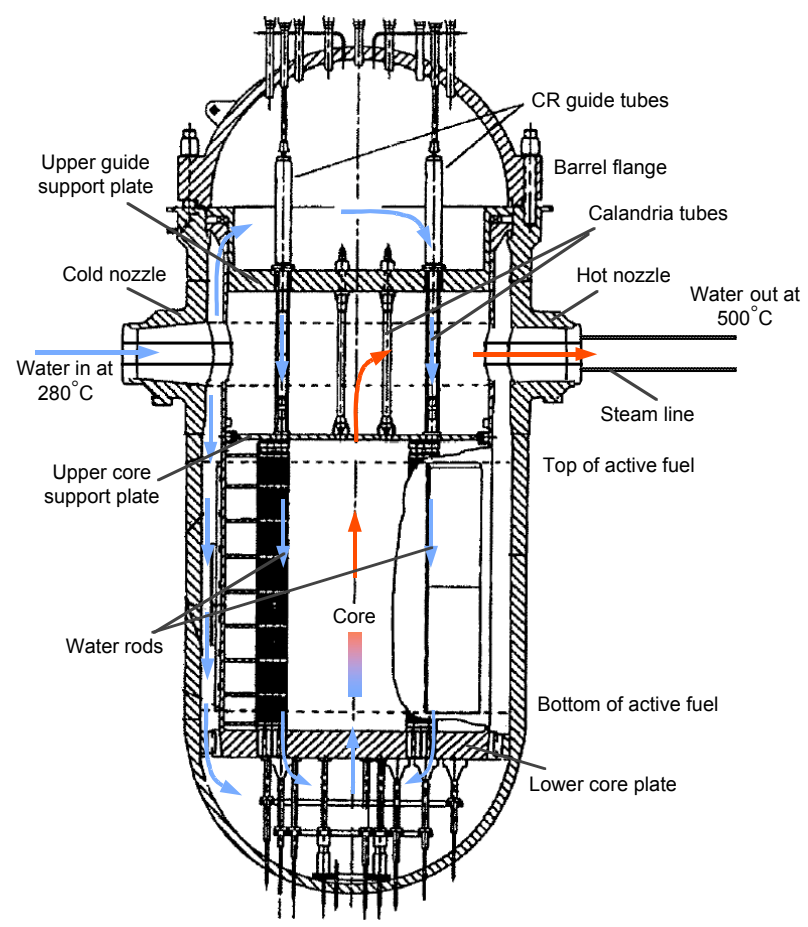

Fig. 11. Representation of the current reactor pressure vessel design.

Table 2. Reference reactor pressure vessel design for the U.S. Generation-IV SCWR.

\begin{tabular}{|c|c|}
\hline Parameter & Value \\
\hline $\begin{array}{l}\text { Height } \\
\text { Design pressure }\end{array}$ & $\begin{array}{l}12.40 \mathrm{~m} \\
27.5 \mathrm{MPa}(110 \% \text { of nominal } \\
\text { pressure) }\end{array}$ \\
\hline Operating temperature & $280^{\circ} \mathrm{C}$ \\
\hline Number of cold/hot nozzles & $2 / 2$ \\
\hline Inside diameter of shell & 5.322 m (209.5 in.) \\
\hline Thickness of shell & 0.467 m (18.4 in) \\
\hline Inside diameter of head & $5.337 \mathrm{~m}(210 \mathrm{in})$ \\
\hline Thickness of head & $0.292 \mathrm{~m}$ (11.5 in) \\
\hline Vessel weight & 780 mt (1.7 million lbs) \\
\hline
\end{tabular}

\subsubsection{SCWR Core and Fuel Assembly Design}

The reference SCWR core design is shown in Figure 12. The core will have 145 assemblies with an equivalent diameter of about 3.9 meters. The core barrel will have inside and outside diameters of about 4.3 and 4.4 meters, respectively. 


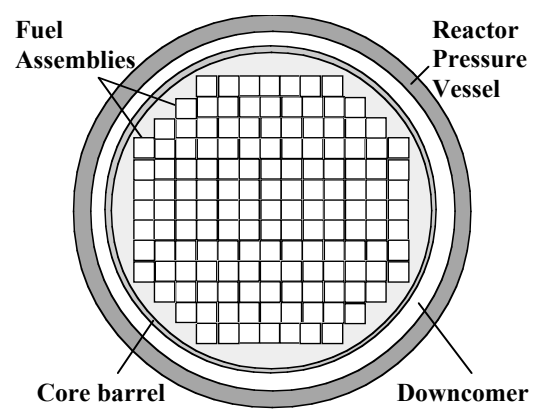

Fig. 12. Sketch of the reference SCWR core.

The reference SCWR fuel assembly design is shown in Figure 13 and the relevant dimensions are listed in Table 3. It may be necessary to insulate the water rod moderator boxes to retain a sufficient moderator density, as well as portions of the vessel internals supplying water to the core. The reference fuel pin dimensions are listed in Table 4.

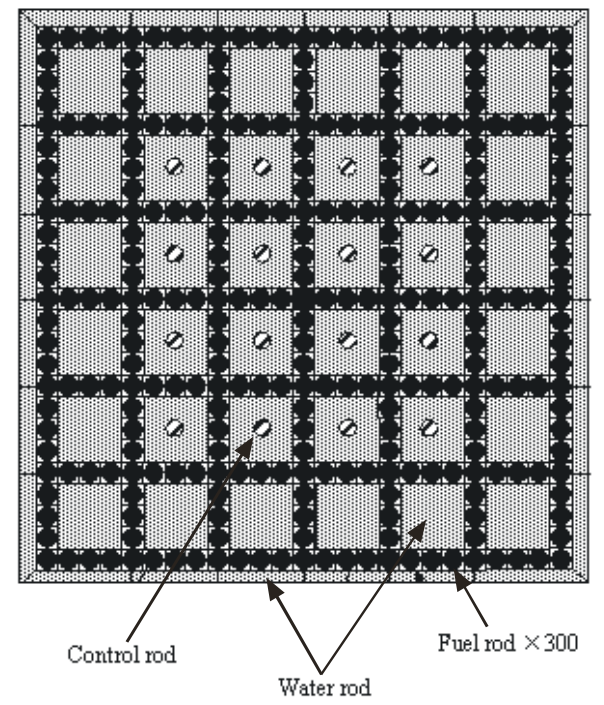

Fig. 13. The SCWR fuel assembly with metal water rod boxes. 
Table 3. Reference fuel assembly design for the U.S. Generation-IV SCWR.

\begin{tabular}{ll}
\hline \multicolumn{1}{c}{ Parameter } & \multicolumn{1}{c}{ Value } \\
\hline Fuel pin lattice & Square 25x25 array \\
Number of fuel pins per assembly & 300 \\
Number of water rods per assembly & 36 \\
Water rod side & $33.6 \mathrm{~mm}$ \\
Water rod wall thickness & $0.4 \mathrm{~mm}$ (plus insulation if needed) \\
Number of instrumentation rods per assembly & 1 \\
Number of control rod fingers per assembly & 16 \\
Active control rod materials & $\mathrm{B}_{4} \mathrm{C}$ for scram, Ag-ln-Cd for control \\
Number of spacer grids & 14 (preliminary estimate) \\
Assembly wall thickness & $3 \mathrm{~mm}$ (plus insulation if needed) \\
Assembly side & $286 \mathrm{~mm}$ \\
Inter-assembly gap & $2 \mathrm{~mm}$ \\
Assembly pitch & $288 \mathrm{~mm}$ \\
\hline
\end{tabular}

With the exception of the plenum length and fill pressure, the fuel pin dimensions are typical of 17 by 17 pressurized water reactor (PWR) fuel assembly pins. However, the fuel pin pitch is considerably smaller than the pitch used in LWRs. The U-235 enrichment and the $\mathrm{Gd}_{2} \mathrm{O}_{3}$ loading and fuel burnup are typical of the values used in high burnup LWR fuel.

Table 4. Reference fuel pin dimensions for the U.S. Generation-IV SCWR.

\begin{tabular}{ll}
\hline \multicolumn{1}{c}{ Parameter } & \multicolumn{1}{c}{ Value } \\
\hline Fuel pin outside diameter & $10.2 \mathrm{~mm}$ \\
Fuel pin pitch & $11.2 \mathrm{~mm}$ \\
Cladding thickness & $0.63 \mathrm{~mm}$ \\
Heated length & $4.27 \mathrm{~m}$ \\
Fission gas plenum length & $0.6 \mathrm{~m}$ \\
Total fuel pin height & $4.66 \mathrm{~m}$ \\
Fill gas pressure at room & $6.0 \mathrm{MPa}$ \\
temperature & \\
\hline
\end{tabular}

\subsubsection{SCWR Pressure Vessel Internals}

The important RPV internals include the lower core support plate, the core former, the core barrel, the upper core support plate, the calandria tubes located immediately above the upper core support plate, the upper guide support plate, the hot nozzle thermal sleeve or insulation, and the control rod guide tubes. The location and approximate shape of most of these components is shown in Figure 11.

Some of these components, including the lower core support plate and the control rod guide tubes in the upper head, will be subjected to normal PWR coolant temperature conditions and will be similar to the components typically used in PWRs. However, a number of the RPV internals, including the core barrel (or possibly the core former), the upper guide support plate, the calandria tubes, and the RPV hot nozzle sleeve, will be in contact with water at the inlet temperature at $280^{\circ} \mathrm{C}$ on one side and water at the hot outlet coolant at a temperature of $500^{\circ} \mathrm{C}$ on the other side. 


\subsubsection{SCWR Power Conversion System}

The reference SCWR system will have a power conversion cycle that is very similar to a supercritical coal-fired plant, with the boiler replaced by the nuclear reactor. The cycle is based on a large single-shaft turbine with one high-pressure/intermediate-pressure unit and three lowpressure units operating at reduced speed $(1800 \mathrm{rpm})$. The steam parameters at the highpressure/ intermediate-pressure unit inlet are $494^{\circ} \mathrm{C}$ and $23.4 \mathrm{MPa}$, well within current capabilities of fossil plants. Similarly to traditional light water reactor (LWR) cycles, a moisture separator-reheater module is located between the high-pressure/intermediate-pressure and the low-pressure turbines, and reheating is achieved with live nuclear steam. Heat rejection occurs in traditional natural-draft cooling towers. Eight feedwater heaters raise the condensate temperature to the reactor inlet level of $280^{\circ} \mathrm{C}$. The main feedwater pumps are turbine-driven and operate at about $190^{\circ} \mathrm{C}$. There are two steam lines with outside diameters of $0.470 \mathrm{~m}(18.5$ in.) and inside diameters of 0.368 (14.5 in.).

\subsection{Materials Requirements for the LFR}

LFR systems are $\mathrm{Pb}$ or $\mathrm{Pb}-\mathrm{Bi}$ alloy-cooled reactors with a fast-neutron spectrum and closed fuel cycle. Options include a wide range of plant ratings, including a long-refueling-interval transportable reactor modules ranging from 10-100 MWe, multi-module systems from 300-500 $\mathrm{MWe}$, and a large monolithic plant at $1200 \mathrm{MWe}$. These options also provide a range of energy products. The current focus of the U.S. program is on transportable reactor module concepts that are small factory-built turnkey units operating on a closed fuel cycle with a very long refueling interval (15 to 30 years) cassette core or replaceable reactor module. It is envisioned that future evolution of the technology could lead to larger central station power plants as they are needed.

The Lead-Cooled Fast Reactor (LFR) is proposed to meet all of the Gen IV goals of: i) NonProliferation; ii) Sustainability; iii) Safety and Reliability; and iv) Economics. Two key technical aspects of the envisioned LFR that offer the prospect for achieving these goals are the use of lead $(\mathrm{Pb})$ coolant and a long-life, cartridge-core architecture in a small, modular system intended for deployment with small grids or remote locations. The $\mathrm{Pb}$ coolant is both a poor absorber and a poor moderator of fast neutrons and enables the traditional sustainability and fuel cycle benefits of a liquid metal-cooled fast spectrum core to be realized. Lead does not interact vigorously with air, water/steam, or carbon dioxide eliminating concerns about exothermic reactions. It has a high boiling temperature $\left(1740^{\circ} \mathrm{C}\right)$ such that the prospect of boiling or flashing of the ambient pressure coolant is realistically eliminated.

\subsubsection{LFR Component Description and Operation Conditions}

\section{LFR-SSTAR System Description [2.4, 2.7]}

The LFR currently being studied in the U.S. Gen IV Program is the Small Secure Transportable Autonomous Reactor (SSTAR) concept, which is a small modular fast reactor. The main mission of the $20 \mathrm{MWe}$ (45 MWt) SSTAR is to provide incremental energy generation to match the needs of developing nations and remote communities without electrical grid connections. This represents a niche market within which costs that are higher than those for large-scale nuclear power plants are competitive, and allows development of LFR technology on a smaller, simpler and lower total cost basis. Design features of the reference SSTAR include a 20-to-30yr-lifetime sealed core, a natural circulation primary, autonomous load following without control rod motion, an internal heat exchanger $(\mathrm{HX})$, and use of a supercritical carbon dioxide $\left(\mathrm{S}-\mathrm{CO}_{2}\right)$ energy conversion system. The incorporation of inherent thermo-structural feedbacks imparts 
walk-away passive safety, while the use of a sealed, cartridge core with a 20-year or longer cycle time between refueling imparts strong proliferation resistance. A schematic view of the reactor is shown in Figure 14.
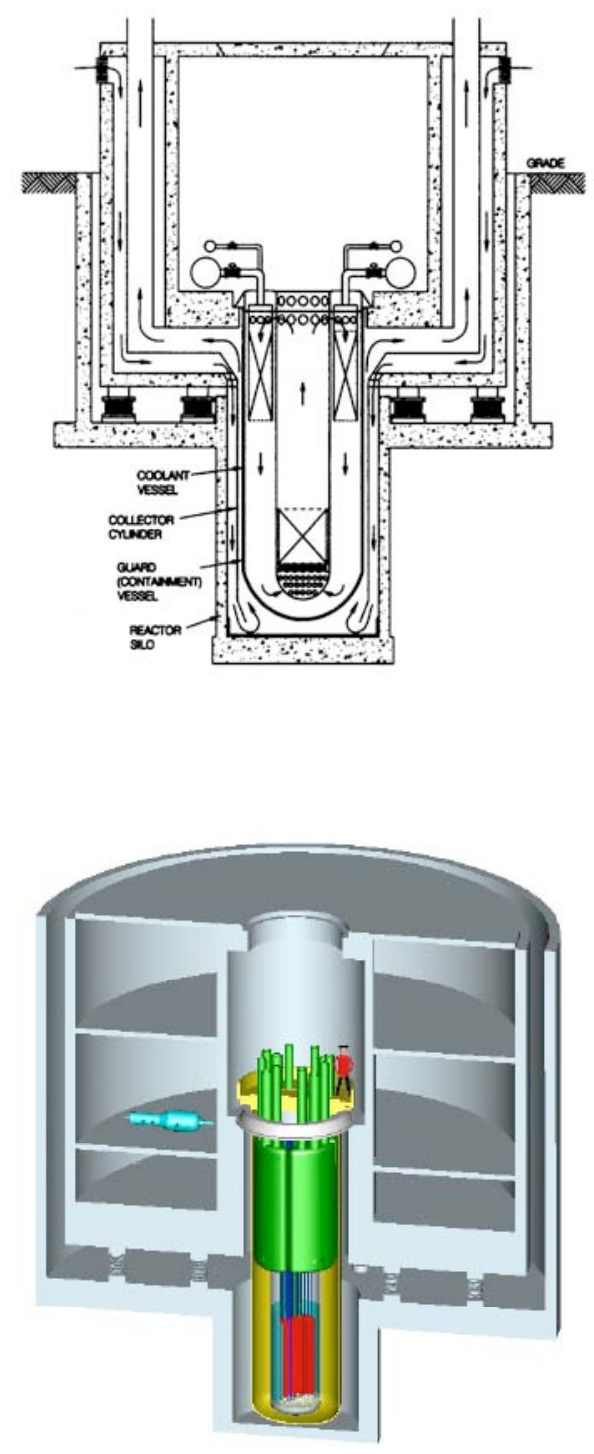

Fig. 14. Schematic view of SSTAR LFR with natural circulation [2.8].

SSTAR utilizes transuranic nitride fuel enriched to nearly $100 \%$ in $\mathrm{N}^{15}$ in a compact core. Heat is removed from the core and transported to in-vessel $\mathrm{Pb}$-to- $\mathrm{CO}_{2}$ heat exchangers by singlephase natural circulation of the $\mathrm{Pb}$ coolant - the need for main coolant pumps is eliminated. The fast spectrum core with nitride fuel and $\mathrm{Pb}$ coolant has strong reactivity feedbacks that enable autonomous load following and provide passive power shutdown in the event of loss-ofnormal heat removal. The core has a long lifetime/refueling interval of 20 years during which access to the core is restricted providing proliferation resistance; the transuranic fuel is self 
protective in the safeguards sense. The $\mathrm{Pb}$ coolant and nitride fuel provide for enhanced passive safety whereby the core and in-reactor heat exchangers remain covered by ambient pressure single-phase primary coolant inside the reactor vessel and single-phase natural circulation removes the core power under all operational and postulated accident conditions. The reference SSTAR reactor system is coupled to a supercritical carbon dioxide gas turbine Brayton cycle power converter that enables potential improvements and cost savings over the traditional Rankine saturated steam cycle including higher cycle efficiency at temperatures attainable with $\mathrm{Pb}$ primary coolant and nitride fuel $\left(650^{\circ} \mathrm{C}\right.$ peak cladding temperature and $561^{\circ} \mathrm{C}$ core outlet temperature for a $405^{\circ} \mathrm{C}$ inlet temperature) as well as a smaller plant footprint with simpler secondary side components. Operating conditions for the SSTAR reactor are listed in Table 5.

Table 5. SSTAR Operating Conditions

\begin{tabular}{|c|c|}
\hline Power, MWe (MWt) & $20(45)$ \\
\hline Reactor Vessel Height, $\mathrm{m}$ & 18.3 \\
\hline Reactor Vessel Outer Diameter, $\mathrm{m}$ & 3.23 \\
\hline Active Core Diameter, $\mathrm{m}$ & 1.02 \\
\hline Active Core Height, $\mathrm{m}$ & 0.80 \\
\hline Active Core Height-to-Diameter Ratio & 0.8 \\
\hline Fuel Volume Fraction & 0.55 \\
\hline Fuel Pin Outer Diameter, cm & 2.7 \\
\hline Fuel Pin Pitch-to-Diameter Ratio & 1.096 \\
\hline Core Hydraulic Diameter, cm & 0.876 \\
\hline Cladding Thickness, mm & 1.0 \\
\hline Fuel Smeared Density, \% & 85 \\
\hline HX Tube Height, $m$ & 6.0 \\
\hline HX Tube Outer Diameter, $\mathrm{cm}$ & 1.4 \\
\hline HX Tube Inner Diameter, cm & 1.0 \\
\hline HX Tube Pitch-to-Diameter Ratio & 1.302 \\
\hline HX Hydraulic Diameter for Pb Flow, cm & 1.22 \\
\hline HX-Core Thermal Centers Separation Height, m & 12.2 \\
\hline Peak Fuel Temperature, ${ }^{\circ} \mathrm{C}$ & 1009 \\
\hline Peak Cladding Temperature, ${ }^{\circ} \mathrm{C}$ & 650 \\
\hline Core Outlet Temperature, ${ }^{\circ} \mathrm{C}$ & 561 \\
\hline Maximum S- $\mathrm{CO}_{2}$ Temperature, ${ }^{\circ} \mathrm{C}$ & 541 \\
\hline Core Inlet Temperature, ${ }^{\circ} \mathrm{C}$ & 405 \\
\hline Core Coolant Velocity, m/s & 0.948 \\
\hline $\mathrm{Pb}$ Coolant Flowrate, $\mathrm{Kg} / \mathrm{s}$ & 1983 \\
\hline $\mathrm{CO}_{2}$ Flowrate, $\mathrm{Kg} / \mathrm{s}$ & 245 \\
\hline $\mathrm{CO}_{2}$ Mass in Brayton Cycle, $\mathrm{Kg}$ & 8737 \\
\hline S-CO ${ }_{2}$ Brayton Cycle Efficiency, \% & 43.8 \\
\hline Plant Efficiency, \% & 43.4 \\
\hline
\end{tabular}

The SSTAR reference reactor system fits inside of a reactor vessel that is about $18 \mathrm{~m}$ tall and $3.2 \mathrm{~m}$ in diameter; small enough to be transported either by rail or barge. The compact $\sim 1.0 \mathrm{~m}$ diameter/0.8 $\mathrm{m}$ height active core is located near the bottom of the vessel. Large diameter (2.7 $\mathrm{cm}$ ) fuel pins are arranged on a triangular pitch. The core is not composed of individual removable assemblies but is a single proliferation resistant cassette that can be accessed only when refueling equipment is brought to the site at the end of the core lifetime. The fuel pins consist of nitride (enriched to nearly $100 \% \mathrm{~N}^{15}$ ) pellets thermally bonded by molten $\mathrm{Pb}$ to the 
silicon-enhanced F/M stainless steel cladding. A short fission gas plenum (about one-fourth of the active core height) is provided at the top of each fuel pin. The molten $\mathrm{Pb}$ coolant flows upwards through the core and the overlying riser region inside of a cylindrical shroud. Near the free surface at the top of the $\mathrm{Pb}$, the coolant enters modular $\mathrm{Pb}$-to- $\mathrm{CO}_{2}$ heat exchangers located in the annulus between the shroud and reactor vessel to flow downwards over the exterior of double-walled tubes containing the upwards flowing $\mathrm{CO}_{2}$. The $\mathrm{Pb}$ continues through the downcomer region beneath the heat exchangers and enters the lower plenum below the core where a flow distributor tends to equalize the pressure at the core inlet. The $\mathrm{Pb}$ flow is driven solely by natural circulation - key is the low core pressure drop reflecting a large coolant hydraulic diameter and short fuel pin height. The $\mathrm{Pb}$ coolant enters the core at $405^{\circ} \mathrm{C}$ (providing adequate margin above the $\mathrm{Pb}$ freezing temperature of $327^{\circ} \mathrm{C}$ ) and exits the core at a $561^{\circ} \mathrm{C}$ mixed mean outlet temperature. The maximum temperature at the cladding inner surface is $650^{\circ} \mathrm{C}$. Corrosion control is maintained through the formation and maintenance of protective oxide $\left(\mathrm{Fe}_{3} \mathrm{O}_{4}\right.$ at lower temperatures) layers upon the steel structural surfaces through maintenance of the dissolved oxygen potential in the $\mathrm{Pb}$ coolant. Shutdown rods provide for startup and shutdown while compensation rods offset small reactivity changes during the 20year core lifetime; control rods are not needed to effect power changes during autonomous load following due to the strong reactivity feedbacks of the fast spectrum core.

The reactor vessel is surrounded by a guard vessel. The exterior of the guard vessel is passively cooled by upward flowing air driven by natural convection; passive air-cooling provides for emergency heat removal in the event that neither the normal operational nor shutdown heat removal paths are available. The reactor system is coupled to a $\mathrm{S}-\mathrm{CO}_{2}$ power converter. Supercritical $\mathrm{CO}_{2}$ at $20 \mathrm{MPa}$ pressure is heated to $541^{\circ} \mathrm{C}$ in the in-reactor $\mathrm{Pb}$-to- $\mathrm{CO}_{2}$ heat exchangers. It expands to about $7.4 \mathrm{MPa}$ in a remarkably small turbine that drives the generator and then passes through two recuperators (a high temperature recuperator followed by a low temperature recuperator) where a portion of the remaining thermal energy is extracted to preheat the compressed $\mathrm{CO}_{2}$ that is returned to the in-reactor heat exchangers. Upon exiting the low temperature recuperator, about $67 \%$ of the $\mathrm{CO}_{2}$ passes through the cooler where heat is rejected from the cycle and the $\mathrm{CO}_{2}$ is cooled to $31.2^{\circ} \mathrm{C}$, compressed in a small compressor to $20 \mathrm{MPa}$, and preheated in the low temperature recuperator. The remaining $33 \%$ of the $\mathrm{CO}_{2}$ is directly recompressed in a second compact compressor and merged with the other flow stream between the low and high temperature recuperators. This flow split/merge approach is necessitated by the significantly greater specific heat of the higher pressure $\mathrm{CO}_{2}$ over the temperature range of the low temperature recuperator. The recuperators and cooler incorporate Printed Circuit Heat Exchangers (PCHEs) to further reduce component volumes. The cycle efficiency of $44 \%$ provides about $20 \mathrm{MWe}$ of electricity for $45 \mathrm{MWt}$ of core thermal power. The SSTAR reactor with $\mathrm{S}-\mathrm{CO}_{2}$ energy conversion is shown in Figure 15. 


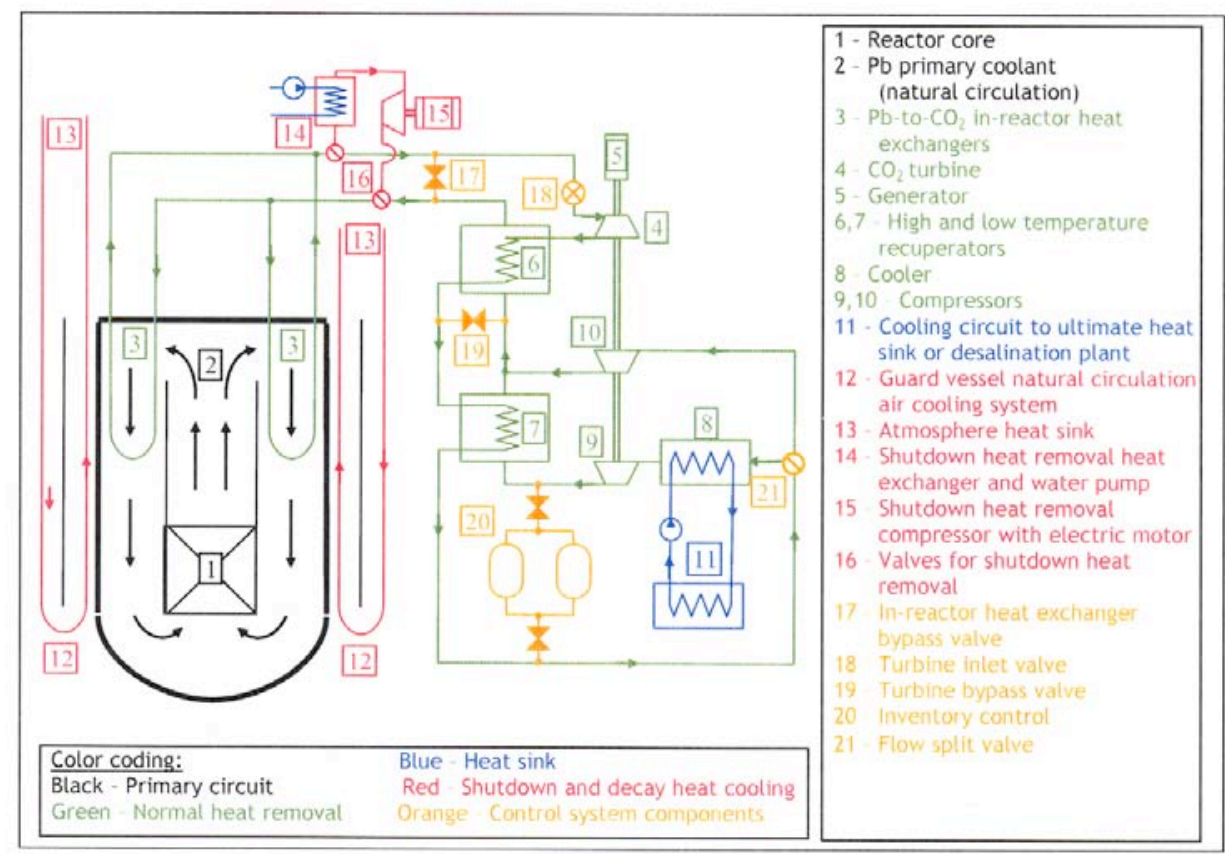

Fig.15. Schematic Illustration of SSTAR Coupled to the S-CO Normal, Shutdown, and Emergency Heat Transfer Paths.

Off normal transients have not been analyzed in detail, but the LFR design has fairly low power density, and very high coolant thermal capacity. Thermal transients will be rather slow and will have very modest peak temperatures.

Near-term LFR systems are limited by material performance to outlet temperatures of about $550-600^{\circ} \mathrm{C}$. Both $\mathrm{Pb}$ and $\mathrm{Pb}-\mathrm{Bi}$ are coolant options for this reactor: $\mathrm{Pb}$ having potential for reduced corrosion, but limiting core $\Delta \mathrm{T}$, and $\mathrm{Pb}$ - $\mathrm{Bi}$ providing more temperature flexibility but raising issues of increased $\mathrm{Po}-210$ and corrosion due to $\mathrm{Bi}$. The favorable properties of $\mathrm{Pb}$ coolant and nitride fuel, combined with development of high temperature structural materials, may extend the reactor coolant outlet temperature into the $750-800^{\circ} \mathrm{C}$ range in the long term, which is potentially suitable for hydrogen production and other process heat applications. In this option, the Bi-alloying agent in the coolant is eliminated. Such higher temperature options would require new materials, coolant technology and fuel development, and are not currently being pursued in the near-term US R\&D program.

\subsubsection{LFR Reactor Vessel}

The LFR working design reactor vessel is an 18-meter high cylinder about 3 meter in diameter. Internal pressure is low, with the liquid lead coolant operating at near atmospheric pressure. However, the weight of the lead coolant can result in significant mechanical stress in both the vessel wall and in the support ring from which the vessel hangs down into a dry-well. There is a close fitting guard vessel outside the reactor vessel that must catch and hold the coolant load in event of loss of primary boundary integrity. All penetrations are in the vessel head, which is more readily inspected and replaced than the vessel itself. 
With annular down-flow of coolant out of the heat exchangers, most of the vessel will operate near the core inlet temperature of about $400^{\circ} \mathrm{C}$, while upper portions of the vessel and head may operate nearer the $560^{\circ} \mathrm{C}$ outlet temperature. It is not yet known how large a fast neutron fluence the vessel will experience but it should be fairly high. There is a reflector around the active core, and the potential for neutron and thermal shielding between the reflector and the downflow plenum that will reduce neutron fluence on the vessel to moderate levels. The current candidate materials for the vessel include the same F/M steels used in the core internals, namely HT-9 or T-91, probably with composition modified for improved corrosion resistance in $\mathrm{Pb}$ or lead-bismuth eutectic (LBE) coolants. Low alloy steel clad with these materials are also possible candidates. Finally, if fast neutron fluence is low enough, austenitic steels might be considered.

\subsubsection{LFR Vessel Internal Components}

LFR core internal components include the reflector, core hold-down fixture to keep the core from floating in the coolant, flow plenums and control rods, drives and channels. These components will operate in the $400-600^{\circ} \mathrm{C}$ range. They must also withstand high fast neutron fluences in the 100-200 dpa range. Mechanical stress will be moderate, limited by component design. Candidate materials include F/M steels HT-9 or T-91, probably with composition modified for improved corrosion resistance in $\mathrm{Pb}$ or LBE coolants.

\subsubsection{LFR Fuel and Cladding}

LFR fuel is being investigated in the Advanced Fuel Cycle Initiative (AFCl) program. The working design is based on nitride pellets (uranium, plutonium and minor actinides) in clad fuel pins built into a monolithic structure without separately removable assemblies. The thermalmechanical response of the core structure is an important part of the autonomous control of the reactor. Candidate materials include F/M steels HT-9 or T-91, probably with composition modified for improved corrosion resistance in $\mathrm{Pb}$ or LBE coolants.

The fuel cladding is the most demanding material issue for the LFR. These challenges to the cladding include:

- The highest temperatures of any non-fuel material, with a peak of $650^{\circ} \mathrm{C}$

- The highest fast neutron fluence, currently set by design limit at $4 \times 10^{23} \mathrm{n} / \mathrm{cm}^{2}$

- High stress from fission gas build up, currently set by design limit and creep properties

- The need for 20-30 years high reliability in flowing liquid $\mathrm{Pb}$.

The cladding performance demand differs from traditional reactors due to the unique features of the SSTAR concept. The cladding must last through the long-core-lifetime. The fuel is not amenable to inspection. Further, significant fuel failure will require premature replacement of the entire core cartridge (or reactor).

Candidate LFR cladding materials include F/M steels HT-9 or T-91, or oxide dispersion strengthened $\mathrm{F} / \mathrm{M}$ steel, all with composition modified for improved corrosion resistance in $\mathrm{Pb}$ or LBE coolants. The oxide dispersion strengthened (ODS) F/M steels are attractive for improved creep resistance, but bring complications in fabrication and uncertainties in long-term irradiation performance. Modifications for corrosion resistance that are being investigated include composition change, such as increased Si to stabilize dense surface oxides, surface treatment, and functionally graded coatings. Austenitic stainless steels with compositional tailoring for 
irradiation-induced swelling resistance could also be candidates. Recent studies have indicated that their corrosion resistance may be superior to F/M steels.

\subsubsection{LFR Heat Exchangers/Steam Generators}

The LFR SSTAR working design uses compact heat exchangers inside the reactor vessel with lead primary coolant on one side and $\mathrm{S}-\mathrm{CO}_{2}$ on the other. This results in a large pressure differential, and resulting high stress in the exchanger materials. Operating temperature covers the $400-560^{\circ} \mathrm{C}$ range. In the event of a heat exchanger leak, analysis indicates that $\mathrm{CO}_{2}$ bubbles rise in the coolant faster than the downflow rate, and that the core would respond safely to bubble passage. Candidate materials include the same F/M steels, with modifications, as for cladding and other core components. If neutron fluence is sufficiently low at the heat exchangers, it is possible that austenitic steels could be considered.

Other LFR concepts may use a steam cycle instead of $\mathrm{S}-\mathrm{CO}_{2}$, resulting in either steam generators or secondary loop heat exchangers internal to the vessel, or a loop design with penetrations in the vessel wall for primary coolant circulation to external steam generators.

\subsubsection{LFR Energy Conversion}

The LFR SSTAR working design uses a S- $\mathrm{CO}_{2}$ Brayton cycle. The materials needs for this will be the same as for other $\mathrm{S}-\mathrm{CO}_{2}$ systems under consideration in the energy conversion cross-cut area, with the addition of compatibility with liquid $\mathrm{Pb}$ at up to $560^{\circ} \mathrm{C}$.

\subsection{Materials Requirements for GFR}

The GFR system features a fast-spectrum, gas-cooled reactor (Figure 16) and closed fuel cycle. The GFR reference design is a helium-cooled system operating at $7 \mathrm{MPa}$ with an outlet temperature of $850^{\circ} \mathrm{C}$ that utilizes a direct Brayton cycle turbine for electricity production and provides process heat for thermochemical production of hydrogen. Through the combination of a fast-neutron spectrum and full recycle of actinides, GFRs will be able to minimize the production of long-lived radioactive waste isotopes and contribute to closing the overall nuclear fuel cycle.

Two alternate system options are currently being considered. The first alternate design is a helium-cooled system that utilizes an indirect Brayton cycle for power conversion. Its secondary system utilizes $\mathrm{S}-\mathrm{CO}_{2}$ at $550^{\circ} \mathrm{C}$ and $20 \mathrm{MPa}$. This allows for more modest outlet temperatures in the primary circuit $\left(-600-650^{\circ} \mathrm{C}\right)$, reducing fuel, fuel matrix, and material requirements as compared to the direct cycle, while maintaining high thermal efficiency $(\sim 42 \%)$. The second alternate design is a $\mathrm{S}-\mathrm{CO}_{2}$ cooled $\left(550^{\circ} \mathrm{C}\right.$ outlet and $\left.20 \mathrm{MPa}\right)$, direct Brayton cycle system. This further reduces temperature in the primary circuit, while maintaining high thermal efficiency $(\sim 45 \%)$, potentially reducing both fuel and materials development costs as compared to the reference design, and reducing the overall capital costs due to the small size of the turbomachinery and other system components. 


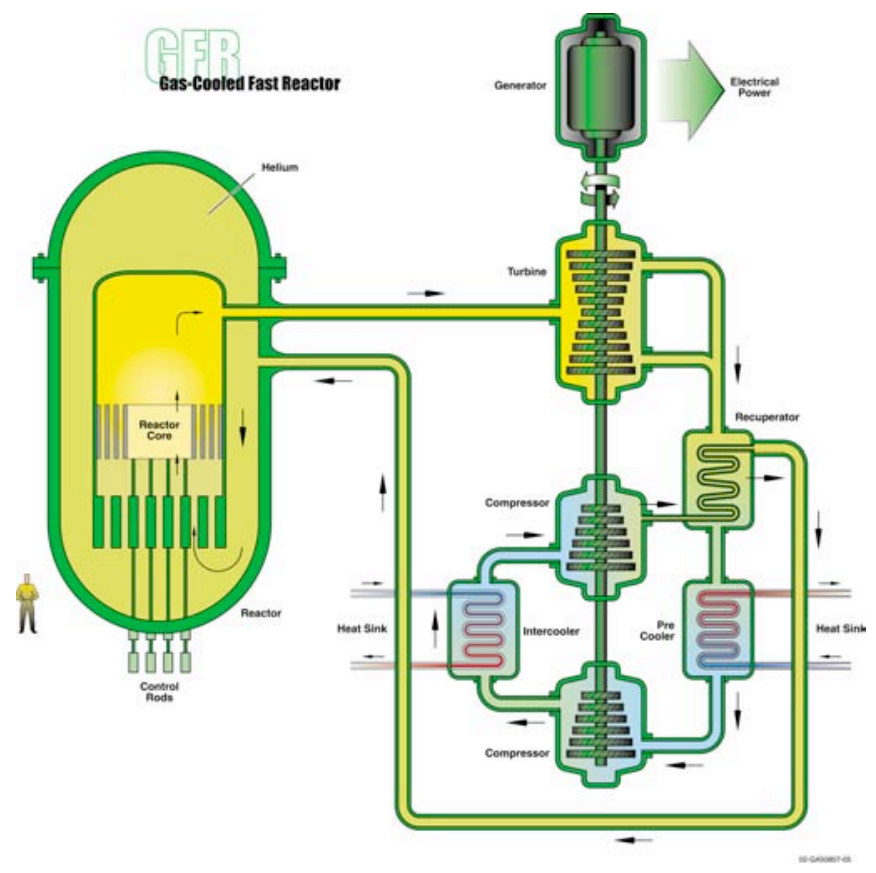

Fig. 16. The gas-cooled fast reactor concept.

Much of the GFR balance of plant will be able to utilize materials being evaluated or qualified for the NGNP, though a number of items specific to the operation of the GFR will need to be evaluated. The largest materials challenge for the GFR, however, will be to select and qualify materials for the core and reactor internals structures, since graphite use will be severely restricted due to its heavy moderation of the neutron spectrum. Use of alternate, neutronically acceptable materials must be demonstrated at the high GFR temperatures and very high neutron exposures that are also compatible with the coolants envisioned.

Key in-core structures include: plate/block type composite fuels with casing/hexagonal canning and gas tubing, solid solution pellet fuel clad and wrapper, and particle basket designs. Materials must be qualified for the fuel and cladding as well as for supporting structures and subassembly structures for control rods and reflectors. The key out-of-core structures include the core barrel and hot gas duct, core support components, the reactor vessel and cross-vessel components. These components choices are highlighted in Figure 17. 


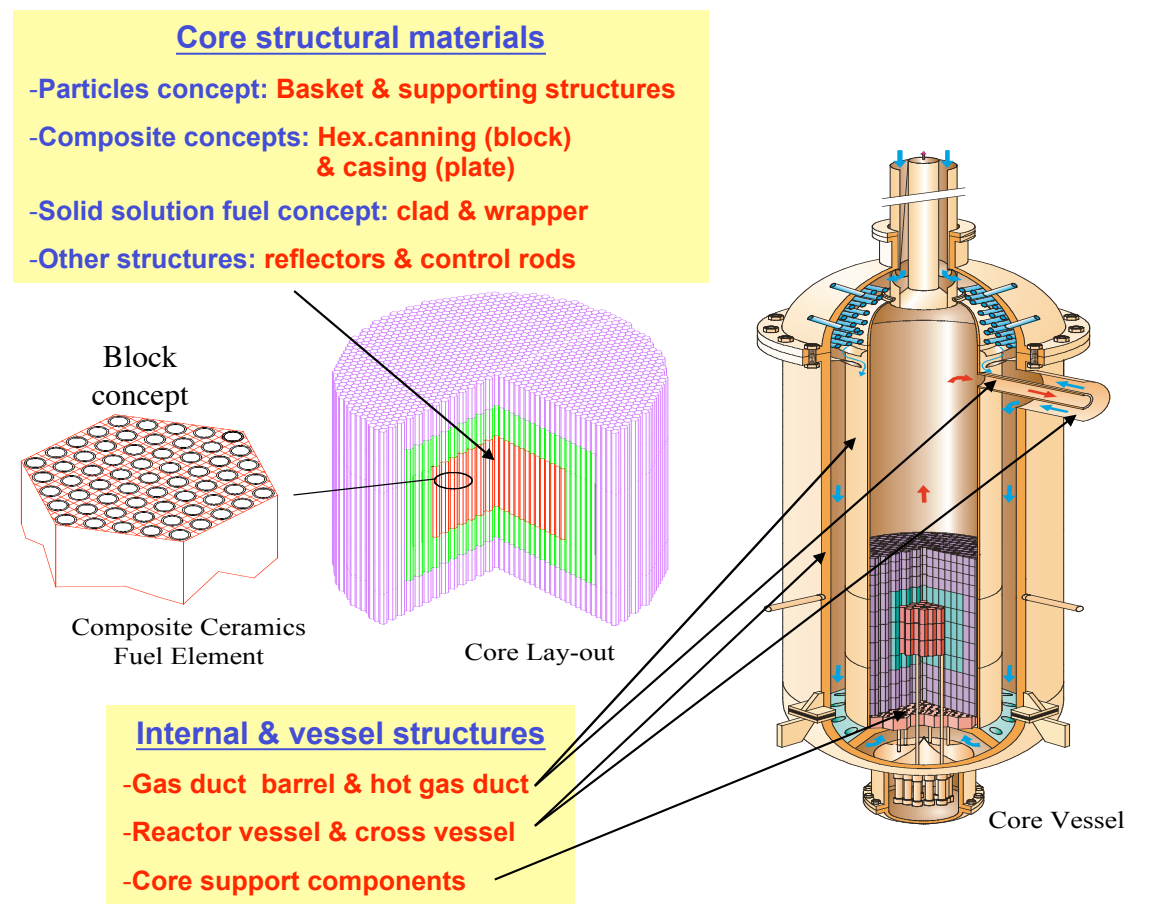

Fig. 17. Main components of the gas-cooled fast reactor concept.

More details on the GFR reactor designs and associated materials requirements are provided in a recent report by Kevan Weaver, et al. [2.5] A summary of target design parameters for the reference GFR system is given in Table 6. Alternate designs include the He-cooled, indirect S$\mathrm{CO}_{2}$ cycle and the indirect S- $\mathrm{CO}_{2}$-cooled, direct cycle systems that were mentioned previously.

Table 6. Target design parameters for the reference GFR system.

\begin{tabular}{ll}
\hline Reactor Parameters & Reference Value \\
\hline Reactor power & $600 \mathrm{MWt}$ \\
$\begin{array}{l}\text { Net plant efficiency (direct cycle helium) } \\
\text { Coolant inlet/outlet temperature and }\end{array}$ & $42 \%$ \\
pressure/Helium flow rate & $490^{\circ} \mathrm{C} / 850^{\circ} \mathrm{C}$ at $7 \mathrm{MPa}, 312.4 \mathrm{~kg} / \mathrm{s}$ \\
$\begin{array}{l}\text { Core structures temperatures (normal } \\
\text { operations) }\end{array}$ & $500-1200^{\circ} \mathrm{C}$ \\
Transient temperature in accident & $1600-1800^{\circ} \mathrm{C}$ \\
conditions & \\
Out-of-core structures & $440-850^{\circ} \mathrm{C}$, low irradiation exposure, \\
& mechanical loading $<50-60 \mathrm{MPa}$ and \\
& high useful life $(400000 \mathrm{~h})$ \\
Average power density & $50-100 \mathrm{MWt} / \mathrm{m}^{3}$ \\
Reference fuel compound & UPuC/SiC $(50 / 50 \%)$ with about $20 \% \mathrm{Pu}$ \\
& content \\
Volume fraction, Fuel/Gas/SiC & $50 / 40 / 10 \%$ \\
Conversion ratio & Self-sufficient $(\mathrm{BR} \sim 0)$ \\
Burnup, Damage (initial values) & $5 \% \mathrm{FIMA} ; 80 \mathrm{dpa}$ \\
\hline
\end{tabular}


The goal of the current materials R\&D plan being developed for the GFR is to examine those materials issues that are expected to potentially limit the viability of the overall system, such as neutronically acceptable core and reactor vessel internals materials. Since detailed component designs, particularly for the reactor core and internals, are unavailable at this early stage in the GFR system design, much of the materials research identified in this plan will focus on identification and viability of materials that meet the conditions that will likely envelop specific components. Where component designs are relatively more mature, such as for the reactor pressure vessel, more specific research tasks are identified.

Considering that many of the materials issues faced by the GFR, outside of the core region, are similar to those for the NGNP that is being developed on a significantly more rapid time scale than the GFR, it is being assumed that any relevant materials R\&D performed for the NGNP will be available and hence will not be repeated within the GFR materials R\&D plan. The resulting GFR materials scoping R\&D plan contained herein is designed to provide the information needed on capabilities of current materials or those that can developed in time to allow a decision on the overall viability of the GFR system concept by 2010 . Potential showstoppers will be identified and resolved. The information generated during this stage of the R\&D is sufficient for the conceptual design of a prototype. It is not sufficient for the final design of the plant. The extended research required to provide the extensive data bases needed to qualify the candidate materials identified during the GFR materials scoping studies, detailed in this document, will be addressed at the conclusion of these studies and after the decision to proceed to the design phase has been made.

\subsubsection{GFR Component Description and Operating Conditions}

\subsubsection{Operating Conditions for Nonmetallic Core Components and Reactor Internals}

Ceramics are being considered for in-core application in the GFR primarily due to their retention of high-temperature properties. Components for which ceramics are the likely option include the reflector, control rod guides, and the upper and lower support plates. Estimates of the temperatures for the various components for each of the design types are provided Table 7 , and range from as low as $300^{\circ} \mathrm{C}$ to as high as $1000^{\circ} \mathrm{C}$. The temperatures listed could change based on the materials used, the effectiveness of the decay heat removal system, and the core design. For all cases, the expected neutron dose is quite high, exceeding $100 \mathrm{dpa}$. The wide range in service temperatures will require likely require the use of several different materials as the radiation resistance of ceramic and ceramic composite materials is strongly affected by temperature of service.

\subsubsection{Operating Conditions for Metallic Core Components and Reactor Internals}

The main core components and their estimated operating conditions are summarized in Table 7. Three different designs will need to be considered as described earlier: the reference design (He direct), alternate design 1 ( $\mathrm{He} / \mathrm{CO}_{2}$ indirect), and alternate design 2 ( $\mathrm{S}-\mathrm{CO}_{2}$ direct). Because the outlet temperatures vary by $300^{\circ} \mathrm{C}$, the structural materials in these three designs will experience substantially different temperatures. Therefore, the candidate materials for specific components in each design will differ in specific cases.

There are several distinct possibilities for the core design. These include the prismatic design where the core is constructed of blocks that incorporate the fuel. Other designs call for more or less conventional rods or plates that clad the fuel or for pebble bed arrangements contained within a core supporting basket-like structure. Control rods and associated sheaths or guides 
are additional in-core components that must be considered. The configurations of in-core structures will be quite different depending on the design chosen. However, all have in common the need to perform under approximately the same high fast neutron fluxes and high temperatures.

The main in-vessel structures outside the core region are the gas duct barrel, hot gas duct, grid plate, upper and lower core support components and thermal insulation. Again, three different designs will need to be considered as described above. Relative to the NGNP, some of the components in the GFR will experience higher temperatures, especially under off-normal conditions. The GFR core barrel, for example, is currently estimated to operate at temperatures up to $850^{\circ} \mathrm{C}$, while that for the NGNP is $600^{\circ} \mathrm{C}$. For off-normal conditions, the corresponding temperatures are 1200 and $1070^{\circ} \mathrm{C}$, respectively. As shown in Table 7 , the normal operating and off-normal temperatures decrease from the reference design to the $\mathrm{He} / \mathrm{S}-\mathrm{CO}_{2}$ indirect design and further decrease to the $\mathrm{S}-\mathrm{CO}_{2}$ direct design. The $\mathrm{S}-\mathrm{CO}_{2}$ design, however, presents a different set of compatibility issues with the use of supercritical $\mathrm{CO}_{2}$ as the coolant. For the reference design and the $\mathrm{He} / \mathrm{S}-\mathrm{CO}_{2}$ design, the most significant demands placed on the reactor internals are the temperatures at which they will be required to operate and the radiation doses to which they will be exposed. For the $\mathrm{S}-\mathrm{CO}_{2}$ design, the radiation doses and exposure to the supercritical $\mathrm{CO}_{2}$ are the most significant operational parameters.

\subsubsection{Operating Conditions for Reactor Pressure Vessel}

The reactor pressure vessel system envisioned for the GFR is similar in many respects to that of the NGNP. It will comprise a large RPV containing the core and internals, a second large vessel for power conversion containing the main turbine, generator, and associated turbo machinery and heat exchangers, and a pressure-containing CV joining the RPV and the PCV. A summary of the anticipated operating conditions for the pressure vessel system is provided in Table 7. Reference [2.1] provides the relevant material needs for the NGNP pressure vessel. The NGNP materials report describes candidate pressure vessel material for lower $\left(850^{\circ} \mathrm{C}\right.$ outlet) and higher (up to $1000^{\circ} \mathrm{C}$ outlet) gas-cooled systems. The outlet temperature envisioned for the GFR is $850^{\circ} \mathrm{C}$. It is noted that the preliminary RPV size for the GFR indicates a smaller diameter and smaller height than that for the NGNP, while the thicknesses are also less, except in the case of the S-CO $\mathrm{CO}_{2}$ design for which the RPV will need to be appreciably thicker than the NGNP vessel. The vessels will be exposed to air on the outside and either helium or supercritical $\mathrm{CO}_{2}$ on the inside. The materials tentatively selected for gas-cooled RPV service are low-alloy F/M steels, alloyed primarily with chromium and molybdenum. The most significant demands placed on the RPV system are the temperatures at which they will be required to operate. Although the currently envisaged operating and off-normal conditions are shown in the Table 7, there are uncertainties regarding the actual temperatures and times, loads, load-time history, time-temperature-load histories, and the temperature and neutron flux gradients through the RPV wall, especially for the $\mathrm{S}-\mathrm{CO}_{2}$ design. Moreover, there is no current estimate for fatigue cycles for the RPV system, although the estimate for the NGNP is for about 150 cycles plus hydrogen cycles for a total of about 600 small cycles. It is recognized that the normal operating temperatures for the RPV system are dependent on the capabilities of the materials of construction. Thus, an iterative approach will be required to eventually match the limiting material capabilities and the design operating conditions. 
Table 7. Normal and off-normal conditions for GFR vessel, core, and internals.

\begin{tabular}{|c|c|c|c|c|c|}
\hline \multirow[t]{2}{*}{ Component } & \multirow[t]{2}{*}{ Design Option } & \multicolumn{2}{|c|}{ Normal Conditions } & Off-Normal Conditions & \multirow[b]{2}{*}{ Notes } \\
\hline & & Temperature & Peak Dose & Temperature & \\
\hline \multirow{3}{*}{$\begin{array}{l}\text { Fuel Matrix- } \\
\text { Cladding }\end{array}$} & He direct & $1200^{\circ} \mathrm{C}$ & \multirow{3}{*}{$\begin{array}{c}15-20 \\
\text { dpa/yr, total } \\
60 \mathrm{dpa}\end{array}$} & Up to $1800^{\circ} \mathrm{C}$ & \\
\hline & $\begin{array}{c}\mathrm{He} / \mathrm{S}-\mathrm{CO}_{2} \\
\text { indirect }\end{array}$ & $1000^{\circ} \mathrm{C}$ & & Up to $1600^{\circ} \mathrm{C}$ & \\
\hline & $\mathrm{S}-\mathrm{CO}_{2}$ direct & $900^{\circ} \mathrm{C}$ & & $1100-1500^{\circ} \mathrm{C}$ & $\begin{array}{l}\text { It may be possible to use metals in } \\
\text { the core, depending on configuration }\end{array}$ \\
\hline \multirow{3}{*}{$\begin{array}{l}\text { Spacers/Wire } \\
\text { Wrap }\end{array}$} & He direct & $490-1000^{\circ} \mathrm{C}$ & \multirow{3}{*}{$\begin{array}{l}15-20 \\
\text { dpa/yr, total } \\
60 \mathrm{dpa}\end{array}$} & Up to $1600^{\circ} \mathrm{C}$ & \\
\hline & $\begin{array}{c}\mathrm{He} / \mathrm{S}-\mathrm{CO}_{2} \\
\text { indirect }\end{array}$ & $300-800^{\circ} \mathrm{C}$ & & Up to $1400^{\circ} \mathrm{C}$ & \\
\hline & $\mathrm{S}-\mathrm{CO}_{2}$ direct & $400-700^{\circ} \mathrm{C}$ & & $900-1300^{\circ} \mathrm{C}$ & \\
\hline \multirow{3}{*}{$\begin{array}{c}\text { Fuel } \\
\text { Subassembly }\end{array}$} & He direct & $490-1000^{\circ} \mathrm{C}$ & \multirow{3}{*}{$\begin{array}{l}15-20 \\
\text { dpa/yr, total } \\
60 \mathrm{dpa}\end{array}$} & Up to $1600^{\circ} \mathrm{C}$ & \\
\hline & $\begin{array}{c}\mathrm{He} / \mathrm{S}-\mathrm{CO}_{2} \\
\text { indirect }\end{array}$ & $300-800^{\circ} \mathrm{C}$ & & Up to $1400^{\circ} \mathrm{C}$ & \\
\hline & $\mathrm{S}-\mathrm{CO}_{2}$ direct & $400-700^{\circ} \mathrm{C}$ & & $900-1300^{\circ} \mathrm{C}$ & \\
\hline \multirow{3}{*}{$\begin{array}{l}\text { Fuel } \\
\text { Subassembly } \\
\text { Duct }\end{array}$} & He direct & $490-1000^{\circ} \mathrm{C}$ & \multirow{3}{*}{$\begin{array}{c}15-20 \\
\text { dpa/yr, total } \\
60 \mathrm{dpa}\end{array}$} & Up to $1600^{\circ} \mathrm{C}$ & \\
\hline & $\begin{array}{c}\mathrm{He} / \mathrm{S}-\mathrm{CO}_{2} \\
\text { indirect }\end{array}$ & $300-800^{\circ} \mathrm{C}$ & & Up to $1400^{\circ} \mathrm{C}$ & \\
\hline & $\mathrm{S}-\mathrm{CO}_{2}$ direct & $400-700^{\circ} \mathrm{C}$ & & $900-1300^{\circ} \mathrm{C}$ & \\
\hline \multirow[t]{3}{*}{ Reflector } & He direct & $490-850^{\circ} \mathrm{C}$ & \multirow{3}{*}{$\begin{array}{l}\text { Up to } 150 \\
\text { dpa }\end{array}$} & Up to $1100^{\circ} \mathrm{C}$ & \multirow{3}{*}{$\begin{array}{l}\text { Normal operating temperatures are } \\
\text { conservative; the high end may be } \\
\text { less. }\end{array}$} \\
\hline & $\begin{array}{c}\mathrm{He} / \mathrm{S}-\mathrm{CO}_{2} \\
\text { indirect }\end{array}$ & $300-650^{\circ} \mathrm{C}$ & & Up to $900^{\circ} \mathrm{C}$ & \\
\hline & $\mathrm{S}-\mathrm{CO}_{2}$ direct & $400-550^{\circ} \mathrm{C}$ & & Up to $800^{\circ} \mathrm{C}$ & \\
\hline \multirow{3}{*}{$\begin{array}{l}\text { Control Rod } \\
\text { Guide }\end{array}$} & He direct & $490-1000^{\circ} \mathrm{C}$ & \multirow{3}{*}{$\begin{array}{l}\text { Up to } 200 \\
\text { dpa }\end{array}$} & Up to $1600^{\circ} \mathrm{C}$ & \\
\hline & $\begin{array}{c}\mathrm{He} / \mathrm{S}-\mathrm{CO}_{2} \\
\text { indirect }\end{array}$ & $300-800^{\circ} \mathrm{C}$ & & Up to $1400^{\circ} \mathrm{C}$ & \\
\hline & $\mathrm{S}-\mathrm{CO}_{2}$ direct & $400-700^{\circ} \mathrm{C}$ & & $900-1300^{\circ} \mathrm{C}$ & \\
\hline \multirow{3}{*}{$\begin{array}{c}\text { Upper } \\
\text { Support Plate }\end{array}$} & He direct & $850^{\circ} \mathrm{C}$ & \multirow{3}{*}{$\begin{array}{l}\text { Up to } 100 \\
\text { dpa }\end{array}$} & Up to $1200^{\circ} \mathrm{C}$ & \multirow{2}{*}{$\begin{array}{l}\text { Normal operating temperatures } \\
\text { assume the gas is well mixed at the } \\
\text { core exit. }\end{array}$} \\
\hline & $\begin{array}{c}\mathrm{He} / \mathrm{S}-\mathrm{CO}_{2} \\
\text { indirect }\end{array}$ & $650^{\circ} \mathrm{C}$ & & Up to $1000^{\circ} \mathrm{C}$ & \\
\hline & $\frac{\mathrm{S}-\mathrm{CO}_{2} \text { direct }}{\mathrm{He} \text { direct }}$ & $\frac{550^{\circ} \mathrm{C}}{490^{\circ} \mathrm{C}}$ & & $\begin{array}{l}\text { Up to } 900^{\circ} \mathrm{C} \\
\text { Up to } 750^{\circ} \mathrm{C}\end{array}$ & \\
\hline \multirow{2}{*}{$\begin{array}{c}\text { Lower } \\
\text { Support Plate }\end{array}$} & $\mathrm{He} / \mathrm{S}-\mathrm{CO}_{2}$ & $300^{\circ} \mathrm{C}$ & \multirow[t]{2}{*}{$\begin{array}{l}\text { Up to } 100 \\
\text { dpa }\end{array}$} & Up to $550^{\circ} \mathrm{C}$ & \\
\hline & $\mathrm{S}-\mathrm{CO}_{2}$ direct & $400^{\circ} \mathrm{C}$ & & Up to $600^{\circ} \mathrm{C}$ & \\
\hline \multirow[t]{3}{*}{ Core Barrel } & He direct & $490-850^{\circ} \mathrm{C}$ & \multirow{3}{*}{$80-100$ dpa } & Up to $1100^{\circ} \mathrm{C}$ & \\
\hline & $\begin{array}{c}\mathrm{He} / \mathrm{S}-\mathrm{CO}_{2} \\
\text { indirect }\end{array}$ & $300-650^{\circ} \mathrm{C}$ & & Up to $900^{\circ} \mathrm{C}$ & \\
\hline & $\mathrm{S}-\mathrm{CO}_{2}$ direct & $400-550^{\circ} \mathrm{C}$ & & Up to $800^{\circ} \mathrm{C}$ & \\
\hline \multirow{3}{*}{$\begin{array}{l}\text { Pressure } \\
\text { Vessel }\end{array}$} & He direct & $490-850^{\circ} \mathrm{C}$ & \multirow{3}{*}{$\begin{array}{l}<1 \text { dpa to } \\
40 \text { dpa }\end{array}$} & Up to $1100^{\circ} \mathrm{C}$ & \multirow{3}{*}{$\begin{array}{l}\text { Dose is dependent on shielding } \\
\text { used, and off-normal temperatures } \\
\text { can be significantly reduced if } \\
\text { insulation is used. }\end{array}$} \\
\hline & $\begin{array}{c}\mathrm{He} / \mathrm{S}-\mathrm{CO}_{2} \\
\text { indirect }\end{array}$ & $300-650^{\circ} \mathrm{C}$ & & Up to $900^{\circ} \mathrm{C}$ & \\
\hline & $\mathrm{S}-\mathrm{CO}_{2}$ direct & $400-550^{\circ} \mathrm{C}$ & & Up to $800^{\circ} \mathrm{C}$ & \\
\hline
\end{tabular}




\subsubsection{Operating Conditions for High Temperature Metallic Components}

For selecting high-temperature metallic materials, considerations of the GFR operating conditions are focused on components that operate outside of the intense radiation field. Such components include piping and heat exchangers. Further, high-temperature materials for the power conversion components, such as the turbine, compressors, coolers, and recuperators, are discussed in the following section. In this sense, the operating conditions of the GFR hightemperature materials differ from the case of the NGNP, where internal metallic support components are subjected to much lower neutron fluences and are included in the category of high-temperature materials.

The anticipated temperatures in the three proposed GFR designs are all relatively lower than those of the NGNP. The reference He-cooled design operates with an outlet temperature of $850^{\circ} \mathrm{C}$ at $7 \mathrm{MPa}$; the $\mathrm{He}-\mathrm{S}-\mathrm{CO}_{2}$ indirect option has an outlet temperature of $600-650^{\circ} \mathrm{C}$ at $7 \mathrm{MPa}$ with a $550^{\circ} \mathrm{C}$ secondary at $20 \mathrm{MPa}$; and the all-S- $\mathrm{CO}_{2}$ will operate with an outlet temperature of $550^{\circ} \mathrm{C}$ at $20 \mathrm{MPa}$. The all-He direct design of NGNP performs with an outlet temperature of up to $1000^{\circ} \mathrm{C}$ at $7.4 \sim 8 \mathrm{MPa}$. From an operating temperature point of view, the candidate high temperature metallic materials for NGNP can be directly considered for GFR applications, with the understanding that since radiation doses in the GFR will be much higher than the NGNP, alloy selection must also address radiation resistance.

As to environmental conditions, the "all-He direct" design option of GFR adds concerns for the effects of helium impurity contaminations that could be more severe than the NGNP, as discussed in sections on power conversion and general corrosion considerations. The other two design options, $\mathrm{He}-\mathrm{S}-\mathrm{CO}_{2}$ indirect and all-S- $\mathrm{CO}_{2}$, add significant compatibility challenges at the anticipated service temperatures.

\subsubsection{Operating Conditions for Power Conversion Components}

The GFR reference design power conversion system is very similar to that for the NGNP and essentially identical in terms of components, pressures, and temperatures to that for the GTMHR. The temperature of the GT-MHR He coolant entering the turbine is $\sim 850^{\circ} \mathrm{C}$ and the temperature at the recuperator inlet is nominally $500^{\circ} \mathrm{C}$. Maximum temperatures in the highand low-pressure compressors and the intercooler and precooler are very significantly lower $\left(<150^{\circ} \mathrm{C}\right)$. The two alternate designs utilize $\mathrm{S}-\mathrm{CO}_{2}$ at $20 \mathrm{MPa}$ in their power conversion systems. One design has He primary coolant at $600-650^{\circ} \mathrm{C}$ transferring heat through an IHX to secondary system supercritical $\mathrm{CO}_{2}$; the $\mathrm{CO}_{2}$ enters the power conversion turbine at $550^{\circ} \mathrm{C}$ (indirect Brayton cycle). The other alternate design utilizes a direct Brayton cycle for power conversion with the primary coolant supercritical $\mathrm{CO}_{2}$ also entering the turbine at $550^{\circ} \mathrm{C}$.

\subsubsection{General Materials Compatibility Considerations in GFR Environments}

The GFR reference design, like thermal-spectrum helium-cooled reactors such as the GT-MHR and the PBMR, uses a direct-cycle helium turbine for electricity generation and generates process heat for thermochemical production of hydrogen. This reference design shares many materials requirements in common with the NGNP. However, the temperatures and composition of the environment are somewhat different. One alternate design also uses a helium-cooled system with an indirect Brayton cycle for power conversion. The secondary system of this alternate design utilizes $\mathrm{S}-\mathrm{CO}_{2}$ at $550^{\circ} \mathrm{C}$ and $20 \mathrm{MPa}$. A second optional design 
is a supercritical $\mathrm{CO}_{2}$ cooled $\left(550^{\circ} \mathrm{C}\right.$ outlet and $\left.20 \mathrm{MPa}\right)$, direct Brayton cycle system. From a corrosion viewpoint, the pressure vessel will operate in air and the internals of reactor will operate in either helium or S- $\mathrm{CO}_{2}$ environments.

For the helium-cooled reactor, it is expected that:

- Inlet/outlet temperatures will be $550 / 850^{\circ} \mathrm{C}$;

- Surface temperatures of materials in the core in contact with the coolant during normal operation will be in the range of 800 to $1000^{\circ} \mathrm{C}$; and

- Surface temperature of materials in the core in contact with the coolant under accident conditions will be in the range 1400 to $1600^{\circ} \mathrm{C}$ for approximately 6 hours (time required for the temperature to rise from normal operating to accident peak and return to near normal operating temperature).

For the $\mathrm{S}-\mathrm{CO}_{2}$-cooled reactor, it is expected that:

- Inlet/outlet temperatures will be $550 / 650^{\circ} \mathrm{C}$;

- Surface temperatures of materials in the core in contact with the coolant during normal operation will be approximately $650^{\circ} \mathrm{C}$; and

- Surface temperature of materials in the core in contact with the coolant under accident conditions will be approximately $1000^{\circ} \mathrm{C}$ for approximately 6 hours (time required for the temperature to rise from normal operating to accident peak and return to near normal operating temperature).

Helium Environment-The interactions between structural materials in controlled-impurity helium atmospheres associated with gas cooled reactors have been the subject of numerous investigations [2.9]. The results of these studies conducted by various organizations in the USA, Germany, England, Norway, Japan, and other places have demonstrated the importance of small changes in impurity levels, high temperatures, and high gas flow rates. Metallic materials can be carburized or decarburized, and oxidized internally or at the surface. These corrosion reactions, depending on the rate, can affect long-term mechanical properties such as fracture toughness.

The simulated advanced high-temperature gas-cooled reactor (HTGR) helium chemistries used in various test programs are shown in Table 8. Because of the low partial pressures of the impurities, the oxidation/carburization potentials at the metallic surface of a gas mixture are established by the kinetics of the individual impurity catalyzed reactions at the surface. As shown, the main impurities are $\mathrm{H}_{2}, \mathrm{H}_{2} \mathrm{O}, \mathrm{CO}$ and $\mathrm{CH}_{4}$. The hot graphite core in an HTGR is assumed to react with all free $\mathrm{O}_{2}$ and much of the $\mathrm{CO}_{2}$ to form $\mathrm{CO}$, and with $\mathrm{H}_{2} \mathrm{O}$ to form $\mathrm{CO}$ and $\mathrm{H}_{2}$. In addition, in cooler regions of the core, $\mathrm{H}_{2}$ reacts with the graphite via radiolysis to produce $\mathrm{CH}_{4}$. Because of the change in surface temperatures around the reactor, and associated changes in reaction mechanisms and rates of reaction on bare metal versus on scaled surfaces, reaction rates and order of reactions are important.

Because of there being little or no graphite in the proposed GFR reactor, the composition of the helium environment may be somewhat different from that for which materials test data are available. Assuming zero graphite, the GFR environment should contain near zero levels of $\mathrm{CH}_{4}$, less $\mathrm{CO}_{2}$ and $\mathrm{CO}$, about the same amount of nitrogen, and more moisture and oxygen than previous helium cooled reactors. However, the surface temperatures are within the range of previous tests. Because it is possible to treat a side stream of the helium environment to reduce the oxygen and moisture, it is very likely that the GFR helium environment can be 
controlled to compositions very similar to that of previous reactors, if desired. As such, the materials' performance issues are mostly known.

Table 8. Composition of helium environments (advanced HTGR) used in past tests.

\begin{tabular}{|c|c|c|c|c|c|c|c|}
\hline Program & 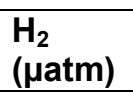 & $\begin{array}{l}\mathrm{H}_{2} \mathrm{O} \\
\text { ( } \mu \text { atm) }\end{array}$ & 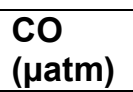 & 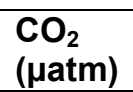 & $\begin{array}{l}\mathrm{CH}_{4} \\
\text { ( } \text { (uatm) }\end{array}$ & $\begin{array}{l}\mathbf{N}_{2} \\
\text { ( } \mu \text { atm) }\end{array}$ & $\begin{array}{l}\text { He (atm } \\
\text { absolute) }\end{array}$ \\
\hline $\mathrm{NPH} / \mathrm{HHT}$ & 500 & 1.5 & 40 & & 50 & $5-10$ & 2 \\
\hline PNP & 500 & 1.5 & 15 & & 20 & $<5$ & 2 \\
\hline AGCNR & 400 & 2 & 40 & 0.2 & 20 & $<20$ & 2 \\
\hline $\begin{array}{l}\text { NPH: Nucl } \\
\text { HHT: High } \\
\text { PNP: Protc } \\
\text { AGCNR: A }\end{array}$ & $\begin{array}{l}\text { process } \\
\text { iperature } \\
\text { e Nuclea } \\
\text { nced Ga }\end{array}$ & oled N & $\mathrm{r} \operatorname{Re}$ & & & & \\
\hline
\end{tabular}

The overall stability of the proposed helium environment must be evaluated in order to ensure that testing proposed in various sections of the program are performed in environments that have consistent chemical potentials. In addition, the corrosion of metals and nonmetals will be evaluated to establish baseline data where it does not exist. These tests will be performed at temperatures to include at least $50^{\circ} \mathrm{C}$ above the proposed operating temperature.

Supercritical $\mathrm{CO}_{2}$ Environment-The chemical potential of the alternate $\mathrm{S}-\mathrm{CO}_{2}$ environment will, at least from a thermodynamic viewpoint, be oxidizing. It is also possible that under certain conditions, the environment may be carburizing. The long-term performance of materials under the oxidizing and/or carburizing conditions must be established for the $\mathrm{S}-\mathrm{CO}_{2}$ environment at temperatures relevant to the GFR, where little data currently exist. Corrosion of metals and nonmetals will be evaluated to establish baseline data. These tests will be performed at temperatures to include at least $50^{\circ} \mathrm{C}$ above the proposed operating temperature. In addition, the spalling, transport, and deposition of radiological corrosion products must be evaluated for the direct $\mathrm{S}-\mathrm{CO}_{2}$ Brayton cycle system.

\subsubsection{High-Temperature Design Methodology Considerations}

The impact and requirements of high temperature design methodology (HTDM) and possible codification needs will vary for each of the three proposed GFR designs. Earlier sections in this report adequately cover these conditions. HTDM and codification of materials and components that operate inside vs. outside the high radiation field will differ. Likewise, HTDM requirements for power conversion components will differ. Several materials may be used in more than one design, although use conditions may differ; consequently, the HTDM requirements may vary accordingly. Regardless, the basic framework for HTDM will be the same for all materials and designs. HTDM issues are considered for the power conversion, reactor core, reactor internals, pressure vessel, and piping and heat exchanger systems. Each is addressed separately as follows.

Power Conversion Components-ASME Section III codification is not believed to be required for GFR power conversion components. As in the NGNP qualification program, the materials R\&D plan for materials selection and qualification will be made by the turbine manufacturer; notwithstanding, the assessment of viability of preliminary candidate materials for use in $\mathrm{S}-\mathrm{CO}_{2}$ is included in the GFR plans as stated earlier. 
Pressure Vessel, Piping, and Heat Exchanger-The GFR HTDM and codification requirements for pressure vessel, piping, and heat exchangers are covered by the NGNP plans. The nature of the GFR will result in significantly higher doses of radiation to core and reactor internals than the NGNP designs. Although the GFR pressure vessel will experience a higher dose level than the NGNP pressure vessel, the primary candidate pressure vessel materials response is reasonably well understood at the doses anticipated. Similarly, the operating conditions of piping and heat exchangers, where intense radiation exposure is not present, are within the envelope of the NGNP designs. No additional work will be required in this area to establish GFR viability unless alternate materials are required.

Core Components and Reactor Internals-Significantly higher doses of radiation to core and reactor internals will occur relative to NGNP components. This in itself, even in cases where the same materials as proposed for the NGNP designs will be used, requires substantial R\&D to assess viability. Further, estimated normal and off-normal operating temperatures are much higher than in the NGNP designs. This is a significant challenge.

\subsection{Materials Requirements For Nuclear Hydrogen Generation Systems}

As part of the Gen IV Integrated Materials Plan, it is appropriate to consider the materials challenges associated with hydrogen generation systems and the anticipated R\&D needed to meet those challenges. While the bulk of the materials R\&D for hydrogen generation systems will be the responsibility of the $\mathrm{NHI}$, it is valuable to include the work within the integrated materials R\&D plan to minimize duplication and optimize synergistic interactions with the work being performed in support of the Gen IV reactor systems.

Currently, the $\mathrm{NHI}$ is investigating both high temperature electrolysis and thermochemical cycles as candidate technologies for the nuclear hydrogen production systems anticipated to be deployed in conjunction with Gen IV reactor concepts. The focus of thermochemical cycle R\&D is on the sulfur based cycles - Sulfur-lodine and Hybrid Sulfur, which involve temperatures in the range of 800 to $1000^{\circ} \mathrm{C}$ and corrosive environments. The Calcium-Bromine cycle is also being evaluated which involves lower peak temperatures $\left(\sim 760^{\circ} \mathrm{C}\right)$. High temperature electrolysis involves temperatures up to $1000^{\circ} \mathrm{C}$ in a steam environment. The multiple technologies provide methods of hydrogen production that could be coupled to the fairly wide range of operating conditions of the different Gen IV reactor concepts, while at the same time providing multiple, potentially redundant paths to minimize risk. Each technology has unique materials challenges that will need to be addressed to enable its successful deployment.

In the past two years, an assessment of the proposed hydrogen production technologies and their associated materials requirements has been performed. It has been led by the $\mathrm{NHI}$ program manager with strong support from the Gen IV materials NTD and staff. Extensive input has been obtained from commercial, academic, and national laboratory experts regarding both the anticipated configurations and operating conditions for each technology as well as the resulting materials challenges. In this iteration of the materials R\&D plans for $\mathrm{NHI}$, high-level materials needs and approaches to addressing them are provided, along with a general priority for the work. The priorities are jointly derived from the criticality of the topic for establishing the viability of the process and early identification of candidate materials to meet that need.

In the sections that follow, descriptions of the three current leading candidate technologies for nuclear hydrogen production are provided along with the anticipated component operating conditions and the resulting prioritized materials R\&D program required to support selection and deployment of the more promising systems. 


\subsubsection{Nuclear Hydrogen Generation System Descriptions}

The two leading candidate systems for production of nuclear hydrogen are the Sulfur lodine (SI) thermochemical cycle and High Temperature Electrolysis (HTE). A second thermochemical cycle that operates efficiently at lower temperatures, the Calcium-Bromine (Ca-Br) cycle is also being evaluated.

\subsubsection{Thermochemical S-I Cycle}

The Sulfur lodine (SI) water splitting cycle for hydrogen production consists of three coupled chemical reactions as shown in Figure 18. First, sulfuric acid and hydrogen iodide are generated in the central low temperature reaction, a.k.a. the Bunsen reaction. The reaction products, sulfuric acid and hydrogen iodide are then decomposed at high and intermediate temperatures respectively in the other two reactions. There are significant chemical separations associated with each chemical reaction. Water is the primary solvent in the system with iodine being an important solvent in the Bunsen reaction. Since the reactants in the SI cycle are recycled through the multiple sections, the only significant inputs to the system are high-temperature process heat and water and the only outputs are hydrogen and oxygen.
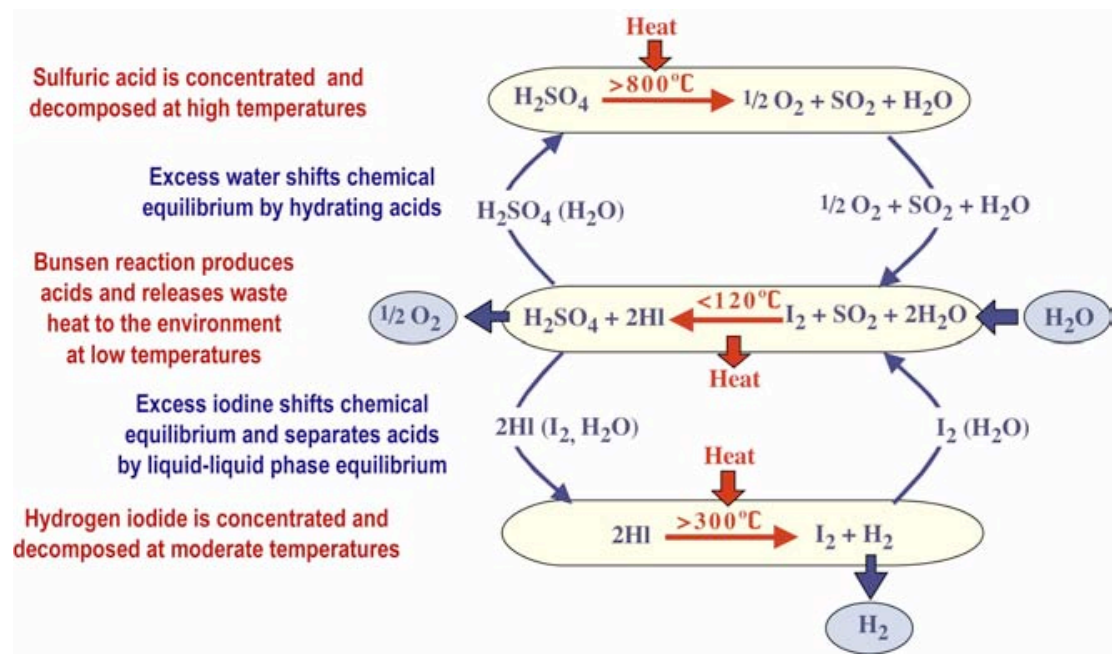

Fig. 18. The Coupled Chemical Reactions of the SI Cycle.

The baseline design for the current SI work has been recently described [2.10]. The overall SI cycle can be divided into three sections:

- Section 1 - Sulfuric Acid and Hydriodic Acid Generation

This Section receives the decomposed sulfuric acid from Section 2 and iodine from Section 3 and uses the Bunsen reaction to produce hydrogen iodide for Section 3. The dilute sulfuric acid is returned to Section 2.

- Section 2 - Sulfuric Acid Concentration and Decomposition

This Section concentrates the sulfuric acid received from Section 1, and then decomposes it into sulfur dioxide, oxygen and water. The decomposed products are returned to Section 1. 
- Section 3 - Hydrogen lodide Decomposition

This Section receives hydrogen iodide from Section 1 and decomposes it to produce hydrogen and iodine. The iodine and un-reacted hydrogen iodide are streamed back into to Section 1.

The three sections include extremely corrosive working environments over a wide range of temperatures and pressures. In order to realize a stable, safe and functional hydrogen production plant, careful selection and qualification of materials used to manufacture the reaction chambers, heat exchangers and other components for each section must be made.

Multiple approaches for generation of hydrogen that utilize sulfuric acid concentration and decomposition as the high-temperature step have been examined. These include the reference case described herein, in which $\mathrm{HI}$ decomposition is accomplished without first extracting the $\mathrm{HI}$ from HIx and an alternate case where phosphoric acid is used to separate the iodine from HIx, thus allowing the $\mathrm{HI}$ to be isolated for decomposition. Additional approaches include following the sulfuric acid decomposition with high temperature electrolysis in a hybrid process. At this point in time, materials needs are considered for the reference case and, to a lesser degree, for the phosphoric acid process. An overview of the SI reference case processing sections is provided below.

\section{Section 1 - Sulfuric Acid and Hydriodic Acid Generation}

The bulk of the Bunsen reaction: $\mathrm{I}_{2}+\mathrm{SO}_{2}+2 \mathrm{H}_{2} \mathrm{O} \rightarrow \mathrm{H}_{2} \mathrm{SO}_{4}+2 \mathrm{HI}$ is currently designed to occur in a heat exchange reactor at elevated pressure. These reaction species also occur in primary and secondary oxygen scrubbers and an $\mathrm{H}_{2} \mathrm{SO}_{4}$ boost reactor.

The output from the main heat exchange reactor consists of three phases that are separated and then processed separately. The gas phase consists of residual $\mathrm{SO}_{2}$ in $\mathrm{O}_{2}$ and this $\mathrm{SO}_{2}$ is removed by the $\mathrm{O}_{2}$ scrubbers. The majority of $\mathrm{O}_{2}$ is vented to atmosphere but a portion is recycled and is used to strip any $\mathrm{SO}_{2}$ remaining in the dense $\mathrm{HIx}$ liquid. The processed $\mathrm{HIx}$ liquid is sent to Section 3 for decomposition. The stripped $\mathrm{SO}_{2}$ is used to react with the water in the light-liquid phase in the $\mathrm{H}_{2} \mathrm{SO}_{4}$ boost reactor. The iodine stream exiting from the boost reactor bottom contains the $\mathrm{HI}$ formed in the boost reactor along with the water required to solubilize the HI. This stream is pumped to the heat exchanger. The overhead liquid product of the boost reactor is passed on to Section 2, where the $\mathrm{H}_{2} \mathrm{SO}_{4}$ is concentrated and decomposed.

Any $\mathrm{SO}_{2}$ remaining in the sulfuric acid is recycled to the beginning of Section 1 , along with water flashed from the sulfuric acid. The gaseous product of the boost reactor is scrubbed in the secondary scrubber, along with the exhaust from the $\mathrm{SO}_{2}$ absorber. The gaseous product of the $\mathrm{O}_{2}$ scrubbers is vented and contains one-half mole of oxygen for every mole of hydrogen produced in the overall process. In a mature hydrogen economy, the oxygen will likely be vented to the atmosphere but for initial plants, the oxygen co-product may be collected for sale. The liquid products of the two oxygen scrubbers are combined with a portion of the $\mathrm{HI} / \mathrm{H}_{2} \mathrm{O}$ recycled from Section 3. This combined stream is used to adsorb much of the $\mathrm{SO}_{2}$ stripped from the HIx.

\section{Section 2 - Sulfuric Acid Concentration and Decomposition}

The high-temperature section of the SI cycle can be described in two parts: concentration and decomposition of sulfuric acid.

\section{Concentration}

The incoming sulfuric acid from Section 1, along with the internally recycled sulfuric acid, is concentrated to about 40 mole \% in a high-pressure four-stage isobaric concentrator. The feed 
to Section 2 and the recycle stream are first pumped up to the operating pressure of the isobaric concentrator at $35 \mathrm{~atm}$ and are then preheated together before entering the concentrator. As the sulfuric acid solution flows through multiple serially connected and heated chambers within the concentrator, water is boiled off within each chamber resulting in an increase in the temperature and the acid concentration of the solution. Upon completion, the concentrator produces a liquid phase of concentrated sulfuric acid and a vapor phase of steam. The small amount of sulfur dioxide that remains in the inlet sulfuric acid is removed with the water. The water vapor boiled off from each chamber is mixed above the chambers and leaves as a single stream. The sensible and latent heat in this stream can be re-used elsewhere in this section. The mixed vapor outlet is condensed and its sensible and latent heats are recovered via a re-boiler in the vacuum distillation column.

The liquid product of the isobaric concentrator is further concentrated in a series of three reduced pressure flashes at nominal pressures of 8 bar, 2 bar and 50 torr before entering a vacuum still. Prior to the first flash, some heat is removed for use later in the process but the subsequent flashes are adiabatic. The vapor from the final adiabatic flash passes through a partial condenser. The condensed liquid from the partial condenser is fed to the vacuum still at a position appropriate to its composition.

The overhead from the still, which is nearly pure water, is returned to Section 1 . The bottom product of the distillation column is azeotropic sulfuric acid $\left(\sim 90\right.$ mole $\left.\% \mathrm{H}_{2} \mathrm{SO}_{4}\right)$ liquid at $212^{\circ} \mathrm{C}$. The concentrated sulfuric acid is pressurized and then decomposed.

\section{Decomposition}

Before the sulfuric acid can be decomposed, it must first be heated and vaporized. Some of the heat required to preheat the stream prior to vaporization is recovered from the liquid product of the isobaric concentrator but the remainder of the heat required for heating, vaporizing, and decomposing the sulfuric acid is provided by high-temperature process heat from the associated nuclear reactor. Some of the sulfuric acid decomposes into $\mathrm{SO}_{3}$ and water as it is vaporized and this reaction proceeds further as the vaporized stream is heated in the recuperator.

The recuperator retrieves much of the heat that remains after sulfuric acid decomposition. Physically, the recuperator is envisioned to be similar to a shell and tube heat exchanger, with the hot fluid flows on the tube side and the cool fluid flows on the shell side. Most of the sulfuric acid will decompose into $\mathrm{SO}_{3}$ and water before exiting the recuperator. The $\mathrm{SO}_{3}$ is then catalytically decomposed into $\mathrm{SO}_{2}$ and $\mathrm{O}_{2}$. A four-stage decomposer/reactor has been tentatively selected to improve process efficiency. As the number of stages is increased, more of the heat can be supplied to the reactor at lower temperatures.

The reactor outlet stream is cooled in the recuperator, transferring heat to its feed, as mentioned previously. The unreacted $\mathrm{SO}_{3}$ combines with water reforming $\mathrm{H}_{2} \mathrm{SO}_{4}$. The reaction products are further cooled and the heat is recovered for use within this section in the product cooler. The product cooler is physically divided into three heat exchangers. Part of the recovered heat is used for the first stage of the isobaric concentrator and the remainder is used to preheat the concentrator feed. Unrecoverable heat is lost to the cooling water. The liquid condensed in the product cooler is recycled to the isobaric concentrator and the gas phase, consisting primarily of $\mathrm{SO}_{2}$ and $\mathrm{O}_{2}$, is recycled to Section 1. The entire sulfuric decomposition reaction occurs at elevated pressure ( $\approx 7$ bar). 


\section{Section 3 - Hydrogen lodide Decomposition}

The $\mathrm{HIx}\left(\mathrm{HI}+\mathrm{I}_{2}+\mathrm{H}_{2} \mathrm{O}\right)$ product from Section 1 is further pressurized and then recuperatively heated to the feed temperature of the reactive distillation column in a network of heat exchangers. This heat is recovered from the two liquid products of the distillation column: the bottom stream contains most of the iodine, and the side outlet is made up from mostly water and hydrogen iodide.

The overhead, hydrogen-rich product of the column is scrubbed in a packed column with water to remove the residual hydrogen iodide from the hydrogen. The high pressure and low temperature of the scrubber result in a relatively low water content $(0.14$ mole $\%)$ in the resulting hydrogen product.

\subsubsection{The Calcium-Bromine Cycle}

The reference calcium-bromine $(\mathrm{Ca}-\mathrm{Br})$ cycle for hydrogen production is a variant of the UT-3 thermo-chemical cycle investigated by the Japan Atomic Energy Research Institute (JAERI). The $\mathrm{Ca}-\mathrm{Br}$ cycle is designed to operate at lower temperatures than the SI system and utilizes regenerative solid-to-gas reactions in multiple, rotating beds to produce $\mathrm{HBr}$ that is then further split to obtain hydrogen. A simplified diagram for a commercial-scale $\mathrm{Ca}$ - $\mathrm{Br}$ cycle is provided in Figure 19. As with the SI cycle where the reactants are recycled through the processing sections, the only significant inputs to the $\mathrm{Ca}-\mathrm{Br}$ system are high-temperature process heat and water and the only outputs are hydrogen and oxygen.

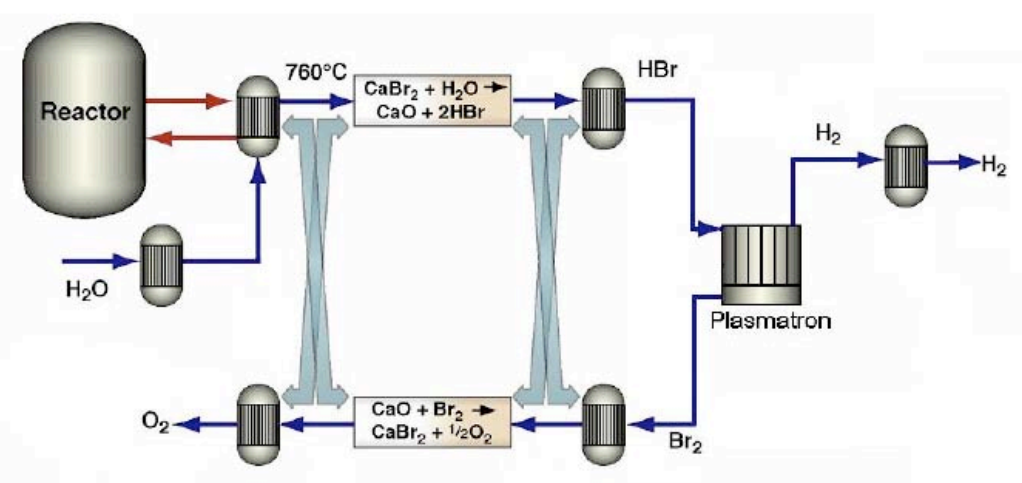

Fig. 19. Simplified diagram showing principle features of $\mathrm{Ca}-\mathrm{Br}$ water-splitting cycle.

To dissociate the $\mathrm{HBr}$ to $\mathrm{H}_{2}$ and $\mathrm{Br}_{2}$, a "plasmatron" system is envisioned. As the name suggests, this system employs plasma-chemical reactions and operates at low temperatures and pressures to produce $\mathrm{H}_{2}$ in a mix of $\mathrm{HBr}$. Following plasma-chemical reactions, the original $\mathrm{CaBr}_{2}$ reagent is regenerated during the production of oxygen. Heat is recovered from the oxygen production stage to produce electricity. A staged, plug-flow operation is employed to minimize the loss of $\mathrm{Br}_{2}$ from the process. The use of gas-solid reactions for the two stages in the proposed process will simplify separations compared with cycles based on gas/gas separations. As long as operations remain in the specified temperature ranges, byproducts such as bromine oxides $\left(\mathrm{Br}_{2} \mathrm{O} ; \mathrm{BrO}_{2}\right)$, hydrobromous acids $(\mathrm{HBrO})$, and calcium hydroxide $\mathrm{Ca}(\mathrm{OH})_{2}$ should not form. Major portions of the system are described below:

Water Splitting with $\mathrm{HBr}$ Formation

Steam is reacted with $\mathrm{CaBr}_{2}$ to crack the water and form two moles of $\mathrm{HBr}$ for every mole of 
water. Water splitting with $\mathrm{HBr}$ formation takes place at a temperature of about $760^{\circ} \mathrm{C}$ in a solidgas reaction where

$$
\mathrm{CaBr}_{2}+\mathrm{H}_{2} \mathrm{O} \rightarrow \mathrm{CaO}+2 \mathrm{HBr}[\text { Equation 1] }
$$

What is not shown in this equation is that the calcium is supported on $75 \mathrm{wt} \% \mathrm{CaTiO}_{3}$ that cycles between $\mathrm{CaBr}_{2}$ and $\mathrm{CaO}$. This stage is carried out in four plug-flow operations, and a low-moisture $\mathrm{HBr}$ product is generated during $\mathrm{H}_{2}$ production. A countercurrent flow employing four beds is envisioned. Consequently, the reaction progressively demands more cycle heat as it moves through the beds that contain higher and higher concentrations of $\mathrm{CaBr}_{2}$. The first bed contacted is low in $\mathrm{CaBr}_{2}$, while the last is nearly pure $\mathrm{CaBr}_{2}$. This endothermic reaction requires heat input directly into each of the plug flow reactor beds. As the reactants in the final bed are consumed, the bed is removed from $\mathrm{HBr}$ production and a new bed rotated into service. The beds removed from the forward $\mathrm{HBr}$ production process are then cycled through the oxygen recovery process described next, where their $\mathrm{CaBr}_{2}$ reactant content is regenerated.

\section{Oxygen Recovery}

Oxygen recovery and the regeneration of the initial $\mathrm{CaBr}_{2}$ reagent is an exothermic process at $577^{\circ} \mathrm{C}$, again in a solid-gas reaction where

$$
\mathrm{CaO}+\mathrm{Br}_{2} \rightarrow \mathrm{CaBr}_{2}+0.5 \mathrm{O}_{2}[\text { Equation 2] }
$$

This regeneration stage of the solid beds uses the $\mathrm{Br}_{2}$ reactant stream discharged from the plasmatron. As a consequence of this sequential system of reactions, there is an inherent difficulty. This difficulty is linked to the significant physical change in dimensions as the calcium cycles between bromide and oxide. The $\mathrm{CaO}$ has a cubic structure that must undergo a significant dimensional change to accommodate the $\mathrm{CaBr}_{2}$ orthorhombic structure. This process must then be reversed. As the calcium reactant undergoes this change in dimensions, sintering will likely occur unless the calcium is carefully dispersed on a suitable support and plugging of pore volumes is possible. Suitable support structures for the calcium that will tolerate this reversible cycling of plug-flow operation for $\mathrm{CaBr}_{2}$ regeneration with the liberation of oxygen must be developed.

The oxygen recovery step rejects significant heat. Possible uses of this heat include recovery within recuperators of the hydrogen production plant, desalination, or even use in a Brayton cycle to produce electric power.

\section{Hydrogen from $\mathrm{HBr}$ Dissociation}

The current reference design includes a single-stage $\mathrm{HBr}$-dissociation step. This represents a modified UT-3 cycle in which hydrogen formation will involve either $\mathrm{HBr}$ electrolysis or the use of a plasma chemistry technique operating near ambient conditions. Decomposition of $\mathrm{HBr}$ to $\mathrm{H}_{2}$ and $\mathrm{Br}_{2}$ using plasma-chemistry dissociation operates at modest process conditions $\left(\sim 100^{\circ} \mathrm{C}\right)$ in a gas phase reaction where

$$
2 \mathrm{HBr}+\text { plasma } \rightarrow \mathrm{H}_{2}+\mathrm{Br}_{2} \text { [Equation 3] }
$$

The products of decomposition $-\mathrm{H}_{2}$ and $\mathrm{Br}_{2}-$ are in different states at standard conditions, $\mathrm{H}_{2}$ is a gas and $\mathrm{Br}_{2}$ is a liquid. Additionally, the main gases involved in the process $\left(\mathrm{H}_{2}, \mathrm{HBr}\right.$, and $\mathrm{Br}_{2}$ ) have very different physical properties. Because of these differences, the direct separation of components can be expected, if a plasma chemical reactor is employed. To accomplish the separation, the $\mathrm{HBr}$ gas with recycled fluids is introduced into the plasma cavity using a 
rotational flow pattern at near-sonic speeds, creating a centrifugal separation of hydrogen products from the bromine at the periphery of the rotating flow.

This process operates at low temperatures and low pressures, making the recovery of the $\mathrm{H}_{2}$ straightforward using conventional technology. A disadvantage of this low-pressure approach is that five stages of compression (with the attendant capital and operating penalties) are required to bring the $\mathrm{H}_{2}$ to purification and pipeline operating conditions. Following compression, the small residual fraction of water and bromine carried over in the vapor phase are removed. $\mathrm{HBr}$ is recovered for recycle using pressure swing absorption (PSA), a standard $\mathrm{H}_{2}$ purification technique. PSA yields a product suitable for delivery to the $\mathrm{H}_{2}$ pipeline, completing the process.

\subsubsection{High-Temperature Electrolysis}

High-Temperature Electrolysis uses the technology of solid-oxide fuel cells (SOFCs) to split steam into hydrogen and oxygen. The cells operate at 750 to $900^{\circ} \mathrm{C}$ and have the electrical potential reversed from that of a typical fuel-cell mode. A schematic diagram of an HTE plant is shown in Figure 20 and a cross-section of an individual cell is shown in Figure 21. Nuclear hydrogen production using HTE utilizes the energy input from nuclear-reactor process heat to reduce the electrical power required to split water into hydrogen by electrolysis, thereby improving the overall efficiency of the process.

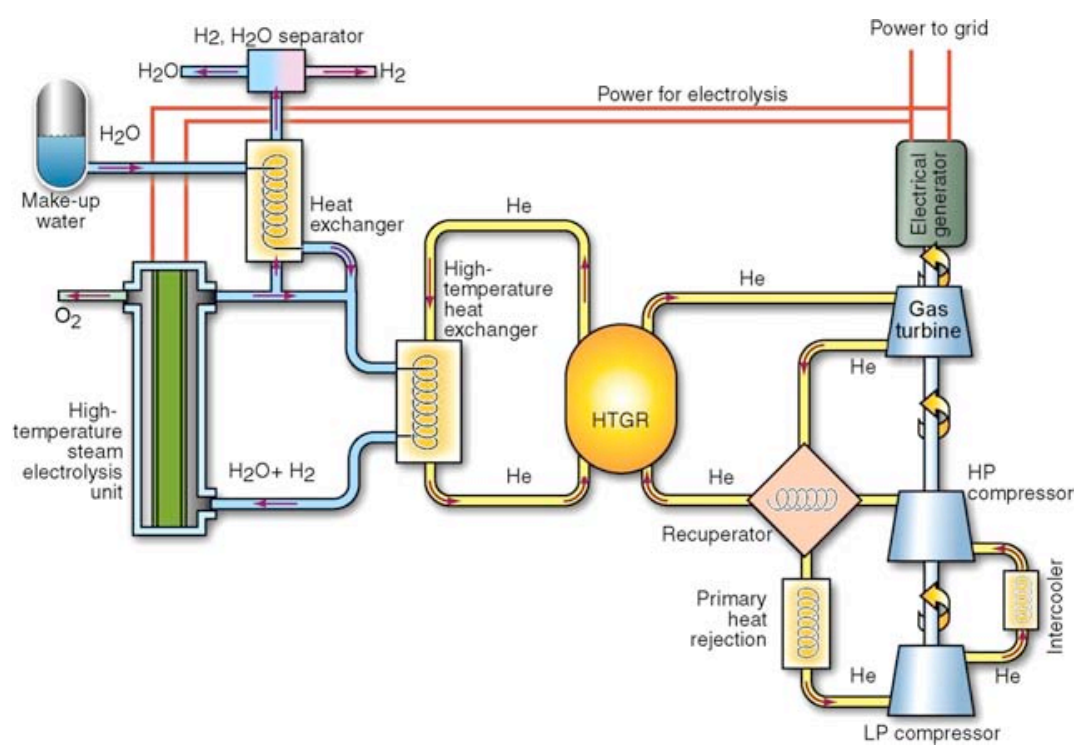

Fig. 20. Simplified diagram of a high-temperature electrolysis plant.

High-temperature electrolysis builds on the technology of SOFCs, using similar materials, but producing hydrogen and oxygen rather than electricity. DOE's Office of Fossil Energy (DOEFE) and commercial interests have had very significant programs for the last two decades to develop SOFCs, particularly for the very severe conditions associated with coal gasification. In comparison, the service conditions for a solid oxide electrolytic cell are generally more benign, operating at lower temperatures $\left(750\right.$ to $\left.900^{\circ} \mathrm{C}\right)$ with the inlet and outlet gases at the cathode consisting of only steam, hydrogen, and oxygen in differing concentrations. The anode of the electrolytic cell is the only region where conditions are likely to be more severe than an SOFC, since pure, high-temperature oxygen will be present, if no diluent is used. 


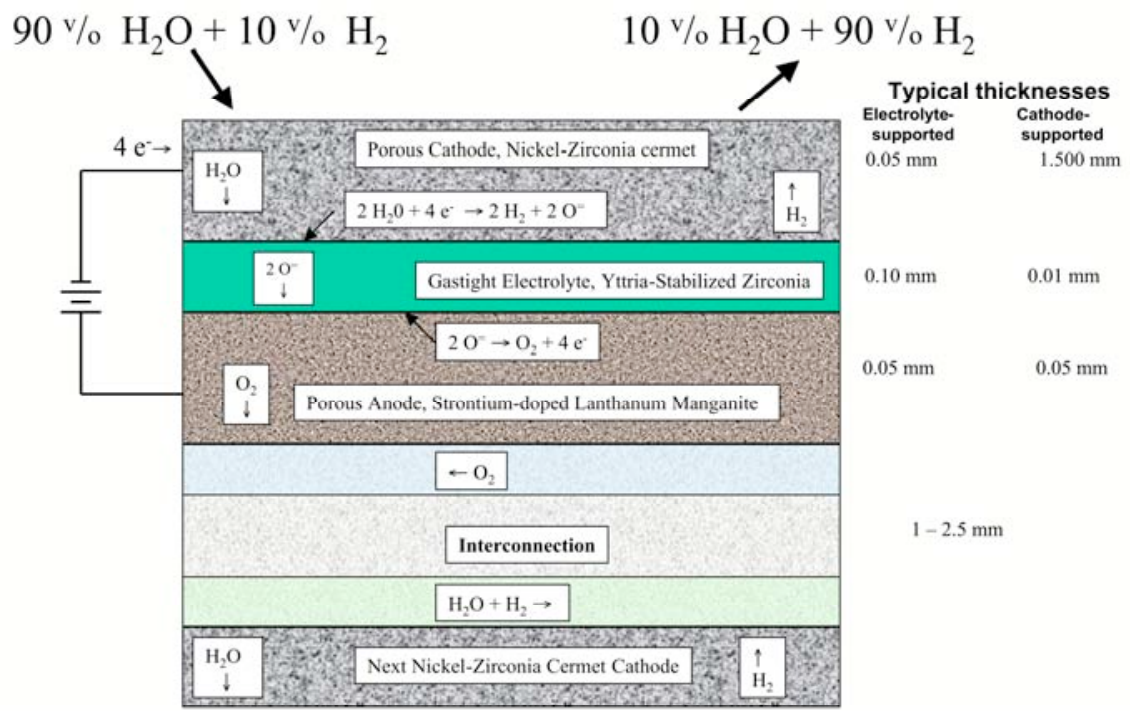

Fig. 21. Components of solid oxide cell used for high-temperature electrolysis.

The HTE system is conceptually simple in comparison to those for the thermochemical cycles being considered for nuclear hydrogen generation. In the HTE system, water is heated to superheated steam in a series of steam generators and superheaters, electrolyzed into hydrogen and oxygen in a water-containing process stream in the cell, and then separated into its constituents by condensation and/or the use of organic membranes. The only other major components are the heat exchangers used to recover the waste heat from the hydrogen and oxygen product streams prior to their discharge.

The materials challenges in the development of HTE are divided into two categories: those within the cells themselves and those in the surrounding plant. The NHI program will address those materials issues in the balance of plant and those materials issues within the cells themselves that are unique to HTE. Other materials issues within the cells will be addressed as part of the larger DOE-FE SOFC programs, hence only the materials issues and recommended R\&D that are anticipated to fall within the NHI program are addressed in this document.

\section{References}

[2.1] G .O. Hayner, et al. September, 2005, Next Generation Nuclear Plant Materials Research and Development Program Plan. INEEL/EXT-05-00758

[2.2] J. Buongiorno, P. MacDonald, W. R. Corwin, L. K. Mansur, R. K. Nanstad, R. W. Swindeman, A. F. Rowcliff, D. F. Wilson, I. G. Wright, and G. Was, September 2003, Supercritical Water Reactor (SCWR) Survey of Materials Experience and R\&D Needs to Assess Viability. INEEL/EXT-03-00693 (Rev. 1)

[2.3] W. R. Corwin, et al., The Gas Fast Reactor (GFR) Survey of Materials Experience and R\&D Needs to Assess Viability, ORNL/TM-2004/99, April 30, 2004 (Draft) 
[2.4] Generation IV Nuclear Energy Systems Ten-Year Program Plan, Fiscal Year 2005 Appendix 4: Lead-cooled Fast Reactor, Office of Advanced Nuclear Research, DOE Office of Nuclear Energy, Science and Technology, March 2005.

[2.5] The Gas-Cooled Fast Reactor (GFR) Material Requirements for the Material Selection and Qualification Program, INEEL/EXT-04-01606 (Rev 0), August 2004

[2.6] Materials Requirements for Nuclear Hydrogen Generation Systems, W. R. Corwin, et al., (Draft) September 21, 2004.

[2.7] W. G. Halsey, N. W. Brown, C. F. Smith, J. J. Sienicki, A. V. Moisseytsev, S. J. Kim, M. A. Smith, W. S. Yang, M. Williamson, and N. Li, Interim Status Report On PreConceptual LFR Design Studies and Evaluations, UCRL-TR-209718, Lawrence Livermore National Laboratory, Livermore, CA, January 2005.

[2.8] J. J. Sienicki, et. al., "Interim Status Report on the Small Secure Transportable Autonomous Reactor (SSTAR)/Lead-Cooled Fast Reactor (LFR) and Related Research and Development," ANL-GenIV-068, Argonne National Laboratory, Argonne, II., September, 2005.

[2.9] O. F. Kimball and D. E. Plumblee, Gas/Metal Interaction Studies in Simulated HTGR Helium, HTGR -85-064, General Electric Company, Schenectady, New York, June 1985.

[2.10] L. C. Brown, G. E. Besenbruch, R. D. Lentsch, K. R. Schultz, J. F. Funk, P. S. Pickard, A. C. Marshall, and S. K. Showalter, "High Efficiency Generation of Hydrogen Fuels using Nuclear Power, Final technical report for the period August 1, 1999 through September 30, 2002", GA-A24285-Rev. 1, General Atomics Document issued December 2003.

\subsection{POTENTIAL CANDIDATE MATERIALS SELECTIONS AND RESEARCH PLANS FOR GEN IV REACTORS}

The materials requirements for the various components of each of the Gen IV reactor concepts that are being actively addressed within DOE's Gen IV Program (NGNP, SCWR, LFR, and GFR) and the systems for nuclear hydrogen production being addressed by DOE's NHI Program were described in the previous sections. Based on those requirements, developed by the SIMs or PM for their individual systems, a list of potential candidate materials for each major component were selected. The materials selected are those that were evaluated to have the greatest reasonable chance of meeting the component requirements, as described, along with a summary of their current status, in the individual reactor needs studies [3.1-3.6].

In the sections that follow, the potential candidate materials for each of the systems will be described along with the anticipated R\&D that will need to be performed to downselect and qualify the materials for Gen IV service. As the descriptions of materials and R\&D needs for each reactor system are better defined, they will be mutually evaluated for optimum incorporation into the overall integrated Gen IV Materials Technology Development Program. 


\subsection{Potential Candidate Materials Selections and Research Plans for NGNP}

Three primary factors will most affect the properties and choice of the structural materials from which the NGNP components will be fabricated. These are effects of irradiation, hightemperature exposure, and interactions with the gaseous environment to which they are exposed. An extensive testing and evaluation program will be required to assess the effects that these factors have on the properties of the potential materials for NGNP construction to enable a preliminary selection of the most promising materials to be made and to then qualify those selected for the service conditions required.

Details of the research plans for the potential candidate materials selected for the NGNP described in this section are largely discussed in conjunction with the components in which they will see service. These plans are being more fully refined as the overall system and component operating conditions become better defined. Updates on the plans will be incorporated into the next revision of this document.

The research necessary to select and qualify the materials for NGNP will, in many cases, precede that for the other reactor systems, by virtue of its accelerated deployment schedule. Hence, it will be possible to utilize the NGNP results, as part of the overall integrated Gen IV Materials Technology Program, to minimize similar research that would otherwise be required for the other reactor systems. Hence, the early definition, scheduling, and execution of the NGNP materials research program will allow the remaining systems to focus on their remaining issues.

\subsubsection{General Considerations for NGNP Materials Research}

\subsubsection{Irradiation}

When a material is irradiated, virtually every property may change. This includes physical dimensions, as well as mechanical, electrical, magnetic, thermo-physical and other properties. The reason for this is that the existing crystal and defect structure is deconstructed and reconstructed on an atom-by-atom basis during irradiation. In a high-dose irradiation, each atom may be displaced from its lattice site numerous times. The standard measure of radiation dose in metallic materials is the displacement per atom (dpa). Conditions during irradiation, such as temperatures, dose, dose rate, and local materials composition, determine the property changes that will ultimately result. Three of the irradiation-induced changes of greatest concern are swelling, irradiation creep, and embrittlement.

Swelling is the isotropic volume expansion of an irradiated material. It occurs by the net absorption of interstitials at dislocations, with a corresponding net number of vacancies accumulating at cavities. It may reach tens of percent or more at high does, e.g., tens to hundreds of dpa. In graphite, which has a very anisotropic crystal structure, swelling can itself be anisotropic and is highly dependent upon texture of the graphitic microstructure and the macroscopic direction of a component with respect to the crystal texture.

Irradiation creep is a shape change in compliance with an applied stress, in excess of ordinary thermal creep. It occurs even at quite low temperatures, where thermal creep is entirely negligible. Dislocation-climb creep occurs by the asymmetrical partitioning of self-interstitials and vacancies to dislocations differently oriented to the stress axis. Climb-enabled glide creep occurs when a dislocation climbs and overcomes an obstacle, permitting it to glide. Creep may therefore result directly from net climb of particularly oriented dislocations, or indirectly from any climb that triggers glide in response to the applied stress.

Embrittlement occurs, broadly speaking, by two processes. In the first type of process, hardening of the material progresses by creation of many types of obstacles by radiation. This 
hardening reduces ductility. Many irradiation-induced hardening centers are so small they are beyond the ability to detect with transmission electron microscopy. However, atom probe fieldion microscopy has contributed significantly to the knowledge of the structure and properties of these ultra-fine hardening features. The second type of process is grain boundary weakening, caused by preferential diffusion of transmutation products, such as helium, or tramp elements, such as phosphorus, to the grain boundary.

Swelling, irradiation creep, and embrittlement have received a great deal of experimental and theoretical attention. As a result, a certain measure of understanding of these phenomena has been achieved, but investigation of these processes in the particular alloys, graphites, and structural composites being considered for NGNP applications will still be required under the particular conditions of interest. The activities needed to assess these changes are incorporated into the following sections of experimental plans.

\subsubsection{High-Temperature Exposure}

At high temperatures, thermally activated processes such as microstructural changes, plastic flow, and some types of fractures produce a number of time-related degradation mechanisms that must be recognized in the design and operation of high-temperature components.

In regard to microstructural changes, there are several concerns to the NGNP. First, the RPV will most likely be fabricated from a F/M that derives its strength from a fine precipitate of carbides formed on highly-dislocated martensite lath boundaries. With time, these precipitates will coarsen and the lath structure will reform into a fine-grain structure with much lower tensile and creep strength than the starting steel. The rate at which this aging process occurs is highly dependent on the elemental constituents that make up the carbide microstructure. A second time-related degradation mechanism that occurs on the structural steels is that of intermetallic phase precipitation. In this process, coarse intermetallic phases precipitate that rob the matrix of solid-solution strengtheners and impart brittleness to the grain boundaries. In stainless steels and nickel-base alloys that will likely be used for the core internal components, piping, and other high-temperature components, some strengthening is often derived from stable carbides and fine dispersions of intermetallics that develop in-service. With time, these beneficial precipitates may coarsen or dissolve in preference to less desirable precipitate phases. Again, loss of strength and embrittlement are concerns. Work is needed in the NGNP materials program to define the kinetics of the precipitation processes and predict the development of metastable, and eventually, the stable microstructures.

High-temperature yield strength and resistance to plastic flow are properties that are important in structural components. Good resistance to thermal transients, mechanical fatigue, ratcheting, and buckling depends on materials with good short-time strength properties. At the extreme temperatures expected in the NGNP components, the yield and flow properties of the structural materials are expected to be very rate sensitive and will be more sensitive to loading rates in the components. To address these issues, the materials testing program needs to produce information that can lead to improved analysis methods that accommodate greater rate dependency of short-time deformation and fracture. For very long service times there are additional concerns. The database on which allowable stresses are based is quite limited for several of the candidate materials, particularly at the upper temperature range that service in the NGNP will require. New deformation and fracture mechanisms may prevail at the long time and low stresses thought to represent steady-state operation of the NGNP. It is critical that predictive continuum damage mechanics models be developed on a sound metallurgical basis. The activities needed to assess both the microstructural stability and effects of temperature on 
both short- and long-term mechanical properties are incorporated into the following sections of experimental plans.

\subsubsection{Helium Gas Cooled Reactor Environment}

From a corrosion viewpoint, the internals of the reactor will operate in a helium environment, and the externals of the reactor, including the pressure vessel, will operate in air. The internal metallic components of the reactor will operate at temperatures up to $950^{\circ} \mathrm{C}$ and the pressure vessel will operate nominally at temperature up to $470^{\circ} \mathrm{C}$ with accident conditions up to $560^{\circ} \mathrm{C}$.

The interactions between structural materials in the helium atmospheres associated with gascooled reactors have been the subject of numerous studies. The USA, Germany, England, Norway, Japan, and other places have demonstrated the importance of small changes in impurity levels, high temperatures and high gas flow rates. Metallic materials can be carburized or decarburized, and oxidized internally or at the surface. These corrosion reactions, depending on their rate, can substantially affect long-term mechanical properties such as fracture toughness, fatigue, crack-growth rate, etc.

Typical simulated advanced HTGR helium chemistries used in various previous test programs are shown in Table 8, as discussed in the helium environment for GFR. Because of the low partial pressures of the impurities, the oxidation/carburization potentials at the metallic surface of a gas mixture is established by the kinetics of the individual impurity catalyzed reactions at the surface. As shown, the main impurities are $\mathrm{H}_{2}, \mathrm{H}_{2} \mathrm{O}, \mathrm{CO}$ and $\mathrm{CH}_{4}$. The hot graphite core is considered as reacting with all free $\mathrm{O}_{2}$ and much of the $\mathrm{CO}_{2}$ to form $\mathrm{CO}$, and with $\mathrm{H}_{2} \mathrm{O}$ to form $\mathrm{CO}$ and $\mathrm{H}_{2}$. In addition, in cooler regions of the core, $\mathrm{H}_{2}$ reacts with the graphite via radiolysis to produce $\mathrm{CH}_{4}$. Because of the change in surface temperatures around the reactor, and associated changes in reaction mechanisms and rates of reaction on bare metal versus on scaled surfaces, reaction rates and order of reactions are important.

The overall stability of the proposed helium environment that will be representative of the NGNP must be evaluated in order to ensure that testing proposed in the various experimental sections that follow is performed in environments that have consistent chemical potentials. In addition, the corrosion of metals and nonmetals must be evaluated to establish baseline data where it does not exist. Therefore, testing in both the helium environment to be used for mechanical properties and general corrosion evaluations of the candidate materials to establish their overall compatibility with that environment will be performed at temperatures up to at least $50^{\circ} \mathrm{C}$ above the proposed operating temperature for the various metallic components. The schedule for these studies that are generally applicable to all metallic components is shown in the following milestone section.

The bulk of the experimental plans needed to assess the effects of the helium environment on mechanical properties of the metallic internal materials, are included in the following sections that deal with individual components. However, in addition to those studies, it will be necessary to assess the stability of the helium environment itself as well at the general effects of corrosion on the various structural materials being considered for use within the primary circuit. Those experimental plans are detailed below. 


\section{Experimental R\&D plans to assess helium environment and general corrosion}

A high-level summary of R\&D plans and schedules for the NGNP materials research needed to meet the stated deployment time schedule is provided below.

\section{Milestones}

FY 2006

- Complete upgrade existing helium corrosion loop

- Initiate evaluation of stability of predicted range of impurities in helium

- Evaluate similarity of performance of recirculating loops at ORNL and INL

FY 2007

- Complete evaluation of stability of predicted range of impurities in helium

- Perform $3000 \mathrm{~h}$ exposure testing of preliminary candidate materials at $1000^{\circ} \mathrm{C}$ in anticipated helium atmospheres

FY 2008

- Perform $3000 \mathrm{~h}$ exposure testing of preliminary candidate materials at $1000^{\circ} \mathrm{C}$ in offnormal helium atmospheres

- Provide recommendations of corrosion resistance for selection of primary candidate materials

- Initiate predictive modeling of long-term performance of candidate materials in NGNP helium coolant

FY 2009

- Initiate confirmatory $3000 \mathrm{~h}$ exposure testing of primary candidate materials at $1000^{\circ} \mathrm{C}$ in anticipated and off-normal helium atmospheres

FY 2010 and 2011

- Conclude confirmatory $3000 \mathrm{~h}$ exposure testing of primary candidate materials at $1000^{\circ} \mathrm{C}$ in anticipated and off-normal helium atmospheres

- Complete predictive modeling of long-term performance of candidate materials in NGNP helium coolant at $1000^{\circ} \mathrm{C}$

FY 2012-2015

- Perform 3000h exposures in helium environments at $950,850,800$, and $750^{\circ} \mathrm{C}$

- Upgrade predictive model of long-term performance of candidate materials

\subsubsection{NGNP High-Temperature Metallic Components}

\subsubsection{Reactor Pressure Vessel System Materials Selection and Issues}

A summary of the anticipated operating conditions and component sizes for the NGNP pressure vessel system is provided in Table 9 . The vessels will be exposed to air on the outside and 
helium on the inside, with emissivity of the chosen material an important factor regarding adequate radiation of heat from the component to the surrounding air to ensure adequate cooling during accident conditions. The materials tentatively selected for gas-cooled RPV service are low-alloy F/M steels, alloyed primarily with chromium and molybdenum.

The currently estimated maximum normal operating temperature of $470^{\circ} \mathrm{C}$ for the RPV and CV is in the creep range for any ferritic or F/M steel currently in any part of the ASME Boiler and Pressure Vessel Code, while the maximum abnormal (off-normal accident) temperature of $560^{\circ} \mathrm{C}$ at one atmosphere for 200 hours provides an even greater challenge. For the ferritic steel option, there are four classes of advanced, higher alloy F/M steels that have been identified as potential candidate alloys, while the $21 / 4 \mathrm{Cr}-1 \mathrm{Mo}$ alloy is listed especially for the lower temperature design. These five alloy classes are listed in the order recommended as priority for consideration as the structural material for the RPV and CV components for the NGNP. Additionally, the class of austenitic stainless steels is listed as well, as a fallback option, but an option that retains the potential for operation at the desired temperatures, especially considering the abnormal temperatures under accident conditions, albeit at a significantly higher capital cost.

Table 9. Reactor pressure vessel system operating conditions affecting candidate material selection for the NGNP.

\begin{tabular}{|c|c|c|c|c|}
\hline \multirow[t]{2}{*}{ Component } & \multicolumn{2}{|c|}{$\begin{array}{l}\text { Normal NGNP System } \\
\text { Operating Conditions }\end{array}$} & \multirow[t]{2}{*}{$\begin{array}{l}\text { Abnormal } \\
\text { Conditions }\end{array}$} & \multirow[t]{2}{*}{$\begin{array}{l}\text { Estimated } \\
\text { Component Size }\end{array}$} \\
\hline & $\begin{array}{l}\text { Temp. }\left[{ }^{\circ} \mathrm{C}\right] \\
\text { Pressure } \\
{[\mathrm{MPa}]}\end{array}$ & $\begin{array}{l}\text { Neutron } \\
\text { Fluence, } \\
\text { E>0.1 MeV } \\
\text { (dpa) }\end{array}$ & & \\
\hline $\begin{array}{l}\text { Reactor } \\
\text { Pressure } \\
\text { Vessel } \\
(\mathrm{RPV})^{*}\end{array}$ & $\begin{array}{l}300-470^{\circ} \mathrm{C} \\
{[7.4-8.0} \\
\mathrm{MPa}]\end{array}$ & $\begin{array}{l}1 \times 10^{19} \mathrm{n} / \mathrm{cm}^{2} \\
\text { per } 60 \text { years } \\
(0.077 \mathrm{dpa})\end{array}$ & $\begin{array}{l}\approx 560^{\circ} \mathrm{C} \text { at } 1 \mathrm{~atm} \\
\text { for } 200 \mathrm{~h}[7.4-8.0 \\
\mathrm{MPa}]\end{array}$ & $\begin{array}{l}\text { Diameter:>9m } \\
\text { Thickness:100- } \\
300 \mathrm{~mm} \\
\text { Height: }>24 \mathrm{~m}\end{array}$ \\
\hline $\begin{array}{l}\text { Cross Vessel } \\
\text { (CV) }\end{array}$ & $\begin{array}{l}300-470^{\circ} \mathrm{C} \\
{[7.4-8.0} \\
\mathrm{MPa}]\end{array}$ & $\begin{array}{l}1 \times 10^{19} \mathrm{n} / \mathrm{cm}^{2} \\
\text { per } 60 \text { years } \\
(0.077 \mathrm{dpa})\end{array}$ & $\begin{array}{l}<300-560^{\circ} \mathrm{C} \text { for } \\
200 \mathrm{~h}[7.4-8.0 \\
\mathrm{MPa}]\end{array}$ & $\begin{array}{l}\text { Diameter: }>2.5 \mathrm{~m} \\
\text { Thickness: }>100 \mathrm{~mm} \\
\text { Length: } 4-5 \mathrm{~m}\end{array}$ \\
\hline $\begin{array}{l}\text { Power } \\
\text { Conversion } \\
\text { Vessel } \\
\text { (PCV) }\end{array}$ & $\begin{array}{l}300^{\circ} \mathrm{C} \\
{[5.0-6.0} \\
\mathrm{MPa}]\end{array}$ & $\begin{array}{l}\text { Negligible } \\
3 \times 10^{14} \mathrm{n} / \mathrm{cm}^{2} \\
\text { per } 60 \text { years }\end{array}$ & $\begin{array}{l}300^{\circ} \mathrm{C} \\
{[5.0-6.0 \mathrm{MPa}]}\end{array}$ & $\begin{array}{l}\text { Diameter: } \approx 7-9 \mathrm{~m} \\
\text { Thickness: } 100- \\
\text { 200mm Height: } \\
\approx 35 \mathrm{~m}\end{array}$ \\
\hline $\begin{array}{l}\text { Closure } \\
\text { Bolting }\end{array}$ & $550^{\circ} \mathrm{C}$ & $\begin{array}{l}1 \times 10^{19} \mathrm{n} / \mathrm{cm}^{2} \\
\text { per } 60 \text { years } \\
(0.077 \text { dpa })\end{array}$ & $\approx 560^{\circ} \mathrm{C}$ at $1 \mathrm{~atm}$ & \\
\hline
\end{tabular}

* Temperatures are dependent on specific reactor design. 
1. Class of $9 \mathrm{Cr}-1 \mathrm{MoVNb}$

a. This class of materials has the most industrially mature high strength database. For example, the $9 \mathrm{Cr}-1 \mathrm{Mo}-\mathrm{V}$ (grade 91) alloy is ASME Code approved to $649^{\circ} \mathrm{C}$ for Section III, Classes 2 and 3 components and is in the final stages of approval for inclusion in Subsection $\mathrm{NH}$ for Class 1 applications.

b. There are, of course, limits to Code applicability involving time at temperature, thickness of forgings, etc.

c. Within this class of alloys, it seems prudent to consider variants such as $9 \mathrm{Cr}-1 \mathrm{MoWV}$ (grade 911), (grade 92), etc., because available research data show significantly improved high temperature strength for those alloys relative to the grade 91 .

2. Class of $7-9 \mathrm{Cr} 2 \mathrm{WV}$

a. Various alloys of this class are currently being developed under the Fusion Materials Program.

b. There is a smaller database than for the $1^{\text {st }}$ class mentioned above, but some of these alloys offer the possibility of better high strength properties.

c. Examples of specific alloys within this group include $\mathrm{F} 82 \mathrm{H}(7.5 \mathrm{Cr} 2 \mathrm{WV})$, JLF1 and EUROFER (9Cr2WV).

d. A potential advantage of these alloys is the fact that they have also been developed to have reduced activation under neutron irradiation with resultant advantages for decommissioning.

3. Class of $3 \mathrm{Cr}-3 \mathrm{WV}$

a. This class of alloys offers good high strength properties, but is one of the newer alloys under development and, as a result, has a very limited database. In relatively modest section sizes evaluated to date, the yield strength of the specific 3Cr3WV alloy under development at Oak Ridge National Laboratory (ORNL) is about twice that of the SA508 grade 3 forging steel used for current LWR RPVs.

b. Because of its lower alloying content, it offers the potential for substantially lower cost than those more highly alloyed steels in the two classes discussed above. However, because of its lower alloying content, environmental effects at high temperatures may be limiting.

c. There are indications that this alloy may not require a post-weld heat treatment.

d. One other alloy in this class is a $2.75 \mathrm{Cr}-1 \mathrm{MoV}$ variant under development in Russia.

4. Class of $12 \mathrm{Cr}-1 \mathrm{MoWV}$

a. The alloy designated HT9 is an older existing alloy within this class of materials.

b. The HT9 alloy has a broad database available, but is has poorer properties than, e.g., $9 \mathrm{Cr}-1 \mathrm{MoVNb}$.

c. There are some more recent $12 \mathrm{Cr}$ variants that offer improved properties relative to the HT9. For example, the HCM 12A alloy has a good database and is currently approved by ASME Code Case 2180 to $649^{\circ} \mathrm{C}$ for application in Sections I and VIII. Additionally, a Japanese alloy designated SAVE12 appears to have good high temperature strength, but the available database needs to be reviewed. 
5. Fallback for lower temperature operation: $2.25 \mathrm{Cr}-1 \mathrm{Mo}$

a. There is an extensive database for this alloy, including data in different operating environments such as helium.

b. Another advantage is the extensive industrial experience with this alloy in many different applications around the world.

c. However, its high-temperature strength is significantly lower than the alloy classes discussed above and, as such, is only applicable for substantially lower vessel temperature, such as in the case of the HTTR at JAERI.

6. Class of austenitic stainless steels (types 304,316 , etc.)

a. There is an extensive database for many of these alloys, including some data in helium with various impurity contents.

b. There is extensive industrial experience with this class of steels in many different applications, including in irradiation environments.

c. The tensile strengths of these alloys are much inferior to the F/M steels, but their strength properties do not degrade as rapidly at high temperatures. However, at temperatures in the range of $650^{\circ} \mathrm{C}$, their maximum allowable stresses are not necessarily superior to some F/M steels. The primary reason for inclusion of the class of stainless steels here is their metallurgical stability at the higher temperatures currently anticipated for the abnormal conditions.

d. In general, stainless steels have superior oxidation and corrosion resistance in many media, but they are not immune to severe degradation in some common environments.

Potential candidate alloys for the PCV could include those for the RPV and CV, but there are lower cost options available because of the lower operating temperatures. Even under abnormal conditions, the PCV will be subjected to temperatures about the same as those currently used for commercial LWR vessels. Moreover, the size of the vessel is well within normal fabrication capability. Thus, the current LWR pressure vessel materials, SA508 grade 3 class 1 forgings or SA533 grade B class 1 plates are potential candidates, as is the $21 / 4 \mathrm{Cr}-1$ Mo alloy, dependent on material compatibility issues. It is noted that the CV is welded to the PCV and the welded joint with dissimilar materials must be a consideration.

Potential candidate alloys for high-temperature closure bolting are alloy 718 and types 304 and 316 stainless steels. Although alloy 718 has superior strength, it is currently approved up to $566^{\circ} \mathrm{C}$ in ASME Section III, Subsection NH. The two types of stainless steels, however, have allowable stress intensities for bolting up to $704^{\circ} \mathrm{C}$. Thus, the anticipated operating and abnormal condition temperatures are lower than the approved temperature limits for those two materials. The estimated irradiation exposure for closure bolting will be assessed to evaluate the need for inclusion of bolting in the irradiation program.

\section{Expected research, testing, and qualification needs for RPV materials}

The first step in the research program on materials for the RPV system will be a comprehensive and detailed review of the potential candidate alloys discussed. The existing database for those alloys will be assembled, analyzed, and evaluated with respect to the design and operating requirements presented above. Principal topics for review will include: fabrication and transportation for the RPV ring forgings, effect of thickness on mechanical and fracture properties, and high-temperature strength, stability, and long-time performance under irradiation of the materials. 
Based on the results of the materials review, detailed research enabling the inclusion of the needed RPV materials into the ASME Code for the materials of construction will be defined and performed. For an alloy such as $9 \mathrm{Cr}-1 \mathrm{MoV}$ (grade 91) that has already attained Code approval for operation to $649^{\circ} \mathrm{C}$, additional testing will be required but not nearly as much as that required for an alloy that is not currently approved for Code use. However, in that regard, given the currently estimated abnormal condition temperature of $560^{\circ} \mathrm{C}$ for $200 \mathrm{~h}$, data would be required up to $610^{\circ} \mathrm{C}$ for ASME Code approval. Such data are not available for most of the potential RPV candidate materials. The extension of the required data bases and ASME Code acceptance of the materials for NGNP RPV service will need to be developed and closely coordinated with the high-temperature design methodology activities covered further below.

Additionally, application-specific information and data are required, including:

1. Effects of the helium coolant on the potential candidate alloys, including the possible use of a weld overlay cladding on the inner surfaces of the RPV and CV, such as type 308 stainless steel.

2. Irradiation effects data on the RPV and CV materials, and possibly the bolting materials are needed for regulatory requirements and for assessment of structural integrity. Similarly, long-time thermal aging data are needed as a complement to the irradiation effects data for potential embrittlement due to either hardening or softening of the RPV materials and the closure bolting materials.

3. The external air environment is significant in that the pressure vessel must be able to radiate heat at temperatures up to $500^{\circ} \mathrm{C}$ throughout the life (60 years) of the reactor and at $560^{\circ} \mathrm{C}$ under accident conditions. It is therefore necessary to have a stable, high-emissivity surface on the pressure vessel material, such as $9 \mathrm{Cr}-1 \mathrm{MoVNb}$ and variants, at elevated temperatures. While the emissivities of steel can be increased by the formation of an oxide film, the conditions under which this film can be created and the stability of this film in air (including the effect of humidity) at operating temperature needs to be established. An industrial partner will be used to provide for scaling of the materials and methods that have proven to be viable. Emissivity data on the various potential candidate materials are needed to ensure adequate radiation from the outer surface to the air in the cavity between the RPV and surrounding concrete during accident conditions, including the possible need to incorporate a high emissivity coating on the outer surface of the RPV. Testing to establish limitations of potential candidate materials emissivity and the performance and durability of proposed surface modifications to improve emissivity must be performed early to provide design feedback and limitations.

4. Determination of the RT $T_{\mathrm{NDT}}$ for Section III, Class 1 components such as the RPV and CV. Fracture toughness data will be required, primarily for regulatory needs, but also for providing complete information to allow for a comprehensive assessment of structural integrity for the pressure boundary components.

5. Damage accumulation data are needed due to long-time high temperature exposure. Particular attention is needed in the area of welding to ensure that the issues of hot cracking and premature creep failures in the heat-affected-zones of $F / M$ steels, observed in the fossil industry, are adequately addressed.

6. Vessel fabricability must be comprehensively evaluated. Availability of the very large forgings required and both their weldability and the attainment of the required throughthickness properties of the higher-alloy steels in such thick sections are key issues. 
The possible requirement for field fabrication, including postweld heat treatment, must be assessed.

7. Currently, the estimated maximum temperature for the RPV and CV materials under abnormal operating conditions is $560^{\circ} \mathrm{C}$ with the potential for operation at that temperature for about $200 \mathrm{~h}$ and, more importantly, at full operating pressure or higher. This temperature is about $90^{\circ} \mathrm{C}$ lower than the aforementioned maximum that is currently approved in Section III, Subsection $\mathrm{NH}$ for $9 \mathrm{Cr}-1 \mathrm{Mo}-\mathrm{V}$ (grade 91). For the other ferritic alloys under consideration, extending application to these abnormal conditions will require reevaluation of the background data used to obtain the currently proposed allowable stresses for Subsection $\mathrm{NH}$, and conduct of additional testing to obtain sufficient data at temperatures to at least $610^{\circ} \mathrm{C}\left(50^{\circ} \mathrm{C}\right.$ beyond the highest envisaged abnormal temperature), reanalysis of all the data, and a proposed Code Case to obtain inclusion for such operation with that material within the ASME Code rules.

\section{Experimental RPV R\&D plans}

A high-level summary of R\&D plans and schedules for the NGNP RPV materials research needed to meet the stated deployment time schedule is provided below.

\section{Milestones}

FY 2006

- Issue RFP to potential irradiation facility host sites, evaluate responses and recommend site selection to DOE.

- Perform site specific design, initiate fabrication of irradiation facility, and complete documentation of site selection.

- Issue draft report: Site selection and design concept for low-flux irradiation facility.

FY 2007

- Perform comprehensive review of the potential candidate alloys, assemble, analyze, and evaluate existing database.

- Complete capsule design and fabrication, and specimen fabrication for irradiation in the low-flux irradiation facility, and begin Phase I irradiations.

FY 2008

- Initiate thermal aging in air for 1000,3000 , and 10,000 hours at $500^{\circ} \mathrm{C}$, followed by short-term aging at accident temperatures, and conduct initial tests.

- Continue Phase I low-flux irradiations of base metals, weldments and aged materials.

FY 2009

- Conduct testing of Phase I low-flux irradiated specimens.

- Initiate Phase II low-flux irradiations of base metals and aged materials,

- Complete testing of specimens that were aged in air up to $10,000 \mathrm{~h}$ at $500^{\circ} \mathrm{C}$ and followed by short-term aging at accident temperatures $\left(560^{\circ} \mathrm{C}\right)$.

FY 2010

- Continue Phase II low-flux irradiations of base metals and aged materials. 
- Procure weldment of one potential candidate RPV material for inclusion in irradiation program and begin fabrication of specimens.

- Based on literature results, select welding techniques and processes and postweld heat treatment schedules for subsequent evaluation, and procure welding consumables.

- Prepare report on evaluation of short-term aged tensile, hardness, creep, and toughness behavior and microstructural stability.

FY 2011

- Conduct testing of Phase II low-flux irradiated base metal specimens.

- Initiate Phase III low-flux irradiations of commercially procured weld metal specimens.

FY 2012

- Continue Phase III low-flux irradiations of commercially procured weld metal specimens.

- Prepare one thick section weld with selected welding technique and begin fabrication of specimens for inclusion in irradiation and thermal aging programs.

- Select and procure emissivity measurement system.

- Evaluate emissivity layer development techniques.

FY 2013

- $\quad$ Conduct testing of Phase III low-flux irradiated weld metal specimens.

- Initiate irradiation of Phase IV low-flux irradiated weld metal specimens.

- Initiate long-term thermal aging study of base and weld metals for tensile, hardness, creep, and toughness behavior and microstructural stability.

- Select emissivity layer development technique that is most compatible with field application.

- Continue evaluation of aged emissivity surfaces.

FY 2014

- Continue irradiation of Phase IV low-flux irradiated weld metal specimens.

- Select two prime candidate base materials for more comprehensive testing, especially as regards irradiation effects

- Work with industrial company to create field applied emissivity layer. Evaluate approaches for aging emissivity surfaces.

- Initiate evaluation of aged emissivity surfaces.

FY 2015

- Conduct testing of Phase IV low-flux irradiated weld metal specimens.

- Initiate Phase V low-flux irradiation of prime candidate materials.

- Continue long term aging studies, emissivity studies, and initiate combined loading cycle tests in impure helium and air of primary potential candidate materials 


\subsubsection{Metallic Reactor Internals Material Selection and Issues}

The components addressed in this subsection may be classified as core supports and core internals. Included are the core barrel, inside shroud, core support floor, and upper core restraint. Also, the SCS shell and SCS tubes are included in this grouping. The conditions that affect the materials selection for these components, as well as the other high temperature components likely to be constructed from metallic alloys, are provided in Table 10. Depending on the specific component, the normal operating temperatures will range from 600 to $1000^{\circ} \mathrm{C}$. However, the maximum temperature estimated for accident conditions ranges from 600 to $1200^{\circ} \mathrm{C}$ from one component to another. The maximum temperature $\left(1200^{\circ} \mathrm{C}\right)$ is by no means a certainty, and possibility exists that an innovative design could significantly reduce this temperature for some components. In regard to loading, these components are not pressure boundary components, except for the SCS tubes. In some cases, however, the weight loads can be quite significant. The fatigue, thermal-fatigue, seismic, and other loadings that could produce damage are largely unidentified at this time. Compatibility with the coolant gas is a requirement for core metallic internals. In addition, radiation and thermal aging effects on properties are important considerations in material selection. Fabrication and joining are always factors to consider. Finally, their code status is important. Metallic core support structures must conform to ASME Sect. III, Div. 1, Subsect. NG. Other core internals may conform to different rules. It is not clear whether the SCS tubes will be considered to be Class 1 or Class 2 components. At this point in time, it is best to assume that the materials of construction, regardless of the applicable subsection, will be limited to those listed in ASME Section II, Part D, Tables $2 \mathrm{~A}, 2 \mathrm{~B}$, and 4 . These tables cover temperatures to $370^{\circ} \mathrm{C}$ for ferritic alloys and $425^{\circ} \mathrm{C}$ for austenitic alloys. Subsect. NH of Section III permits construction to higher temperatures for a limited number of materials. These are $21 / 4 \mathrm{Cr}-1 \mathrm{Mo}$ steel (Class 1), $304 \mathrm{H}$ stainless steel, $316 \mathrm{H}$ stainless steel, alloy $800 \mathrm{H}$, and the recently codified $9 \mathrm{Cr}-1 \mathrm{Mo}-\mathrm{V}$ steel. Potential candidate materials for the internals, as well as the other high temperature components likely to be constructed from metallic alloys, are listed in the Table 11. These materials include alloys for which significant databases exist and new state-of-the-art alloys which are being developed for other high-temperature applications. Alloy 617, alloy X, and alloy XR are the leading potential metallic candidates for service above $760^{\circ} \mathrm{C}$. These alloys were chosen because they have been developed for use in earlier gas-cooled reactor projects. However, the upper limit of these materials is judged to be $1000^{\circ} \mathrm{C}$. Any component that could experience excursions above $1000^{\circ} \mathrm{C}$ would have to have very high temperature capability in regard to strength and corrosion resistance. Carbon-carbon composites are the leading near-term potential candidates, but an ODS alloy could be an alternative for service in components that might experience temperature excursions to $1200^{\circ} \mathrm{C}$. 
Table 10a. Conditions affecting materials selection for high-temperature metallic NGNP components.

\begin{tabular}{|c|c|c|c|c|c|c|}
\hline Condition & SCS Tube & $\begin{array}{l}\text { Core } \\
\text { Barrel }\end{array}$ & $\begin{array}{l}\text { Core } \\
\text { Support } \\
\text { Floor }\end{array}$ & SCS Shell & $\begin{array}{l}\text { Inside } \\
\text { Shroud }\end{array}$ & $\begin{array}{l}\text { Upper } \\
\text { Core } \\
\text { Restraint }\end{array}$ \\
\hline $\begin{array}{l}\text { Normal } \\
\text { Temperature }\end{array}$ & $600^{\circ} \mathrm{C}$ & $600^{\circ} \mathrm{C}$ & $600^{\circ} \mathrm{C}$ & $600^{\circ} \mathrm{C}$ & $600^{\circ} \mathrm{C}$ & $600^{\circ} \mathrm{C}$ \\
\hline $\begin{array}{l}\text { Maximum } \\
\text { Temperature }\end{array}$ & $600^{\circ} \mathrm{C}$ & $700^{\circ} \mathrm{C}$ & $700^{\circ} \mathrm{C}$ & $1200^{\circ} \mathrm{C}$ & $1200^{\circ} \mathrm{C}$ & $1200^{\circ} \mathrm{C}$ \\
\hline Loading & $\begin{array}{l}\text { Thermal } \\
\text { Stress, } \\
\text { LCF/HCF }\end{array}$ & $\begin{array}{l}\text { Core } \\
\text { Weight }\end{array}$ & $\begin{array}{l}\text { Core } \\
\text { Weight }\end{array}$ & $\begin{array}{l}\text { Own } \\
\text { Weight }\end{array}$ & $\begin{array}{l}\text { Own } \\
\text { Weight }\end{array}$ & $\begin{array}{l}\text { Own } \\
\text { Weight }\end{array}$ \\
\hline $\begin{array}{l}\text { Environment } \\
\text { Issues }\end{array}$ & $\begin{array}{l}\text { Helium, } \\
\text { Pressurized } \\
\text { water, SCC, }\end{array}$ & Helium & Helium & $\begin{array}{l}\text { Helium, } \\
\text { Off Normal } \\
\text { Helium }\end{array}$ & $\begin{array}{l}\text { Helium, } \\
\text { Off Normal } \\
\text { Helium }\end{array}$ & $\begin{array}{l}\text { Helium, } \\
\text { Off Normal } \\
\text { Helium }\end{array}$ \\
\hline $\begin{array}{l}\text { Radiation } \\
\text { Issues }\end{array}$ & $\begin{array}{l}\text { Not } \\
\text { significant }\end{array}$ & $\begin{array}{l}\text { Negligible } \\
<0.005 \mathrm{DPA}\end{array}$ & $\begin{array}{l}\text { Negligible } \\
<0.005 \text { DPA }\end{array}$ & $\begin{array}{l}\text { Negligible } \\
<0.005 \mathrm{DPA}\end{array}$ & $\begin{array}{l}\text { Negligible, } \\
\text { Avoid Co }\end{array}$ & $\begin{array}{l}\text { Negligible, } \\
\text { Avoid Co }\end{array}$ \\
\hline Aging Issues & Some & Some & Some & $\begin{array}{l}\text { None, if CC } \\
\text { composite }\end{array}$ & $\begin{array}{l}\text { None, if CC } \\
\text { composite }\end{array}$ & $\begin{array}{l}\text { None, if CC } \\
\text { composite }\end{array}$ \\
\hline Joining Issues & Some & Some & Some & $\begin{array}{l}\text { N/A, if CC } \\
\text { composite }\end{array}$ & $\begin{array}{l}\mathrm{N} / \mathrm{A} \text {, if CC } \\
\text { composite }\end{array}$ & $\begin{array}{l}\mathrm{N} / \mathrm{A} \text {, if CC } \\
\text { composite }\end{array}$ \\
\hline $\begin{array}{l}\text { Manufacturing } \\
\text { Issues }\end{array}$ & None & None & None & $\begin{array}{l}\text { Major, if CC } \\
\text { composite }\end{array}$ & $\begin{array}{l}\text { Major, if CC } \\
\text { composite }\end{array}$ & $\begin{array}{l}\text { Major, if CC } \\
\text { composite }\end{array}$ \\
\hline $\begin{array}{l}\text { Prime } \\
\text { Candidate } \\
\text { Materials }\end{array}$ & $\begin{array}{l}\text { 316FR, } \\
800 \mathrm{H}\end{array}$ & $\begin{array}{l}800 \mathrm{H}, \\
\text { 316FR }\end{array}$ & $\begin{array}{l}800 \mathrm{H} \\
316 \mathrm{FR}\end{array}$ & $\begin{array}{l}\text { CC } \\
\text { composite, } \\
\text { Alloy } 617\end{array}$ & $\begin{array}{l}\text { CC } \\
\text { composite, } \\
\text { Alloy } 230\end{array}$ & $\begin{array}{l}\text { CC } \\
\text { composite, } \\
\text { Alloy } 230\end{array}$ \\
\hline
\end{tabular}

Table 10b. Conditions affecting materials selection for high-temperature metallic NGNP components.

\begin{tabular}{|c|c|c|c|c|c|c|c|}
\hline Condition & $\begin{array}{l}\text { IHX } \\
\text { Indirect }\end{array}$ & $\begin{array}{l}\text { Hydrogen } \\
\text { HX }\end{array}$ & $\begin{array}{l}\text { Hot } \\
\text { Duct }\end{array}$ & Bellows & $\begin{array}{l}\text { He } \\
\text { Circulator }\end{array}$ & $\begin{array}{l}\text { Primary to } \\
\text { Secondary } \\
\text { Piping }\end{array}$ & Recuperator \\
\hline $\begin{array}{l}\text { Normal } \\
\text { Temp }\end{array}$ & $950^{\circ} \mathrm{C}$ & $950^{\circ} \mathrm{C}$ & $600^{\circ} \mathrm{C}$ & $600^{\circ} \mathrm{C}$ & $600^{\circ} \mathrm{C}$ & $950^{\circ} \mathrm{C}$ & $600^{\circ} \mathrm{C}$ \\
\hline $\begin{array}{l}\text { Maximum } \\
\text { Temp }\end{array}$ & $950^{\circ} \mathrm{C}$ & $950^{\circ} \mathrm{C}$ & $700^{\circ} \mathrm{C}$ & $700^{\circ}$ & $600^{\circ} \mathrm{C}$ & $950^{\circ} \mathrm{C}$ & $600^{\circ} \mathrm{C}$ \\
\hline Loading & $\begin{array}{l}\text { Thermal } \\
\text { Transients }\end{array}$ & $\begin{array}{l}7 \mathrm{MPa}, \\
\text { Cycles }\end{array}$ & $\begin{array}{l}\text { Own } \\
\text { Weight }\end{array}$ & Fatigue & $\begin{array}{l}\text { Fatigue, } \\
\text { Creep Fat. }\end{array}$ & $7 \mathrm{MPa}$ & \\
\hline $\begin{array}{l}\text { Environment } \\
\text { Issues }\end{array}$ & Helium & $\begin{array}{l}\text { Helium, } \\
\text { Heat } \\
\text { transfer } \\
\text { fluid }\end{array}$ & Helium & Helium & Helium & $\begin{array}{l}\text { Helium, } \\
\text { Heat Trans } \\
\text { Fluid }\end{array}$ & \\
\hline $\begin{array}{l}\text { Radiation } \\
\text { Issues }\end{array}$ & None & None & None & None & None & None & None \\
\hline $\begin{array}{l}\text { Aging } \\
\text { Issues }\end{array}$ & Some & Some & Some & Some & Some & Some & Some \\
\hline $\begin{array}{l}\text { Joining } \\
\text { Issues }\end{array}$ & Some & Some & Some & Some & Some & Some & Some \\
\hline $\begin{array}{l}\text { Manufacturing } \\
\text { Issues }\end{array}$ & Major & Some & Some & Major & Some & Major & Some \\
\hline $\begin{array}{l}\text { Prime } \\
\text { Candidate } \\
\text { Materials }\end{array}$ & Alloy 617 & $\begin{array}{l}\text { Alloy } 617 \\
\text { Alloy } 230\end{array}$ & $\begin{array}{l}\text { Alloy } \\
800 \mathrm{H}, \\
316 \mathrm{FR}\end{array}$ & $\begin{array}{l}\text { Alloy } \\
800 \mathrm{H}, \\
316 \mathrm{FR}\end{array}$ & $316 \mathrm{FR}$ & $\begin{array}{l}\text { Alloy } 617 \text {, } \\
\text { Alloy XR }\end{array}$ & 347 SS \\
\hline
\end{tabular}


Table 11. Potential candidate materials selection for high-temperature metallic NGNP components.

\begin{tabular}{|c|c|c|c|c|c|}
\hline NOMINAL COMPOSITION & UNS No. & $\begin{array}{c}\text { COMMON } \\
\text { NAME }\end{array}$ & $\begin{array}{c}\text { CODE } \\
\text { MAX TEMP }\end{array}$ & $\begin{array}{c}\text { DATA } \\
\text { MAX TEMP }\end{array}$ & $\begin{array}{c}\text { HELIUM } \\
\text { EXPERIENCE }\end{array}$ \\
\hline $\mathrm{Ni}-16 \mathrm{Cr}-3 \mathrm{Fe}-4.5 \mathrm{Al}-\mathrm{Y}$ & & Haynes 214 & & 1040 & \\
\hline $63 \mathrm{Ni}-25 \mathrm{Cr}-9.5 \mathrm{Fe}-2.1 \mathrm{Al}$ & N06025 & VDM 602CA & 980 & 1200 & \\
\hline $\mathrm{Ni}-25 \mathrm{Cr}-20 \mathrm{Co}-\mathrm{Nb}-\mathrm{Ti}-\mathrm{Al}$ & & Inconel 740 & & 815 & \\
\hline $60 \mathrm{Ni}-22 \mathrm{Cr}-9 \mathrm{Mo}-3.5 \mathrm{Nb}$ & N06625 & Inconel 625 & 900 & & \\
\hline 59Ni-23Cr-16Mo-Fe-Al & N06059 & VDM 59 & 760 & & \\
\hline 53Ni-22Cr-14W-Co-Fe-Mo & N06230 & Haynes 230 & 980 & 1100 & \\
\hline $\mathrm{Ni}-22 \mathrm{Cr}-9 \mathrm{Mo}-18 \mathrm{Fe}$ & N06002 & Hastelloy X & 900 & 1000 & Yes \\
\hline $\mathrm{Ni}-22 \mathrm{Cr}-9 \mathrm{Mo}-18 \mathrm{Fe}$ & & Hastelloy XR & & 1000 & Yes \\
\hline $46 \mathrm{Ni}-27 \mathrm{Cr}-23 \mathrm{Fe}-2.75 \mathrm{Si}$ & N06095 & Nicrofer 45 & 815 & & \\
\hline $45 \mathrm{Ni}-22 \mathrm{Cr}-12 \mathrm{Co}-9 \mathrm{Mo}$ & N06617 & Inconel 617 & 980 & 1100 & Yes \\
\hline $\mathrm{Ni}-33 \mathrm{Fe}-25 \mathrm{Cr}$ & N08120 & HR-120 & 900 & 930 & \\
\hline $35 \mathrm{Ni}-19 \mathrm{Cr}-1$ 1/4Si & N08330 & RA330 & 900 & & \\
\hline $33 \mathrm{Ni}-42 \mathrm{Fe}-21 \mathrm{Cr}$ & N08810 & Incoloy 800 & 980 & 1100 & Yes \\
\hline $33 \mathrm{Ni}-42 \mathrm{Fe}-21 \mathrm{Cr}$ & N08811 & $800 \mathrm{HT}$ & 900 & 1100 & \\
\hline $21 \mathrm{Ni}-30 \mathrm{Fe}-22 \mathrm{Cr}-18 \mathrm{Co}-3 \mathrm{Mo}-3 \mathrm{~W}$ & R30566 & Haynes 556 & 900 & 1040 & \\
\hline $18 \mathrm{Cr}-8 \mathrm{Ni}$ & S30409 & $304 \mathrm{H}$ SS & 815 & 870 & Yes \\
\hline $16 \mathrm{Cr}-12 \mathrm{Ni}-2 \mathrm{Mo}$ & S31609 & $316 \mathrm{H}$ SS & 815 & 870 & Yes \\
\hline $16 \mathrm{Cr}-12 \mathrm{Ni}-2 \mathrm{Mo}$ & & 316FR & & 700 & \\
\hline $18 \mathrm{Cr}-10 \mathrm{Ni}-\mathrm{Nb}$ & S34709 & $347 \mathrm{H} \mathrm{SS}$ & 815 & 870 & \\
\hline $18 \mathrm{Cr}-10 \mathrm{Ni}-\mathrm{Nb}$ & & $347 \mathrm{HFG}$ & 730 & 760 & \\
\hline 18Cr-9Ni-3Cu-Nb-N & & Super 304 & 815 & 1000 & \\
\hline 15Cr-15Ni-6MnNb-Mo-V & S21500 & Esshete 1250 & 700 & 900 & \\
\hline $20 \mathrm{Cr}-25 \mathrm{Ni}-\mathrm{Nb}$ & & NF 709 & & 1000 & \\
\hline $23 \mathrm{Cr}-11.5 \mathrm{Ni}-\mathrm{N}-\mathrm{B}-\mathrm{Ce}$ & & NAR-AH-4 & 815 & 1000 & \\
\hline
\end{tabular}

For service in the temperature range of 600 to $760^{\circ} \mathrm{C}$, alloy $800 \mathrm{H}$ appears to be a leading candidate. A restricted chemistry version of $800 \mathrm{H}$, namely alloy $800 \mathrm{HT}$, is considered, as well. Alternative alloys to $800 \mathrm{H}$ exist, but they have little experience in nuclear systems at temperatures above $600^{\circ} \mathrm{C}$.

For temperatures at $600^{\circ} \mathrm{C}$ and below, a wide choice of materials is available. Those alloys contained in ASME Sect. III, Subsection NH are leading candidates. An alternative low carbon 316 stainless steel (316FR) is considered to be a strong candidate since the steel could achieve Code approval with less effort than other alternatives.

Compatibility with the helium coolant and irradiation resistance of the potential candidate materials needs to be addressed. The experience base that exists must be evaluated for the different alloys regarding temperatures, fluences, and environments and/or expectations based upon what type of data or models must be determined.

\section{Expected research, testing, and qualification needs for metallic reactor internals} materials

The first step in the research program on materials for the metallic reactor internals will be a comprehensive and detailed review of the potential candidate alloys identified in Table 11. The existing database for those alloys will be assembled, analyzed, and evaluated with respect to 
the design and operating requirements described above. Principal topics for review will include: high-temperature strength, stability, and long-time performance under irradiation of the materials, effects of helium typical of gas reactor coolant on the mechanical and physical properties of the materials, codification status, prospects, and needs, including maturity and limitations of the high-temperature design methodology for each material selected.

The review will compile the sources for the data and lead to a draft "handbook" of representations for the data that will aide in the down-select of candidates for more detailed evaluations. During this same period of review, an evaluation will be undertaken of available resources needed for the production of engineering design data. Test procedures and guidelines will be developed that will be consistent with the requirements of regulating bodies. Sources will be identified for the supply of the required products of candidate alloys.

The neutron fluences accumulated in the metallic core internal materials are expected to be low relative to the tolerances of the structural alloys. Nevertheless, these will be reviewed and details developed for confirmatory testing and evaluation.

To some extent, the DOE-supported program on the ultrasupercritical steam boiler will provide much needed guidance on welding alloy 617, alloy 230, and Inconel 740. Most of the potential candidate alloys identified for service at $760^{\circ} \mathrm{C}$ and below have been welded in thick sections. These include alloy $800 \mathrm{H}$ and $316 \mathrm{FR}$ stainless steel. This work will be reviewed to evaluate the maturity of the infrastructure for producing relatively thick-section welds of the advanced alloys needed for service to $1000^{\circ} \mathrm{C}$.

\section{Experimental metallic reactor internals materials R\&D plans}

A brief summary of R\&D plans and schedules for the NGNP metallic reactor internals materials needed to meet the deployment time schedule is provided below. The schedule for these tasks is contingent upon funding availability.

\section{Milestones}

FY 2006

- Continue baseline mechanical, fracture, and physical property tests in impure helium and in air, adding fatigue and crack growth testing and weldments

- Construct isochronous curves to 10,000 hours

- Initiate complex stress and strain testing in helium to evaluate parameters describing cumulative damage

- Re-evaluate the materials data requirements for constitutive equation refinement for design methodology

- Rank candidate alloys on their performance in mechanical testing and microstructural evaluations aged to 10,000 hours and provide input to computational modeling activity

- Fabricate irradiation capsules

- Compare microstructural evaluations of aged materials with computational models to qualify microstructural parameters for damage prediction models and rank candidate weld metals

- Provide comparative data for constitutive behavior of weld versus base metal for the design methodology activity

- Verify and further refine the procurement specification of Alloy 617 
- Procure Alloy 617 with controlled material specification (CMS) and Alloy 230 for testing

- Conduct scoping tests on CMS 617 and 230

- Initiate post exposure testing on CMS 617 and Alloy 230 to assess effects of environmental aging on specimen exposed in helium

- Initiate testing on negligible creep of Gr91

FY 2007

- Continue post exposure testing on CMS 617 and Alloy 230 to assess effects of environmental aging on specimen exposed in helium

- Testing and evaluate negligible creep of Gr91 for RPV application

- Initiate creep crack and creep-faitigue crack growth testing in air on CMS 617 and Alloy 230

- Evaluate results from testing in air to reformulate continuum damage models to accommodate aging, environmental, and cyclic loading effects

- Evaluate alloy $800 \mathrm{H}$ and alloy 617 for U.S. and international design codes and determine additional testing needs

- Evaluate existing data of Alloy X and XR

- Assess needs for shift to alternate alloys, if results indicate a favorable trend

- Evaluate aging to $25,000 \mathrm{~h}$ and incorporate results into continuum damage models for high-temperature life prediction

- Evaluate damage concepts utilized in the API-ASME post construction rules

- Perform irradiations of base metals, weldments and aged materials

FY 2008

- Evaluate results from testing in helium to reformulate continuum damage models to accommodate aging, environmental, and cyclic loading effects

- Complete creep crack and creep-fatigue crack growth testing in air on CMS 617 and Alloy 230

- Perform creep crack and creep-fatigue crack growth testing in helium on CMS 617 and Alloy 230

- Perform tests on Alloy $800 \mathrm{H}$ and Alloy 617 to meet additional need for U.S. and international design codes determined in FY07 evaluation

- Perform test on alternate alloys, if results from previous years indicate a favorable trend

- Provide additional weld data for modeling efforts and code rule development

- Review ultrasupercritical steam fabrication technology for infrastructure needs

FY 2009

- Complete primary irradiated and aged materials testing programs

- Provide data to assist the development of code rules accounting for aging effects

- Initiate testing on properties of specified product forms 
FY 2010 and beyond

- Complete supplementary long-term aging and creep test program

- Perform testing on specified product forms

\subsubsection{Intermediate Heat Exchanger Materials Selection and Issues}

The conditions that effect the selection of materials for the IHX are also provided in Table 10. For the Indirect Power Generation Cycle, the normal operating temperature is $950^{\circ} \mathrm{C}$ and the maximum temperature in the event of an accident is thought to be similar to the normal operating temperature. Pressure is $7 \mathrm{MPa}$, but the difference from primary to secondary circuit is small $(0.1 \mathrm{MPa})$ and the $\mathrm{IHX}$ will be contained within a pressure vessel. Environmentally induced degradation of the metals from impurities in the helium is a concern. Aging effects are a concern for very long-time thermal exposure since embrittlement could affect the performance of the IHX during thermal transients. Welding and fabrication issues exist that will depend on the IHX design details. Again, the leading potential candidates for service at $950^{\circ} \mathrm{C}$ listed in Table 11 are alloy 617, alloy X, and alloy XR. Other nickel base alloys will be considered. These include CCA617, Inconel 740 , and alloy 230 . There is a possibility that the compact IHX could be fabricated from a $\mathrm{C}_{\mathrm{f}} / \mathrm{C}$ composite.

Alternate IHX designs such as tube-and-shell introduce concerns that can only be addressed when more is known about the performance requirements. The operating temperature and environment for the indirect power generation cycle are not likely to change. Rather, the loading conditions will require a database that is extended to a broader range of design criteria than the reference compact IHX configuration. Except for the fact that the tube and shell IHX would be helium to helium, the design and associated materials issues might be similar to the heat exchangers already evaluated in the German and Japanese gas-cooled programs.

\section{Expected research, testing, and qualification needs for IHX materials}

A detailed assessment of the materials requirements for heat exchanger designs will be undertaken prior to any experimental work. The leading potential candidate alloys will be identified in the course of this assessment. Most likely, these materials will be Alloy 617, Alloy XR, and Alloy X. New alloys such as CCA617, Alloy 740, and Alloy 230 will be considered as alternates. An assessment will be undertaken of the potential of $C_{f} / C$ composites for the compact IHX.

The baseline materials data generation program for the IHX will focus on the characterization of the material of construction as it is influenced by the specific fabrication procedures needed to produce the compact IHX configuration. The material performance requirements will be developed and a list of leading candidates will be identified. It will be necessary to decide if the fabrication processes should be selected to produce a material of optimum metallurgical condition or if an off-optimum material condition is satisfactory. At $950^{\circ} \mathrm{C}$, most of the wrought nickel base alloys require relatively coarse grain size for good creep strength but fatigue resistance is best for fine grain size.

Exploratory testing will be undertaken to establish the effect of fabrication variables on the subsequent creep and fatigue properties. Materials of comparable chemistry, grain size, and processing history will be used to produce data, which can then be used to model the performance of the IHX.

It will be determined if the metallurgical state of materials included in the testing program for the core supports and internals are suitable for the IHX. If so, mechanical testing and aging work on 
materials for the $\mathrm{IHX}$ will not be needed. Bench testing small models of the IHX will be performed to add confidence to life prediction methodologies. Metallurgical evaluations will be undertaken.

Manufacturing issues related to the compact counter-flow IHX will be addressed as part of the research and testing activities. It has yet to be demonstrated that such a unit can be manufactured from the high-temperatures alloys that are the leading candidates, so it is clear that the manufacturing of such a unit will produce several issues to be resolved. Issues include the production of a high-integrity diffusion bond between the sheets of metal used to build the module, the control of conditions that result in an optimum grain size in the metal ligament, the development of methods for non-destructive evaluation (NDE) of the unit, and the design and fabrication of joints between the unit and the inlet and outlet piping systems.

As part of the development of the fabrication technology for the IHX, the interfaces of the bonded plates will be metallurgically and mechanically evaluated. The specific mechanical tests will be determined after completion of exploratory testing.

A research effort that helps to develop the fabrication technology will be undertaken, and a testing plan will be developed to examine the performance of the configuration under various loading conditions. Included in the testing will be thermal transients.

A review will be undertaken of German and Japanese experiences with materials in "more conventional" IHX units for gas-cooled reactors. Any materials technology needed to advance the conventional units will be identified after this review.

\section{Experimental IHX materials R\&D plans}

Since even the preliminary design for the heat exchangers in the NGNP has not been identified, much of the initial planning on materials needs done to date has focused on relatively generic issues expected to be germane to most very high-temperature metallic heat exchanger concepts. These plans will need to reevaluated and focused more closely on specific designs, once they have been identified.

A brief summary of R\&D plans and schedules for the NGNP IHX materials needed to meet the deployment time schedule is provided below. The bulk of the research needs for these materials will be addressed by the more extensive program outlined for materials in the HTDM task. Supplemental tasks addressing component-specific needs are included below. The schedule for these tasks is contingent upon funding availability.

\section{Milestones}

FY 2006

- Evaluate relevance of metallic internals research program for additional needs for IHX materials

- Initiate development of procedures for bench testing of small IHX models

FY 2007 and 2008

- Initiate testing of IHX bench models for metallurgical performance

- Initiate testing of materials compatibility for specialized metallurgical condition of IHX materials

- Initiate evaluation of manufacturing issues associated with IHX fabrication 
FY 2009 and beyond

- Complete materials testing programs

- Complete assessment and development of fabrication methods and required infrastructural needs

\subsubsection{Recuperator, Piping, and Valve Materials Selection and Issues}

The piping, valves, and recuperators include a number of components that operate at a wide range of conditions. These are also listed in Table 10 and include the hot duct and bellows in the cross vessel, the butterfly valve and ducting in the SCS helium circulator, and the recuperators in the power generation unit. Normal operating temperatures for these components range from 600 to $950^{\circ} \mathrm{C}$, with only modest increases for accident conditions. The mechanical loading in the hot duct is due to its own weight but the bellows will experience loads associated with the expansion it is designed to accommodate. The loads are not well defined but will include fatigue-type conditions. Additionally, changes in the system design from the reference concept to indirect cycles or other coolants would dramatically affect operating conditions.

The status of most components in the reference concept turbine system is covered below, but the recuperator is included here. The operating temperature is relatively low, with a $600^{\circ} \mathrm{C}$ inlet gas temperature from the turbine exhaust and a less than $200^{\circ} \mathrm{C}$ outlet temperature. Recuperator technology for the temperatures and pressures of operation is relatively mature, using fine-grained 300 series stainless steels, such as type 347 . Since relatively thin sections will be present, there is concern that environmental effects could be significant. Also, long-time exposure of 300 series stainless steels often leads to sigma phase embrittlement.

The primary-to-secondary piping operates at $950^{\circ} \mathrm{C}$ and will experience an operating pressure as high as $7 \mathrm{MPa}$. Creep-type conditions will prevail. Further, thermal stresses and expansion loads are always a concern in such piping systems. Again, the materials in all components are subject to environmental and aging-induced degradation.

The leading potential candidate alloys for all components discussed above are identical to those selected for the metallic core components. Alloy 617 is the lead for service above $760^{\circ} \mathrm{C}$. Alloy $800 \mathrm{H}$ is the lead for 600 to $760^{\circ} \mathrm{C}$. A number of choices exist for alloys that are intended for service to $600^{\circ} \mathrm{C}$.

\section{Expected research, testing, and qualification needs for recuperator, piping, and valve materials}

An initial comprehensive and detailed review of the potential candidate alloys identified in Table 11 will be performed. Since most of the relevant information needed for materials for the recuperators, piping, and valves will be included in that needed for the metallic reactor internals, only limited additional review will be required, but will include the status of weldment strength factors for piping, weld categories, and dissimilar weld metals and the identification of the technologies that need to be developed to provide confidence in the adequacy of existing construction codes and the reliability of life-prediction models for these NGNP components.

\section{Experimental R\&D plans for recuperator, piping and valve materials}

A brief summary of R\&D plans and schedules for the NGNP recuperator, piping and valve materials needed to meet the deployment time schedule is provided below. The bulk of the research needs for these materials will be addressed by the more extensive program outlined for the reactor internals. Supplemental tasks addressing component-specific needs are included below. The schedule for these tasks is contingent upon funding availability. 


\section{Milestones}

FY 2006

- Perform comprehensive review of the potential candidate alloys

- Initiate baseline testing and aging of piping materials

- Review performance requirements for the primary to secondary piping and the hydrogen plant HX for supplemental materials needs

- Develop details of testing program to address special joining issues identified in the comprehensive review

FY 2007

- Perform detailed evaluation of recuperator needs based on manufacturer experience for similar operating conditions

- Review updated creep, rupture, relaxation, and fabrication technology data accumulated on recuperator materials from DOE-sponsored work on microturbines

- Initiate limited testing to produce data design analysis of the recuperator

- Initiate confirmatory testing to improve confidence in the predictive methods for recuperator performance in helium

- Initiate testing of similar and dissimilar welds in piping

FY 2008 and 2009

- Provide initial required creep data for high temperature design methodology task

- Perform model tests of recuperators and bellows for metallurgical performance

- Evaluate the performance of constitutive equations, analysis methods, and continuum damage models based on data from tests on welded piping

- Perform commercial scale demonstration of capability to provide high-quality thin sheets for producing recuperator corrugated heat exchange surfaces.

FY 2010

- Complete primary materials testing program on aged and unaged materials

- Provide materials data needed for development of continuum damage models for piping materials

- Identify primary failure mechanisms from model testing

FY 2011 and beyond

- Complete very long-term creep behavior assessment of piping materials

\subsubsection{Power Conversion System Materials Selection and Issues}

Three very important components in the NGNP power conversion system (PCS) are the turbine inlet shroud, the turbine blades and disks, and the recuperator (described in the previous section). The first two, covered in this section, will operate continuously at very high temperatures, $\sim 950^{\circ} \mathrm{C}$ for the inlet shroud and perhaps almost as high for the turbine blades. Off-normal (accident) temperatures for all of these components are about the same as their maximum operating temperatures. The pre-cooler and inter-cooler (both $\mathrm{He}-\mathrm{H}_{2} \mathrm{O}$ heat exchangers) are also important components but operate under conditions and temperatures that 
are standard commercial technology. Additionally, changes in the system design from the reference concept to indirect cycles or other coolants would dramatically affect operating conditions.

Preparation of a materials test program in support of these component materials requires knowledge and understanding of the materials requirements for those applications. For the turbine inlet shroud collar and the turbine shroud insulation package container/boundary, the property of greatest importance is very high-temperature creep strength. Further, it is extremely important that the creep behavior (strength and ductility) not be degraded by gas-metal interactions (reaction of the material with impurity gases in the primary coolant helium to cause carburization, decarburization, and/or internal oxidation) or by microstructural changes resulting from holding at elevated temperatures for long periods of time (thermal aging).

Prime potential candidates for the non-insulated turbine inlet shroud collar are Alloy 617 and the cast Ni-base alloys shown in Table 12 for the turbine blades; the insulation boundary/container material could be Alloy 617 or a $C_{f} / C$ composite.

Table 12. Operating conditions affecting candidate material selection for NGNP higher temperature PCS components and potential candidate materials.

\begin{tabular}{|c|c|c|c|c|}
\hline $\begin{array}{c}\text { PCS } \\
\text { Component }\end{array}$ & $\begin{array}{l}\text { Operating } \\
\text { Temperature/Life }\end{array}$ & $\begin{array}{l}\text { Neutron } \\
\text { Fluence }\end{array}$ & Environment & $\begin{array}{l}\text { Potential } \\
\text { Candidate } \\
\text { Materials }\end{array}$ \\
\hline $\begin{array}{l}\text { Turbine Inlet } \\
\text { Shroud }\end{array}$ & $950^{\circ} \mathrm{C} / 7$ years & Negligible & Helium & $\begin{array}{l}\text { Alloy } 617 \\
\text { Cast Ni-base } \\
\text { [see Blades] } \\
C_{f} / \text { C Composites } \\
\text { [insulation } \\
\text { package] }\end{array}$ \\
\hline $\begin{array}{l}\text { Turbine } \\
\text { Blades }\end{array}$ & $\begin{array}{l}850 \text { to } 950^{\circ} \mathrm{C} \text { with } \\
\text { blade cooling } / 7 \\
\text { years }\end{array}$ & Negligible & Helium & $\begin{array}{l}\text { Alloy } 713 \text { LC } \\
\text { IN-100 } \\
\text { IN-738 } \\
\text { Mar-M } 247 \\
\text { Nimonic alloy } \\
115 \text { [wrought] }\end{array}$ \\
\hline Turbine Discs & $\begin{array}{l}750^{\circ} \mathrm{C} \text { with } \\
\text { cooling/>7 years }\end{array}$ & Negligible & Helium & $\begin{array}{l}\text { Hastelloy X } \\
\text { Hastelloy XR } \\
\text { Hastelloy S } \\
\text { Alloy } 617 \\
\text { Alloy } 625 \\
\text { Nimonic } 80 \mathrm{~A}\end{array}$ \\
\hline
\end{tabular}




\section{Expected research, testing, and qualification needs for PCS materials}

Early work should be initiated on the turbine shroud material to assure that adequate long-term creep data is available in the temperature range $950^{\circ} \mathrm{C}$ to $1050^{\circ} \mathrm{C}$. Long-term in reference to the collar may be relatively short as the collar could be replaced at each 7 -year maintenance period; however, it is likely that a much longer life is desired for the insulation package container. Confirmatory demonstrations of the manufacturing processes are needed for the forming and welding procedures required for the turbine inlet shroud collar and the shroud thermal insulation boundary/container and the recuperator.

The situation relative to the turbine blade material is essentially identical to that described above. Temperatures, environments, service periods, and many of the candidate materials are identical. In addition to the creep and environmental work it will be necessary to address questions relative to both low-cycle and high-cycle fatigue at very high temperatures and the effects of gas-metal interactions on fatigue behavior. Creep-fatigue interactions will also require study.

A large number of wrought Ni-base alloys are potentially appropriate to the turbine disk application. Of these, Hastelloy X and Hastelloy XR and Alloy 617 (also a candidate for the turbine inlet shroud collar) have been studied extensively in simulated gas-cooled reactor environments. Creep and tensile strength data should be available for all candidate materials; further studies will likely be needed on fracture toughness and crack growth properties. Some confirmatory environmental exposures are desirable on the down-selected materials but effects at the temperature of application $\left(\sim 750^{\circ} \mathrm{C}\right)$ should be relatively minimal. Testing efforts aimed at the materials for the recuperator should be minimal. All needed mechanical property data are available; confirmatory environmental exposures are desirable but no adverse effects are expected.

The manufacturing technology is an important issue for the bellows. The hot ducting and bellows operate at $600^{\circ} \mathrm{C}$ but could reach $700^{\circ} \mathrm{C}$ in event of an accident. Alloy $800 \mathrm{H}$ is the leading candidate. Nevertheless, there have been several instances of early failures in bellows fabricated from alloy $800 \mathrm{H}$ and operating at temperatures in the range of 600 to $650^{\circ} \mathrm{C}$. These failures may be related to fabrication technology. Some testing will be undertaken to demonstrate that failures of $800 \mathrm{H}$ components in the refining and petrochemical industries are understood and can be avoided in the NGNP components. The testing will be largely confirmatory and will include aging effects and environmental effects studies under simple and complex loading conditions.

The helium circulator operates at $600^{\circ} \mathrm{C}$. There are no pressure stresses, but some concern exists in regard to high-cycle fatigue and creep-fatigue. Stainless steels may be considered for this application. However, ferritic steels, such as $21 / 4 \mathrm{Cr}-1 \mathrm{Mo}$ steel, and F/M steels, such as $9 \mathrm{Cr}-1 \mathrm{Mo}-\mathrm{V}$ steel, are potential candidates. The material selection will be based to some extent on the fatigue or creep-fatigue resistance of the candidate alloys. It is expected, for example, that the high yield strength of the F/M steels will produce favorable fatigue resistance in the absence of severely oxidizing environments. It is important that an assessment of the loading conditions be undertaken before the leading potential candidates are identified. 


\section{Experimental PCS materials R\&D plans}

A brief summary of R\&D plans and schedules for the NGNP PCS materials needed to meet the deployment time schedule is provided below. None of these activities other than assessments should be initiated until designs and materials candidates become reasonably firm. The schedule for these tasks is contingent upon funding availability.

\section{Milestones}

FY 2007

- Perform comprehensive review of the potential candidate alloys.

- Procure leading potential candidate materials

- Initiate mechanical and thermal-physical properties testing program of unaged materials

- Initiate aging of materials in helium

FY 2008

- Initiate fatigue, creep-fatigue, and fracture toughness testing

- Initiate creep and thermal-physical properties testing of aged materials

- Determine corrosion allowables for long-term helium exposure

- Complete selection of primary candidate materials

- Procure additional primary candidate materials

FY 2009 and 2010

- Initiate fatigue, creep-fatigue, and fracture toughness testing of aged materials

- Demonstrate formability and weldability of shroud collars

- Fabricate and initiate mechanical properties testing of shroud weldments

- Demonstrate castability of cast Ni-base candidates for turbine inlet shroud collars and turbine blades

FY 2011 and beyond

- Complete materials testing programs

- Conduct commercial demonstration of the capability to provide turbine disk materials in the size and geometry required

\subsubsection{High-Temperature Design Methodology}

The current elevated temperature nuclear design criteria and material coverage (Subsection $\mathrm{NH}$ ) originate largely from the LMR program of the late 1960s, ' 70 s, and early ' $80 \mathrm{~s}$. A HighTemperature Structural Design (HTSD) Technology task within the nationwide Materials and Structures Technology program supported the development and experimental confirmation of design criteria to guard against creep, creep-fatigue, and ratcheting failures. The Mechanical Properties Design Data task provided the uniaxial data for design and quantification of the criteria. In companion efforts, the HTSD Technology task provided simplified methods and recommended constitutive equations for inelastic design analyses, and the Design Data task provided the uniaxial stress-strain and creep data needed for designers to implement the 
equations. All of this work was based on experimental data from common heats of materials, so that the resulting design methods, criteria, and data were as consistent as possible. An Argonne National Laboratory report prepared for the NRC provides a good overview of Subsection NH and its associated cases and their shortcomings for HTGR components [3.7]. Today, DOE supports two similar tasks at ORNL for Gen IV - a HTSD task and a High Temperature Metallic Material task. The structural design and materials tasks are very dependent upon one another, and as such are referred to jointly as HTDM. The HTSD task is outlined here, which does include specific testing for constitutive and life prediction model verification. Some of these activities are included and funded within the crosscutting activities for HTDM in section 4.4. Additional materials related tasks that will support HTDM in providing necessary material properties data, such as uniaxial creep testing of RPV materials, metallic internals, and metallics for the IHX are discussed in the preceding sections of this report.

While not included explicitly with the research requirements for each individual component, time-dependent failure modes and time- and rate-dependent deformation response to timevarying thermal and mechanical loadings will characterize the design of NGNP metallic components operating at high temperatures. The primary role of the HTSD Technology task, which is an integral and inseparable part of the overall NGNP materials program, is two-fold. First it will provide the data and models required by ASME Code [3.8] groups to formulate timedependent failure criteria that will assure adequate life for components fabricated from the selected NGNP materials [3.1]. Second, it will provide the experimentally-based constitutive models that are the foundation of the inelastic design analyses specifically required by Subsection NH of Section III of the ASME Boiler and Pressure Vessel Code, which governs design of elevated-temperature Class 1 nuclear components. This task is thus a key part of the codification and utilization of the selected NGNP structural materials.

A secondary role of the task deals with regulatory acceptance. Safety assessments, required by $\mathrm{NRC}$, will depend on time-dependent flaw growth and the resulting leak rates from postulated pressure-boundary breaks. This requires a flaw assessment procedure capable of reliably predicting crack-induced failures as well as the size and growth of the resulting opening in the pressure boundary. Identification of an overall proven procedure is a part of this task.

The challenges, requirements, activities, and ASME Code considerations for designing hightemperature NGNP components are summarized in the following sections. Additional details are provided in an R\&D plan for development of HTSD Technology [3.9].

\section{Challenges and Requirements for High Temperature Structural Design}

High-temperature components respond to thermal and mechanical loadings inelastically. Their responses are very rate dependent and both strain and cyclic softening can occur. Each time the secondary and peak stress is cycled due to start-ups, shut-downs, and other changes in operational levels, the stress-strain state at each location in the component undergoes a complex cycle involving plasticity and creep, or at higher temperatures, time-dependent viscoplastic behavior. The subsequent stress state during operation may bear little resemblance to that envisaged for the primary pressure stress alone, and the accumulated cyclic strains can be considerably larger than those due to creep alone.

Early in the development of ASME Subsection NH (rules for Class 1 elevated-temperature nuclear components), it was recognized that without a reasonably accurate prediction of the complex, multiaxial time-dependent stress-strain behavior throughout a component, structural integrity could not be assured. This was especially true in light of the recognition that elevated- 
temperature failures are likely to occur at notch-like geometric discontinuities and at weldments (metallurgical discontinuities) where the material response is most complex. Subsection NH is thus predicated on the use of inelastic design analysis to accurately predict stress-strain-time response at critical component locations.

Simplified procedures based on simplifying models of stress-strain behavior, are also provided, and these can often be used to avoid fully detailed inelastic analyses. The existing simplified inelastic design procedures in $\mathrm{NH}$ have not been proven adequate or inadequate for very high temperature design applications such as the NGNP. Furthermore, they have yet to be approved by ASME for application to materials that exhibit mostly tertiary creep behavior, such as Alloy 617. Confirmatory structural tests are also required to validate design criteria in Subsection $\mathrm{NH}$ and associated code cases. The process to develop design code and criteria for very high temperature applications is not always a straight forward one; it will require an iterative process between coupon testing, constitutive modeling, simplified methods development, failure modeling such as creep-fatigue interaction, and structural testing for validation.

\section{ASME Code Section III, Subsection NH and Associated Cases}

The design rules of Subsection NH for Class 1 elevated-temperature components consist of: (1) load-controlled (primary) stress limits, and (2) strain, deformation, and fatigue limits (Appendix $T$ in $\mathrm{NH}$ ). The load-controlled stress limits are in the form of time-dependent allowable stresses based on both short-time tensile test results and long-term creep test results. Allowable stress reduction factors for weldments are given, as are reduction factors to account for the degrading effects of prior service. Only elastic analysis results are required to satisfy the primary stress limits. The second category of design rules - strain, deformation, and fatigue limits - are much more problematic. These rules deal with the complex loading and behavior resulting from primary plus cyclic secondary and peak stresses. They are aimed at preventing failures due to excessive deformation, creep-fatigue damage, and inelastic buckling, and they require inelastic design analysis results or, in some cases, simplified procedures for their satisfaction. The rules [3.8] include strain accumulation limits, creep-fatigue criteria, buckling limits, and special limits for welds.

The materials that are currently covered, allowable life times, and maximum allowable temperatures are limited in Subsection $\mathrm{NH}$ as shown in Table 13. Comparison of temperatures in Table 13 with the anticipated upper Gen IV reactor system temperatures in Table 44 in Section 4.4 of this report indicates that the current Code coverage is inadequate for the NGNP, GFR, and LFR (long-term version) components. For example, when temperatures during abnormal events are considered, only the temperature limits for Alloy $800 \mathrm{H}$ come close to those required for the NGNP vessels. Coverage is inadequate for use of all materials for use in the very-high-temperature NGNP components. 
Table 13. Current subsection NH materials and maximum allowable times and temperatures.

\begin{tabular}{|c|c|c|}
\hline \multirow{2}{*}{ Material } & \multicolumn{2}{|c|}{ Temperature $\left({ }^{\circ} \mathrm{C}\right)$} \\
\hline & $\begin{array}{l}\text { Primary stress limits } \\
\text { and ratcheting rules }\end{array}$ & Fatigue curves \\
\hline 304 stainless steel & 816 & 704 \\
\hline 316 stainless steel & 816 & 704 \\
\hline $2 \frac{1}{4} \mathrm{Cr}-1$ Mo steel & $593^{b}$ & 593 \\
\hline Alloy $800 \mathrm{H}$ & 760 & 760 \\
\hline $\begin{array}{l}\text { Modified } 9 \mathrm{Cr}-1 \text { Mo steel } \\
(\text { Grade } 91)^{\mathrm{C}}\end{array}$ & $593^{b}$ & 538 \\
\hline $\begin{array}{l}{ }^{\mathrm{a}} \text { Allowable stresses extend to } \\
{ }^{\mathrm{b}} \text { Temperatures up to } 649^{\circ} \mathrm{C} \text { ar } \\
{ }^{\mathrm{c}} \text { Modified } 9 \mathrm{Cr}-1 \mathrm{Mo} \text { steel } \mathrm{h}\end{array}$ & $\begin{array}{l}\text {,000 h (34 years) unl } \\
\text { llowed for up to } 1000 \\
\text { been approved for } \mathrm{Si}\end{array}$ & $\begin{array}{l}\text { otherwise noted. } \\
\text { ction } \mathrm{NH} \text { but has }\end{array}$ \\
\hline
\end{tabular}

Aside from the fact that many preliminary candidate Gen IV materials are not included in Subsection $\mathrm{NH}$, there are several generic shortcomings that will require resolution.

1) The maximum temperatures permitted will have to be significantly increased.

2) Allowable time-dependent stresses will have to be extended beyond the current $300,000 \mathrm{~h}$ maximum to $600,000 \mathrm{~h}$

3) Environmental effects (e.g., impure helium in the case of NGNP) need to be incorporated into the failure criteria, particularly creep-fatigue.

4) Current simplified inelastic methods and stress classification techniques need to be assessed for very high temperature applications, and improved or alternate approaches developed.

5) The current linear damage accumulation rule for creep-fatigue has significant shortcomings, particularly at higher temperatures and longer times. These shortcomings must be remedied.

6) Design criteria for weldments and notches were identified in the Clinch River Breeder Reactor Plant (CRBRP) to require remedies and must be addressed for Gen IV systems [3.10].

Four current Code cases and a draft Code case are relevant. Case N-499 was developed for HTGRs. N-499 permits Class 1 components fabricated from SA-533, Grade B steel to exceed the normal $371^{\circ} \mathrm{C}$ low-temperature design limit for short periods for Levels $B, C$, and $D$ events. A similar case might be developed for the gas-cooled reactor vessel materials under off-normal conditions. Case N-201 provides rules for construction of core support structures made of ferritic steels, austenitic stainless steels, and high-nickel alloys, for which metal temperatures do not exceed those in Section II, Part D, of the ASME Code. This Case, with modifications, might be useful for the metallic core internals of Gen IV systems. The basis for the Case is the same high-temperature structural design methodology as that on which Subsection $\mathrm{NH}$ is based. Code case $\mathrm{N}-253$ provides rules for Class 2 and 3 components for elevated temperature service. Unless exemption rules are met, the case essentially defaults to the criteria of Subsection NH. Code case N-290, which covers expansion joints in Class 1 liquid-metal piping and is based on design by test verification, might have application to bellows used in Gen IV systems. The Japanese have developed design by analysis procedures that would replace some of the more onerous aspects of $\mathrm{N}-290$ [3.11]. 
A draft Code case developed in the 1980s for design of nickel-base Alloy 617 components to $982^{\circ} \mathrm{C}$ is directly pertinent to NGNP and other Gen IV systems with very-high-temperature components [3.12]. The case was approved by ASME Subsection $\mathrm{NH}$ and submitted to its parent group, the Subcommittee on Design, for approval. However, further action on the case was suspended when the DOE project was canceled. The case, of considerable value to Gen IV, can serve as a springboard for establishing very-high-temperature component Code rules. The draft case, while having the same framework as Subsection $\mathrm{NH}$, has several unique features that are ramifications of the very-high-temperature material behavior. This behavior includes: a) the lack of clear distinction between time-independent and time-dependent behavior, b) the high dependence of flow stress on strain rate, and c) softening with time, temperature and strain.

To summarize, the design rules of Subsection $\mathrm{NH}$ that are based on the separation of time- and rate-independent response, or on strain-hardening idealizations of material behavior, required careful reconsideration. In addition to inheriting the known shortcomings of Subsection $\mathrm{NH}$, the draft case has a number of gaps and shortcomings that would have to be overcome before it could be satisfactorily and reliably applied. These were identified as the case was being developed, and they are tabulated below because of their relevance to this plan.

- Actions Required to Complete Case

- $\quad$ Alloy 617 must be added to the low-temperature rules of Section III.

- Weldment stress rupture factors must be added.

- Thermal expansion coefficients must be added.

- Additional isochronous stress-strain curves, covering temperatures below $649^{\circ} \mathrm{C}$ and above $950^{\circ} \mathrm{C}$, must be added.

- Material Data Needs

- Weldment fatigue data are needed.

- A more complete creep-fatigue database must be developed.

- The synergistic effects of aging, environment, loading, and temperature should be better understood.

- $\quad$ The effects of aging on toughness must be characterized.

- Structural Design Technology Needs

- An experimentally validated constitutive model must be developed.

- Some very-high-temperature, time-dependent tests of simple Alloy 617 structural models are needed to (1) provide a better understanding of structural behavior and failure modes, (2) validate inelastic analysis methods, and (3) provide application feedback for the case.

- Simplified ratcheting evaluation procedures need to be developed for temperatures above $649^{\circ} \mathrm{C}$.

- The use of linear damage fractions as the basis of creep-fatigue rules is probably the biggest shortcoming of the draft case. A basic effort is needed to identify and experimentally validate a more suitable damage theory.

\section{NGNP Requirements}

Reflecting the scope of the overall materials program, the High-Temperature Structural Design Technology task will have two thrusts: (1) medium-high-temperature pressure boundary metals (e.g., pressure vessels) and (2) metals for very-high-temperature components. For purposes of this plan it is assumed that both pressure boundary and very-high-temperature materials will be included in the rules of Subsection $\mathrm{NH}$ or their associated Code cases. 
The most promising candidate materials for the pressure boundary components are the higher-alloy $9 \mathrm{Cr}$ and $12 \mathrm{Cr}$ steels. For very-high-temperature components, the most likely material candidates are variants or restricted chemistry versions of Alloy 617, variants of Alloy $800 \mathrm{H}$, and variants of Alloy 230.

While the initial thrust of the High-Temperature Structural Design Technology task is focused on NGNP requirements, the results will apply as well to the other Gen IV reactor concepts. Modified $9 \mathrm{Cr}-1$ Mo steel, for example, is a candidate structural material for all four Gen IV reactor systems considered here. Nickel-base alloys, including 617, are candidates for veryhigh-temperature components in each concept except SCWR. As GFR, SCWR, and LFR requirements become better defined, the parameters and common materials covered by the High-Temperature Structural Design Technology task will be expanded to include them.

\section{Scope and Schedule}

The required and planned HTDM activities are illustrated in a flow chart in Figure 22. Design procedures may be developed with assumed or simplified models to predict material behavior. Separation of the effect of material behavior and safety factors embedded in design allowables from actual structural design procedures permits direct comparison of simplified design methods. This is not to say that material behavior is not important. In fact, parallel activities for the development of experimentally based constitutive equations used to predict the actual stress-strain behavior of materials in components are possible and desired. The material models must be validated with simple uniaxial testing, followed by biaxial testing. The ability to predict the stress-strain state of material in a structure is only the second step. Material models and simplified inelastic design methods must then be used to predict the stress-strain state in various simplified structures and loading conditions indicative of Gen IV reactor applications. The prediction of the stress-strain history of material of a component is required as input into models to conservatively predict various failure modes in components. This requires the integration of yet another parallel task - tensile, creep, and creep-fatigue testing combined with the development of appropriate life prediction models to generate the code design allowables to prevent various failure modes. Failure modes include ductile rupture from short-term loading, creep rupture from long-term loading, creep-fatigue failure, gross distortion due to incremental collapse and ratcheting, loss of function due to excessive deformation, buckling due to shortterm and long-term loading. Finally, the overall design process and allowables must be validated with actual structural testing. Careful selection of component-like coupon test samples and simplified structures will permit cost effective and practical testing. To a limited extent, this task may be conducted in parallel with the other activities, but will rely heavily on interim and final results of the tasks previously discussed above. The structural tests must be designed to address specific failure modes and aspects of the design criteria. Comparison of actual structural test results with model predictions inevitably will require modification of one or more aspects of the design process and criteria, followed by additional verification testing. While the process is iterative, experience of U.S. National Laboratories, design organizations, consultants, international experts, and DOE and NRC staff coupled with the existing NH procedures will be a tremendous advantage towards the ultimate goal - the NRC granting licenses for the design, construction, and operation of Gen IV reactors. 


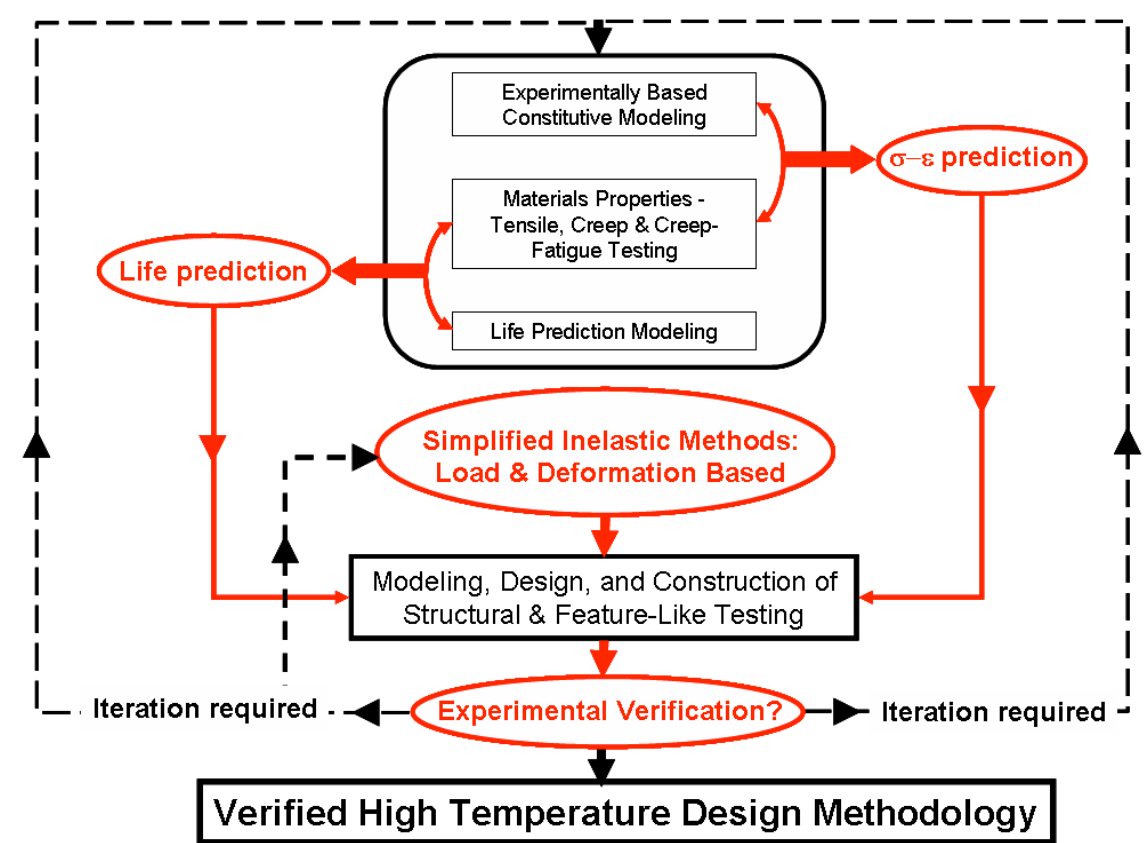

Fig. 22. Flow Chart for Visualization of Interdependency of Tasks Within High Temperature Design Methodology Project

\section{Resolution of Identified Shortcomings, Issues, and Regulatory Concerns}

Experience has shown that once detailed design assessments are undertaken, shortcomings and issues with the design methodology and criteria will arise, requiring additional R\&D for their resolution. In addition, the licensing process will likely result in the identification of further R\&D requirements, as it did in the case of the Clinch River Breeder Reactor Plant (CRBRP) project. Thus, it is anticipated that the High Temperature Design Methodology development project will continue through the FY-12 to FY-15 timeframe to resolve the shortcomings, issues, and regulatory concerns that are identified relative to NGNP and other Gen IV concepts.

\section{Plans \& Priorities}

The following overall strategy will be used to establish the required HTSD technology, consisting of unified constitutive equations for design analyses, design criteria (creep-fatigue, etc.), simplified method and criteria, and structural testing. Because of the extremely short time available, the projected funding will be applied in decreasing priority to (1) developing simplified criteria and constitutive modeling which can be used in rapid feasibility assessments of the structural viability of very-high-temperature components in conceptual and early preliminary design phases, (2) completing work on the draft Code case for Alloy 617, or a variant thereof, for very-high-temperature components, and (3) verifying, through confirmatory structural tests, the validity of the current criteria, inelastic analysis methods, and simplified methods for modified 9Cr-1Mo steel (Grade 91), and adapting, if necessary, the criteria and design methods for other pressure boundary components. While the above two materials are leading contenders for use in NGNP and other Gen IV systems, even if they are not chosen their early consideration will allow the design methodology development to build on the considerable previous experience and provide a framework for including subsequent material candidates. The effort will be expanded as material down-selection occurs and projected funding increases. 
Much of this effort provides required technological support and recommendations to the ASME Code Subsection NH Subgroup on Elevated Temperature Design (SG-ETD), which is the group responsible for the development of the Subsection $\mathrm{NH}$ rules and for approving new materials into Subsection $\mathrm{NH}$. To that extent, the pace and direction of the activities will also be dictated by the deliberations and decisions of the Subgroup.

\section{Summary of FY-05 Results \& Activities}

Initial efforts on this task began in FY-04, with two thrusts. The first was more detailed program planning, based on preliminary literature reviews and discussions with key individuals active in the development and application of high-temperature design methods [3.9]. The second focused on identification of simplified criteria that can be used in rapid feasibility assessments of the structural viability of very-high-temperature components in conceptual and preliminary design phases [3.13].

Limited funding in FY-05 was applied towards the development of simplified methods and ASME Code participation. Crosscutting activities closely parallel NGNP activities; as such, the following activities were addressed jointly with funding from NGNP and Crosscutting: participation in ASME Section III, Subsection NH code meetings; service as Secretary of $\mathrm{NH}$, and fostering and the formation of a DOE-ASME collaborative agreement to support Gen IV codification needs.

\section{Support of ASME Section III Code:}

An imperative requirement for ASME codification is that key participants in the High Temperature Design Methodology, composed of both High-Temperature Structural Design \& Materials Tasks, and knowledgeable representatives from design organizations, be actively involved in ASME Subsection NH. A High Temperature Design Methodology Coordinating Committee, chartered by DOE, was proposed in FY04. An important first step towards this goal occurred in FY2005 when a joint DOE-ASME collaboration agreement was reached, lead by technical experts at ORNL, Idaho National Laboratory (INL), stakeholders, and Subsection $\mathrm{NH}$. This three year agreement initiates organization and task activities within ASME Section III in support of codification needs for Gen IV reactors. Initially twelve main tasks were identified, with funding of one million dollars to support efforts on 4-5 of these tasks in FY06. Additional activities on the remaining tasks will take place, pending available funding. A summary of the tasks is provided below. Additional details can be found in [3.14].

Verification of allowable stresses in ASME Section III, Subsection NH with emphasis on alloy 800h and grade 91 steel (9cr-1mo-v or modified $9 \mathrm{cr}-1 \mathrm{mo})$

Currently, five materials are approved for the construction of Class I nuclear components other than bolts under the rules of ASME Section III, Subsection NH (III-NH). Two of these materials, namely $800 \mathrm{H}$ and $9 \mathrm{Cr}-1 \mathrm{Mo}-\mathrm{V}$ steel, are candidates for the construction of components for the VHTR concept included in the Gen IV Nuclear Reactor Program. The major research that produced the database for these materials was undertaken in the 1970s and 1980s. Since then, considerable long-time experience has been gained for both materials and data analysis methods for setting the allowables have been refined. These actions have produced changes in both the time-independent and time-dependent allowable stresses in ASME Section II for Sections I and VIII, D1. There is a need to review these changes and 
their impact on the allowable stresses in III-NH.

Regulatory safety issues in structural design criteria of ASME Section III Subsection NH and for very high temperatures for VHTR \& Gen IV

The Nuclear Regulatory Commission has not accepted (nor rejected) Subsection $\mathrm{NH}$ of Section III of the ASME Code "Class 1 Components in Elevated Temperature Service." Further, the Advisory Committee on Reactor Safeguards (ACRS) reviewed similar elevated temperature structural design criteria proposed for the CRBR and generated a list of technical issues and safety concerns which they believed still needed to be resolved [3.8]. DOE agreed to fund R\&D efforts to answer their concerns to the satisfaction of the U.S. NRC and the ACRS prior to requesting an Operating License for CRBR. The structural design criteria being used at that time were fundamentally similar to the current criteria in Subsection $\mathrm{NH}$ of Section III of the ASME Code. A paper on the NRC review summarized the situation as follows: "In a general sense, the NRC review of the CRBRP confirms the adequacy of the high-temperature structural design methodology that has been developed over the last 20 years..." and "The design criteria and basic approach to design evaluation have been accepted, and no major inadequacies were discovered. The review identified and resolved a number of issues relative to Code interpretation, and it identified areas where more detailed evaluation techniques would be useful. The required confirmatory programs would both improve design assurance of the CRBRP, and simplify design and evaluation of future plants." [3.8]. The four major areas of concern were 1) weldment safety evaluation, 2) notch weakening, 3) design analysis methods, codes, and standards, and 4) adequacy of tube sheet designs for the steam generator. The programs that were developed to address these concerns were not conducted when the program funding was terminated. It is clear that the confirmatory programs need to be completed. Assessment and identification of additional possible safety issues relative to Gen IV, and specifically VHTR, are needed. Ultimately, any safety issues need to be resolved from a regulatory perspective in order to assure that the technology needed to support the licensing of VHTR and Gen IV will be in place to support Design Efforts in a timely manner.

Improvement of ASME Subsection NH Rules for Grade 91 Steel-(negligible creep and creepfatigue)

Mod9Cr1Mo (grade 91) is a candidate for the Reactor Pressure Vessel of VHTR and is also thought to be a potential candidate as a material for internals. Two important issues related to the use of Mod9Cr1Mo exist: negligible creep and creep-fatigue.

For the RPV, the issue to be addressed is related to the definition of negligible creep conditions. This need is linked to the choice to operate the RPV in the negligible creep domain so as to avoid the implementation of a surveillance program in the significant creep regime. This point is all the more important in that there is interest to increase the value of the core inlet temperature.

For internals, the major concern is creep-fatigue. Procedures are available in nuclear codes (ASME, RCC-MR, etc.) to cope with creep-fatigue but most of those procedures have been established for austenitic stainless steels and do not necessarily take account of peculiarities of martensitic steels such as Mod9Cr1Mo (e.g. softening and elastic-relaxation behavior). There is therefore a need to compare existing procedures and to confront numerical 
application with experimental results. A specific point to investigate is the definition of the creep-fatigue damage envelope for which significant differences are found from one procedure to another.

Updating of ASME Nuclear Code Case N-201 to accommodate the needs of core support structures in High Temperature Gas Cooled Reactors currently in development

ASME Nuclear Code Case N-201 contains rules for construction of core support structures under Subsection NG for service at elevated temperatures. The rules of this Code Case are similar to those contained in Subsection $\mathrm{NH}$, Class 1 Components in Elevated Temperature Service. Both Subsection NH and Code Case N-201-4 were developed before the requirements for Gen IV VHTRs were known and therefore require additions or amendment to be of value in the design and construction of the currently proposed VHTRs.

Part A of the current Code Case N-201-4 provides design rules for the construction of core support structures fabricated from five materials: ferritic steels $1 \mathrm{Cr}-0.5 \mathrm{Mo}-\mathrm{V}$ and $2.25 \mathrm{Cr}-\mathrm{I}$ Mo, Type 304 and 316 stainless steel (SS), and Alloy $800 \mathrm{H}$. Part A applies at times and temperatures where creep effects do not need to be considered. For Part B of the Code Case, "Rules for Construction of Subsection NG, altered for service at elevated temperature to suitably account for creep and stress-rupture effects," the permissible materials are limited to four, $2.25 \mathrm{Cr}-\mathrm{I}$ Mo, Type 304 and 316 stainless steel (SS), and Alloy $800 \mathrm{H}$, with varying maximum permitted temperature for use.

The maximum permitted temperature of $815^{\circ} \mathrm{C}\left(1500^{\circ} \mathrm{F}\right)$ is SS 304 and 316 and $760^{\circ} \mathrm{C}$ $\left(1400^{\circ} \mathrm{F}\right.$ for alloy $\left.800 \mathrm{H}\right)$ these materials cannot be used when exposed to temperatures at or near the core gas outlet temperature for construction of VHTRs with core outlet temperatures of $900^{\circ}$ to $1000^{\circ} \mathrm{C}$. Hence, the scope of the code case needs to be expanded to include the materials with higher allowable temperatures or extend the temperature limits of current materials and to confirm that the design methodology used is acceptable for design of core support structure components at the appropriate elevated temperatures.

Collect Available Creep-Fatigue Data and Study Existing Creep-Fatigue Evaluation Procedures for Grade 91 Steel and Hastelloy XR

Creep-fatigue is a failure mode of great concern for reactors operated at elevated temperatures. ASME Section III Subsection NH incorporates procedures for creep-fatigue damage evaluation, which is one of the major features that distinguish it from other parts of Section III. NH deals with such materials as conventional steels, Mod9Cr-1Mo and Alloy $800 \mathrm{H}$. Temperature range and service duration covered in the code vary in range of temperature and time, up to $750^{\circ} \mathrm{C}$ and approximately 34 years, respectively.

There are noticeable deviations between what is required in the design of Gen IV \& VHTR reactors and what the current NH covers. Structural materials of primary choice in Gen IV \& VHTR reactors are Mod9Cr-1Mo and Hastelloy XR. Alloy 617 and Haynes 230 are also candidate materials similar to Hastelloy $X R$. Gas temperature ranges expected in current design study are up to $600^{\circ} \mathrm{C}$ or higher for Mod9Cr-1Mo and $950^{\circ} \mathrm{C}$ for Hastelloy XR; various design strategies will lower the actual metal temperature to varying degrees. However, components such as the intermediate heat exchanger will experience the full gas temperature. Design life for the reactor is 60 years. Mod9Cr-1Mo has recently been incorporated in $\mathrm{NH}$, while Hastelloy XR, Haynes 230, and Alloy 617 have not been incorporated yet (a draft code 
case for Alloy 617 exists). Temperature range and design life are well above the range covered by the current $\mathrm{NH}$. Some experts consider the current creep-fatigue criteria for Mod9Cr-1Mo in $\mathrm{NH}$ to be overly conservative because is the limits are based on the interim results of Clinch River project. The project was interrupted many years ago when a good understanding of creep-fatigue in Mod9Cr-1Mo had not been achieved; consequently, the interaction diagram was intentionally constructed to error on the conservative side until the need (and associated funding required) to better understand the interaction arose. Nothing has been prepared for creep-fatigue evaluation of Hastelloy XR, and Haynes 230 . The degree of conservatism and methods used in the creep-fatigue procedure for Alloy 617 in the draft code also requires a critical review.

Considering the gap between the basis for creep-fatigue procedures in $\mathrm{NH}$ and that needed in Gen IV \& VHTR, creep-fatigue data acquisition and establishment of better creep-fatigue criteria for primary materials (Mod9Cr1Mo and Hastelloy XR, Haynes 230, and Alloy 617) are desired. However, because performing material tests from scratch requires extremely large resources, it is appropriate to start with analyzing existing data and creep-fatigue criteria. Therefore, collecting creep-fatigue data on Mod9Cr-1Mo and Hastelloy XR and studying existing creep-fatigue evaluation procedures, which will lead to identification of research and development items in the near future, are required.

\section{NH Evaluation and Simplified Methods}

T. E. McGreevy, et al., addressed the need for simplified inelastic design methods, and future directions [3.14]. However, closely linked to these methods are the development of creepfatigue design and assessment procedures. While activity in this area has already been indicated in the previous task, additional activity in this area is required. The activity should include the review of creep-fatigue methodologies, including crack growth, damage-based and strain-based methods. Likely sources will include GE Report DOE-ET-34202-80 and ORNL5073. Identify applications and areas of difficulty in connection with Grade 91 steel and Alloy $617 / 230 / 800 \mathrm{H}$ materials. Aging, crack initiation, surface and environmental effects on these materials will be examined. Data and methodology will be critically evaluated in the light of likely VHTR cycles and assessment requirements. The report will comment on the adequacy of existing methods and will include recommendations to address problems. These could include life prediction models, extrapolation of data, test data and techniques. This activity will not be conducted in vacuum relative to other activities that address creep-fatigue, rather it serves as a parallel but non-duplicate path at addressing creep-fatigue. Addressing such a complicated problem with several different concepts is desired.

Identifying Future Test Needs to Validate Elevated Temperature Design of VHTR

The VHTR/PBMR has features that no preceding reactors have had. Very high operating temperatures is one of those features and this requires challenging tasks such as development of new materials and extension of elevated temperature design methodologies far beyond the range that existing ones cover in terms of operating temperature, service duration, environment, etc in ASME Section III.

To implement new materials and guide the development and verification of new design methodologies for codes and standards subject to authorization by regulatory bodies, validation tests using structural and/or component models are indispensable. This includes 
changes in design margins, constitutive equations, and design methods. Test programs should be developed to ensure complete validation of points of concern in the design of VHTR/PBMR, particularly focusing on phenomena for which not enough experience has been accumulated through operation of existing plants, such as very high temperature, irradiation in helium environment, and failure modes and degradation mechanisms foreseen associated with them.

Structural and/or component tests are usually very time consuming and costly. In the development of test programs it is strongly desired that the programs should be developed based on thorough information on what has been accomplished in the past to support the validation, and to identify what has not been addressed or failed to be adequately addressed. Therefore, identifying future test needs by reviewing knowledge and information on what has been accomplished so far is required.

Environmental and Neutron Fluence Effects in Structural Design Criteria of ASME Section III Subsection NG \& NH and for Very High Temperature VHTR \& Gen IV Designs

Subsection NG of the ASME Code for Nuclear Components: "Class 1 Components in Elevated Temperature Service," does not cover either environmental (corrosion) effects or the effects of irradiation. Moreover, the extension of the design criteria to the higher temperatures $\left(950^{\circ} \mathrm{C}\right)$ needed for VHTR and Gen IV reactors introduces much more aggressive Environmentally Assisted Cracking (EAC) issues. It has been the policy of ASME Codes on new construction not to include environmental effects. Recently, however, the ASME Code Subgroup on Fatigue Strength developed proposed new water reactor environmental fatigue design curves. The technology supporting this development is concerned with quantifying the detrimental effects of corrosive attack as a function of the corrosion potential and mechanism, temperature, and strain rate, etc. Crack growth rates are increased by factors of 10 to 50 for carbon, low alloy and stainless steels vs. the crack growth rates in air.

The effects of irradiation have been considered in the design criteria used for reactors, and also in the design of nuclear fuel elements. The strains resulting in creep tensile instability cracking are greatly reduced by irradiation effects. The strain hardening capacity of structural materials is reduced, thereby allowing strain concentrations along very narrow, shear bands or slip lines where the strains are in order of magnitude higher than calculated using continuum mechanics. Tests on fractured irradiated materials show that the strains immediately adjacent to the cracks can be 10 to 100 times higher than the average or continuum strains. As a result, cracking in irradiated materials occurs at calculated creep strains of 1 to 5 percent, where the actual local shear strains are near 100 percent.

The goal of this task is to initiate action to address environmental and neutron effects from a Design Code viewpoint, and to formulate supplemental rules and criteria applicable to VHTR concepts.

Development of ASME Code Rules for the Gas Cooled Reactor Intermediate Heat Exchanger $\underline{(I H X)}$

"Needs for Intermediate Heat Exchanger (IHX)" has been ranked as a priority item by AREVA to support the VHTR program and appears on the list of items generated by the ASME Board of Nuclear Codes and Standards (BNCS) New Reactors Task Group. From the standpoint of elevated temperature design, the critical section of the IHX is the internal heat transfer matrix. 
Generally, the outer shell is designed as the primary pressure retaining member and is maintained at a temperature cool enough to minimize creep effects. The inner, heat transfer matrix is, however, exposed to the full reactor outlet temperature. This matrix also serves as the boundary between primary and secondary coolant so it does have a pressure boundary function even though it is not exposed to the full pressure differential between the gas and atmospheric pressure.

Since the heat transfer matrix is not part of the external pressure boundary, and designs will likely include an isolation valve to isolate any failure of the IHX to the nuclear plant, and not a hydrogen plant, one could question the need for ASME Code rules to cover this structure. When this issue was raised with potential reactor system suppliers they reiterated the importance of Code coverage from both the standpoint of achieving a reliable design and also protecting the secondary circuit from contamination from the gasses in the primary circuit. There is also a precedent with ASME Section VIII tube and shell heat exchangers where the tubes are designed as a pressure boundary in accordance with the Code.

The intent of this task is to determine how and where within ASME codes and standards the IHX, safety valve, etc. would be addressed. In order to answer this question, many technical questions need to be addressed to determine how the function of such components affects the plants, safety, etc. While the strict timeline for construction of a reactor with an IHX calls for immediate activity in this area, the level and type of effort, including necessary discussions of many details related to manufacturing, design, and operation of an IHX requires commitment on behalf of the Department of Energy, reactor firms, and IHX manufacturers, and ASME. As such, activities in this area will likely be on hold until that time.

\section{Flaw Assessment and Leak Before Break (LBB) Approaches in ASME}

In the current version of ASME-NH, little information is given on how to address flaw assessment in the elevated temperature domain. Actions have been carried out in Europe to cover this topic and these actions led to the writing of rules in UK (R5, R6) and to French rules in the RCC-MR, Appendix A16 [3.15 - 3.17].

In addition, LBB approaches can provide useful arguments in the frame of defense-in-depth analyses which are aimed at demonstrating the robustness of a given design. LBB methodologies have been developed for PWRs and Fast Reactors (FRs) but their application to HTRs and VHTRs would require further investigations.

The objective of this activity should be to perform a status report of rules presently available and to propose recommendations for further work within ASME. The work should consist of a synthesis of approaches available for LBB assessment and more generally for fracture mechanics methods (crack growth and stability calculations). The work should clarify to what extent existing methods would be applications for VHTR and Gen IV.

The output of the task would be recommendations for the definition of rules to be introduced in the ASME Code. A program would be defined indicating necessary tests to be carried out to establish a set of material properties for flaw assessment methods and/or specific tests to validate LBB approaches for HTRs and VHTRs. The results will be useful in discussions with U.S. NRC before launching significant activities on this subject.

The proposed Coordinating Committee is expected to form with increasing interest, activity, and support from DOE and stakeholders. The committee historically was not an ASME committee, 
but included extensive participation at ASME Subsection NH meetings. The historical model is proposed in addition to the Steering Committee. The ASME Steering Committee oversees all tasks within the ASME-DOE agreement, including those not relevant to $\mathrm{NH}$. In addition to a representative from DOE, this committee would have materials and structures participants from national labs, Code group representatives, and participants from stakeholders (design organizations). The role of the committee would be a more focused coordination to:

- identify needs based on a consideration of components, temperatures, loading conditions, and materials of key interest,

- establish priorities,

- assure proper coordination between high-temperature structural design technology development, Code activities, and the supporting materials tasks, and

- review progress and convey results to the design organizations in a timely manner.

A guiding principle of the High Temperature Design Methodology task will be to meet the needs of designers as required in the pre-conceptual, conceptual, preliminary, and final stages of design. This means that in addition to the development of an experimentally verified technology as an end product, interim needs for structural design guidance, methods, and criteria will be met on a continuing basis.

\section{Simplified Methods Development - Load Based Design Criteria}

An evaluation was conducted of the application of the load based design criteria found in $\mathrm{NH}$ to a VHTR [3.14]. Comparisons with life predictions using isochronous curves, a creep model including "damage" effects (an Omega model), and the limit load reference stress were made on various notched samples, plates, beams, and pressure vessel components of Alloy 617 at $900^{\circ} \mathrm{C}$. Figure 23 illustrates several of the simple notched structures investigated. Figure 24 illustrates the dimensions and cross-section of a sphere/nozzle and cylinder/nozzle intersection that was analyzed; these types of models were used during the LMFBR program for validation of design procedures. An illustration of simple beams, plates, and flathead structures with uniformly distributed loads that were investigated is provided in Figure 25 . The load based criteria in $\mathrm{NH}$ were found to be conservative; however, they were found to be excessively conservative in cases where redistribution of stress occurs during creep. This is illustrated in Figure 26 where the $\mathrm{NH}$ predictions deviate from the predictions of several other types of analysis. The $\mathrm{NH}$ procedures only deal with relaxation within a section; no allowance is included for the possibility that section bending and membrane forces also undergo long range relaxation. This is clearly evident in beam, plate, and flat head problems analyzed in Figure 26. Furthermore, stress linearization was problematic and resulted in an overly conservative life prediction in the case of a thick tee under internal pressure. Existing $\mathrm{NH}$ load based design criteria are deemed acceptable. Other load based design methods that use isochronous curves or the reference stress approach are proposed as alternatives; these methods also eliminate the need for stress classification and may have great value for core internals and various attachments. Additional research in this area should be pursued, including experimental validation of the analysis predictions. 
axisymmetric "yoyo" notch plane strain notch in bending plane strain ligament in tension
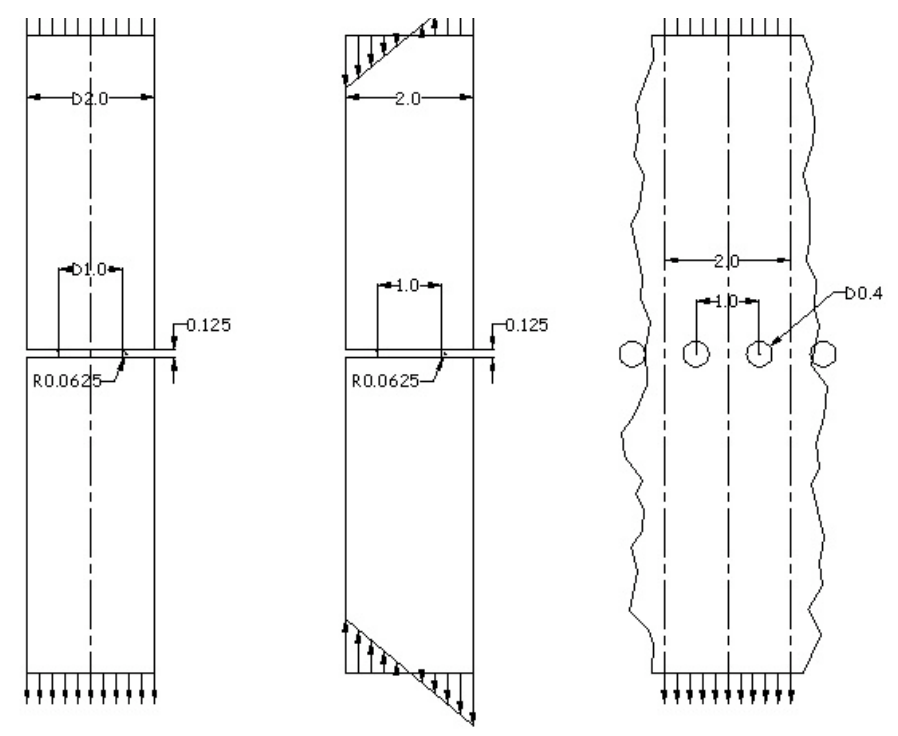

Fig. 23. Dimensions (inches) of several simply notched structures

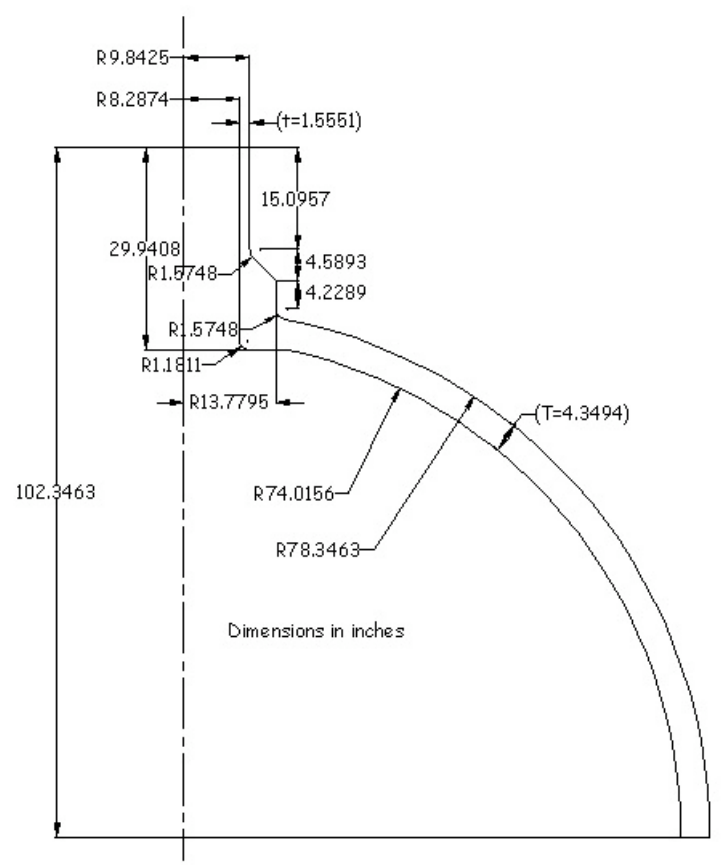

Fig. 24. Dimensions (inches) and cross-section of sphere/nozzle and cylinder/nozzle intersection 


\section{WWWWWWWWW}

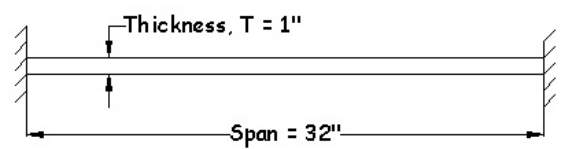

FIXED END, PLANE STRESS BE AM

FIXED EDGE CIRCULAR PLATE

FIXED EDGE SQUARE PLATE

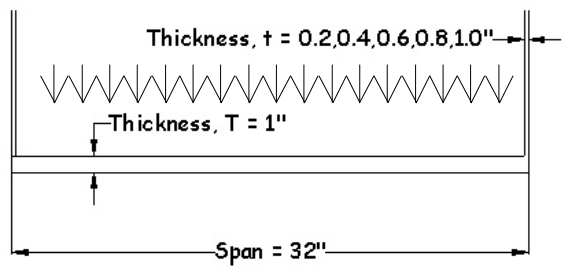

FLATHE AD CLOSURE

Fig. 25. Beams, plates, and flathead structures with uniformly distributed loads were investigated (dimensions in inches).

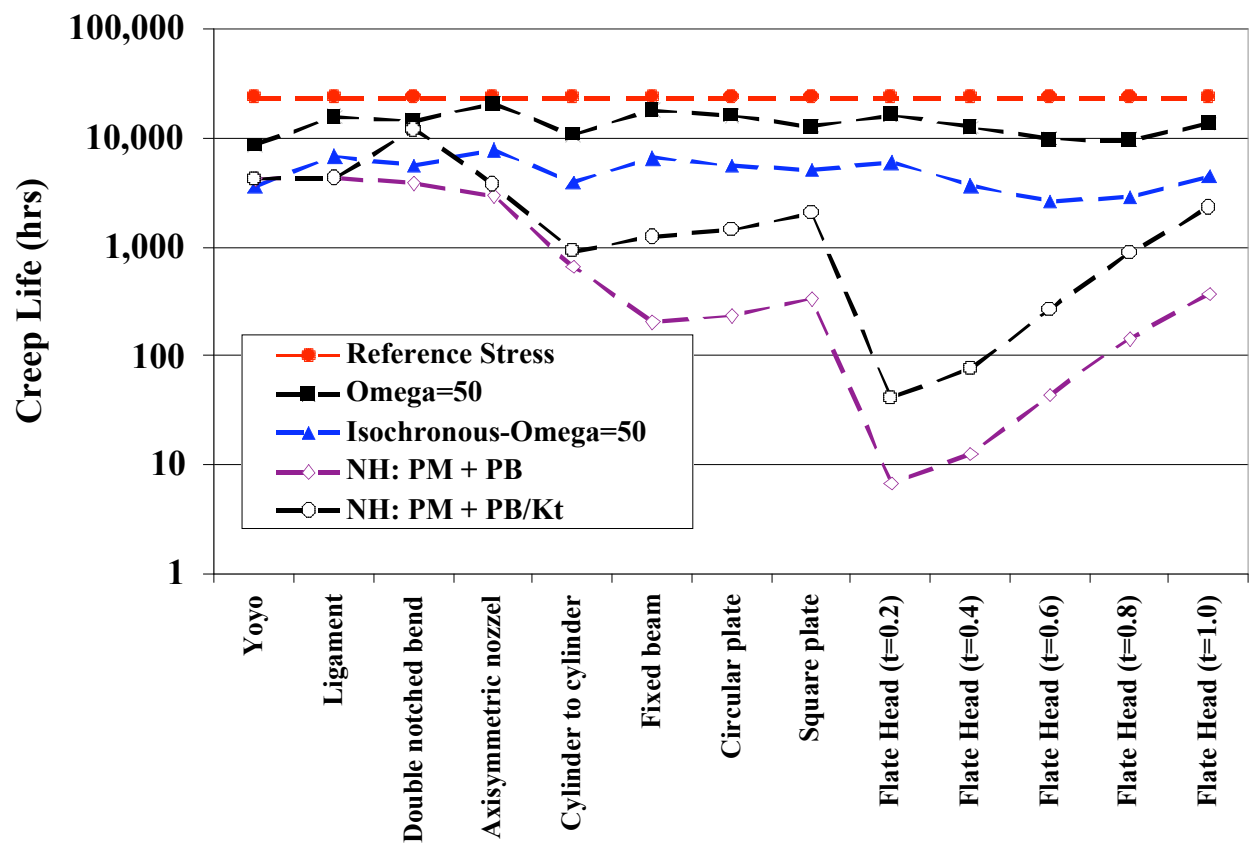

Fig. 26. Comparison of predicted creep lives at constant reference stress for notched specimens, pressure vessel components, beams, and plates

\section{Simplified Design Methods - Deformation Based Design Criteria:}

$\mathrm{NH}$ deformation based design criteria were also evaluated and compared to cyclic reference 
stress approaches [3.14]. The existing simplified inelastic design method, the B-1 test, failed to predict ratchetting for a simple thin tube of Alloy 617 under static pressure and cyclic thermal loading from $400^{\circ} \mathrm{C}$ to $\sim 900^{\circ} \mathrm{C}$. Additional analysis of a thick tube and thick tee joint were conducted. In all cases, the normalization procedure required in implementing the Btests in Appendix $\mathrm{T}$ of $\mathrm{NH}$ is questionable due to significant variations in the yield strength with temperature. A modified B-test(s) may be required. Normalizing by either a) the average of $S_{y L}$ and $S_{y H}$, b) $\left.S_{y H}, c\right)$ an appropriate yield stress from isochronous curves, or d) some other appropriate yield stress, remains uncertain - additional research is required. The effect of loading rate on yield stress was not examined; additional research is required here as well. Alternative procedures that eliminate the need for stress classification should also be considered, similar to the findings of the load based design criteria in this report. Alternatives include methods that depend upon the geometry of the component, and are typically implemented with finite element methods. The alternatives include: a) using cyclic reference stresses with a constant yield stress, b) using cyclic reference stresses where the fictitious yield stress varies with temperature, c) performing rapid cycle analysis with temperature dependent properties, and d) the use of isochronous curves (monotonic or cyclic). Such approaches were unrealistic at the time of the development of $\mathrm{NH}$; however, today's tremendous computational power enables these methods to be entertained as a routine analysis tool. A significant amount of additional research in this area remains.

\section{Milestones}

FY 2006

- Provide interim report on progress, participation, and support of DOE and Gen IV activities in ASME Section III, Subsection NH and the DOE-ASME collaboration agreement.

- Complete interim assessment and development of the simplified inelastic design method known as the Bree model, for very high temperature metallic applications.

FY 2007

- Provide interim report on progress, participation, and support of DOE and Gen IV activities in ASME Section III, Subsection NH and the DOE-ASME collaboration agreement.

- Complete interim development of the reference stress for use in load based design analysis.

FY 2008

- Provide interim report on progress, participation, and support of DOE and Gen IV activities in ASME Section III, Subsection NH and the DOE-ASME collaboration agreement.

- Complete interim development of the use of the cyclic reference stress for use in deformation based design analysis. 
FY 2009

- Provide interim report on progress, participation, and support of DOE and Gen IV activities in ASME Section III, Subsection NH, and final results of the DOE-ASME collaboration agreement.

- Complete initial proposal for modified and new simplified inelastic design methods including the Bree model and reference stress approaches in ASME Subsection $\mathrm{NH}$ for high temperature metallic design.

FY 2010 through FY2015

- Provide interim reports on progress, participation, and support of DOE and Gen IV activities in ASME Section III, Subsection NH.

- Develop, design, build, conduct, and compare structural features and component testing results to predicted behavior for validation of very high temperature structural design methodology.

\subsubsection{NGNP High-Temperature Non-Metallic Components}

\subsubsection{Materials Selection and Issues for Reactor Core Graphite, Reflector, and Supports}

Graphite is the major structural component and nuclear moderator in the NGNP core. The graphites used previously in the high temperature gas reactor programs in the USA are no longer in production and thus replacement graphites must be found. Hence, it will be necessary to qualify new grades of graphite for use in the NGNP. Fortunately, likely potential candidates currently exist, including fine grained isotropic, molded or isostatically pressed, high-strength graphite suitable for core support structures, fuel elements and replaceable reactor components, as well as near isotropic, extruded, nuclear graphite suitable for the abovementioned structures and for the large permanent reflector components. These candidates would meet the requirements of the draft American Society for Testing and Materials (ASTM) materials specification for the Nuclear Grade Graphite. Graphite is a complex material whose structure and properties reflect the raw materials used in its manufacture, the processing techniques, and the thermal history of the material. The understanding of neutron irradiation damage in graphite is well developed. However, fundamental models relating structure at the micro and macrostructural level to the irradiation behavior are less well developed.

Graphite is composed of a composite structure manufactured from a filler coke and pitch binder. Nuclear graphites are usually manufactured from isotropic cokes (petroleum or coal-tar derived) and are formed in a manner to make them near-isotropic or isotropic materials. After baking, (carbonization) the artifact is typically impregnated with a petroleum pitch and re-baked to densify the part. Impregnation and re-bake may occur several times to attain the required density. Graphitization typically occurs at temperatures $>2500^{\circ} \mathrm{C}$. Additional halogen purification may be required. Typical manufacturing times are 6-9 months.

The forming and densification processes impart property variations within the billet. The properties will be somewhat different in the forming direction compared to the perpendicular to forming direction. Moreover, a density gradient will exist from billet edge to center. These variations must be quantified for the selected grades of graphite. In addition, variations in properties will arise from billet to billet within a batch, and between production lots. Finished 
graphite is machined to the complex geometries required for the reactor components (fuel elements, reflector blocks, core support post, etc.).

\section{Experimental R\&D plans for core graphite, reflector, and support materials}

Early in the program, it will be necessary to review and document the existing data, from all available sources, on the properties of these new grades of graphite. Irradiation data from ongoing experiments in the Petten Reactor (European program) will be of great value. $A$ complete properties database on the new (available) candidate grades of graphite must be developed to support the design of graphite core components. Data is required for the physical, mechanical (including radiation induced creep) and oxidation properties of graphites. Moreover, the data must be statistically sound and consider in-billet, between billets, and lot-to-lot variations of properties. The data will be needed to update and benchmark existing design models for graphite performance. Since the available near-isotropic, extruded graphites are somewhat similar to the prior grade $\mathrm{H}-451$, design models for $\mathrm{H}-451$ can be incrementally adjusted for the currently available graphites as new data becomes available. This review will provide data that will be input into the preliminary selection process.

As part of the preliminary selection process, a radiation effects database must be developed for the currently available graphite materials. As mentioned above, there is the potential to leverage data from European Union activities in the area of irradiation experiments on PBMR graphites (Petten Reactor irradiation experiments are currently being initiated). However, it is anticipated that a substantial number of additional graphite irradiation tests will be needed to complete the database. Since NGNP graphite service temperatures are anticipated to be as much as $200^{\circ} \mathrm{C}$ greater than that in the GT-MHR, additional data are required for all properties at these higher temperatures, including radiation damage effects. Therefore, in order to be qualified for the NGNP, existing graphite behavior models need to be modified based on sound materials physics and then validated/verified against new data for the currently available graphite grades. Property data must support the service conditions, including effects of higher temperature, helium gas (plus air and water), and neutron irradiation effects. Irradiation creep data for the candidate graphites must also be obtained.

Candidate graphite materials are known (see below). However, certain tests must be conducted to verify the candidate's relevant material properties meet the claims of the manufacturer. The preliminary selection process will need limited irradiation response data for the different grades of graphite. These test results will be used to establish the general behavior of a particular grade of graphite and confirm that it behaves similarly to previously "qualified" (for other nuclear reactors), near-isotropic, nuclear grades of graphite.

Nuclear graphite codes and standards development is required in support of the NGNP. American Society for Testing and Materials standard test methods are required for determining key physical and mechanical properties, for example the critical strain energy release rate $\left(\mathrm{K}_{\mathrm{Ic}}\right)$, the crystalinity on the graphite (by X-ray diffraction), coefficient of thermal expansion, and the air oxidation rate. American Society of Mechanical Engineers design codes must be developed for the graphite core supports structures and Carbon-Carbon $\left(C_{f} / C\right)$ composite structures to be used in the NGNP. Activities on the graphite design code are already in hand by a Project Team under the auspices of ASME Section III. $\mathrm{C}_{f} / \mathrm{C}$ composites are required for NGNP components such as control rod structural elements, upper vessel insulation support structure, and insulation shroud covers.

The fine-grained isotropic, molded or isostatically pressed, high-strength graphite suitable for core support structure includes Carbone USA grade 2020 and Toyo Tanso grade IG-110. Toyo Tanso grade IG-110 was used in the Japanese HTTR for fuel blocks and in the Chinese HTR- 
10 pebble bed reactor. These fine-grained materials are also suitable for the fuel elements and replaceable reactor components.

New near isotropic, extruded, nuclear graphites have been developed in the United States and Europe for the South African PBMR. The new, currently available graphites are GrafTek (UCAR) grade PCEA-a petroleum coke graphite, and SGL Grade NBG-10-a pitch coke graphite based on United Kingdom Advanced Gas-Cooled Reactor (AGR) fuel sleeve graphite. This graphite may be a candidate for the fuel elements and replaceable reactor components. Moreover, SGL has developed two vibrationally molded grades, NBG-17 and NBG-18. Both grades use the same formulation and NBG-10, except that NBG-17 has a smaller grain size. NBG-18 has been selected by PBMR for their permanent core structure. Grades NBG-17 and grade PCEA are being considered by Framatome for prismatic fuel elements.

Graphites suitable for the large permanent reflector components are currently in production (e.g., SGL grade HLM or GrafTek [UCAR] grade PGX). Some data are available for these graphite grades. Grade PGX was used for the permanent reflector of the Japanese HTTR, also PGX and HLM were used in Fort St. Vrain for the core support and permanent reflectors respectively. Fine-grain, high strength, graphite's are available from POCO Graphite, Inc. However, the available billet sizes are small and very expensive, thus not suited for NGNP core applications.

Near-isotropic, extruded, nuclear graphite's (e.g., grade H-451 manufactured by SGL Carbon) were developed in the 1970's for large helium cooled reactors such as the Fort St. Vrain reactor. However, grade $\mathrm{H}-451$ graphite has not been manufactured in the United States for more than 25 years.

There is a substantial database for Grade $\mathrm{H}-451$, including data for the effects of neutron irradiation on the properties, statistical variation of properties, oxidation behavior, etc. This body of data was considered sufficient to license the Fort St. Vrain reactor. Moreover, graphite behavior models were developed for Grade H-451 graphite. Fine grained isotropic, molded or isostatically pressed, high strength graphites suitable for core support structure (e.g., Carbone USA grade 2020 or Toyo Tanso grade IG-110) are available today. These fine-grained materials are suitable for the fuel elements and replaceable reactor components, but they are more expensive than medium-grain, near-isotropic, extruded or vibro-molded graphite.

\section{Reactor Graphite R\&D Tasks}

The initial research and development activities in the graphite area focus on those tasks of an urgent nature, i.e., their completion directly impacts the initial design phase of the NGNP, or are long-lead time items. The work described here will take place at several DOE laboratories and commercial companies. All work will be documented in the form of reports, which will be submitted to NGNP Materials Program Manager for approval.

\section{Graphite Selection Strategy}

Several candidate graphites have been identified for components within the NGNP (Table 14). In selecting candidate graphites for the major components of the NGNP several factors must be considered. The inclusion of all of the graphites in the materials program is clearly cost prohibitive. Consequently, the scope of the NGNP graphite program should take in account of other activities within the Generation-IV International Forum (GIF) for graphite database development (especially irradiation experiments) and the graphite needs of the prospective reactor suppliers. Moreover, the criteria for selection of graphites should consider if the particular graphite can satisfy multiple reactor vendor design requirements and are there sustainable precursors for extended production runs over the reactor's lifetime. By limiting the 
amount of material that needs to be irradiated for testing, there will be a reduction in cost and in schedule for this effort.

A strategy paper describing the selection process, the acquisition process and material receipt and storage requirements for the purchased graphite will be developed and submitted to the NGNP Materials Program Manager for approval. The report will solicit input from the INL, ORNL, GIF members, and potential reactor vendors.

\section{Procure a representative quantity of NGNP core graphite}

The production time for graphite is typically 9 months, and for a specialty materials such as nuclear graphite, could be as long as 12 months. It is anticipated that a representative "production lot" would represent several extrusion runs, sufficient to fill a baking furnace run ( 20 tons). It is anticipated that only half the baking furnace load would be taken through graphitization. Consequently, procurement discussions must be held and bids must be sought during FY-05 if graphite is to be available in a timely manner for subsequent R\&D activities. In FY05, the acquisition process for the selected graphite(s) was implemented. It is further anticipated that the purchase costs for the selected graphite(s) would not be incurred until FY06. Characterization of graphite billets will provide data needed for design, and will underpin the ASME design code.

Table 14. Candidate graphites for the core components of the NGNP.

\begin{tabular}{lll}
\hline $\begin{array}{l}\text { NGNP } \\
\text { Concept }\end{array}$ & Component Description & Candidate Grades \\
\hline Prismatic Block & Fuel Element \& Replaceable Reflector & Graftek PCEA \\
& & SGL Carbon NBG-17 \\
& & Toyo Tanso IG-110 or -430 \\
Prismatic Block & Large Permanent Reflector & Graftek PGX \\
& & SGL Carbon HLM \\
Prismatic Block & Core Support Pedestals \& Blocks & Graftek PCEA \\
& & SGL Carbon NBG-10 or-17 \\
& & Carbone USA 2020 \\
& & Toyo Tanso IG-110 or -430 \\
Prismatic Block & Floor Blocks \& Insulation Blocks & Graftek PCEA \\
& & SGL Carbon NBG-18 \\
Pebble Bed & \multirow{2}{*}{ Reflector Structure } & Graftek PCEA \\
& & SGL Carbon NBG-18 \\
Pebble Bed & Insulation Blocks & Toyo Tanso IG-110 \\
& & Graftek PCEA \\
\hline
\end{tabular}

\section{HFIR Rabbit Capsule Graphite Post Irradiation Examination}

A series of 36 NGB-10 nuclear graphite bend-bar samples have been irradiated in rabbit capsules in the High Flux Isotope Reactor (HFIR) at ORNL. Each of the 18 rabbit capsules additionally contained a SiC temperature monitor. Irradiation of the capsules was completed in FY-04. Post Irradiation examination (PIE) of the samples will include determination of the following irradiation effects data:

Volume Change

Dimensional Change (parallel \& perpendicular to extrusion) 
Dynamic Modulus (parallel to extrusion)

Flexural Strength (parallel to extrusion)

Thermal Diffusivity \& Conductivity (parallel \& perpendicular to extrusion)

Structural Change (via SEM examination)

High Temperature Annealing Study $\left(\sim 1500^{\circ} \mathrm{C}\right)$

Graphite PIE will be conducted at ORNL and a PIE report was issued as an ORNL Technical Memorandum to the NGNP program manager for approval in FY-05. Additional PIE will be conducted in FY 2006, including interrogation of the SiC temperature monitors, thermal diffusivity and high temperature stored energy release.

Graphite Irradiation Creep Capsule Design \& Experiments

A creep capsule will be designed for the Advanced Test Reactor (ATR) by engineers at INL with ORNL consultation. The graphite samples will be loaded under compressive stress and irradiated at representative temperatures. The experimental parameters will be determined in consultation with NGNP stakeholders. In addition to creep rate data, post irradiation examination of the control samples will yield valuable irradiation effects data for the NGNP (thermal conductivity, cte, strength, etc.). The capsule design was completed in FY-05 and all necessary QA documentation prepared. Capsule construction and bench testing will commence in FY-06. Specimen preparation and pre-irradiation characterization will be conducted at ORNL during FY-06.

\section{High Dose Graphite Irradiation Creep Capsule Design \& Experiment}

High dose graphite creep experiments are needed to support Pebble Bed type VHTRs. Anticipated irradiation temperature are 600,900 , and $1200^{\circ} \mathrm{C}$ to peak doses of 30,20 and 15 dpa, respectively. The irradiations will be conducted in the HFIR at ORNL. The HFIR creep capsules will be smaller than those planned for the ATR and consequently fewer graphite grades will be included. The target grades are PCEA and NGBG-18. It is anticipated that this work would be part of an INERI with the Republic of South Africa.

\section{Fracture Toughness of Nuclear Graphite}

ASTM Committee DO2-F has identified a test method for determining $K_{\mathrm{lc}}$ based upon the existing standard C1421 (for advanced ceramics at ambient temperatures). This standard should be modified for application to graphite and ruggedness tests performed using several different graphites. Once a modified version of the standard test method has been established round-robin testing will commence. Participation by INL is anticipated, along with other NGNP stakeholders. ORNL will analyze the $\mathrm{K}_{\mathrm{Ic}}$ data and develop the ASTM required research report with precision and bias data. A standard test method for determining the $\mathrm{K}_{\mathrm{lc}}$ value of graphite will be prepared and approved through the ASTM DO2-F committee. The establishment of a standard method is a prerequisite for generation of graphite fracture toughness data needed to support the ASME design code development discussed in Codes and Standards Development.

\section{Codes and Standards Development}

ASME design code development is required for the graphite core structures of the NGNP, and also for the $\mathrm{C}_{\mathrm{f}} / \mathrm{C}$ composites structures of the core. These activities are currently being undertaken by a project team (chaired by Tim Burchell) under Section III of ASME. Typically the committee will meet four times a year in conjunction with ASME "Code Week". Participation of both ORNL and INL staff is anticipated in this activity. Standard test methods are also required for the generation of data that may be used in the design code. Such methods are developed 
through the ASTM and are then adopted by the ASME. The ASTM DO2-F committee of Manufactured Carbons and Graphites is currently engaged in the final stages of developing Standard Materials Specifications for Nuclear Grade Graphite (one has successfully been balloted and another is still in development), and is also developing several standard test methods for graphites (crystalinity by XRD, surface area, thermal expansion, fracture toughness, and graphite oxidation for example). Participation of ORNL staff in DO2-F committee work is vital to the completion and adoption of such standard test methods.

The development of the draft ASTM DO2-F standard test method for air oxidation of graphite would be aggressively pursued at ORNL and INL. A round robin evaluation of the oxidation method will be conducted. Similarly, ORNL will lead an assessment effort to determine the applicability of the existing ASTM method for surface area to graphite. The method will then be adopted into ASTM C-781 (Standard Practice for Testing Graphite and Boronated Graphite Components for High-Temperature Gas-Cooled Nuclear Reactors).

\section{Irradiation Behavior Model Development}

Mathematical models must be developed that describe and predict the behavior of nuclear graphite under neutron irradiation. Such models should be based upon physically sound principles and reflect known structural and microstructural changes occurring in graphites during fast neutron irradiation, such as changes in crystalinity, pore shape, coefficient of thermal expansion (bulk and single crystal), etc. Models for the graphite irradiation dimensional changes and irradiation creep behavior are a priority. Existing irradiation data may be used for model development, but validation of the models must be conducted using irradiation data obtained on the newer nuclear graphites being considered for the NGNP. Input data for such models must be obtained from the NGNP candidate graphites. Several modeling approaches will be explored. For example, models based on microstructural changes as described by bulk and crystal CTE changes, or fundamental atom-displacement models (ab-initio calculations) linked to finite element codes, will be examined.

\section{High Temperature Graphite Irradiation Experiments}

There are few data for the irradiation behavior of graphite at temperatures $>1000^{\circ} \mathrm{C}$. Hence, a high temperature graphite irradiation capsule will be designed which will be capable of irradiating graphite samples at temperatures up to $1500^{\circ} \mathrm{C}$. An evaluation will be made to determine the most appropriate HFIR vehicle for these irradiations based upon capsule size limitations, ease of attaining the desired temperatures, and availability of space in the HFIR (e.g. rabbit capsule, target capsule or reflector capsule). Design of the first capsule will be completed in FY-06, along with the final version of the experimental plan and required QA documentation. Irradiation data to be determined on the candidate graphite(s) will include dimensional changes, elastic constants, strength and coefficients of thermal expansion. Pre- and post-irradiation examination will be conducted at ORNL.

Post irradiation examination of graphites from the Materials Elevated Temperature Swelling (METS) capsules will be conducted. The graphites include grades H-451, PCEA and NBG-10. PIE data to be obtained include dimensional change behavior and thermal conductivity. These data will provide input to the high temperature capsule designs.

\section{IAEA Graphite Irradiation Data Review}

Historical and ongoing graphite irradiation data available through the International Atomic Energy Agency (IAEA) must be reviewed. This will be a joint effort between INL and ORNL requiring discussion with principle investigators and researchers from the GIF partners. A NGNP white paper report will be issued outlining directions for requirements for future irradiation capsules, follow on PIE work, and requirements for future data collection. 
Seventh International Nuclear Graphite Specialists Meeting (INGSM-7)

ORNL will organize and host the seventh International Graphite Specialists Meeting at the Research Support Center at ORNL (Sept 10-13, 2006).

A brief summary of R\&D plans and schedules for the NGNP graphite core materials needed to meet the deployment time schedule is provided below. The schedule for these tasks is contingent upon funding availability.

\section{Milestones}

FY 2006

- Complete fabrication and inspection of specimens for AGC-1 experiment

- Complete the PIE of irradiated graphite from HFIR rabbit capsules

- Complete interim nuclear graphite model development including incorporation of new data and FEMLAB and CARES code work at INL

- Complete test plan development for high temperature irradiation capsule in HFIR, perform capsule design and initiate fabrication of the capsule

- Complete the PIE of the high temperature scoping graphite irradiations in HFIR METS capsules

- Provide update of status of ASME graphite core structures project team

- Provide update on status of development of ASTM D02-F standard test method for air oxidation of graphite

FY 2007

- Perform a review of both historical and ongoing graphite irradiation data available through the IAEA and GIF partners.

- Initiate characterization to establish statistical variation of mechanical and thermalphysical properties within and among lots

- Initiate microstructural characterization to establish filler particle, pore size distribution, purity, Boron equivalent, and crystalinity factors

- Initiate long-term oxidation in off-normal helium environment

- Continue irradiation effects experiments, including dimensional changes and property changes

- Design and fabricate additional capsules for irradiation-creep irradiations

- Continue codes and standards development

- Complete graphite physical and mechanical properties evaluations for NGNP

- Complete preliminary graphite oxidation effects studies of NGNP graphites

- Complete preliminary irradiation effects studies of NGNP graphites

FY 2008

- Perform PIE of qualification irradiations to determine effects of irradiation temperature and fluence on property data 
- Assess oxidation as a function of helium impurity content to provide input for design specifications

- Establish oxidation kinetic data for the graphites for air-ingress accident simulation and modeling.

- Develop improved methods for NDE of graphite billets and in-service inspections

- Continue codes and standards development

- Continue final characterization of baseline physical and mechanical properties of NGNP graphites

- Continue irradiation creep studies of NGNP graphites

FY 2009

- Complete required ASME Code revisions

- Continue standards development

- Complete final graphite oxidation effects studies of NGNP graphites

- Continue graphite irradiation effects of properties studies of NGNP graphites

- Complete final characterization of baseline physical and mechanical properties of NGNP graphites

- Continue irradiation creep studies of NGNP graphites

FY 2010

- Continue graphite irradiation effects of properties studies of NGNP graphites

- Continue graphite standards development

- Continue irradiation creep studies of NGNP graphites

FY 2011

- Continue irradiation creep studies of NGNP graphites

- Continue graphite irradiation effects of properties studies of NGNP graphites

- Continue graphite standards development

FY 2012

- Continue graphite irradiation effects of properties studies of NGNP graphites

- Continue irradiation creep studies of NGNP graphites

- Complete graphite standards development

FY 2013

- Continue irradiation creep studies of NGNP graphites

- Continue graphite irradiation effects of properties studies of NGNP graphites

FY 2014

- Complete graphite irradiation effects studies 
- Continue irradiation creep studies of NGNP graphites

FY 2015

- Complete irradiation creep studies of NGNP graphites

\subsubsection{Ceramic Materials Selection and Issues for Thermal Insulation}

High temperature fibrous insulation must be used throughout the reactor system and the power conversion unit notably in the hot duct, upper plenum shroud, SCS helium inlet plenum, and turbocompressor. These materials are typically considered for lifetime operation. The insulation is required to retain its resiliency and physical characteristics during normal operating and conduction cooldown accident conditions.

Operating conditions for fibrous insulation include low neutron fluence $(<0.01 \mathrm{dpa}$ ) and gamma flux, and high temperatures. The currently envisioned design will require fibrous insulation to operate at normal, and off-normal temperatures of up to $1000^{\circ} \mathrm{C}$ and $1200^{\circ} \mathrm{C}$, respectively. Mechanical loads on the thermal insulation result from differential thermal expansion, acoustic vibration, seismic vibration, fluid flow friction, and system pressure changes. Typical operating conditions are listed in Table 15.

Fibrous insulation was used in The Fort Saint Vrain HTGR and in other gas reactors in Germany and Japan. Test programs to support the acquisition of design and performance data were conducted on Kaowool and Quartz-et-Silica fibrous mats. Limited irradiation effects test data is available. Tests to determine fatigue properties as a function of acoustic noise were planned but not conducted.

Insulation design surveys have indicated that a suitable insulation system, where significant structural support is not required, for NGNP applications is the use of $\mathrm{Al}_{2} \mathrm{O}_{3}$ and $\mathrm{SiO}_{2}$ mixed ceramic fiber mats $\left(\mathrm{K}_{\mathrm{th}}<0.1 \mathrm{~W} / \mathrm{m}-\mathrm{K}\right)$ contained between metallic or carbon-carbon composite cover plates attached to the primary structure that requires insulation. However, the operating normal and off-normal temperatures $\left(1000\right.$ and $\left.1200^{\circ} \mathrm{C}\right)$ are aggressive for application of the Kaowool. As example, the pumpable Kaowool temperature limit for continuous operation is $1093^{\circ} \mathrm{C}$. Maximum temperature rating is typically $1260^{\circ} \mathrm{C}$ for the highest performing $\mathrm{Al}_{2} \mathrm{O}_{3}$ and $\mathrm{SiO}_{2}$ mixed ceramic fiber mat insulation. Typically, by reducing the fraction of silica in the wool, or through simultaneous reduction of silica and addition of $\mathrm{ZrO}_{2}$, insulating mats can achieve continuous and maximum operating temperatures of 1300 and $1400^{\circ} \mathrm{C}$ respectively. High-purity alumina mat can achieve operating temperatures above $1500^{\circ} \mathrm{C}$. However, these higher temperature mats would not take advantage of previous data and experience gained with the Kaowool product, therefore a premium would be paid for their use.

The canisters are in direct contact with the hottest gas conditions in the reactor. Thus, the materials chosen for these canisters will need to withstand up to $1000^{\circ} \mathrm{C}$ for 60 years, or up to $1200^{\circ} \mathrm{C}$ for up to 50 hours and then $1100^{\circ} \mathrm{C}$ for 100 hours during a loss of flow condition (LOFC) followed by a conduction cooldown transient. For this reason non-metallic materials such as carbon-carbon composites may be required for some of these canisters. The metallic canister materials would be chosen from the list of materials identified in Table 11. The carbon-carbon composites will be chosen from those materials identified in Table 15.

The insulating materials previously discussed fairly modest mechanical performance requirements, therefore low specific density fibrous materials can be considered. However, for applications such as the top and bottom insulator blocks, the ceramic floor block, and possibly the canisters holding the fibrous insulation of the hot gas duct, the mechanical loading and need 
for creep resistance is such that monolithic or composite materials are needed. Typical operating parameters for these systems are also provided in Table 15. Given that the operating temperatures are modest and the neutron fluence is low, achieving a lifetime material appears a

Table 15. Conditions affecting materials selection for reactor internals thermal insulation and potential candidate NGNP materials.

\begin{tabular}{|c|c|c|c|c|c|c|}
\hline \multirow[t]{2}{*}{ Component } & \multirow[t]{2}{*}{ Sub-components } & \multicolumn{3}{|c|}{ Normal NGNP operating conditions } & \multirow{2}{*}{$\begin{array}{l}\text { Abnormal } \\
\text { operating } \\
\text { conditions }\end{array}$} & \multirow{2}{*}{$\begin{array}{c}\text { Potential } \\
\text { Candidate NGNP } \\
\text { Materials }\end{array}$} \\
\hline & & $\begin{array}{l}\text { Nominal } \\
\text { Temp } \\
\left({ }^{\circ} \mathrm{C}\right) \\
\end{array}$ & $\begin{array}{c}\text { Neutron } \\
\text { fluence with } \\
\mathrm{E} \geq 0.1 \mathrm{MeV}\end{array}$ & Medium & & \\
\hline $\begin{array}{l}\text { SCS unit } \\
\text { metalworks } \\
\text { Insulation }\end{array}$ & $\begin{array}{l}\text { Conical shell at } \\
\text { SCS HX }\end{array}$ & 1000 & $\begin{array}{c}3 \cdot 10^{16} \mathrm{~cm}^{-2} \\
\text { per } 60 \text { years }\end{array}$ & Helium & $\begin{array}{l}\sim 1200^{\circ} \mathrm{C} \\
\begin{array}{l}\text { At start of cool } \\
\text { down. }\end{array} \\
\text { Then } \sim 1000^{\circ} \mathrm{C}\end{array}$ & $\begin{array}{c}\text { carbon-carbon } \\
\text { composite canisters } \\
\text { with refractory } \\
\text { fibrous mat }\end{array}$ \\
\hline \multirow{4}{*}{ Hot gas duct } & $\begin{array}{l}\text { Outer shell of } \\
\text { thermal insulation } \\
\text { element unit }\end{array}$ & 1000 & & & $\begin{array}{l}1000^{\circ} \mathrm{C} \\
\text { At start of } \\
\text { cooldown }\end{array}$ & $\begin{array}{l}\text { carbon-carbon } \\
\text { composite canisters } \\
\text { with refractory } \\
\text { fibrous mat }\end{array}$ \\
\hline & $\begin{array}{l}\text { Inner shell of } \\
\text { thermal insulation } \\
\text { element unit }\end{array}$ & 650 & $\begin{array}{c}2 \cdot 10^{17} \mathrm{~cm}^{-2} \\
\text { per } 60 \text { years }\end{array}$ & Helium & $\begin{array}{l}1000^{\circ} \mathrm{C} \\
\text { At start of } \\
\text { cooldown }\end{array}$ & $\begin{array}{l}\text { carbon-carbon } \\
\text { composite canisters } \\
\text { with refractory } \\
\text { fibrous mat }\end{array}$ \\
\hline & Thermal Insulation & $600-1000$ & & & $\begin{array}{c}1000^{\circ} \mathrm{C} \\
\begin{array}{l}\text { At start of cool } \\
\text { down }\end{array}\end{array}$ & $\begin{array}{l}\text { (Mix of refractory } \\
\text { fibers held with high } \\
\text { temperature screen } \\
\text { and wire stays.) }\end{array}$ \\
\hline & $\begin{array}{l}\text { Metal support } \\
\text { bottom Plate } \\
\text { insulation }\end{array}$ & & & & $\sim 700^{\circ} \mathrm{C}$ & $\begin{array}{l}\text { Carbon-carbon } \\
\text { composite blocks }\end{array}$ \\
\hline \multirow[t]{5}{*}{$\begin{array}{l}\text { In-vessel } \\
\text { metalworks } \\
\text { Insulation }\end{array}$} & $\begin{array}{l}\text { SCS entrance } \\
\text { structural tubes } \\
\text { Insulation }\end{array}$ & 600 & $\begin{array}{c}2.0 \cdot 10^{17} \mathrm{~cm}^{-2} \\
\text { per year }\end{array}$ & Helium & $\begin{array}{l}\sim 1200^{\circ} \mathrm{C} \\
\begin{array}{l}\text { At start of cool } \\
\text { down. }\end{array} \\
\text { Then } \sim 1000^{\circ} \mathrm{C}\end{array}$ & $\begin{array}{l}\text { carbon-carbon } \\
\text { composite canisters } \\
\text { with refractory } \\
\text { ceramic fiber mats }\end{array}$ \\
\hline & $\begin{array}{l}\text { Upper Plenum } \\
\text { Shroud Insulation }\end{array}$ & & & & $\begin{array}{l}\sim 1200^{\circ} \mathrm{C} \\
\begin{array}{l}\text { At start of cool } \\
\text { down. }\end{array} \\
\text { Then } \sim 1000^{\circ} \mathrm{C}\end{array}$ & $\begin{array}{l}\text { carbon-carbon } \\
\text { composite canisters } \\
\text { with refractory } \\
\text { ceramic fiber mats }\end{array}$ \\
\hline & $\begin{array}{l}\text { Ceramic Floor } \\
\text { Block }\end{array}$ & 600 & $\begin{array}{c}4.5 \cdot 10^{16} \mathrm{~cm}^{-2} \\
\text { per year }\end{array}$ & Helium & $600^{\circ} \mathrm{C}$ & $\begin{array}{l}\text { Graphite, Alumina, } \\
\text { Mullite, Composite }\end{array}$ \\
\hline & $\begin{array}{l}\text { Top Insulator } \\
\text { Block }\end{array}$ & 700 & $\begin{array}{c}1.5 \cdot 10^{16} \mathrm{~cm}^{-2} \\
\text { per year }\end{array}$ & Helium & $1100^{\circ} \mathrm{C}$ & $\begin{array}{l}\text { Graphite, Alumina, } \\
\text { Mullite, Composite }\end{array}$ \\
\hline & $\begin{array}{l}\text { Bottom Insulator } \\
\text { Block }\end{array}$ & 1050 & $\begin{array}{c}1.5 \cdot 10^{16} \mathrm{~cm}^{-2} \\
\text { per year }\end{array}$ & Helium & $600^{\circ} \mathrm{C}$ & $\begin{array}{l}\text { Graphite, Alumina, } \\
\text { Mullite, Composite }\end{array}$ \\
\hline
\end{tabular}


desirable, attainable goal. Graphite is a potential candidate material for both top and bottom insulator blocks. The bottom insulator block will most likely be a refractory ceramic. However, consideration will be given to improved low-thermal conductivity graphites for all three functions along with commercially available refractory ceramics such as alumina, mullite and composite materials. Assuming a high-quality, high-purity commercial material, radiation effects will not be an issue. The properties that will drive the selection are the non-irradiated thermophysical properties in particular thermal conductivity, compressive strength and fracture toughness, and cost. When comparing full density brick forms of mullite and alumina, significant differences in properties are noted. In particular, high density alumina brick will possess significantly higher thermal conductivity as compared to mullite (and very similar to low-conductivity graphites) but exhibit extremely high compressive stress and somewhat higher fracture toughness as compared to mullite. Creep, which will be of particular importance, will also be lower for alumina as compared to the mullite.

\section{Expected research, testing, and qualification needs for ceramic insulation materials}

The first step in the research program on ceramic insulation materials for the NGNP will be a comprehensive and detailed review of the potential candidate materials identified in Table 15. Preparation of a materials test program in support of ceramic insulation materials requires knowledge and understanding of the materials requirements dictated by the operating conditions of those components.

Data on the manufacture and performance of fibrous insulation are needed to ensure that the selected materials are capable of lasting for the life of the plant. The data include: physical properties (heat resistance, heat conductivity and heat capacity), long term thermal and compositional stability, mechanical strength at temperature, resistance to pressure drop, vibrations and acoustic loads, radiation resistance, corrosion resistance to moisture- and airhelium mixtures, stability to dust release and gas release, thermal creep, and manufacturing tolerances and mounting characteristics. The acquisition of these data requires testing of insulation specimens or small assemblies of thermal insulation panels and application of appropriate ASTM standards. This standards development work will be supported within this program. Moreover, application of current non-destructive evaluation techniques, especially in support of the monolithic insulators, is included within this test plan. Specific test rigs and facility requirements include helium flow, vibration, and acoustic test equipment as well as an irradiation facility and hot cell. Prototype assemblies testing is not planned to include neutron irradiation. However, this decision will be made following the neutron and gamma irradiation testing.

\section{Experimental ceramic insulation materials R\&D plans}

A brief summary of R\&D plans and schedules for the NGNP ceramic insulation materials needed to meet the deployment time schedule is provided below. The schedule for these tasks is contingent upon funding availability.

\section{Milestones}

FY 2007

- Perform comprehensive review of the potential candidate insulation materials

- Assemble, analyze, and evaluate existing database 
- Initiate screening tests for mechanical and thermal properties of fibrous and monolithic insulations materials

FY 2008

- Initiate baseline testing of mechanical and thermal-physical properties

- Initiate neutron and gamma irradiations for effects on mechanical and thermal-physical properties

- Initiate long-term aging for dimensional stability of compacts and assemblies

- Initiate ASTM standards development

FY 2009

- Initiate acoustic vibration and pressurization-depressurization endurance testing

- Initiate qualification irradiations to provide to determine effects of irradiation temperature and fluence on property data for primary candidate materials

- Initiate environmental stability testing

- Initiate dust and gas release testing

- Initiate NDE development for monolithic materials

FY 2010 and 2011

- Complete pressurization-depressurization endurance testing

- Complete dust and gas release testing

- Complete baseline testing of mechanical and thermal-physical properties

- Complete neutron and gamma irradiations and PIE for effects on mechanical and thermal-physical properties

- Initiate technology and manufacturability transfer

- Initiate performance testing of insulation prototypes

FY 2012

- Complete acoustic vibration

- Complete environmental stability testing

- Complete long-term aging for dimensional stability of compacts and assemblies Perform PIE to determine irradiation creep effects

- Complete technology and manufacturability transfer

- Complete performance testing of insulation prototypes

- Complete NDE development for monolithic materials

\subsubsection{Reactor Structural Composites Materials Selection and Issues}

The use of $\mathrm{C}_{f} / \mathrm{C}$ composite is desired for many applications within the reactor because of its strength retention at high temperatures. For example, $\mathrm{C}_{\mathrm{f}} / \mathrm{C}$ will likely be needed for the control rod sheath for a prismatic NGNP because metallic materials cannot withstand high temperature 
of $1050^{\circ} \mathrm{C}$ or higher found in the core. The anticipated $\mathrm{C}_{f} / \mathrm{C}$ composite material components of the NGNP are listed in Table 16.

$\mathrm{C}_{f} / \mathrm{C}$-composite materials are typically developed for specific applications and are not available off the shelf. The composite architecture (i.e., fiber type, fraction, orientation, lay-up) and processing conditions are selected to tailor the $\mathrm{C}_{\mathrm{f}} / \mathrm{C}$-composite material for a specific application. Thus, prototype components must be produced from which material test specimens will be cut and subjected to the appropriate thermal and irradiation conditions in the materials test program.

A fortunate aspect of $C_{f} / C$ is that existing data has shown that the $C_{f} / C$ components that are not in the core of the reactor are not expected to experience neutron exposures high enough to cause any problems with strength, swelling, thermal conductivity, etc. Existing data has shown that $\mathrm{C}_{\mathrm{f}} / \mathrm{C}$ can easily withstand the neutron doses in all the components with the exception of the control rods. This data shows that $\mathrm{C}_{f} / \mathrm{C}$ composite control rods will likely be the need to changed at least twice, hence the need to also evaluated silicon-carbide/silicon-carbide $\left(\mathrm{SiC}_{f} / \mathrm{SiC}\right)$ composites for longer life applications.

There is recent evidence that control rods fabricated from $\mathrm{SiC}_{f} / \mathrm{SiC}$ composites have the potential to survive for the full reactor lifetime within the high radiation environment within the core. Unfortunately, these $\mathrm{SiC}_{f} / \mathrm{SiC}$ composites have not been as fully characterized as $\mathrm{C}_{\mathrm{f}} / \mathrm{C}$ composites, so there is more uncertainty in the applicability. It is therefore necessary to evaluate both $\mathrm{C}_{f} / \mathrm{C}$ and $\mathrm{SiC}_{f} / \mathrm{SiC}$ for the control rod material.

A preliminary list of selection factors for primary ceramic composites candidate materials is provided in Table 17. 
Table 16. Conditions affecting materials selection for structural composites and potential candidate NGNP materials.

\begin{tabular}{|c|c|c|c|c|c|c|}
\hline Component & $\begin{array}{c}\text { Sub- } \\
\text { components }\end{array}$ & $\begin{array}{l}\text { Nominal } \\
\text { Temp } \\
\text { (C) }\end{array}$ & $\begin{array}{c}\text { NGNP op } \\
\text { conditions } \\
\text { Neutron } \\
\text { fluence } \\
\text { with } \\
E \geq 0.1 \\
\text { MeV }\end{array}$ & rating & $\begin{array}{l}\text { Abnormal } \\
\text { operating } \\
\text { conditions }\end{array}$ & $\begin{array}{l}\text { Potential Alternative } \\
\text { Composite } \\
\text { Candidate Materials }\end{array}$ \\
\hline CPS drive & $\begin{array}{l}\text { Control rod } \\
\text { guide tube }\end{array}$ & $\begin{array}{c}600 \\
\text { at CRD } \\
\text { to } \\
\text { UPS } \\
\text { Interface. }\end{array}$ & $\begin{array}{l}3 \cdot 10^{16} \\
\mathrm{~cm}^{-2} \\
\text { per } \\
\text { year }\end{array}$ & Helium & $\begin{array}{l}\text { Working } \\
\text { fluid } \\
\text { temperature } \\
\text { in cooldown } \\
\text { mode } \\
\text { through } \\
\text { RCCS can } \\
\text { increase to } \\
1200^{\circ} \mathrm{C} \\
\text { within } 100 \mathrm{~h}\end{array}$ & $\begin{array}{c}\mathrm{C}_{\mathrm{f}} / \mathrm{C} \\
\mathrm{SiC}_{\mathrm{f}} / \mathrm{SiC}\end{array}$ \\
\hline $\begin{array}{l}\text { SCS unit } \\
\text { metalwork }\end{array}$ & $\begin{array}{l}\text { Conical } \\
\text { shell at } \\
\text { SCS HX }\end{array}$ & 1000 & $\begin{array}{l}3 \cdot 10^{16} \\
\mathrm{~cm}^{-2} \\
\text { per } 60 \\
\text { years }\end{array}$ & Helium & $\begin{array}{c}\sim 1200^{\circ} \mathrm{C} \text { at } \\
\text { start of cool } \\
\text { down. } \\
\text { Then } \\
\sim 1000^{\circ} \mathrm{C}\end{array}$ & $\mathrm{C}_{f} / \mathrm{C}$ \\
\hline \multirow{2}{*}{$\begin{array}{l}\text { Hot gas } \\
\text { duct }\end{array}$} & $\begin{array}{l}\text { Outer shell } \\
\text { of thermal } \\
\text { insulation } \\
\text { element unit }\end{array}$ & 1000 & $\begin{array}{c}2 \cdot 10^{17} \\
\mathrm{~cm}^{-2}\end{array}$ & \multirow{2}{*}{ Helium } & $\begin{array}{l}1000^{\circ} \mathrm{C} \text { at } \\
\text { start of } \\
\text { cooldown }\end{array}$ & $\mathrm{C}_{f} / \mathrm{C}$ \\
\hline & $\begin{array}{l}\text { Inner shell } \\
\text { of thermal } \\
\text { insulation } \\
\text { element unit }\end{array}$ & 650 & $\begin{array}{l}\text { per } 60 \\
\text { years }\end{array}$ & & $\begin{array}{l}1000^{\circ} \mathrm{C} \text { at } \\
\text { start of } \\
\text { cooldown }\end{array}$ & $\mathrm{C}_{f} / \mathrm{C}$ \\
\hline \multirow[t]{2}{*}{$\begin{array}{c}\text { Vessel } \\
\text { internals }\end{array}$} & $\begin{array}{c}\text { SCS } \\
\text { entrance } \\
\text { tubes \& } \\
\text { chamber } \\
\text { insulation } \\
\text { assembly }\end{array}$ & 600 & $\begin{array}{l}2.0 \cdot 10^{17} \\
\mathrm{~cm}^{-2} \text { per } \\
\text { year }\end{array}$ & Helium & $\begin{array}{c}\sim 1200^{\circ} \mathrm{C} \text { at } \\
\text { start of cool } \\
\text { down. } \\
\text { Then } \\
\sim 1000^{\circ} \mathrm{C}\end{array}$ & $\mathrm{C}_{f} / \mathrm{C}$ \\
\hline & $\begin{array}{l}\text { Upper core } \\
\text { restraint }\end{array}$ & & & & $\sim 1200^{\circ} \mathrm{C}$ & $\mathrm{C}_{f} / \mathrm{C}$ \\
\hline
\end{tabular}


Table 17. Relative strengths of ceramic composite materials for NGNP applications.

\begin{tabular}{|c|c|}
\hline Pros & Cons \\
\hline \multicolumn{2}{|l|}{$\mathrm{SiC}_{\mathrm{f}} / \mathrm{SiC}$ Composites } \\
\hline Good oxidation resistance & Higher cost than $C_{f} / C$ \\
\hline Higher cracking stress than $C_{f} / C$ & Less industrial experience than $C_{f} / C$ \\
\hline \multicolumn{2}{|c|}{ Greater radiation damage resistance than $\mathrm{C}_{f} / \mathrm{C}$} \\
\hline \multirow[t]{2}{*}{ Fewer change-outs, lasts longer } & Lack of manufacturing/infrastructure \\
\hline & $\begin{array}{l}\text { Qualification - different weaves require a } \\
\text { new qualification. ASME specification issue. }\end{array}$ \\
\hline \multicolumn{2}{|c|}{$\begin{array}{l}\mathbf{C}_{\mathrm{f}} / \mathbf{C} \text { Composites (Note: Replacement for super alloys. Could be used for guide tubes }[\sim 10 \text { feet } \\
\text { long, telescope feature] and the Upper Core Restraint structure.) }\end{array}$} \\
\hline Good material for accident situation. & $\begin{array}{l}\text { More Radiation damage/shrinkage than } \\
\mathrm{SiC}_{f} / \mathrm{SiC} \text {. }\end{array}$ \\
\hline Flaking is less likely than $\mathrm{SiC}_{f} / \mathrm{SiC}$. & $\begin{array}{l}\text { Qualification - different weaves require a } \\
\text { new qualification. ASME specification issue. }\end{array}$ \\
\hline Eliminates metal from the core. & Lack of design criteria. \\
\hline \multicolumn{2}{|c|}{$\begin{array}{l}\text { Good Residual properties (e.g., strength). } \\
\text { Strength and fracture resistance is greater than } \\
\text { graphite. }\end{array}$} \\
\hline \multicolumn{2}{|l|}{$\mathrm{C}_{\mathrm{f}} / \mathrm{SiC}$ Composites } \\
\hline Higher thermal conductivity than $\mathrm{SiC}_{f} / \mathrm{SiC}$ & Possible Radiation damage \\
\hline Higher strength & $\begin{array}{l}\text { Qualification - different weaves require a } \\
\text { new qualification. ASME specification issue. }\end{array}$ \\
\hline Higher moderating power & Poor static fatigue performance \\
\hline
\end{tabular}

\section{Expected research, testing, and qualification needs for NGNP structural composites}

Currently there are several manufacturers of $C_{f} / C$ composites that may be suitable for reactorcore components (pitch-based matrix with pitch-based fibers). However, these manufacturers have not qualified any of their recent high-performance materials for nuclear applications. Additionally, large-sized $\mathrm{SiC}_{f} / \mathrm{SiC}$ composites are not as available as $\mathrm{C}_{f} / \mathrm{C}$ composites and much of the knowledge about the behavior of $\mathrm{SiC}_{f} / \mathrm{SiC}$ composites has been generated with laboratory-sized samples using simple testing conditions. Moreover, because these composite materials have undergone rapid development within the last 10 years, only very limited data is available for the newest, radiation-resistant materials. Therefore, a more detailed effort will be needed for $\mathrm{SiC}_{\mathrm{f}} / \mathrm{SiC}$ components. Also, the infrastructure for manufacturing $\mathrm{SiC}_{\mathrm{f}} / \mathrm{SiC}$ composites is much more limited, and not as mature as that for $\mathrm{C}_{f} / \mathrm{C}$, and will likely need to be developed or enhanced.

For $\mathrm{C}_{\mathrm{f}} / \mathrm{C}$ materials, there are limited mechanical and thermal-physical property data at elevated temperatures that will need to be augmented. In addition, the manufacturers and their prime candidate materials must be examined for repeatability, quality, and eventual size of manufacture, as many of the parts will be very large. More importantly, the weave patterns that will be evaluated in this program have never been examined in this application. Thus, this material must be baselined to determine if the parts indeed meet the specification required for both thermal and mechanical properties. The scale-up of parts will be aided by stress-analysis 
codes, which are quite mature for $\mathrm{C}_{\mathrm{f}} / \mathrm{C}$; however, the codes will need to be adapted for the specific fiber architectures selected.

The first experimental areas for research in this program will be to examine the two most potentially life-limiting processes of irradiation effects and oxygen effects. The irradiation effects program will perform a side-by-side comparison of the two most radiation resistant forms of CFC and SiC currently available. Following a pre-irradiation evaluation of $\mathrm{SiC}_{f} / \mathrm{SiC}$ tubular structures, irradiation to NGNP-relevant doses on statistically meaningful populations of samples will be carried out. In parallel, an environmental effects study will be carried out on $\mathrm{SiC}_{f} / \mathrm{SiC}$ to ascertain the stability of the fiber matrix interface in NGNP atmosphere. Additionally, the primary failure mode under stress will be studied to determine whether $\mathrm{SiC}_{\mathrm{f}} / \mathrm{SiC}$ tubular structures can withstand long-term loading produced by NGNP control rod applications.

The graphite composite to be studied was manufactured by Fiber Materials Inc., (FMI-222) and is a balanced weave, pitch fiber, pitch matrix composite. It has been selected because of its high-quality and radiation-effects database. SiC composites for this study will be fabricated by Hypertherm in collaboration with ORNL and Pacific Northwest National Laboratory (PNNL). Both flat plate and tubular geometries will be studied. The architecture to be manufactured will be studied in the initial phases of the collaboration. The fibers to be infiltrated will be Nicalon Type-S, based on their previous, excellent radiation performance. The matrix will be fully crystalline beta-SiC deposited by chemical vapor infiltration.

The first phase of the composite R\&D effort above focuses on providing verification of the viability of the composite control rod concept. The following R\&D phase will primarily provide the engineering data which are more relevant to the reactor system design and the confidence regarding the practical reliability of the NGNP-grade $\mathrm{C}_{f} / \mathrm{C}$ and $\mathrm{SiC}_{\mathrm{f}} / \mathrm{SiC}$ in the reactor environment and the accident scenario. For these purposes, properties and mechanisms governing the lifetime and reliability will be thoroughly characterized, including aging, creep/fatigue, fracture toughness, and the irradiated lifetime envelope. Again, the effect of neutron irradiation at very high temperatures on various mechanical and thermophysical properties will be the key to understand and evaluate the composite lifetime/reliability issues. Full-scale prototype control segments will also be fabricated with the most promising constituents/architectures for both $\mathrm{C}_{f} / \mathrm{C}$ and $\mathrm{SiC}_{\mathrm{f}} / \mathrm{SiC}$, and will be subjected to the complete baseline characterization. Continued support to the ASTM testing guidelines and the ASME code development are also essential in all R\&D phases. Additional evaluation of lowcost/high-performance alternative $\mathrm{SiC}_{f} / \mathrm{SiC}$ may be considered, in this case the candidate materials such as Tyranno ${ }^{\mathrm{TM}}$-SA3 $\mathrm{SiC}$ fiber composite and the liquid phase-sintered 'NITE' composite demonstrate fundamental irradiation and corrosion resistances. The development of a comprehensive R\&D program based on the most updated knowledge will be performed at the end of the first phase R\&D effort.

\section{Irradiation Program}

\section{Long-Term Stability, Strength and Thermal Properties}

Irradiation will be carried out in the peripheral target tube position of the High Flux Isotope Reactor. The irradiation matrix is given in Table 18. This matrix compliments ongoing ORNL fusion irradiations $18 \mathrm{~J} \mathrm{(} 10 \mathrm{dpa}, 800^{\circ} \mathrm{C}+$, data available $\left.>2007\right)$ and the proposed Futurix-MI irradiation $\left(>50 \mathrm{dpa}, \sim 1000^{\circ} \mathrm{C}\right.$, data available $>2008$.) The primary target irradiation 
temperature $\left(950^{\circ} \mathrm{C}\right)$ was selected based on the draft NGNP materials plan. The bounding temperatures of 800 and $1100^{\circ} \mathrm{C}$ were chosen to allow comparison to the U.S. fusion $14 \mathrm{~J}$ and $18 \mathrm{~J}$ experiments along with the NGNP graphite scoping irradiation program nearing completion $\left(300,500\right.$, and $800^{\circ} \mathrm{C}$.) Moreover, the proposed irradiation matrix will provide valuable information on the performance of $\mathrm{SiC}_{\mathrm{f}} / \mathrm{SiC}$ in an appropriate temperature range for the GFR concept $\left(500-1200^{\circ} \mathrm{C}, 80\right.$ dpa.) Additional irradiation of $\mathrm{C}_{\mathrm{f}} / \mathrm{C}$ composite samples newly fabricated in NGNP program is considered but not included in Table 18. Assuming materials begin irradiation in the first year of program, the highest dose capsules will be available in the third year of the program. If desirable, a subset of three capsules identical to BS1-3 could be irradiated to higher dose (e.g. $80 \mathrm{dpa}$ ) in support of GFR for little extra cost. Data from these materials would be available $\sim 2009$.

Table 18. HFIR irradiation matrix.

\begin{tabular}{|c|c|c|c|}
\hline Capsule Group & Material & Temperature $\left({ }^{\circ} \mathrm{C}\right)$ & Dose(dpa) \\
\hline BS1 & \multirow{3}{*}{$\begin{array}{c}\mathrm{SiC}_{f} / \mathrm{SiC} \\
\text { Type S / ML }\end{array}$} & \multirow{3}{*}{800} & 10 \\
\hline BS2 & & & 20 \\
\hline BS3 & & & $>30$ \\
\hline $\mathrm{BC} 1$ & \multirow{3}{*}{$\begin{array}{c}\mathrm{C}_{\mathrm{f}} / \mathrm{C} \\
\mathrm{FMI}-222\end{array}$} & \multirow{3}{*}{800} & 10 \\
\hline $\mathrm{BC} 2$ & & & 20 \\
\hline $\mathrm{BC} 3$ & & & 30 \\
\hline TS1 & \multirow{3}{*}{$\begin{array}{c}\mathrm{SiC}_{\mathrm{f}} / \mathrm{SiC} \\
\text { reference } \\
\text { NGNP }\end{array}$} & \multirow{3}{*}{$800^{* \top 1 \mathrm{tbd}}$} & 10 \\
\hline TS2 & & & 20 \\
\hline TS3 & & & 30 \\
\hline TS4 & \multirow{3}{*}{$\begin{array}{l}\mathrm{SiC}_{f} / \mathrm{SiC} \\
\text { reference } \\
\text { NGNP }\end{array}$} & \multirow{3}{*}{$950^{*}$} & 10 \\
\hline TS5 & & & 20 \\
\hline TS6 & & & 30 \\
\hline TS7 & \multirow{3}{*}{$\begin{array}{c}\mathrm{SiC}_{f} / \mathrm{SiC} \\
\text { reference } \\
\text { NGNP }\end{array}$} & \multirow{3}{*}{$1100^{\star \top 2 ~ t b d}$} & 10 \\
\hline TS8 & & & 20 \\
\hline TS9 & & & 30 \\
\hline
\end{tabular}

*Primary target temperature

*T1,T2 The low and high bounding temperature, respectively, to be finalilzed. 


\section{Irradiation Creep}

It is expected that the NGNP control rods will be subjected to low stress, long-duration tensile loads within a high temperature irradiation environment. A significant concern for these materials is creep or environmental degradation under combined load and irradiation. It will be necessary to first characterize the creep behavior of composite materials in the absence of irradiation with $\mathrm{He}$ atmospheres containing oxygen impurity levels that bracket the expected operating conditions for the NGNP. Irradiation creep tests in prototypic reactor environments will be carried out in the ATR.

In the first phase of the program, time-dependent creep of either SiC composite tubes or alternative architectures will be proven in the laboratory setting. Once the techniques for such testing are validated experimentally and by comparison with the ongoing modeling at PNNL, an experimental program will be mounted to determine the out-of-pile creep response for tubular samples. Based upon experience gained from the out-of-pile tests, an experimental program to generate in-reactor creep information will be initiated. In-pile experimental creep design input will be derived from out-of-pile experience, preform architecture, ATR reactor core dimensions, temperature and time in reactor. Specific environment and irradiation parameters are to be decided based on reactor design input.

As part of this validation study, the sensitivity of $\mathrm{SiC}_{f} / \mathrm{SiC}$ to low-level impurities will be included. Long-term, environmental effects derived from impurities such as oxygen, hydrogen or moisture must be considered in terms of composite irradiation creep. Experimental and modeling data on SiC tubular structures, especially in oxygen-containing irradiation environments, will be required similar to current studies on $C_{f} / C$ composite structures. It is envisioned that this program will be conducted in parallel with the carbon fiber composite creep program and apply similar irradiation vehicle design.

\section{Environmental Effects}

The high-purity He environment presumed for the NGNP provides some interesting issues for materials degradation at high temperatures. Carburization of metals is observed in lowoxygen-potential environments but is reduced in high-oxygen-potential environments. Control of the oxygen potential is seen as an effective means of reducing carburization of metals and alloys in the NGNP, but the effects of increased oxygen potential on the corrosion rates of $\mathrm{SiC}_{\mathrm{f}} / \mathrm{SiC}$ and $\mathrm{C}_{\mathrm{f}} / \mathrm{C}$ will need to be established. A focus of this research will be to determine the corrosion mechanisms and rates associated with degradation of the fiber/matrix interphase in the $\mathrm{SiC}_{f} / \mathrm{SiC}$ and $\mathrm{C}_{f} / \mathrm{C}$ materials. This has been shown to the critical mechanism that shifts the degradation or failure modes from fiber creep domination to interphase degradation. Testing and modeling of newer $\mathrm{SiC}_{f} / \mathrm{SiC}$, will have to be performed to generate a failure mechanism map using simulated HTGR gas environments.

Typical simulated advanced HTGR helium chemistries used in various previous test programs are shown in Table 8. As shown, the main impurities are $\mathrm{H}_{2}, \mathrm{H}_{2} \mathrm{O}, \mathrm{CO}$ and $\mathrm{CH}_{4}$. The hot graphite core is considered as reacting with all free $\mathrm{O}_{2}$ and much of the $\mathrm{CO}_{2}$ to form $\mathrm{CO}$, and with $\mathrm{H}_{2} \mathrm{O}$ to form $\mathrm{CO}$ and $\mathrm{H}_{2}$. In addition, in cooler regions of the core, $\mathrm{H}_{2}$ reacts with the graphite via radiolysis to produce $\mathrm{CH}_{4}$. The overall stability of the proposed helium environment that will be representative of the NGNP must be evaluated in order to ensure that testing proposed is performed in environments that have consistent chemical potentials. Therefore, testing of both the helium environment to be used for mechanical properties and general corrosion evaluations of the candidate materials to establish their overall compatibility with that environment will be performed at temperatures up to at least $50^{\circ} \mathrm{C}$ above the proposed operating temperature for the $\mathrm{SiC}_{f} / \mathrm{SiC}$ materials. 
Creep-crack growth studies on $\mathrm{SiC}_{f} / \mathrm{SiC}$ composite bars will be used to investigate the degradation mechanisms at $1000^{\circ} \mathrm{C}$ in the simulated NGNP environment. Concurrent thermogravimetric measurements will be used to study environmental mass loss and corrosion mechanisms. A mechanical-chemical model of creep crack growth in $\mathrm{SiC}_{\mathrm{f}} / \mathrm{SiC}$, which has been developed at PNNL, will be used to calculate crack growth rates and compare them to measured growth rates [3.18,3.19]. Life-prediction models for $\mathrm{SiC}_{\mathrm{f}} / \mathrm{SiC}$ in NGNP environments will be constructed and tested based on these results.

\section{Failure Mode Testing}

$\mathrm{SiC}_{\mathrm{f}} / \mathrm{SiC}$ tubes will be tested in tension, compression, and using burst testing at $1000^{\circ} \mathrm{C}$ in inert and simulated NGNP environments to determine likely failure modes of control rod guide tubes. This will be done as a function of tube architecture and design. The output of the creep crack growth model and life-prediction models will be used to guide the choice of strain rate and loading parameters.

\section{Post Irradiation Examination}

Post irradiation testing will be carried out in established hot-cell facilities at ORNL and PNNL. Testing will include, but not be limited to, the following:

- Thermal conductivity ASTM E 1461-01

- Irradiation-induced dimensional change

- Sonic Elastic Modulus

- Room temperature strength

- Burst strength of tubes

- Slow crack growth testing of irradiated bars in simulated NGNP gas

- Scanning and transmission electron microscopy of irradiated materials.

\section{ASTM Guideline Support}

The need for continued ASTM guideline development has been highlighted as a critical issue for both $\mathrm{C}_{f} / \mathrm{C}$ and $\mathrm{SiC}_{f} / \mathrm{SiC}$ composites under NGNP. Currently there are few national or international full-consensus standards for evaluating advanced ceramics and ceramic matrix composites (CMCs) in particular. Technical and pragmatic issues related to standardization efforts for CMCs must be evaluated for full consensus standards [that is, ASTM Subcommittee C28.07 on Ceramic Matrix Composites, Comit Europen de Normalisation (CEN) Subcommittee TC184/SC1 on Ceramic Composites, and International Organization for Standardization (ISO) Technical Committee TC206 on Fine, Advanced, Technical Ceramics]. This task will provide for continued involvement of key personnel involved in these efforts, and in particular to ensure guidelines for testing of tubular $\mathrm{SiC}_{\mathrm{f}} / \mathrm{SiC}$ structures is moved forward.

\section{Experimental structural composite materials R\&D plans}

A brief summary of R\&D plans and schedules for the NGNP structural composite materials needed to meet the deployment time schedule is provided below. The schedule for these tasks is contingent upon funding availability.

The draft plans for FY 2009 and beyond have been developed based on an assumption that the presently studied $\mathrm{SiC}_{f} / \mathrm{SiC}$ and $C_{f} / C$ composites demonstrate key viability in FY $2005-2008$. Although it is likely that the $\mathrm{SiC}_{f} / \mathrm{SiC}$ and $\mathrm{C}_{f} / \mathrm{C}$ composites will successfully demonstrate the extended lifetime under high temperature irradiation and the fundamental fabricability, the long 
range future R\&D plans will be modified if a major viability issue is identified in the FY 2005 2008 phase.

\section{Milestones}

FY 2006

- Perform second round of processing for optimized infiltration

- Perform baseline thermophsyical chacterization of two different $C_{f} / C$ composites with braided architecture.

- Measure fracture toughness of braided $C_{f} / C$.

- Begin planning for baseline irradiations plan for comparing braided $\mathrm{C}_{\mathrm{f}} / \mathrm{C}$ to standard FMI 222.

- Prepare for irradiation of reference NGNP-grade $\mathrm{SiC}_{f} / \mathrm{SiC}$ specimens

- Carry out PIE of BS and BC bends bar capsules

- Complete crack growth testing.

- Conduct failure mode testing of reference NGNP-grade $\mathrm{SiC}_{\mathrm{f}} / \mathrm{SiC}$ to be irradiated.

- Conduct out-of-pile creep testing. Finalize geometry for in-pile creep test.

- Begin design effort on in-pile creep.

- Begin to qualify vendors

- Continue Involvement in ASTM guideline development.

FY 2007

- Begin baseline irradiation program of braided $\mathrm{C}_{f} / \mathrm{C}$.

- Initiate PIE of reference NGNP-grade $\mathrm{SiC}_{f} / \mathrm{SiC}$

- Conclude failure mode testing.

- Summarize experiment and modeling verification of creep testing.

- Complete report on composite fabrication effort.

- Complete construction of in-pile creep experiment.

- Initiate aging and evaluation of aged potential candidate test materials

- Continue Involvement in ASTM guideline development.

FY 2008

- Complete higher-level PIE including TEM.

- Complete PIE of Braided $\mathrm{C}_{\mathrm{f}} / \mathrm{C}$.

- Begin creep testing of $\mathrm{C}_{\mathrm{f}} / \mathrm{C}$.

- Begin corrosion and aging testing of $\mathrm{C}_{\mathrm{f}} / \mathrm{C}$.

- Initiate in-pile creep experiment.

- Completion of ASTM guideline for baseline $\mathrm{SiC}_{\mathrm{f}} / \mathrm{SiC}$ tube testing.

- Issue report for the FY05-08 effort 
- Complete aging of potential candidate test materials and continue characterization of mechanical and thermal-physical properties

FY 2009 to 2015

- Full-scale prototype demonstration and characterization for both $\mathrm{C}_{\mathrm{f}} / \mathrm{C}$ and $\mathrm{SiC}_{\mathrm{f}} / \mathrm{SiC}$ (procurement, complete baseline characterization)

- Complete aging testing of $\mathrm{C}_{f} / \mathrm{C}$

- Complete corrosion testing of $\mathrm{C}_{\mathrm{f}} / \mathrm{C}$

- Complete high level PIE of $\mathrm{C}_{\mathrm{f}} / \mathrm{C}$ including TEM

- Lifetime-limiting properties assessment (complete characterization of aging/creep/fatigue effects on mechanical and thermal-physical properties)

- Support to extended ASTM guideline and ASME code development.

- Fracture toughness evaluation (test method development and irradiation effect)

- Lifetime envelope determination (temperature and neutron fluence)

- Low-cost / high-performance alternative $\mathrm{SiC}_{\mathrm{f}} / \mathrm{SiC}$ evaluation

\subsection{Potential Candidate Materials Selections and Research Plans for SCWR}

Three primary factors will most affect the properties and choice of the structural materials from which the SCWR components will be fabricated. These are effects of irradiation, hightemperature exposure, and interactions with both the sub- and supercritical water environment to which they are exposed. An extensive testing and evaluation program will be required to assess the effects that these factors have on the properties of the potential materials for SCWR construction to enable a preliminary selection of the most promising materials to be made and to then qualify those selected for the service conditions required.

The potential candidate materials selected for the SCWR and the details of the research plans deemed necessary to establish the viability of the reactor concept with regard to materials performance are described in the following sections.

\subsubsection{General Considerations for SCWR Materials Research}

A discussion of two of the three primary considerations for SCWR service, irradiation and hightemperature exposure, are described in the corresponding section on NGNP Materials in this report. The third primary consideration, materials interactions with both the sub- and supercritical water environment, is described below.

\subsubsection{Water Chemistry and Corrosion Issues in SCWRs}

The single greatest unknown that will impact the viability and eventual operation of the SCWR is the chemistry of supercritical water in the presence of radiation. While the impact of the SCWR water chemistry will be most important in-vessel, it is possible, dependent on design, that there will be spillover effects on the power conversion systems for which water chemistry control is also very important. This section attempts to outline potential issues that may need to be addressed. Even though these corrosion considerations are quite pervasive across multiple components, there is no particular section on specific corrosion materials R\&D tasks and funding needs in this report. In lieu of that, the R\&D to address the various corrosion issues has 
been incorporated into the overall R\&D described for each component, as needed, in the component requirement sections that follow.

The mechanisms for environmentally sensitive cracking in water-cooled reactors that have been observed include intergranular stress corrosion cracking (IGSCC), irradiation-assisted stress corrosion cracking (IASCC), and corrosion fatigue. These mechanisms are affected by several variables including:

- Metallurgical structure, including the presence of $\mathrm{M}_{23} \mathrm{C}_{6}$ phases, phase morphology, and depletion of the $\mathrm{Cr}$ in zones adjacent to grain boundaries;

- Irradiation effects on grain boundary impurity segregation; and

- The aqueous environment, especially the presence of oxidizers and reducers.

In the case of IASCC of austenitic stainless steels, an additional parameter is a fluence threshold that is approximately equivalent to 1 displacement per atom (dpa). Further, nickelbase super alloys are sensitive to the presence of impurities including phosphorous, silicon, boron, and sulfur.

While materials have been identified that function in LWRs, the performance of these same materials in a SCWR is uncertain and will be dependent on the environment of the SCWR. In this respect, while operating temperatures have been proposed, the water chemistry is ill defined.

There are several aspects of the water chemistry of the SCWR that will impact the corrosion behavior of materials of construction. The concentrations of the transient and stable species due to radiolysis of the water, and the higher thermal decomposition of the water due to the higher operating temperature (as compared to LWRs), may well be significantly different. The chemical potential of oxygen and hydrogen peroxide, which will be significantly different in the supercritical fluid, will affect the corrosion potential of the water. This in turn determines whether magnetite $\left(\mathrm{Fe}_{3} \mathrm{O}_{4}\right)$ or hematite $\left(\mathrm{Fe}_{2} \mathrm{O}_{3}\right)$ forms and the morphology of these films, which are important to corrosion control on low alloy steels, heat affected zones, etc.

The chemical potential of the hydrogen should change as much as the chemical potential of the oxygen and hydrogen water chemistry may be just as effective in reducing the oxygen content. However, a decrease has been observed in the critical reaction rate of the $\mathrm{OH}$ radical with hydrogen above $300^{\circ} \mathrm{C}$. Because the radiolysis in the core is kinetically controlled, it might require much more hydrogen to suppress the oxygen and peroxide generation. If too much is required, metal hydriding could occur. The trade-off between these effects will, to a large extent, determine how much of the LWR and fossil plant water chemistry control experience is applicable to the SCWR. The control of $\mathrm{pH}$, while theoretically possible, may be difficult in practice, especially in the 300 to $500^{\circ} \mathrm{C}$ temperature range. The $\mathrm{pH}$ of the water is important in setting the corrosion potential and rate, and to some extent, the mode of corrosion. A range of $\mathrm{pH}$ has been successfully employed in LWRs, and this approach will need to be explored.

There is indeed a wide body of experience regarding performance of materials in water environments relevant to the SCWR that has been developed in LWR and supercritical fossilfired power plants. Control of the water chemistry has been critical to the continued operations of LWRs. The boiling water reactor (BWR) would normally operate with an oxygen overpressure and is also slightly acidic because air carries $\mathrm{CO}_{2}$, which leads to formation of carbonic acid. The result is a rather aggressive environment, which could cause excessive corrosion of the reactor materials. In BWRs, the general expectation is that the propensity for 
SCC will increase with increasing oxygen content, and hydrogen is generally added to the feedwater to recombine with oxygen and suppress the corrosion potential below the threshold for SCC. However, it takes a significant hydrogen overpressure to induce recombination of oxygen with hydrogen. In recent years, thin layers of noble metals (i.e., platinum and rhodium) have been deposited on the surface of BWR structural materials to suppress the corrosion potential even at relatively low hydrogen injection levels. On the other hand, the PWR is an indirect cycle, less susceptible to air infiltration. However, an oxygen overpressure would be present in PWRs as well due to diffusion of radiolytic hydrogen out of the system. Therefore, hydrogen is also injected in the primary coolant of PWRs, but at somewhat lower rates than in BWRs. Also, a minimum high temperature (about $300 \mathrm{C}$ ) $\mathrm{pH}$ of 6.9 is required to avoid heavy crud deposits on the fuel rods and boron must be added to the coolant in the form of boric acid as a neutron absorber for reactivity control. Therefore, to counter the effect of the boric acid on the $\mathrm{pH}$, lithium hydroxide is dissolved into the PWR primary water.

In once-through fossil-fired units (the circuit does not include a steam-separation drum) of the type considered in the SCWR, the quality of the water is controlled by treatment of the feedwater. In the U.S., two major approaches are used:

(i) The all-volatile treatment (AVT), which is based on measures to practically eliminate oxygen from the system to prevent corrosion. In this treatment the $\mathrm{pH}$ is adjusted (ammonia) to 9.2-9.6 for all-ferrous systems (8.8-9.1 for mixed ferrous-copper systems), and the oxygen content of the water is controlled to $<5 \mathrm{ppb}$ (cation conductivity is in the range $0.2-0.4 \mu \mathrm{S} \cdot \mathrm{cm}^{-1}$ ). This is accomplished by de-oxygenation in the condenser and deaerator, followed by the addition of oxygen-scavenging chemicals such as sodium sulfite (decomposes above 6.2 MPa) or, more recently, hydrazine. A problem with this approach is that the normally protective oxide formed on ferrous alloys is unstable in the feedwater train, leading to dissolution and transport of corrosion products, as well as erosion-corrosion attack of the economizer inlet tubes.

(ii) Oxygenated treatment (OT) used only for all-ferrous systems), in which the $\mathrm{pH}$ is adjusted (ammonia) to 8.0-8.5 and then, following purification in the condenser, demineralizer/condensate polisher, and deaerator (to $<0.2 \mu \mathrm{S} \cdot \mathrm{cm}^{-1}$ ), oxygen is added to the level of 30-150 ppb. The resulting high-purity water minimizes corrosion of the feedwater train up to the economizer inlet. The controlled, but limited oxygen content promotes the formation of a more protective layer of $\mathrm{Fe}_{3} \mathrm{O}_{4}$, in which the pores are blocked by $\mathrm{FeOOH}$; this modified magnetite layer also has a lower solubility than magnetite in the feedwater. Adoption of oxygenated water treatment has resulted in a significant reduction of water-steam-side corrosion-related problems in fossil-fired units.

The water chemistry guidelines for AVT, OT and for LWRs are compared in Table 19. Guidelines for determining the most appropriate water treatment system for a given plant configuration are available in a series of reports published by EPRI. 
Table 19. Typical primary water chemistry of supercritical fossil plants and LWRs.

\begin{tabular}{|c|c|c|c|c|c|c|}
\hline Items & Fossil AVT ${ }^{a}$ & Fossil AVT $^{b}$ & Fossil OT & $\mathrm{BWR}^{\mathrm{C}}$ & $\mathrm{PWR}^{\mathrm{c}, \mathrm{d}}$ & SCWR \\
\hline Pressure, $\mathrm{MPa}$ & $25-30$ & $25-30$ & $25-30$ & 6.9 & 15.5 & 25 \\
\hline Inlet temp. ${ }^{\circ} \mathrm{C}$ & $\sim 280$ & $\sim 280$ & $\sim 280$ & 278 & 286 & 280 \\
\hline Outlet temp. ${ }^{\circ} \mathrm{C}$ & $540-600$ & $540-600$ & $540-600$ & 285 & 324 & 500 \\
\hline $\begin{array}{l}\text { Conductivity (inlet) } \mu \mathrm{S} \\
\mathrm{cm}^{-1}\end{array}$ & $<0.2$ & $<0.2$ & $<0.15$ & $<0.1$ & $1-40$ & $?$ \\
\hline Oxygen, ppb & $1-10$ & $<5$ & $30-150$ & $50-200$ & 100 & $?$ \\
\hline Hydrogen, ml/kg (STP) & na & na & na & $0-50^{e}$ & $25-50^{f}$ & $?$ \\
\hline $\mathrm{LiOH}, \mathrm{ppm}$ & $\mathrm{DC}$ & $\mathrm{DC}$ & $\mathrm{DC}$ & $\mathrm{DC}$ & $0.6-4$ & $\mathrm{DC}$ \\
\hline Boron, ppm & $\mathrm{DC}$ & $\mathrm{DC}$ & $\mathrm{DC}$ & $\mathrm{DC}$ & $0-2000$ & $\mathrm{DC}$ \\
\hline $\mathrm{Cl}^{-}, \mathrm{ppm}$ & na & na & na & $<0.1$ & $<0.15$ & $?$ \\
\hline $\mathrm{F}^{-}, \mathrm{ppm}$ & na & na & na & $<0.1$ & $<0.15$ & $?$ \\
\hline $\mathrm{Fe}, \mathrm{ppb}$ & $<5$ & $<10$ & $<5$ & $<1-2$ & na & $?$ \\
\hline $\mathrm{Cu}, \mathrm{ppb}$ & $<2$ & $<2$ & na & $<0.1-0.3$ & na & $?$ \\
\hline Silica, ppb & $<20$ & $<20$ & na & na & na & $?$ \\
\hline $\mathrm{pH}$ (room temperature) & $9.2-9.6$ & $8.8-9.1$ & $8.0-8.5$ & $6.5-7.0$ & $6.9-7.4$ & $?$ \\
\hline \multicolumn{7}{|c|}{$\begin{array}{l}\text { plants with all ferrous condenser/feedwater system } \\
\text { b plants with mixed metallurgy } \\
\text { c P. M. Scott } 1998 \text {. } \\
\text { d IAEA } 1997 . \\
\text { e EPRI recommends use of the lower number. } \\
\text { f In the feedwater. } \\
\text { DC = not applicable because of the direct cycle. } \\
\text { na = not available }\end{array}$} \\
\hline
\end{tabular}

\subsubsection{Reactor Pressure Vessel Materials Selection and Issues}

It is assumed that the RPV design will include a feature to insulate the outlet nozzle from the outlet coolant temperature of $500^{\circ} \mathrm{C}$ and ensure vessel operation at $280^{\circ} \mathrm{C}$. The inner surface of the vessel will be exposed to water at $280^{\circ} \mathrm{C}$ and would be clad with a weld overlay of Type 308 stainless steel. The outer surface will be insulated, most likely in a manner similar to existing PWRs. Given the operating temperature of $280^{\circ} \mathrm{C}$ and an expected irradiation exposure similar to that of current generation PWR, the primary candidate materials for the RPV shell are those currently used in PWRs, namely SA 508 Grade 3 Class 1 forging (formerly designated SA 508 Class 3) or SA 533 Grade B Class 1 plate. The RPV thickness given above assumes one of those materials. Of those two materials, which have similar chemical compositions and the same design stress intensities in the ASME Code, the SA 508 Grade 3 Class 1 forging is preferred to eliminate the need for axial welds. It is also desirable to fabricate a forging of sufficient height to keep circumferential welds outside the region adjacent to the reactor core (the so-called beltline region) and preliminary information from the Japan Steel Works indicates that it will probably be possible to do so.

The knowledge gained over the past few decades regarding the radiation embrittlement of current LWR materials must be utilized in the preparation of the material specifications for the RPV materials. For example, minimization of sensitizing elements such as copper and phosphorus is critical for mitigation of embrittlement and undesirable segregation, while the nickel content should be kept relatively low yet high enough to maintain the strength and fracture toughness of the A508 Grade 3 Class 1 steel. In this regard, the thickness of the SCWR vessel shell and nozzle course forgings may present difficulties. Therefore, special attention must be paid to the chemical composition and heat treatment specifications to allow for 
through-thickness hardening to maintain the necessary strength and fracture toughness, yet to also ensure minimization of radiation embrittlement sensitivity.

Similar to the RPV shell, the RPV bolted closure head and welded bottom head will operate at $280^{\circ} \mathrm{C}$ and the materials of construction will be similar. The materials and fabrication of the heads, including the control rod drive mechanism housings, head bolts, etc. will incorporate the latest materials of choice for current LWRs and currently designed advanced LWRs. Information regarding RPV supports is not yet available and the choice of materials will depend upon the specific design.

If the design cannot incorporate an insulated nozzle, the material choices for the RPV shell, heads, and nozzles must be different than those discussed above because part of the vessel would operate at $500^{\circ} \mathrm{C}$. In this case, the design feasibility of a separate nozzle course insulated from the lower shell course and bolted head should be determined. If such a configuration is not feasible, then the use of a Cr-Mo alloy that maintains strength to higher temperatures would be required for the RPV. A vast amount of experience exists in the nonnuclear industry for long-time operation in this higher temperature range for $21 / 4 \mathrm{Cr}-1 \mathrm{Mo}$ steel, some experience with $3 \mathrm{Cr}-1 \mathrm{Mo}$, and less with $9 \mathrm{Cr}-1 \mathrm{Mo}$. An exacerbating issue in this case is that the portion of the vessel shell exposed to significant irradiation may operate at temperatures from 280 to $500^{\circ} \mathrm{C}$, depending on the specific design. Thus, if the current design changes to incorporate an integral nozzle, the issues regarding the RPV would be different and more uncertain relative to material behavior, and would likely require significantly more development and qualification efforts than associated with the current insulated nozzle design. However, as stated earlier, for the purpose of this current plan, it is assumed that an insulated nozzle will be accommodated in the design.

Regarding the thickness of the RPV shell, consideration should also be given to the potential use of higher strength materials that could result in a significant decrease of the required reactor pressure vessel wall thickness. There are a number of advantages that would accrue with a steel of significantly higher strength:

(1) Given the same design pressure, use of a steel with a $50 \%$ higher strength would allow for more than a $30 \%$ reduction in shell thickness;

(2) Thinner sections allow smaller ingots to be cast;

(3) Thinner plates or forgings ensure more uniform compositions and properties in the final product after heat treatment and hot-rolling or forging;

(4) Given the capacity, even larger-height forgings can be fabricated;

(5) Heat treatment of thinner sections is easier (more economical), and thinner sections can be cooled more rapidly, thus ensuring a more uniform through-thickness microstructure;

(6) During plant fabrication, thinner sections would offer advantages in material handling, welding, and vessel transportation;

(7) Thinner sections are easier to inspect, the results are more reliable, the probability of flaw detection is enhanced, and the flaw density would likely be lower; and

(8) If extremely large vessels are designed, thinner sections would be more amenable to field fabrication.

Two potential materials are A508 Grade 4N Class 1 and a developmental steel, 3Cr-3WV. The A508 Grade $4 \mathrm{~N}$ Class 1 forging is a generally bainitic (typically lower bainite) steel with a minimum specified yield strength of $585 \mathrm{MPa}(85 \mathrm{ksi})$ compared with $344 \mathrm{MPa}(50 \mathrm{ksi})$ for the A508 Grade 3 Class 1 forging discussed above. Thus, the design stress intensities would likely be about $70 \%$ higher for that alloy. Although that steel contains about $3.5 \mathrm{wt} \%$ nickel, irradiation 
results near to that of the SCWR operating temperature of $280^{\circ} \mathrm{C}$ indicate it could be suitable from the standpoint of irradiation resistance. The A508 Grade $4 \mathrm{~N}$ typically has a 41-J Charpy temperature below $-100^{\circ} \mathrm{C}$ that could be lowered to below $-150^{\circ} \mathrm{C}$ with an upper-shelf energy greater than $275 \mathrm{~J}(200 \mathrm{ft}-\mathrm{lb})$ by enhanced control of tramp elements such as, phosphorus, sulfur, arsenic, and antimony, as well as manganese and silicon.

The 3Cr-3WV steel mentioned is a "reduced-activation" low alloy steel with a base composition of nominally Fe-3Cr-3W-0.25V-0.1C. Preliminary tests on the steel indicate that this bainitic steel develops a combination of strength and toughness that would appear to make it a suitable candidate for pressure vessels, piping, and other pressure boundary components of Generation IV reactors. The steel is presently being investigated as a possible replacement for $21 / 4 \mathrm{Cr}$ $1 \mathrm{Mo}$ and modified $9 \mathrm{Cr}-1 \mathrm{Mo}$ steels in the petrochemical and power-generation industries. In the section sizes investigated to date, the $3 \mathrm{Cr}-3 \mathrm{WV}$ steel has strength more than double the 345 MPa (50 ksi) used to design with the A533B steel. Additionally, the Charpy impact toughness of the steels is as good or better than that of A533 grade B class 1 plate.

\subsubsection{Expected Research, Testing, and Qualification Needs for SCWR RPV Materials}

For the current design, achievement of the required through-thickness mechanical properties needs to be demonstrated. Such a demonstration would consist of the full range of mechanical properties, tensile, Charpy impact, drop-weight, and fracture toughness testing through the thickness, including appropriate metallographic evaluation of the microstructure. Additionally, nondestructive inspections prior to the destructive evaluations should be conducted and coordinated with the destructive evaluations to demonstrate soundness of the forging through the thickness.

If the significant SCWR fatigue component in excess of that for current LWRs is demonstrated, then fatigue data will be required to demonstrate structural adequacy for the forging and the welds. Similarly, if the water chemistry of the water exposed to the RPV is different than that for current LWRs, environmental assisted fatigue crack growth data for the forging, weld metal, and stainless steel cladding at the operating temperature and in the water environment will be required.

Initially, both the A508 Grade 4N Class 1 and 3Cr-3WV steels will be investigated at low level with in the SCWR materials program to provide a backup for the traditional LWR vessel materials in case, inadequate through-thickness properties or other unexpected issues limit their use as well as to establish the viability of their use for reducing fabrication and construction costs of SCWR reactors. Both experimental and analytical studies would need to be conducted to evaluate the hardenability of those steels relative to that of A508 Grade 3 Class 1 . In the case of the A508 Grade 4N steel, relatively thick section data are available and a literature review will be conducted to assess the specific needs relative to the viability of that material for the SCWR application. Given the results from those studies, the evaluations would proceed to fabrication of heavy-section forgings of sufficient thickness to assess the potential for one or both of the steels to be considered viable candidates for the RPV material.

If they are considered viable and desirable, an assessment would also be made regarding inclusion of one or both of those steels in a comprehensive material evaluation program that would include all the mechanical and physical properties needed for inclusion in the ASME Boiler and Pressure Vessel Code. This would include a full range of mechanical properties, including strength, toughness, fatigue, and creep, in the metallurgical condition representative of that for the anticipated section size, including welds. Likewise, the effects of irradiation on the 
strength and fracture toughness to an exposure beyond that predicted for the SCWR RPV would be required.

\subsubsection{Experimental RPV R\&D Plans}

A brief summary of major R\&D activities and schedules for the SCWR RPV materials is provided below. The development tasks for the RPV are dependent on 1) the incorporation of an insulated outlet nozzle to maintain the RPV shell nominal operating temperature at $280^{\circ} \mathrm{C}$, and 2) consideration of optional higher strength materials to reduce the RPV shell thickness. In the first case, the required tasks and costs are relatively low for the $280^{\circ} \mathrm{C}$ RPV operating temperature, while they would be significantly higher for an operating temperature of $500^{\circ} \mathrm{C}$ associated with an integral hot nozzle (costs not estimated for this report). For the second case, the total tasks and costs are substantial for the necessary developmental costs, but the potential advantages for fabrication and operation of the RPV are significant. The tasks and schedules below assume RPV fabrication with current LWR RPV steels but include a preliminary evaluation program for development of higher strength steels.

The schedule for these tasks is not well defined because it is highly contingent upon funding availability, which is not fully known at this time. It is, however, laid out as though the required funding would be available to meet the earliest logical schedule of the tasks identified and it will be subject to revision, based on actual funding availability.

\section{Milestones}

FY 2007

- Evaluate steel making and fabrication capabilities for RPV design with current LWR RPV steels

- Initiate demonstration of fabrication capability for RPV thickness

- Perform detailed review and assessment of data for optional higher strength RPV steels

FY 2008

- Initiate preliminary testing of optional high strength steels in thick sections

- Initiate preliminary radiation effects and thermal aging testing

- Begin fabrication of irradiation experiments for reactor internals prime candidate materials for SCWR

- Prepare progress report on demonstration of RPV fabrication capabilities for SCWR

FY 2009 and 20010

- Initiate demonstration of welding and NDE capability for optional high strength steels

- Initiate development of procedures for application of stainless steel cladding to optional high strength steels

- Assess higher strength RPV steels together with manufacturers capabilities, prepare report for SCW

- Begin fabrication studies of higher strength RPV steels for SCWR 
- Initiate radiation effects and thermal aging studies of higher strength RPV steels for SCWR

FY 2011 and beyond

- Complete preliminary testing of optional high strength steels in thick sections

- Complete development of procedures for application of stainless steel cladding to optional high strength steels

- Complete demonstration of fabrication capability for RPV thickness

- Complete preliminary radiation effects and thermal aging testing

- Complete demonstration of welding and NDE capability for optional high strength steels

- Prepare progress report on fabrication results for thick section fabrication on conventional RPV steels for SCWR

- $\quad$ Place specimens of higher strength RPV steels in reactor for SCWR

- Complete demonstration of fabrication capability for thick-section conventional RPV steels, write comprehensive report for SCWR

- Prepare final report on all tests of higher strength of RPV steels for SCWR

- Initiate development of procedures for cladding of higher strength steels for SCWR

- Complete final reports on radiation effects and thermal aging of higher strength RPV specimens and on procedures for cladding of higher strength RPV steels for SCWR

\subsubsection{RPV Internals Materials Selection and Issues}

The greatest materials challenge presented by the SCWR will be qualification of materials for service within the vessel that see both high temperature and radiation exposure and must simultaneously survive the relatively aggressive supercritical water environment. The present section identifies the structural materials that are candidates for the components of the core and of the associated support structures and addresses the principal issues related to their selection and performance. In the first category are the fuel cladding, fuel rod spacers (spacer grid or wire wrap), water rod boxes, fuel assembly ducts, and control rod guide thimbles. The second category includes control rod guide tubes, the upper guide support plate (UGS), calandria tubes, upper core support plate (UCS), lower core plate (LCP), core former, core barrel, and threaded structural fasteners. Insulation materials will also be needed for the reactor pressure vessel internals components that separate the hot outlet coolant (about $500^{\circ} \mathrm{C}$ ) from the inlet coolant $\left(280^{\circ} \mathrm{C}\right)$. These materials have not yet been adequately identified and, therefore, are not discussed in this section.

Table 20 lists the in-core components together with summaries of the anticipated irradiation conditions and mechanical loads for normal operating conditions, as well as the temperature excursions expected for abnormal conditions. Also listed are materials typical of those in use for similar components in currently operating PWRs and BWRs. The last two columns of the table provide recommendations for potential candidate materials for the SCWR, together with brief notes to further explain or augment other entries in the table. Table 21 follows an identical format for the support structures. An approach to further the down-selection of prime candidates is described based on combined evaluations in supercritical water and under irradiation. 
Table 20. Operating conditions and candidate materials for the in-core reactor components of the SCWR. All components listed are part of replaceable fuel assembly.

\begin{tabular}{|c|c|c|c|c|c|c|c|c|}
\hline \multirow[t]{2}{*}{ Component } & \multicolumn{3}{|c|}{ Normal Conditions } & \multirow{2}{*}{$\begin{array}{c}\text { Abnormal } \\
\text { Conditions } \\
\text { Temperature }\end{array}$} & \multicolumn{2}{|c|}{ Current LWR Mtls } & \multirow{2}{*}{$\begin{array}{l}\text { Candidate } \\
\text { SCWR } \\
\text { Materials }\end{array}$} & \multirow[t]{2}{*}{ Notes } \\
\hline & Temperature $^{1}$ & $\begin{array}{l}\text { Peak } \\
\text { Dose }^{2}\end{array}$ & Loads $^{3}$ & & PWR & BWR & & \\
\hline Fuel cladding & $280-620^{\circ} \mathrm{C}$ & $15 \mathrm{dpa}$ & $\begin{array}{l}\text { Pressure drop } \\
\text { across } \\
\text { cladding, grid- } \\
\text { cladding and } \\
\text { fuel-cladding } \\
\text { interactions } \\
\sigma \text { up to } 100 \\
\mathrm{MPa}\end{array}$ & $\begin{array}{l}\text { Up to } 840^{\circ} \mathrm{C} \text { for } \\
<30 \mathrm{sec}\end{array}$ & Zircaloy 4 & Zircaloy 2 & $\begin{array}{l}\text { Fe-Ms, Low- } \\
\text { swell S.S. }\end{array}$ & \\
\hline $\begin{array}{l}\text { Spacer } \\
\text { grids/wire } \\
\text { wrap }\end{array}$ & $280-620^{\circ} \mathrm{C}$ & $15 \mathrm{dpa}$ & $\begin{array}{l}\text { Hold the fuel } \\
\text { pins together }\end{array}$ & $\begin{array}{l}\text { Up to } 840^{\circ} \mathrm{C} \text { for } \\
<30 \mathrm{sec}\end{array}$ & $\begin{array}{l}\text { Zircaloy } 4, \\
\text { Inconel } \\
718\end{array}$ & $\begin{array}{l}\text { Zircaloy 4, } \\
\text { Inconel } \\
\text { X750, } 304 \\
\text { S.S. }\end{array}$ & $\begin{array}{l}\text { Fe-Ms, Low- } \\
\text { swell S.S. }\end{array}$ & \\
\hline $\begin{array}{l}\text { Water rod } \\
\text { boxes }\end{array}$ & $\begin{array}{l}280-300^{\circ} \mathrm{C} \text { inner } \\
280-500^{\circ} \mathrm{C} \\
\text { outer }\end{array}$ & $15 \mathrm{dpa}$ & $\Delta \mathrm{P}<0.1 \mathrm{MPa}$ & $\begin{array}{l}\text { Up to } 700^{\circ} \mathrm{C} \text { for } \\
<30 \mathrm{sec}\end{array}$ & $N / A$ & Zircaloy 2 & $\begin{array}{l}\text { Fe-Ms, Low- } \\
\text { swell S.S. }\end{array}$ & May need to insulate. \\
\hline $\begin{array}{l}\text { Fuel Assembly } \\
\text { duct }\end{array}$ & $\begin{array}{l}280-500^{\circ} \mathrm{C} \text { inner } \\
280-300^{\circ} \mathrm{C} \\
\text { outer }\end{array}$ & $15 \mathrm{dpa}$ & $\Delta \mathrm{P}<0.1 \mathrm{MPa}$ & $\begin{array}{l}\text { Up to } 700^{\circ} \mathrm{C} \text { for } \\
<30 \mathrm{sec}\end{array}$ & N/A & Zircaloy 4 & $\begin{array}{l}\text { Fe-Ms, Low- } \\
\text { swell S.S. }\end{array}$ & May need to insulate. \\
\hline $\begin{array}{l}\text { Control Rod } \\
\text { Guide Thimble }\end{array}$ & $280-300^{\circ} \mathrm{C}$ & $15 \mathrm{dpa}$ & $\begin{array}{l}\text { Low hydraulic } \\
\text { and thermal } \\
\text { stresses }\end{array}$ & $280-300^{\circ} \mathrm{C}$ & Zircaloy 4 & N/A & $\begin{array}{l}\text { Zircaloy 4, } \\
\text { Zr-Nb alloy }\end{array}$ & $\begin{array}{l}\mathrm{Zr} \text { alloy selected for } \\
\text { superior neutron economy. }\end{array}$ \\
\hline \multicolumn{3}{|c|}{$\begin{array}{l}\text { 1. Peak temperatures in PWRs are } 320- \\
370^{\circ} \mathrm{C} \\
2 \text {. Design estimates for typical high burnup } \\
\text { LWR fuel } \\
\text { 3. In addition, all reactor internals will be } \\
\text { subject to seismic and pipe break loads. } \\
4 \text { Condition II events only (LOCAs, LOFAs, } \\
\text { ATWSs are excluded) }\end{array}$} & \multicolumn{5}{|c|}{$\begin{array}{l}\text { Fe-Ms (Ferritic-Martensitic) steels, e.g., T91 (9Cr-1Mo-V), A-21 (9Cr-TiC mod), } \\
\text { NF616 (9Cr), HCM12A (12Cr), 9Cr-2WVTa, MA-957. } \\
\text { Existing low-swell stainless steels, e.g., D-9 (14.5Cr-14.5Ni, 2Mo, Ti stab), PNC } \\
\sim \text { D-9 mod w/P). }\end{array}$} & \\
\hline
\end{tabular}




\title{
Table 21. Operating conditions and candidate materials for the core structural support reactor components of the SCWR.
}

Component

\begin{tabular}{|c|c|c|}
\hline & Temperature ${ }^{1}$ & ${ }_{2}^{\text {Peak Dose }}$ \\
\hline $\begin{array}{c}\text { Upper Guide } \\
\text { Support (UGS) } \\
\text { plate }\end{array}$ & $\begin{array}{l}280^{\circ} \mathrm{C} \text { upper } \\
500^{\circ} \mathrm{C} \text { lower }\end{array}$ & $0.021 \mathrm{dpa}$ \\
\hline $\begin{array}{l}\text { Calandria } \\
\text { Tubes }\end{array}$ & $\begin{array}{l}280^{\circ} \mathrm{C} \text { inner } \\
500^{\circ} \mathrm{C} \text { outer } \\
\text { (w/o } \\
\text { insulation) }\end{array}$ & $0.021 \mathrm{dpa}$ \\
\hline $\begin{array}{c}\text { Upper Core } \\
\text { Support (UCS) } \\
\text { plate }\end{array}$ & $500^{\circ} \mathrm{C}$ & $0.021 \mathrm{dpa}$ \\
\hline $\begin{array}{l}\text { CR guide } \\
\text { tubes }\end{array}$ & $280^{\circ} \mathrm{C}$ & $\begin{array}{c}0.00001 \\
\text { dpa }\end{array}$ \\
\hline $\begin{array}{l}\text { Lower core } \\
\text { plate }\end{array}$ & $280-300^{\circ} \mathrm{C}$ & 0.39 dpa \\
\hline Core Former & $\sim 280-600^{\circ} \mathrm{C}$ & $67.1 \mathrm{dpa}$ \\
\hline $\begin{array}{l}\text { Core barrel or } \\
\text { shroud }\end{array}$ & $\begin{array}{l}280^{\circ} \mathrm{C} \text { core } \\
\text { region, } \\
500^{\circ} \mathrm{C} \text { above } \\
\text { core }\end{array}$ & 3.9 dpa \\
\hline $\begin{array}{l}\text { Threaded } \\
\text { fasteners }\end{array}$ & $280-500^{\circ} \mathrm{C}$ & $<4 \mathrm{dpa}^{4}$ \\
\hline
\end{tabular}

1. Peak temperatures in PWRs are $320-370^{\circ} \mathrm{C}$

2. Design estimates for $60 y$

3. All reactor internals will be subject to

seismic and pipe break loads

4. $50 \mathrm{dpa}$ for baffle bolts and formers in

PWRs

\begin{tabular}{l|l|l|l|}
$\begin{array}{c}\text { Abnormal } \\
\text { Conditions } \\
\text { Temperature }\end{array}$ & PWR & BWR & $\begin{array}{c}\text { Candidate } \\
\text { SCWR } \\
\text { Materials }\end{array}$ \\
$\begin{array}{l}\text { Lower side at up } \\
\text { to } 700^{\circ} \mathrm{C} \text { for }<30 \\
\text { sec }\end{array}$ & 304L S.S & 304L S.S. & $\begin{array}{l}\text { Advanced S.S., } \\
\text { Fe-Ms }\end{array}$ \\
\hline
\end{tabular}

\section{Significant hydraulic and thermal loads}

Significant

Low hydraulic. Low

hydraulic. High hydraulic.

Moderate thermal.

thermal.

Significant

hydraulic. Low

thermal. Supports

core.

Significant

hydraulic. High

thermal.

Significant

thermal.

\section{$280^{\circ} \mathrm{C}$ inner $700^{\circ} \mathrm{C}$ outer}

Up to $700{ }^{\circ} \mathrm{C}$ for $<30 \mathrm{sec}$

\section{N/A}

N/A

/A

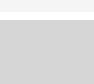

(2)

304 S.S.

NIA

$700^{\circ} \mathrm{C}$

N/A Fe-Ms
304L S.S 304L S.S.

316L

Advanced S.S

Fe-Ms, 304L

Fe-Ms, Low-

Fe-Ms, Low-
Swell S.S.

\begin{abstract}
Fe-Ms (Ferritic-Martensitic) steels, e.g., T91 (9Cr-1Mo-V), A-21 (9Cr-TiC mod), NF616 (9Cr), HCM12A (12Cr), 9Cr-2WVTa MA-957.
\end{abstract}

Existing low-swell stainless steels, e.g., D-9 (14.5Cr-14.5Ni, 2Mo, Ti stab), PNC $\sim \mathrm{D}-9$ mod w/P). Advanced stainless steels, e.g., HT-UPS ( PNC), AL-6XN (20Cr-24Ni-6Mo-0.2Cu-0.2N), etc.

Notes

Must insulate between the region above the core $\left(500^{\circ} \mathrm{C}\right)$ and the upper plenum $\left(280^{\circ} \mathrm{C}\right)$ to limit the thermal loads in the UGS.

Must insulate to limit the heat

transfer from the coolant to the moderator and control the thermal loads in the calandria tubes.

The water rod box penetrations may cause some locally high thermal stresses.

\section{May want to use the same} material as for the UGS, UCS,

and calandria tubes

May want to use the same material as for the UGS, UCS, and calandria tubes

Must insulate either the core former or core barrel to control the thermal loads in the barrel.

Must insulate the core barrel above the core region and insulate either the core barrel or core former in the core region.

\begin{tabular}{l|l|l|l}
316 & 304,600, & Advanced S.S., & The current design is an all \\
S.S./CW & $316,316 \mathrm{~L}$ & IN-718, 625, 690 & welded core former and barrel.
\end{tabular}


There is substantial experience with commercial compositions of austenitic stainless steels and some high nickel alloys in currently operating light water reactors. Typically these components operate at temperatures well below the temperatures at which significant swelling occurs, so that swelling has not been a major problem. However there has been some concern regarding possible swelling in low temperature/low dose rate regimes. Of much greater concern has been the failure of components, after many years in both BWRs and PWRs, as a result of IASCC in both stainless steels and high nickel alloys.

Where temperatures significantly above $300^{\circ} \mathrm{C}$ or doses above several dpa are expected, as in the SCWR reactor internals, the structural materials recommended in both Tables 20 and 21 are primarily F/M steels and low swelling variants of austenitic stainless steels. For these conditions austenitic stainless steels, such as AISI 304 and 316, which have not been tailored for low swelling, cannot be used. The swelling behavior of both alloys is sensitive to small changes in heat-to-heat chemistry and significant dimensional changes in the reactor internals can occur even at doses of $\sim 15 \mathrm{dpa}$.

The range of compositions within the $\mathrm{Fe}-\mathrm{Cr}-\mathrm{Ni}$ alloy system within which alloys with acceptable mechanical behavior and dimensional stability currently exist, or could be developed, may be divided into four broad categories namely, a) austenitic stainless steels, b) F/M steels, c) high alloys (Fe $<50$ wt. \%) and d) Ni-based alloys.

Within the austenitic stainless steel family, compositional options include:

a) Composition-restricted 316 stainless steels with nitrogen modifications such as the French breeder program 316 and the Japanese 316 FR,

b) 316- type stainless steel micro-alloyed with Ti, B and P, such as the Japanese PNC 316 alloy (although $B$ is not a desirable alloying element in reactors), and D9 modifications,

c) High nitrogen austenitic and possibly duplex (austenite/ferrite) steels, and

d) Steels containing $\mathrm{Cr}$ and $\mathrm{Ni}$ in the $20-30 \%$ range such as Al-6XN, and the US HT-UPS alloys.

Many of the improved stainless steels identified in Tables 20 and 21 have been produced in a variety of product forms on a commercial scale. However, there is little basis at present for predicting the behavior of any of these materials in terms of their stress corrosion cracking and irradiation-assisted stress corrosion cracking behavior under supercritical water conditions which are the greatest unknowns that will affect their performance in the SCWR. Compositions are available that have demonstrated low swelling up to doses of 50-100 dpa in both mixed spectrum and fast reactors in the temperature regime of highest swelling in non-tailored alloys, i.e., $450-550^{\circ} \mathrm{C}$. It should be noted that many of the low swelling alloys also exhibit superior creep strength relative to 316 stainless steel. The low carbon versions of 304 and 316 are not considered for low dose applications because of their poor resistance to IGSCC. However, samples of both these alloys should be included in the program to serve as benchmarks against which to compare performance of the newer alloys.

Ferritic-martensitic steels in the $9-12 \% \mathrm{Cr}$ range are intrinsically more swelling resistant than austenitic steels. Low swelling has been demonstrated at doses of 50-100 dpa in neutron irradiations. The early commercial model for these alloys for applications to reactor internals was the Alloy HT-9, containing $12 \% \mathrm{Cr}$ and $1 \%$ Mo produced by Sandvik. Newer alloys that show better properties are based on $9 \% \mathrm{Cr} 1 \%$ Mo such as $\mathrm{T} 91$ and a series of reduced activation alloys in which the $\mathrm{Mo}$ and $\mathrm{Nb}$ are replaced with $\mathrm{W}, \mathrm{V}$, and $\mathrm{Ta}$, such as the Japanese 
F82H and the U.S. 9Cr-2WVTa alloy. Additionally, steels such as NF616 and HCM12A from Japan and E911 from the EU have been developed for $620^{\circ} \mathrm{C}$ operation.

A class of advanced ferritic steels that has received considerable interest for nuclear applications in recent years is the ODS steels. In these ODS steels, the cubic-centered structure provides the irradiation swelling resistance while the dispersed oxides (e.g., yttrium oxides) provide enhanced high-temperature strength. The high-temperature creep strength of these alloys is exceptional, i.e., at $650^{\circ} \mathrm{C}$ it can be three to four times larger than for the traditional F/M steel HT-9. Some grades of this class of alloys exhibit low ductility and large anisotropy in creep strength, but these shortcomings may be eliminated by careful selection of the alloying elements. Significant international activities are ongoing to optimize this class of materials, particularly in Japan.

The main issues with all ODS alloys relative to their application in the SCWR are (i) significant uncertainties regarding their compatibility with the supercritical-water coolant, (ii) high cost of fabrication and (iii) weldability. Nevertheless, because of their potential, inclusion of some ODS alloys (e.g., MA957) are recommended in the SCWR materials development program.

For the control rod thimbles, Zircaloy 4 or a zirconium-niobium alloy is recommended based upon proven performance in LWRs at the anticipated low operating temperatures (about $300^{\circ} \mathrm{C}$ ) and their very low thermal neutron absorption cross section.

In several cases the high nickel alloys have been recommended as alternates to the steels. Their swelling behavior may be acceptable up to reasonably high doses. However, these alloys should be considered only if it is found that low-swelling austenitic steels or the F/M class of alloys do not perform satisfactorily in the supercritical water environment or do not have sufficient strength for applications such as threaded structural fasteners.

\subsubsection{Expected Research, Testing, and Qualification Needs for SCWR RPV Internals Materials}

The corrosion and stress corrosion cracking (SCC) behavior of alloys in supercritical water will be the dominant feature of the initial phases of the R\&D program. For the four broad categories of alloys to be considered as candidates for the reactor internal components, namely austenitic stainless steels, F/M steels, high alloys ( $\mathrm{Fe}<50 \mathrm{wt} \%$ ), and nickel-based alloys, there is insufficient knowledge at present regarding their behavior in supercritical water to rank these alloy categories in terms of overall corrosion resistance.

The materials program for the reactor internal components will comprise two distinct but overlapping activities: research and development activity to define a limited number of prime candidate alloys and a materials engineering design data activity. The first activity entails a sequenced set of testing and performance evaluation stages over an initial 7-year time frame in which an initially large number of potential candidate materials is reduced to a limited number of prime candidates through exposure to, and testing in, increasingly complex and hostile environments. This R\&D program is intended to ensure the viability of the SCWR. It will produce the technical data that defines alloy compositions and thermo-mechanical treatments with the demonstrated capability to meet the intended service conditions of the major reactor internal components. The second activity involves a more extensive evaluation and qualification of the prime candidates to develop a materials engineering design database of sufficient breadth and depth to meet code case and licensing requirements. This would encompass 
repetitive testing to establish confidence limits, and development of information on heat-to-heat variations and on various product forms including welds.

Based on this initial screening phase work, a reduced number of materials exhibiting promising behavior will be selected for the second phase of the R\&D program which will include a) SCC initiation and crack growth rate measurements of irradiated materials, utilizing material subjected to neutron and proton sources, coupled with exposure to simulated SCWC water chemistry conditions and b) a series of neutron irradiation experiments to establish the mechanical behavior and dimensional stability of candidate alloys as a function of neutron dose and irradiation temperature. Relatively simple irradiation capsules (e.g., HFIR rabbit-type) could be used to produce large numbers of specimens irradiated to doses up to $\sim 23 \mathrm{dpa}$ for post irradiation tests in supercritical water conditions. Accelerator-based irradiations with $\sim 3 \mathrm{MeV}$ protons also provide a means of introducing displacement damage and microstructural changes, from which important information can be derived on the mechanisms of IASCC phenomena and provide guidance on the selection of alloys and metallurgical conditions.

The primary component of the third phase of the R\&D program will be the testing of a reduced number of promising candidate materials in a supercritical water (SCW) loop to obtain data on corrosion and IASCC resistance in prototypical conditions and provide important water chemistry control data.

The irradiation test program has two aspects: a) the investigation of susceptibility to IASCC phenomena and $b$ ) the establishment of the constitutive behavior for creep, swelling, ductility fracture toughness, etc. These two separate irradiation experiment activities may be coupled to some extent. To investigate the susceptibility of materials to IASCC under supercritical water conditions, it is obviously desirable to simulate reactor environmental conditions by exposing materials to the simultaneous effects of displacement damage, ionizing radiation, and stress in a supercritical water environment. This type of environment is difficult to achieve. It is therefore necessary instead to rely on a variety of testing methods and conditions that reproduce to some extent the primary features of the environmental conditions that control corrosion and cracking phenomena.

Supercritical water conditions, ranging from the low temperature inlet conditions in the SCWR around $280^{\circ} \mathrm{C}$ up to the higher temperature regimes above the pseudo-critical point, where the coolant changes from being essentially a compressed liquid to a fluid (gas) of nearly an order of magnitude lower density. The effects of oxygen, hydrogen and other impurity concentrations on the corrosion and SCC behavior of each material needs to be studied and information is needed on both the susceptibility to crack initiation and on the crack growth behavior. A fully integrated, complementary program on the effects of radiolysis on the supercritical water chemistry is essential in order to provide information on the radiolytic yields and their recombination rates as a function of density and temperature.

Relatively simple irradiation capsules (e.g., HFIR rabbit-type) may be used to produce large numbers of specimens irradiated to doses up to $\sim 5 \mathrm{dpa}$ for post irradiation controlled extension rate tests (CERT) in supercritical water conditions. Although the radiation damage is decoupled from the other environmental factors, this approach has the advantage of conducting cracking tests in laboratory controlled environments using information on water chemistry derived from separate experiments on radiolysis.

This type of relatively inexpensive irradiation as well as accelerator-based irradiations with $\sim 3$ $\mathrm{MeV}$ protons could also be used to provide low dose specimens for the investigation of 
microstructural and microcompositional evolution. Following irradiation, specimens can be mechanically loaded in well-controlled SC water chemistry environments to investigate cracking susceptibility.

In addition to the irradiation of specimens in helium-filled capsules for post irradiation controlled CERT in supercritical water conditions, it may also be possible to develop an environmental capsule with in-situ monitoring of radiolytic species and chemical corrosion potential, in which the materials are irradiated in contact with water in sealed high-pressure containers. The ongoing irradiation would produce continuous radiolysis leading to products such as oxygen and hydrogen as well as other products such as peroxide that are implicated in IASCC. These specimens could be further tested following irradiation under controlled CERT conditions as above.

None of the irradiation methods mentioned above is an exact duplication of conditions in the SCWR. The neutron irradiations in gas capsules and the proton irradiations in vacuum fail to introduce radiation effects simultaneously with corrosion and/or stress corrosion cracking processes. In addition, the proton irradiations do not introduce radiation damage with consequent changes in properties throughout a specimen, but only affect regions within tens of micrometers of the proton entry surface. In contrast, the neutron irradiations in water capsules do include simultaneous exposure of specimens to irradiation and an oxidizing environment. However, neutron irradiations of closed water capsules suffer in comparison to an exposure in a flowing loop in that the water chemistry is constantly changing in a manner that cannot be easily measured. The problem can be minimized by introducing $\mathrm{pH}$ and electro chemical potential (ECP) probes and by employing as large a capsule as possible natural circulation to provide a low flow rate of refreshed supercritical water.

The water capsules are being considered specifically for the SCWR project and are not known to have been used before. For this reason the neutron irradiations in water capsules will be subject to an evaluation phase prior to committing to the full cost of including them in the program.

Based upon a judicious use of these and possibly additional techniques, it is intended to reduce the number of candidate material conditions to a small number of prime candidate alloys for comprehensive testing and evaluation in a pumped loop facility in a test reactor so as to more closely achieve prototypical conditions in flowing supercritical water. However, it should be noted that even such a loop may not completely reproduce the SCWR environment. There is expected to be no truly prototypical environment available until the SCWR itself begins operation. It will therefore be necessary to include provisions for the SCWR to include an advanced materials irradiation program, in addition to a surveillance program, with capabilities to irradiate specimens of candidate structural materials for possible improvements in subsequent cores or structures and for next generation SCWRs.

Materials showing promise of acceptable performance in supercritical water will be the focus of an irradiation testing program to determine a full range of mechanical behavior and physical properties. Properties to be determined include tensile, creep, fatigue, fracture and microstructural and dimensional stability. The irradiations will be carried out to a recommended $150 \%$ of the nominal expected dose of $15 \mathrm{dpa}$.

The phased R\&D program will result in the identification of a limited number of prime candidate materials with the potential to meet the requirements of all in-vessel components. The program will then make a transition into a materials engineering activity, which will provide the extensive 
materials property database required for design, licensing construction and operation. The product of this phase will be a specification for producing materials in the required product forms, an approved data base on properties, the structural assessment methods required to support design, construction, and licensing, and a reliable basis for the prediction of materials performance throughout the expected lifetime including off-normal events.

\subsubsection{Experimental Reactor Internals Materials R\&D Plans}

A brief summary of R\&D plans and schedules for the SCWR reactor internal materials is provided below. The tasks are intended to provide the information needed to quantify the influence of supercritical water, irradiation, and high-temperature exposure on the corrosion, SCC, and IASCC resistance of materials candidates for the power conversion, as well as their long term stability.

The schedule for these tasks is not well defined because it is highly contingent upon funding availability, which is not known at this time. It is, however, laid out as though the required funding would be available to meet the earliest logical schedule of the tasks identified and it will be subject to revision, based on actual funding availability.

\section{Milestones}

FY 2006

- Perform initial corrosion and SCC screening tests of unirradiated materials in supercritical water

- Select samples from irradiated archival material for evaluation screening tests of SCC in supercritical water

FY 2007

- Initiate determination of unirradiated mechanical properties data for candidate materials

- Complete development and installation of SCC test facility for irradiated materials

- Complete corrosion and SCC screening tests of unirradiated materials in supercritical water

- Initiate evaluation of SCC on ion irradiated and archival neutron irradiated materials

- Initiate corrosion and SCC testing of primary candidate materials for core support components in supercritical water at simulated in-reactor chemistry

- Complete compilation of available information on solubility of SCWR power conversion systems candidate materials in supercritical steam

- Initiate measurements of solubility of SCWR candidate materials in supercritical steam

FY 2008 and 2009

- Complete compilation, evaluation and new testing for unirradiated mechanical properties data for reactor internals for SCWR

- Complete corrosion and SCC testing of primary candidate materials for core support 
components in supercritical water at simulated in-reactor chemistry

- Complete fabrication and place first irradiation experiments into reactor for SCWR

- Initiate post-irradiation mechanical properties testing, microstructural characterization of replaceable fuel assemble candidate materials

- Initiate post-irradiation corrosion and IASCC testing in supercritical water testing of replaceable fuel assemble candidate materials

- Prepare final report on unirradiated mechanical properties for SCWR

- Complete measurements of solubility of SCWR candidate materials in supercritical steam

- Complete corrosion and SCC testing of primary candidate materials for SCWR core support components in supercritical water

- Initiate post-irradiation corrosion and IASCC testing of SCWR core support materials in supercritical water

FY 2010 and 2011

- Complete post-irradiation mechanical properties testing, microstructural characterization of replaceable fuel assemble candidate materials

- Complete testing and write final report on corrosion and SCC tests on unirradiated materials in supercritical water for SCWR

- Remove first low-dose core structural material specimens from reactor, evaluate mechanical properties and corrosion for SCWR

- Complete facility construction for irradiation of SCWR candidate materials in pumped flow loop for corrosion and IASCC testing in supercritical water

- Remove intermediate dose structural material specimens from reactor, carry out extensive mechanical property, microstructural and corrosion characterizations for SCWR

FY 2012 and Beyond

- Initiate irradiation of candidate materials in supercritical pumped flow loop, postirradiation mechanical properties testing, microstructural characterization, and corrosion and IASCC testing in supercritical water

- Complete post-irradiation corrosion and IASCC testing in supercritical water testing of replaceable fuel assemble candidate materials

- Complete irradiation of candidate materials in supercritical pumped flow loop, postirradiation mechanical properties testing, microstructural characterization, and corrosion and IASCC testing in supercritical water

- Complete final report on corrosion and SCC tests with simulated in-reactor chemistry for SCWR

\subsubsection{Pump, Piping, and Valve Materials Selection and Issues}

The issues and concerns regarding the pumps, valves, and piping for the SCWR can be divided into those associated with the feedwater lines and the steam lines. 
Issues for components of the feedwater system will be similar to those being considered in the more conventional advanced LWR technologies, where ASME Section III is the applicable construction code. A wide selection of materials is available in ASME Section III, although the choices for the SCWR may be different for Class 1 components than for Class 2 and Class 3 components. Valves in the feedwater lines can be manufactured from materials similar to pump casings. The choice between ferritic steels and stainless steels for the feedwater line piping must consider the chemistry of the water and the potential for flow assisted corrosion. Experience has shown that flow-assisted corrosion (FAC) is the dominant degradation mechanism of LWR piping system. Also, fatigue and stress corrosion cracking are concerns. Carbon steels piping materials in operating LWRs, such as seamless pipe SA-106 Grade C, clad carbon steels, and seamless stainless steels pipes such as SA-312 TP304H, TP304L, TP316L are the primary candidate materials for the feedwater lines. Of these many materials, the grades that have been included in the LWR environmental strain-fatigue and fatigue crack growth studies would be preferred. Although seam welded piping has been installed in LWRs, it should be avoided unless the piping has been subsequently reworked and renormalized. Wrought products should be preferred over cast products.

The SCWR feedwater pumps will be low flow/high head pumps located on the feedwater lines outside the containment and are expected to operate at approximately $190^{\circ} \mathrm{C}$. These pumps will resemble in many ways the state-of-the-art pumps developed for supercritical fossil power. The materials candidates for pump casing are a forged low-alloy steel, such as SA-508 Class 2 or Class 3. An austenitic cladding with controlled delta ferrite content would be required if a lowalloy steel is selected. Alternatively, an austenitic stainless steel such as SA-336 Gr F304 could be considered. The materials candidates for pump internals are a high-strength casting such as SA-487 CA-6NM-A (normalized and tempered 13Cr-4Ni steel).

The steam line piping is the greater concern. The issues related to the steam line system are more akin to those addressed in the design, construction, and operation of supercritical fossil power plants. Creep and time-dependent material degradation are active in fossil plant steam line systems at temperatures above $370^{\circ} \mathrm{C}$ for ferritic steels and above $425^{\circ} \mathrm{C}$ for austenitic alloys. The philosophy behind the ASME Power Piping Code (B31.1), which covers fossil plant piping, is significantly different from the philosophy of ASME Section III.

The outlet temperature of $500^{\circ} \mathrm{C}$ is less than the temperature at which many supercritical fossil power plants operate, but the pressure $(25 \mathrm{MPa})$ is comparable. Whereas ASME Section III has incorporated a wide selection of ferritic piping steels for service to $370^{\circ} \mathrm{C}$ and austenitic alloys for service to $425^{\circ} \mathrm{C}$ the high-temperature extension Subsection NH is limited to Grade 22 Class 1, Grade 91, and three austenitic alloys $(304 \mathrm{H}$ stainless steel, $316 \mathrm{H}$ stainless steel, and Alloy $800 \mathrm{H}$ ). The steam line temperature is sufficiently low to enable the use of one of these materials, providing that FAC is not a problem. Alternate materials would include 316FR stainless steel. This steel qualifies as an " $L$ " grade, yet has properties equivalent to, or superior to, Type $316 \mathrm{H}$ stainless steel. The database is sufficient to meet the needs for inclusion into Subsection $\mathrm{NH}$.

The steam line piping system between the isolation valve and the turbine could be designed to meet the requirements of B31.1, which would allow a greater choice of materials, allowing the use of alloy P92 $(9 \mathrm{Cr}-2 \mathrm{~W})$, which is used in fossil-fired supercritical plants. However, supplementary requirements to address fatigue and other damage accumulation mechanisms would be needed. 


\subsubsection{Expected Research, Testing, and Qualification Needs for Pump, Piping, and Valve Materials}

A number of issues are expected as a result of the 60-years intended life of the SCWR, based on experiences of the fossil power piping systems in the last 20 years. Fossil plants have experienced cracking in welds in $316 \mathrm{~N}$ stainless steel piping and in thick-section dissimilar metal welds after more than 100,000 hours of operation with steam at $540^{\circ} \mathrm{C}$. Aging effects and the performance of weldments and seam welded piping, must be addressed from a Code and reliability standpoint.

The compatibility of the materials with the coolant water must be evaluated. A database that includes the experiences of pumps operating in the pressure range of interest should be assembled and utility experience brought to bear on issues regarding pump maintenance and reliability. The potential for fatigue, corrosion fatigue, and fatigue crack growth of a flawed component needs to be assessed.

The extensive database collected on the candidate piping materials should be re-evaluated in light of the specific environment and operating conditions of the SCWR. The long-time data produced in the time period since ASME Subsection NH should be incorporated into the reevaluation of the time-dependent allowable stresses and stress intensities. A careful review of the factors contributing to cracking in weldments should be undertaken and techniques to accelerate damage mechanisms should be developed. The fitness-for-service assessment methodology developed by the Metals Properties Council should be expanded to include a continuum damage mechanics model suitable for high temperature applications. Factors such as microstructural coarsening, cavitation, and wastage will be accommodated by the model to predict remaining life of a component exposed to long-time, high-temperature service.

\subsubsection{Experimental R\&D Plans for Pump, Piping, and Valve Materials}

A brief summary of R\&D plans and schedules for the SCWR pump, piping and valve materials is provided below. The schedule for these tasks is not well defined because it is highly contingent upon funding availability, which is not known at this time. It is, however, laid out as though the required funding would be available to meet the earliest logical schedule of the tasks identified and it will be subject to revision, based on actual funding availability.

\section{Milestones}

FY 2007

- Complete compilation of available information on solubility of SCWR power conversion systems candidate materials in supercritical steam

- Initiate fatigue, thermal fatigue, and fatigue crack growth testing in simulated supercritical water at simulated chemistry

- Initiate development materials data needed to modify ASME and related construction codes for extended life and new materials

- Initiate corrosion fatigue testing for SCWR pump materials in supercritical water

- Initiate evaluation of factors affecting steam condensation and stability of corrosive species in SCWR power conversion systems 
- Perform FAC and corrosion fatigue testing for pump materials in supercritical water at simulated chemistry

- Initiate evaluation of potential for creep-fatigue, thermal fatigue, and dissimilar metal weld cracking of steam line piping valves

- Initiate development of continuum damage models for steam line piping materials

FY 2008 and 2009

- Perform FAC and corrosion fatigue testing for valve materials in supercritical water at simulated chemistry

- Initiate evaluation of potential for dissimilar metal weld cracking in steam line piping

- Initiate corrosion fatigue testing for valve materials in supercritical water at simulated chemistry for SCWR

FY 2010

- Complete evaluation of potential for creep-fatigue, thermal fatigue, and dissimilar metal weld cracking of steam line piping valves

FY 2011 and beyond

- Complete fatigue, thermal fatigue, and fatigue crack growth testing in simulated supercritical water at simulated chemistry

- Complete development materials data needed to modify ASME and related construction codes for extended life and new materials

- Complete development of continuum damage models for steam line piping materials

- Complete evaluation of potential for dissimilar metal weld cracking in steam line piping

\subsubsection{Power Conversion System Materials Selection and Issues}

In this section of the plant, steam at about $500^{\circ} \mathrm{C}$ and $25 \mathrm{MPa}$ is supplied from the reactor, expanded through the turbine, condensed, cleaned, pumped to $25 \mathrm{MPa}$, and then heated to $280^{\circ} \mathrm{C}$ before re-entering the containment and reactor vessel. The major components of the PCS are external to the reactor vessel and include the steam turbine and associated valving; the condenser; the demineralizer/condensate polisher; the feedwater preheaters; and the deaerator.

\subsubsection{Turbines}

Fossil-fired supercritical steam power plants operate with steam conditions typically of 540 to $600^{\circ} \mathrm{C}$ and 25 to $30.5 \mathrm{MPa}$. As a result, there is a well-established manufacturing base for turbines for operation at the supercritical steam conditions of interest in the SCWR, as well as extensive experience in their use. The extent to which this experience is relevant to the SCWR case largely depends on similarities and differences in the quality of the steam, in particular, the extent to which the level and types of impurities in the steam are different from those in fossilfired practice. One difference is that, whereas in fossil-fired plants the steam exiting the highpressure turbine is returned to the steam generator for reheating in a separate circuit before being sent to the intermediate-pressure and low-pressure turbines; reheating in LWRs is accomplished with live steam in order to minimize the complication of the steam circuit. Another modification adopted is the addition of moisture separators. 
Turbine problems have been one of the three leading causes of outages of fossil-fired and nuclear power plants. The main materials causes of these outages have involved mainly thermal fatigue cracking of rotors and discs; condensate-related corrosion or stress corrosion cracking of the last stages of the turbine; and solid particle erosion of the first stage guide vanes.

Attempts to correlate the susceptibility to SCC to alloy microstructural differences (segregation/temper embrittlement) in rotors and discs resulting from the initial metallurgical processing routes, or to the operating history of the turbine have not provided much guidance. SCC occurs only in wet steam at crevices or locations where access to the steam is limited, and depends on the contaminants present in the steam. Steam in fossil-fired units invariably picks up impurities from sources such as condenser/pump leaks; demineralizer/condensate polisher leaks; de-mineralizer breakdown; and from the feed water and the water treatment chemicals used. Such impurities will deposit from the steam whenever their solubility is exceeded due to changes in steam temperature and pressure. The contaminants most implicated in SCC are usually chlorides, sulfates, hydroxides, and phosphates of sodium and iron.

The design criterion for steam turbine blades is high-cycle fatigue: un-notched for the airfoil area, and notched for the blade root area. Locations at which pitting and SCC have been observed in fossil-fired practice have included the attachment of the blades to the discs, so that there is need for careful consideration in the design of the blade-disc mating surfaces to incorporate lessons learned for minimizing susceptibility to SCC. The next-to-last row of blades in the low-pressure turbine is also susceptible to pitting corrosion from deposition of impurities condensed from the steam. Such pitting can eventually result in fatigue of the blades and/or imbalance of the turbine.

The last row of blades in the low-pressure turbine is susceptible to erosion by water droplets shed from the preceding vanes. The severity of water droplet erosion depends on (1) the moisture content of the steam entering the last-but-one stage blades (amount of water); (2) the steam pressure between the next-to-last and last stage (higher steam density will accelerate smaller droplets); and (3) blade tip speed (relative drop velocity from blade to vane).

Since SCWRs are intended to operate essentially continuously near maximum load at temperatures significantly higher than BWRs, it is expected that their potential for solid particle erosion will be similar to that for the present fleet of fossil-fired supercritical steam power plants. The potential for solid particle erosion damage depends on the physical dimensions of the flakes of oxide and the frequency of exfoliation events that, in turn, varies significantly among the alloy types that are used for the upstream piping. Exfoliation is triggered when the stresses in the growing oxide scales exceed some critical value; these stresses result from the thickness of the scale (accommodation between the volume of oxide formed and the volume of alloy consumed), as well as from the mismatch in the coefficients of thermal expansion of the scale and the underlying alloy during cooling from operating temperature. Relationships have been developed for time, oxide-scale thickness, and tendency for scale exfoliation for some of the candidate alloys used in fossil plants, and these can provide guidance on the time at temperature at which exfoliation problems might be expected.

The materials considerations for the SCWR should be based primarily on fossil plant practice, with two caveats:

(i) The maximum alloy temperature required in the SCWR is not higher than the maximum alloy temperature allowed in fossil service 
(ii) The threat of SCC from oxidizing or other species resulting from radiolysis of the water is not greater than that from the water conditions prevailing in the supercritical fluid in fossil plants.

With respect to the latter point, it is noted that current LWR's and likely the SCWR operate with a hydrogen-modified water chemistry in the reactor, wherein hydrogen is added to the water to cause rapid recombination of aggressive oxidizing species produced by radiolysis. If uncontrolled these oxidizing species cause a form of degradation at low doses in components within the reactor vessel known as IASCC. In fossil SCW plants, on the other hand, in current practice oxygen is added to the water to protect alloy heat transfer surfaces by the selective formation of oxides. Integration of these seemingly mutually exclusive approaches may be required in the SCWR to ensure optimum lifetimes of components.

The alloys typically used in fossil supercritical steam turbine are listed in Table 22 along with those recommended for SCWR service.

Table 22. Summary of alloy candidates for steam turbines.

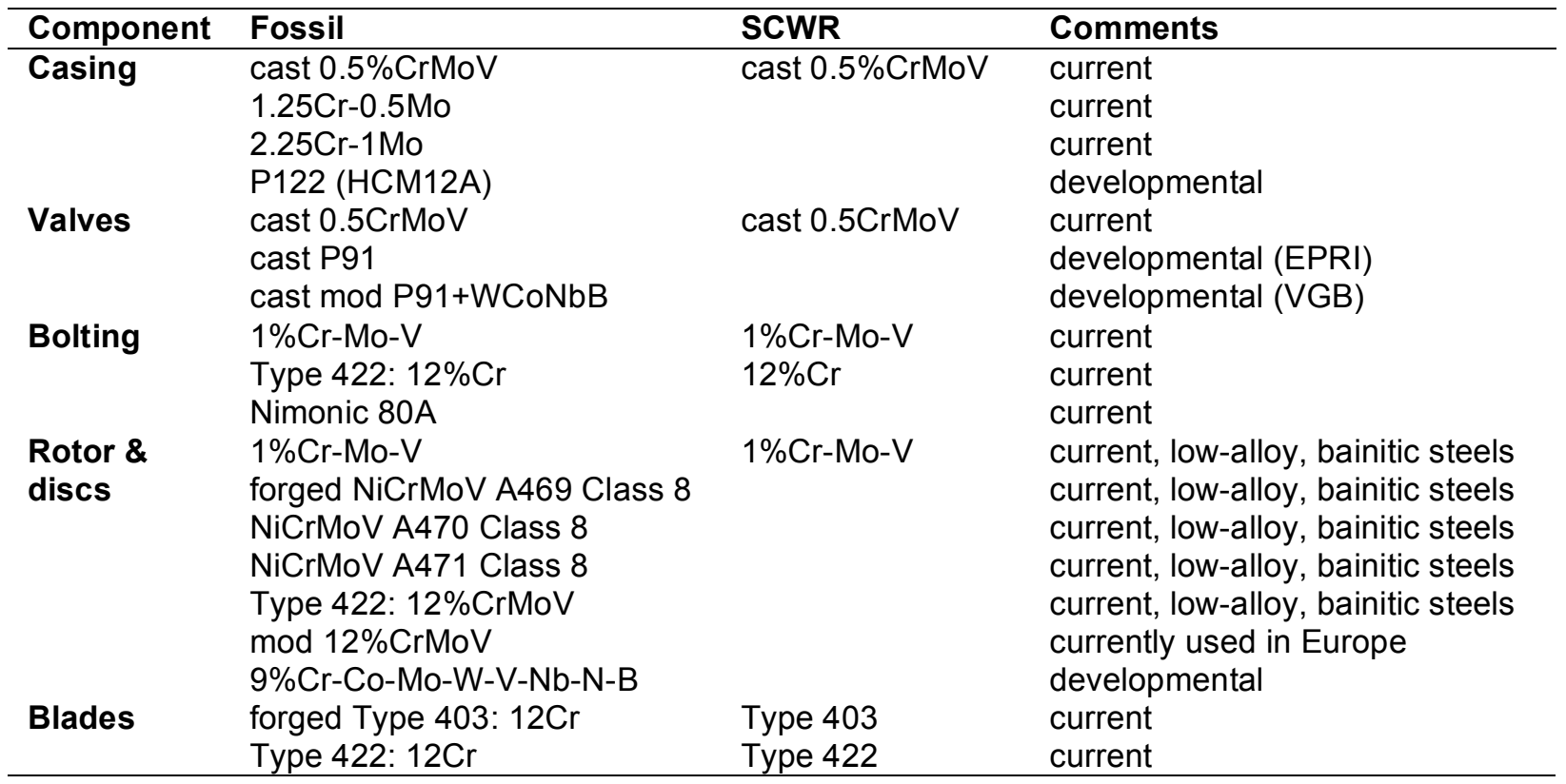

\subsubsection{Condensers}

Condensers used in LWRs and in the SCWR are of similar design to those in fossil-fired units. The exhaust from the low-pressure turbine typically enters the top of the condenser, and passes through the air removal, impingement, and condensing sections. The mode of construction follows conventional heat exchanger practice: the condenser tubes are rolled into the tube sheets and welded in place. These tubes typically are oriented horizontally in the condenser, and are supported along their lengths by various tube-support sheets.

The tubes used to handle the cooling water must resist corrosion by the cooling water itself, which may be of poorly-controlled purity, and may include seawater. Consequently, any in- 
leakage of the cooling water into the condensate can potentially lead to a rapid upset of the water chemistry. If the impurities introduced from such sources cannot be eliminated by the demineralizer and deaerator, there are likely to be very serious consequences for the whole of the water-wetted circuit.

There do not appear to be any special needs for alloy selection for the condenser in the SCWR design, as long as the water chemistry guidelines developed for the control of corrosion in supercritical fossil plants can be followed. The suggested alloy selection as is shown in Table 23.

Table 23. Summary of alloy candidates for condenser circuit.

\begin{tabular}{|c|c|c|c|}
\hline Component & Fossil & SCWR & Comments \\
\hline Condenser tubes & $\begin{array}{l}\text { Carbon steel, } \\
\text { Duplex } \\
\text { stainless } \\
\text { steels, } \\
\text { Titanium }\end{array}$ & $\begin{array}{l}\text { Carbon steel, } \\
\text { Duplex } \\
\text { stainless } \\
\text { steels, } \\
\text { Titanium }\end{array}$ & $\begin{array}{l}\text { Based on fossil experience* } \\
\text { where SCC on coolant side is } \\
\text { an issue }\end{array}$ \\
\hline Condenser body & Carbon steel & Carbon steel & Based on fossil experience ${ }^{*}$ \\
\hline Demineralizer & Carbon steel & Carbon steel & Based on fossil experience \\
\hline Deaerator & Carbon steel & Carbon steel & Based on fossil experience \\
\hline $\begin{array}{l}\text { Low pressure } \\
\text { feedwater heater }\end{array}$ & Carbon steel & Carbon steel & Based on fossil experience \\
\hline $\begin{array}{l}\text { High pressure } \\
\text { feedwater heater }\end{array}$ & Carbon steel & Carbon steel & Based on fossil experience \\
\hline Condensate pumps & F304L & F304L & Must be weldable \\
\hline
\end{tabular}

*depends on specifics of water chemistry

\subsubsection{Expected Research, Testing, and Qualification Needs for PCS Materials}

The major research activities for PCS materials will be the definition and control of water chemistry and its impact on the qualification of the candidate materials for corrosion and stress corrosion resistance in supercritical water. In the SCWR system, a major concern is the solubility of the materials that will be in contact with the fluid, and the extent that these species and/or exfoliated corrosion products will be transported to the external circuit, where they may be deposited in the turbine or be accumulated in the demineralizer. The main area of unknown is the quantification of the solubility/corrosion in the prevailing water chemistry and at the higher temperature employed in the SCWR, compared to BWR experience. The range of impurities expected in the steam in the SCWR, and the extent to which they can be controlled, are obviously questions that must be addressed in order to provide a rational basis for assessing the potential threat to the turbine of SCC and associated fatigue. This involves materials for discs and rotors, and materials for blading at temperatures up to the maximum steam temperature.

During abnormal operating conditions, the fuel cladding is expected to experience a peak temperature of up to $840^{\circ} \mathrm{C}$ for up to $30 \mathrm{sec}$, at which point the safety systems will reduce the temperature to the range $280-350^{\circ} \mathrm{C}$ in $1-2$ minutes, at least in less than 10 minutes. The SCWR turbine will be protected by immediately by-passing it when an abnormal event occurs; as a result it isn't expected for the turbine to see these high temperatures; the steam lines might see the high temperatures, but just for 1 or 2 seconds (maybe even less) before the main steam 
isolation valves close and the containment is isolated. However, it will be necessary to assess the effects of the thermal transient on the performance and degradation of the PCS materials.

Data have been developed for the typical classes of alloys used for the superheater and reheater piping employed in fossil plants upstream of the turbine to quantify the threat of solid particle erosion. The effort required will consist largely of assembling data from all available sources relating to fossil plant experience, the analytical approaches used to analyze those data, and models or algorithms developed for prediction purposes. It is realized that the available data likely will address the behavior of a few, long-established alloys, probably T-22 and Type 347/321. Nevertheless, it is expected that there will be sufficient similarity with the oxidation behavior of alloys from similar alloy classes, as well as understanding of reasons for any differences, that acceptable interpretation of the existing data will be possible for the range of alloys needed in the SCWR. However, a task has been included for the generation of data as a check on any extrapolations made for alloys different from those for which plant data are available.

\subsubsection{Experimental PCS Materials R\&D Plans}

A brief summary of R\&D plans and schedules for the SCWR PCS materials is provided below. The tasks are intended to provide the information needed to quantify the influence of supercritical steam on the corrosion, SCC, and IASCC tendencies of the materials candidates for the power conversion. Some of the information that must be generated is common to the reactor core and the external circuit and, since there is a limited capability for simulating the supercritical steam conditions, some of the testing has been amalgamated with the needs for the core components. The additional corrosion tasks listed below address the need for information to evaluate any differences in corrosion product formation, transportation, and deposition in the turbine. The tasks on solid particle erosion are intended to determine the level of assurance available for predicting the tendency for scale exfoliation, and to extend the capability to the materials of interest in the SCWR.

As it is unclear what chemical species, if any, associated with in-reactor chemistry will appear in the power conversion system. Corrosion and SCC testing of materials associated with the power conversion system in supercritical water at simulated in-reactor chemistry have not been included.

The schedule for these tasks is not well defined because it is highly contingent upon funding availability, which is not known at this time. It is, however, laid out as though the required funding would be available to meet the earliest logical schedule of the tasks identified and it will be subject to revision, based on actual funding availability.

\section{Milestones}

FY 2007

- Complete compilation of available information on solubility of candidate materials in supercritical steam

- Initiate measurements of solubility of candidate materials in supercritical steam

- Complete measurements of solubility of candidate materials in supercritical steam

- Initiate corrosion and SCC testing in supercritical water 
- Complete evaluation of factors affecting condensation and stability of corrosive species in steam turbines

FY 2008 and 2009

- Initiate corrosion and SCC testing SCWR power conversion systems materials in supercritical water

- Complete evaluation of factors affecting condensation and stability of corrosive species in SCWR power conversion systems

- Complete collection and evaluation of solid particle erosion in supercritical steam from fossil experience for SCWR applicability

- Initiate testing to predict oxide scale growth, frequency and mode of scale spallation of SCWR power conversion systems materials

FY 2010 and beyond

- Complete testing to predict oxide scale growth, frequency and mode of scale spallation

\subsection{Potential Candidate Materials Selections and Research Plans for LFR}

Three primary factors will most affect the properties and choice of the structural materials from which the LFR components will be fabricated. These are effects of irradiation, high-temperature exposure, and interactions with molten lead or lead-bismuth coolants to which materials in the primary circuit are exposed. An extensive testing and evaluation program will be required to assess the effects that these factors have on the properties of the potential materials for LFR construction to enable a preliminary selection of the most promising materials to be made and to then qualify those selected for the service conditions required.

Structural materials needs for LFR systems can be divided into five general classes, those for: cladding, reactor vessel, internals, heat exchangers, and balance of plant. For each of these classes, a variety of candidate materials exist, so the associated R\&D to assist in a more refined selection will be addressed in the following sections. Additionally, in the long term, technological advancement is expected to transition the ability of the LFR to operate from the lower temperature $\left(550^{\circ} \mathrm{C}\right)$ to the higher temperature $\left(800^{\circ} \mathrm{C}\right)$ concepts. Materials capable of higher temperature exposure will be needed to support the $800^{\circ} \mathrm{C}$ systems and these materials are likely to differ from those used at lower temperature.

Initial research efforts will concentrate on establishing the technology for lower temperature operation with a smaller effort on advanced materials for higher temperature operation. Given the modest R\&D program currently underway, the materials selection and required research for the LFR system is still in a fairly early developmental state. Updates on the potential candidate materials and required materials research for the LFR will be provided in subsequent revisions of this document.

\subsubsection{General Considerations for LFR Materials Research}

Two of the three primary considerations for LFR service, fast neutron irradiation and hightemperature exposure, are similar to considerations for NGNP and GFR Materials in this report. Irradiation-induced swelling of structural alloys at the very high fluences anticipated for LFR internal components will be a significant limitation for selection and operation of metallic materials. The third primary consideration, materials interactions with molten lead or lead- 
bismuth coolants, is unique to LFR concepts and is described below.

\subsubsection{Materials Compatibility and Corrosion with $\mathrm{Pb}$ and $\mathrm{Pb}$-Coolants in LFRs}

Materials compatibility concerns for structural metal alloys that are in contact with the coolants for the LFR will be very significant. General corrosion, thermal-gradient-induced mass transfer, and even stress corrosion cracking and liquid metal embrittlement are all potential failure mechanisms that must be addressed.

Most of the historical understanding of structural metals in a $\mathrm{Pb}$ or $\mathrm{Pb}-\mathrm{Bi}$ environment is derived from Russian programs, in which significant development was performed to understand and deploy materials and coolant chemistry control schemes for lead-alloy cooled systems. Outside of Russia, the technological readiness level of lead-alloy nuclear coolant technology is at a much earlier development stage, but the partial knowledge of the Russian experience available to the Western technical community has been factored into this materials plan. Russian leadbismuth eutectic (LBE) nuclear coolant technology relies on active control of the oxygen thermodynamic activity in LBE to control corrosion and coolant contamination. Within this framework, a series of structural materials were developed and tested in Russia for enhanced corrosion resistance and acceptable lifetime for operating temperatures below $550^{\circ} \mathrm{C}$, with fuel cladding temperature below $650^{\circ} \mathrm{C}$. Unfortunately, the most advanced Russian alloys, although similar to some Western alloys, have no direct U.S. or European counterpart.

The oxygen control technique, when properly applied, leads to the formation of "self-healing" protective oxide films on the surfaces of the materials in contact with lead-alloys. This is because the base element (typically $\mathrm{Fe}$ ) and alloying elements $(\mathrm{Cr}, \mathrm{Ni})$ of many structural materials have higher chemical affinity for oxygen than for the coolant alloy constituents. Without such protective measures, $\mathrm{Fe}, \mathrm{Cr}$ and especially $\mathrm{Ni}$ all have non-negligible solubility in lead-alloys that causes severe dissolution attacks. Oxygen sensors and control systems are thus important components of the reference coolant technology. Alloying materials with elements promoting tenacious and protective oxides (e.g. Si and $\mathrm{Al}$ ), or treating/coating the surface with appropriate materials for enhanced corrosion resistance, have been developed and tested with oxygen control. An important focus of current R\&D is to assess corrosion processes and weight loss under controlled conditions.

For materials used for operating conditions at the high end of the reference technology (above $500^{\circ} \mathrm{C}$ ), it is necessary in some cases to precondition them, i.e. pre-oxidize them so that the kinetics are favorable for growth of protective oxide film during operations. There has been little systematic evaluation and development in this area.

Temperature gradient mass transfer will likely be an important phenomenon in these systems and experiments should be designed specifically to investigate it. In a system with a temperature difference and with alloy constituents that are soluble in the coolant, it is possible to dissolve from the higher temperature regions and reprecipitate on cooler regions. Because there is a temperature gradient, equilibrium levels could never be established in the coolant, so there is an "engine" that unavoidably transfers mass from one part of the system to another. This would occur in addition to other forms of corrosion. In some liquid metal systems temperature gradient mass transfer has turned out to be the primary issue, even leading to complete blockages in some cases. Test loops with higher temperature and lower temperature sections and appropriate specimens in each region would be needed to assess this issue.

Ongoing R\&D of lead-alloy spallation target and coolant technology worldwide for accelerator driven systems (ADS) has advanced the state of the art in the West considerably. Corrosion 
tests by various international groups indicate that there are qualified structural materials (U.S., European and Japanese) for the temperature and flow conditions of the Russian reactors. However, to achieve the high potential aimed for in the advanced reactor system concepts, a significant amount of R\&D is needed in the areas of materials and coolant chemistry control.

\subsubsection{Materials for In-Core Use for the SSTAR LFR Concept}

Core materials need to have good high temperature mechanical properties and be resistant to void swelling, irradiation creep, and embrittlement. Because of the use of Pb as coolant, SSTAR has the potential to operate at higher temperatures than traditional liquid metal-cooled fast reactors. A peak cladding temperature of $\sim 650^{\circ} \mathrm{C}$ is expected. This was also the cladding temperature in Rapsodie, Phenix French fast breeder reactors (FBRs), and $620^{\circ} \mathrm{C}$ in Super Phenix nuclear power plant. Transient conditions might raise these temperatures to $\sim 1000^{\circ} \mathrm{C}$ or more. The cladding is a very thin $(1.5 \mathrm{~mm}$ in the SSTAR concept) and highly stressed component $(\sim 15 \mathrm{MPa})$. In conventional reactors, if the fuel cladding fails the fuel rods are removed and replaced. In SSTAR concept, fuel pins are integral to the core and will have a long residence time (20-30 years). Doses in the range of 150-200 dpa are expected, hence very high integrity of the cladding is required.

In the 80's, FBRs used conventional austenitic steels as core component structural materials but several effects that appeared in the FBRs fuel element subassembly (fuel pin and wrapper) relative to dimensional instabilities (bowing, dilatation, length increase) showed that it was essential to select better material candidates if high burn-up targets $(150,000 \mathrm{MWd} / \mathrm{t})$ were required. Changes in the alloy composition were made seeking to improving swelling resistance and irradiation creep behavior. This led to the development of several commercial F/M alloys (HT9, T91, MA956 and MA957 among them) and low-swelling austenitics.

In the 90's, HT9 (12Cr-1MoVW) was the original candidate ferritic alloy for fusion reactor internals. Due to better irradiation embrittlement behavior, T91 ( $9 \mathrm{Cr}-1 \mathrm{MoVNb}$ ), is now considered an alternative to HT9 for structural material applications. T91 is a modified version of $9 \mathrm{Cr}-1 \mathrm{Mo}$ steel. Here, the word modified applies to the addition of $\mathrm{Nb}$ and $\mathrm{V}$ in order to increase creep rupture strength. The allowable stresses for the modified alloy are twice that of typical $9 \mathrm{Cr}-1 \mathrm{Mo}$ alloys at temperatures of $550^{\circ} \mathrm{C}$ and above.

The LFR materials R\&D is currently focused on these F/M materials, and modifications to both composition and surfaces. A leading modification is $\mathrm{Si}$ addition to stabilize protective oxides in liquid $\mathrm{Pb}$.

\subsubsection{Cladding Materials Selection and Issues}

Cladding material for LFR systems must be compatible with metal or nitride fuel, corrosion resistant in lead or lead-bismuth coolants, and have adequate strength, ductility, toughness, and dimensional stability over the operating temperature range and to doses up to $200 \mathrm{dpa}$.

Because of the desire to operate to high dose, F/M steels are the primary candidates for cladding in the lower temperature LFR. Because of the extensive work on HT9 for the earlier LMR program, for lower temperature $\left(550^{\circ} \mathrm{C}\right.$ outlet) LFR systems, HT9 is the initial reference cladding material. However, other steels, as discussed below, offer substantial strength and toughness advantages over HT9, and will probably perform better. 
The corrosion resistance of HT9 or any other F/M steel still needs to be proven before it is chosen as the cladding. Both Russian experience and preliminary U.S. corrosion studies indicate that elevated silicon levels may be required to provide adequate corrosion resistance when using oxygen control as the method for cladding corrosion protection. Additionally, earlier U.S. work has indicated that the formation of intermetallic or nitride surface layers based on $\mathrm{Zr}$, $\mathrm{Ti}$, and/or Al may provide satisfactory corrosion resistance. If alloys with higher silicon are required, the irradiation test base must be established for the new higher silicon alloys.

\section{Material Background}

The martensitic steel HT9 was developed by Sandvik, Sandviken, Sweden, for the powergeneration industry in the 1960s. It was introduced into the U.S. fast reactor and fusion materials programs in the 1970s. However, since that time, several improved F/M steels have been developed for the power-generation industry that are significant improvements over HT9. Table 24 outlines the evolution of five generations of elevated-temperature steels over the last 60 years, beginning with $21 / 4 \mathrm{Cr}-1$ Mo steel (T22) in the 1940s.

Table 24. Evolution of ferritic/martensitic steels for power-generation industry.

\begin{tabular}{cccccc}
\hline Generation & Years & Steel Modification & $\begin{array}{c}10^{5} \text { h Rupture } \\
\text { Strength }(\mathrm{MPa})\end{array}$ & Steels & $\begin{array}{c}\text { Max-Use } \\
\text { Temperature } \\
\left({ }^{\circ} \mathrm{C}\right)\end{array}$ \\
\hline 0 & $1940-60$ & 40 & $\begin{array}{c}\text { T22, T9 } \\
\text { EM12, }\end{array}$ & $520-538$ \\
1 & $1960-70$ & $\begin{array}{c}\text { Addition of Mo, Nb, V } \\
\text { to Simple Cr-Mo } \\
\text { steels }\end{array}$ & 60 & $\begin{array}{c}\text { HCM9M, } \\
\text { HT9, HT91 } \\
\text { HCM12, T91, } \\
\text { HCM2S }\end{array}$ & 565 \\
2 & $1970-85$ & $\begin{array}{c}\text { Optimization of C } \\
\text { Nb,V }\end{array}$ & 100 & $\begin{array}{c}\text { NF616, E911, } \\
\text { HCM12A } \\
\text { NF12, } \\
\text { SAVE12 }\end{array}$ & 620 \\
4 & $1985-95$ & $\begin{array}{c}\text { Partial Substitution of } \\
\text { W for Mo and Add Cu } \\
\text { Increase W and Add } \\
\text { Co }\end{array}$ & 140 & 180 & 650 \\
\hline
\end{tabular}

For these newer steels, no historic lead corrosion data exist, and limited irradiation data exist, although it would not be expected that these steels will behave differently from steels for which more extensive data are available (HT9, EM12, FV448, 1.4914, etc.). Fairly extensive irradiation data were developed in the U.S. fusion materials program on modified $9 \mathrm{Cr}-1 \mathrm{Mo}$ (T91), a second-generation steel. The T91 showed significantly improved irradiation resistance compared to that of HT9, primarily because of the lower carbon concentration in T91. In particular, under irradiation conditions where HT9 develops an increase in the ductile-brittle transition temperature of $120-150^{\circ} \mathrm{C}$, the modified $9 \mathrm{Cr}-1 \mathrm{Mo}$ developed a shift of only $52-54^{\circ} \mathrm{C}$. For the very high neutron exposures anticipated for some LFR components, the reduced radiation sensitivity may be critical.

Other candidate materials that emerged from the fusion program include the reduced-activation $9 \mathrm{Cr}-2 \mathrm{WVT}$ Ta steel developed in the U.S. fusion materials program. Extensive irradiation testing of this steel showed still more improvement than T91 in irradiation resistance compared to HT9. These results are indications that, although HT9 can and should serve as a reference material for potential F/M steels, given the irradiation experience available, there is every indication that better steels than HT9 are available and should be exploited, if their corrosion resistance is sufficient. 
Based on the observations on the $9 \mathrm{Cr}$ steels T91 and 9Cr-2WVTa, the third-generation steel NF616 (a 9Cr-0.5Mo-1.8WVNB steel) may offer the same possibility of improved irradiation resistance plus better elevated-temperature strength than either of these two steels. One potential problem with the $9 \mathrm{Cr}$ steels is corrosion resistance, which may mean the need for a higher chromium concentration. Therefore, another third generation steel, HCM12A (a 12Cr$0.5 \mathrm{Mo}-1.0 \mathrm{WVNbN}$ steel), should be given consideration. To obtain further significant improvements in high-temperature creep strength from ferritic steels, ODS steels will likely have to be produced and evaluated (see Section 3.2.3 on SCWR RPV Internals Materials Selection and Issues for more information on ODS steels).

Qualification of any of these materials requires establishing both corrosion resistance and acceptable mechanical performance and dimensional stability. Corrosion testing of all of the F/M steels is important in increasing the potential operating temperature of LFR systems. A final possibility is to coat HT9 or another steel in a manner that provides corrosion protection but maintains the acceptable mechanical and dimensional stability performance. Coating and surface modification technology is an important component of the cladding and core internals development program and will need to be evaluated, particularly for the higher desired operating temperatures.

For significantly higher temperature $\left(800^{\circ} \mathrm{C}\right)$ applications, steels are not likely to be successful as cladding materials. For the higher temperature applications, ceramics, refractory metals, or coated refractories may be necessary. For these high-temperature candidates, the existing materials database comes from the fusion and space programs. Figure 27 outlines the currently expected operating regimes for many alloys, including the high temperature candidates, but supporting data are limited and not sufficient for qualifying a material for reactor operation. Moreover, the inclusion of materials in Figure 27 is based only on mechanical properties and dimensional stability metrics and does not consider corrosion.

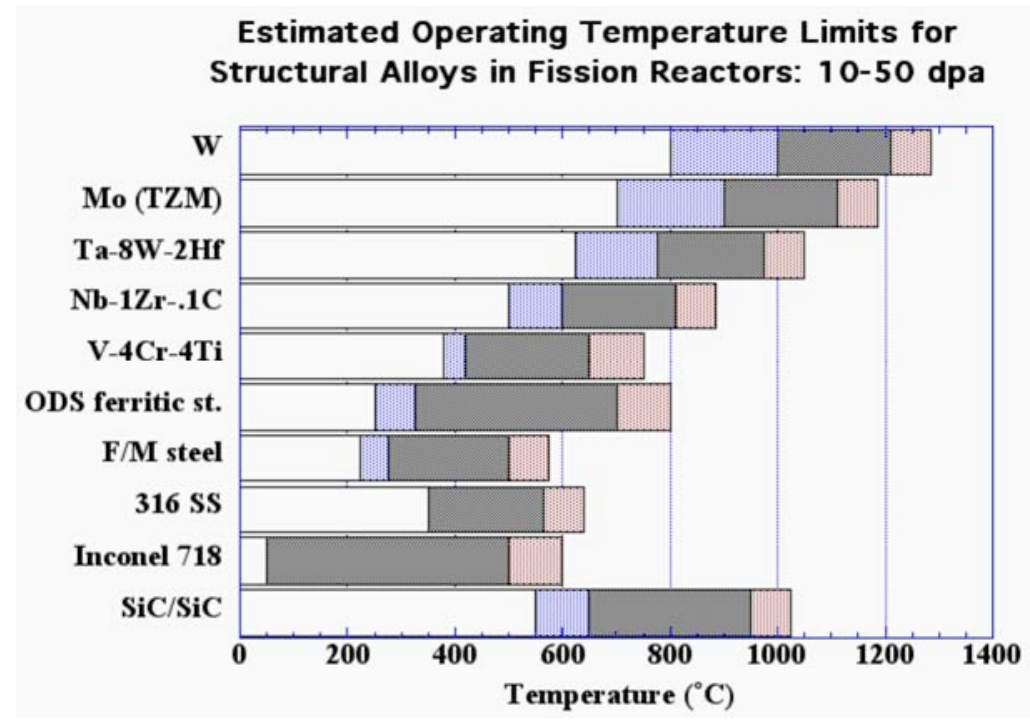

Fig. 27. Estimated temperature range of candidate alloys based on mechanical properties and dimensional stability considerations only (no corrosion consideration). 
The stippled regions represent a potential expanded operational region dependent on additional data. [from S. J. Zinkle, and N. M. Ghoniem, Fusion Engineering and Design 51-52 (2000) 5571]

Potential materials candidates for LFR cladding are tabulated in Table 25.

Table 25. Candidate alloys for LFR cladding.

\begin{tabular}{|c|c|c|c|c|}
\hline Alloy & $\begin{array}{c}550^{\circ} \mathrm{C} \\
\text { Candidate }\end{array}$ & $\begin{array}{l}>550^{\circ} \mathrm{C} \\
\text { Candidate }\end{array}$ & $\begin{array}{l}\text { Corrosion/Stress } \\
\text { Corrosion Database }\end{array}$ & $\begin{array}{l}\text { Radiation } \\
\text { Database }\end{array}$ \\
\hline HT9 & Yes & No & Incomplete & Extensive \\
\hline EP-823 & Yes & No & $\begin{array}{l}\text { Russian data partially } \\
\text { accessible }\end{array}$ & $\begin{array}{c}\text { Russian data } \\
\text { partially accessible }\end{array}$ \\
\hline SUS 444 & Yes & No & Incomplete & Incomplete \\
\hline Fe-Si alloy & Yes & Incremental & Incomplete & Incomplete \\
\hline T91 & Yes & Incremental & Incomplete & Incomplete \\
\hline $9 \mathrm{Cr}-2 \mathrm{WVTa}$ & Yes & Incremental & Incomplete & Incomplete \\
\hline HCM12A & Yes & Incremental & Incomplete & Incomplete \\
\hline HCM12 & Yes & Incremental & Incomplete & Incomplete \\
\hline NF616 & Yes & Incremental & Incomplete & Incomplete \\
\hline E911 & Yes & Incremental & Incomplete & Incomplete \\
\hline $\mathrm{N}$-modified $9 \mathrm{Cr}$ & Yes & Incremental & Incomplete & Incomplete \\
\hline Fe-base ODS & Yes & Incremental & Incomplete & Incomplete \\
\hline Alloy 800H & No & Yes (low dose) & Incomplete & Incomplete \\
\hline V-4Cr-4Ti & No & Yes & Incomplete & Incomplete \\
\hline $\mathrm{Ta}$ & No & Yes & Incomplete & Incomplete \\
\hline W & No & Yes & Incomplete & Incomplete \\
\hline SiC composite & No & Yes & Incomplete & Incomplete \\
\hline
\end{tabular}

\section{Potential SSTAR Cladding Material}

The current LFR working design (SSTAR) is considering both HT9 and T91 as potential fuel cladding, as well as modifications of these materials.

\section{Swelling Properties}

Swelling behavior has been studied for both HT9 and T91 after irradiation in EBR-II at several temperatures $420-650^{\circ} \mathrm{C}$ and doses $70-125 \mathrm{dpa}$ [3.20] and at the Fast Flux Test Facility (FFTF) at $420^{\circ} \mathrm{C}$ and $200 \mathrm{dpa}$ [3.21]. $\mathrm{HT} 9$ and $9 \mathrm{Cr}-1 \mathrm{Mo}$ swelling was compared to simple $\mathrm{Fe}-\mathrm{Cr}$ alloys that have been irradiated in EBR-II and FFTF at $425^{\circ} \mathrm{C}$ to 200 dpa [3.22]. HT9 has shown good swelling resistance: $1 \%$ swelling was reported in $\mathrm{HT} 9$ after irradiation at $420^{\circ} \mathrm{C}$ for $200 \mathrm{dpa}$. We also know that the incubation dose for swelling increases from $\sim 45 \mathrm{dpa}$ in austenitic steel to above 100 dpa in F/M steels.

Recently (2000), Garner et al., compared the behavior of fcc-austenitic and bcc-F/M alloys irradiated to high doses [3.23]. The results show that F/M can exhibit very long transient regimes of swelling prior to the onset of steady-state swelling. Also, HT9 and $9 \mathrm{Cr}-1 \mathrm{Mo}$ results are comparable with $9 \mathrm{Cr}$ alloys irradiated in FFTF, see Figure 28 taken from [3.24]. 


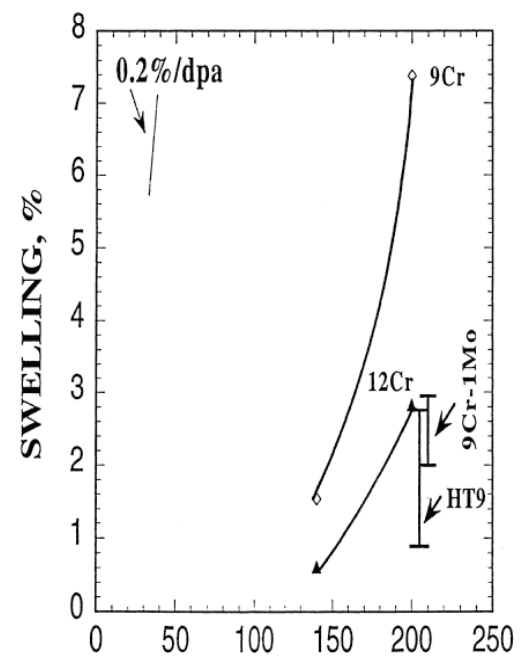

Fig. 28. Swelling observed in HT9 and $9 \mathrm{Cr}-1$ Mo steels irradiated in FFTF to 208 dpa at $\sim 400{ }^{\circ} \mathrm{C}$.

According to the current understanding, the lower swelling rate in $F / M$ steels $(0.2 \% / d p a)$, i.e. lower than that of austenitic steels $(\sim 1 \% / \mathrm{dpa})$, is currently attributed to the fact that austenitic steels have an fcc structure and void nucleation proves to be more difficult in the F/M bcc structure. These commonly held concepts have been reviewed in the same reference [3.23]. The authors conclude that: "typical solute-bearing F/M steels can exhibit very long transient regimes of swelling, especially when irradiated under well-controlled temperature conditions, (as where those of the FFTF experiments), but eventually they will swell at an accelerated rate of $\sim 0.2 \% / \mathrm{dpa}$ and possibly greater".

Also, the effect of composition (increase in the $\mathrm{Cr}$ content in the range from $0-20 \mathrm{wt} \%$ ) was investigated in the same reference [3.23]. The authors show that contrary to the current perception, "both pure $\mathrm{Fe}$ and $\mathrm{Fe}-\mathrm{Cr}$ alloys have potentially high intrinsic swelling rates that are camouflaged by very long transient regimes". Finally it is suggested that the large differences in total swelling for fcc and bcc alloys are "a consequence of the transient regimes being very much longer in the bcc metals".

The theoretical analysis is reference [3.25] shows that the lower swelling of high-nickel $\mathrm{Fe}-\mathrm{Ni}-\mathrm{Cr}$ austenitic alloys is because of a longer incubation dose for cavities than is observed in lownickel $\mathrm{Fe}-\mathrm{Ni}-\mathrm{Cr}$ alloys. There it was also pointed out that $\mathrm{F} / \mathrm{M}$ steels exhibit a long incubation dose for swelling. After incubation, they are expected to swell significantly but at lower rates than the austenitic alloys.

Active research is being conducted to develop models that interpret the results of irradiation experiments. However, as mentioned in ref [3.26] the theoretical understanding of the mechanisms responsible for swelling remains on a qualitative level. Multi-scale modeling (MMM) is required to quantify the analysis.

Research (including LFR staff collaboration) is ongoing on the development of the keystone of MMM, the Fe-Cr interaction potential. The numerical simulation of the swelling of F/M irradiated steels highly depends on the selection of this potential. This is difficult because ferritic steels have an open (body centered cubic) crystalline structure and are ferromagnetic. Bonding in bcc metals have some covalent character that is not properly described in classic potentials, and 
additionally, point defect properties (like formation energies of the various interstitials) depend on the magnetic structure that is neither included in the potentials.

Because of these complications, practically all the modeling data generated for steels is produced for idealized pure Fe with atomic potentials that do not even reproduce all the characteristics of the perfect system; in particular, they do not have the allotropic bcc-fcc transition at high temperature. A formalism is under development that is able to use a new generation of classic potentials that account for the thermodynamic properties of the system. This is a step forward to accomplish the objective of explaining the mechanisms responsible of swelling of neutron irradiated steels.

\section{Creep Properties}

Creep resistance of $\mathrm{F} / \mathrm{M}$ steels decreases above $550^{\circ} \mathrm{C}$, and the question is raised whether or not they are suitable for clad tubes. The most important property for any structural material expected to operate at elevated temperatures is thermal creep [3.27]. Creep properties of the conventional high-chromium F/M steels seem to limit the upper operating temperature to 550$600^{\circ} \mathrm{C}$. It is for this reason that at this time, the initial candidate for the cladding, F/M HT-9 steel $(12 \mathrm{Cr}-1 \mathrm{MoWV})$ is questioned, and in the future a stronger cladding material than HT9 will be assumed for the SSTAR design. This means that the fission gas plenum height will decrease from its former value.

At present, SSTAR has an active core height of $80 \mathrm{~cm}$. The fission gas plenum to active core height ratio is 3.5 , meaning that the fission gas plenum height is $2.8 \mathrm{~m}$. This value will be decreased. The argument to obtain this number is based on the fact that thermal creep damages the cladding. To prevent these cladding failures, the "Total Thermal Creep Strain Criterion" is accepted. The criterion requires that the thermal creep strain should not be $>1 \%$.

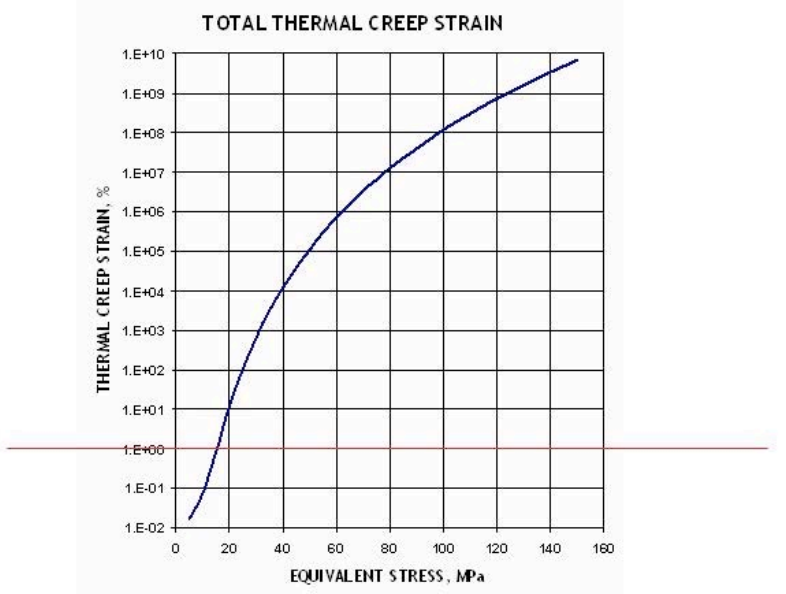

\section{Fig. 29. Strain-stress curve for HT9 F/M type steels at high $\mathrm{T} \sim 650^{\circ} \mathrm{C}$ (blue line), Total Thermal Creep Strain Criterion (red line).}

The HT9 strain-stress curve at $\sim 650^{\circ} \mathrm{C}$ shows that such a small allowable thermal creep strain limits the stress to max. $15 \mathrm{MPa}$. This translates into a large fission product (FP) gas plenum height of $\sim 2.4 \mathrm{~m}$ or larger. In Ref. [3.28], a conservative approach is used and a stress of 11 $\mathrm{MPa}$ is taken in the initial design. This stress corresponds to a plenum height of $2.8 \mathrm{~m}$ (Figure 30). 


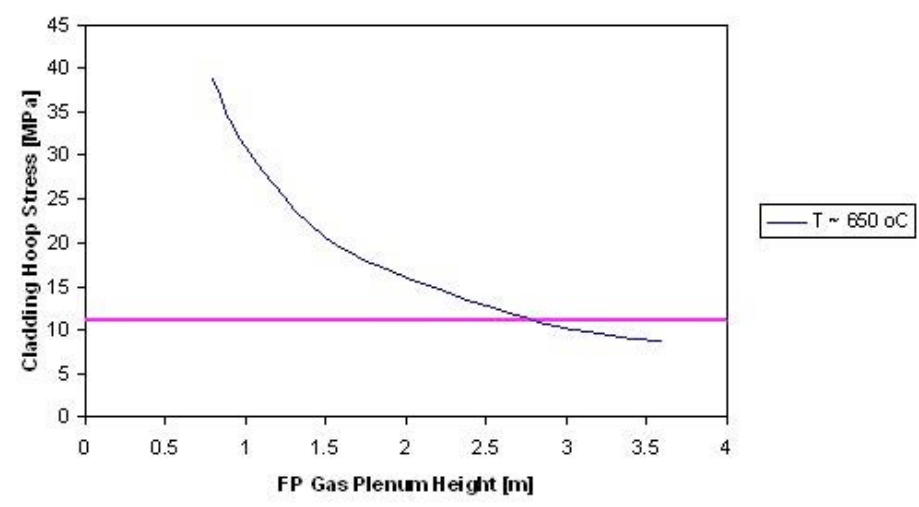

Fig. 30. Cladding hoop stress decreases with increasing plenum height (black line). Maximum Stress Value of $11 \mathrm{MPa}$ (straight line).

Therefore, development of fuel pin cladding materials and structural materials having greater strength at high temperatures is indicated in Ref [3.28]. If the SSTAR cladding temperature is to be increased to $650^{\circ} \mathrm{C}$, the creep strength of the $\mathrm{F} / \mathrm{M}$ steel must be improved. As starting point of comparison Figure 31 presents a Larson-Miller diagram for T91 [3.29]. The Larson-Miller Parameter is defined as $L M P=T(30+\log t)$ where $T$ is given in $\mathrm{K}$ and $\mathrm{t}$ is time in hours.

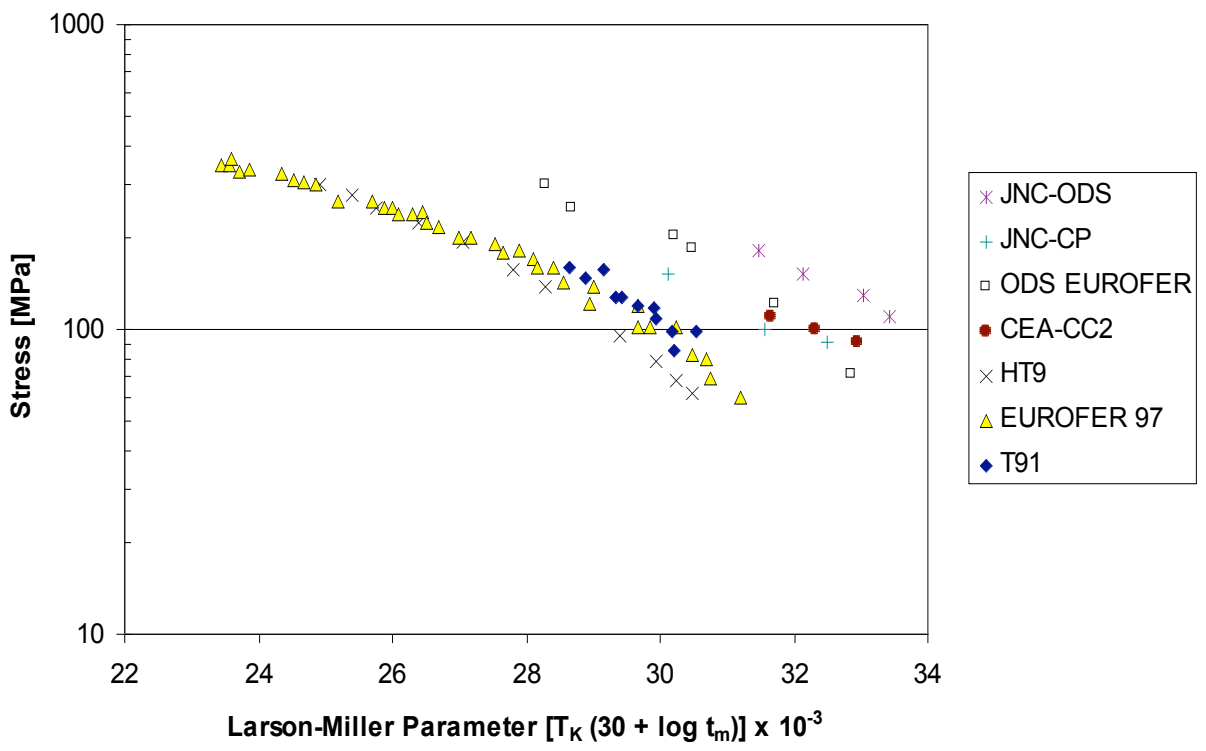

Fig. 31. Larson-Miller curve for T91 (mod. 9Cr-1Mo) as compared to other F/M steels.

Figure 31 shows results published in 2004 by Ukai et al. [3.30] of creep rupture tests of JNC-CP and CEA-CC2 claddings obtained at $700^{\circ} \mathrm{C}$, using internally helium gas pressurized specimens in the hoop stress range 90-150 MPa and rupture times up to $7000 \mathrm{~h}$. JNC-CP, CEA-CC2 types of cladding exhibit similar strength levels and the same trend of hoop stress vs. rupture time. JNC-ODS shows that the ODS F/M alloys option could be retained for the LFR materials matrix 
since it could extend the cladding operating temperature to $\mathrm{T} \sim 800^{\circ} \mathrm{C}$ [3.31]. ODS materials seem to offer greater strength at temperatures above $600^{\circ} \mathrm{C}$. This is shown in Figure 32 where ODS MA957, 12Y1 and 12YWT creep resistance are compared with that of a commercial F/M steel $9 \mathrm{Cr}-\mathrm{WMoVNb}$.

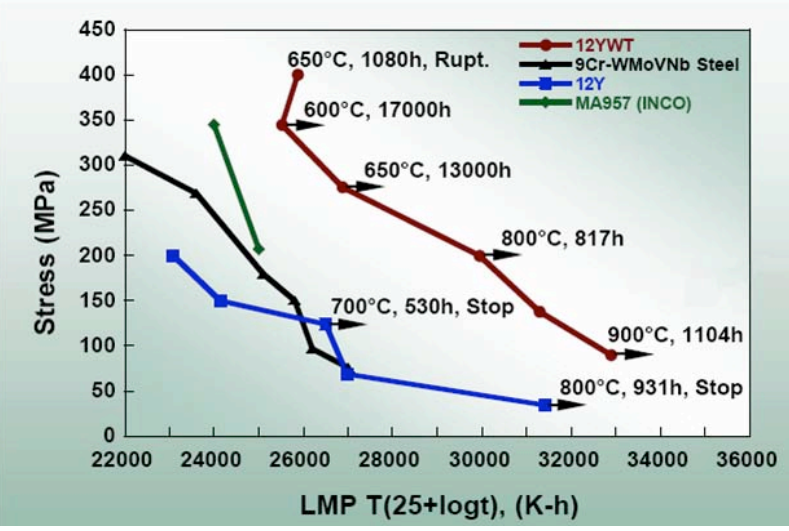

Fig. 32. Larson-Miller diagram for the creep-rupture strength of four ODS steels and a conventional F/M steel. The arrows indicate that the test is still in progress or it was discontinued prior to rupture.

ODS steel MA957 (Fe-14Cr-03.Mo-0.9Ti+0.25Y $\mathrm{Y}_{2} \mathrm{O}_{3}$ ) having greater strength was developed by the International Nickel Company (INCO) [3.31]. MA957 is a $14 \mathrm{Cr}$ ferritic steel strengthened with a fine dispersion of $\sim 5 \mathrm{~nm}$ yttrium oxide particles. This steel together with MA956 (Fe-19Cr0.33Ti-5Al-0.4Y-0.15O-0.02C) are commercial ODS steels.

ODS 12YWT (MA Fe-12Cr-3W-0.4Ti + Y2O3) alloy exhibits excellent high temperature creep strength superior to the other materials (see the upper curve in Figure 32). Note that in this case LMP $=\mathrm{T}(25+\log \mathrm{t})$.

Concerning irradiation creep, recently (2004) MA957 alloys have been shown to have better creep resistance than traditional $\mathrm{F} / \mathrm{M}$ steels above $550^{\circ} \mathrm{C}$ [3.32]. The temperature dependence of irradiation creep compliance of MA957 and HT9 during irradiation is reported in [3.32] (Figure 33). There we see that at $600^{\circ} \mathrm{C}$ the creep compliance increases while that of MA957 is roughly independent of temperature.

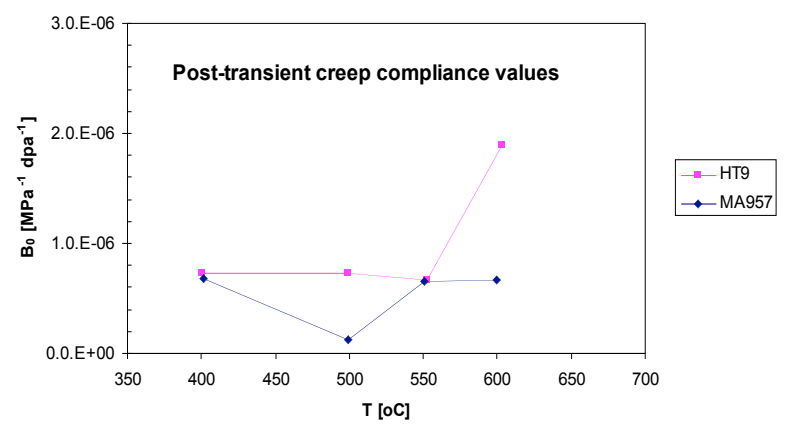

Fig. 33. Temperature-dependent irradiation creep compliance of MA957 and HT9 during irradiation. 
These are again results that were obtained from PIE of FFTF samples emphasizing the worth of that database. In fact, only a limited amount of information is currently available concerning the stability of oxide particles in ODS ferritic steels under neutron irradiation. Two experimental ODS ferritic alloys were irradiated in JOYO [3.33]. No irradiation experiments have been done to study the irradiation behavior of 12YWT alloy yet. Only one study using $3.2 \mathrm{MeV} \mathrm{Fe+ion}$ irradiation with simultaneous He injection has been performed [3.34].

Reduced creep strength is acceptable for materials that withstand low operating temperatures or low stress. The concern then becomes the toughness properties, especially small ductile to brittle transition temperatures (DBTT) shifts.

\subsubsection{Core Internals Materials Selection and Issues}

Core internals include ducts, grid plates, core barrel, and other piping. In lower temperature LFRs. these can be constructed of either F/M steels for higher dose components or austenitic stainless steels for lower dose components. Advances in structural steels will allow operating temperatures to rise above $550^{\circ} \mathrm{C}$, but steels available at present will not support $800^{\circ} \mathrm{C}$ options. The only alternative steels presently on the horizon for possible $800^{\circ} \mathrm{C}$ operation are the ODS steels (see above), but they are still in an early development stage. For the $800^{\circ} \mathrm{C}$ options, new classes of refractory metals or ceramics are likely to need to be developed. The requirements for internals are very similar to those of cladding with the exception that core internals do not have any interaction with fuel and will operate at lower temperatures and doses than the cladding.

Because transitions between F/M and austenitic materials may occur, properties of welds will also be important for some core internals applications.

For F/M components, the candidates are the same as for cladding. For austenitic components where the neutron exposure is low enough to avoid the inevitable swelling that occurs at high doses, cold-worked 316 stainless steel is the primary candidate, with 304 also a nearer term possibility. 316 and 304 have an established mechanical properties and irradiation performance databases. Corrosion resistance of 316 and 304 in lead alloy coolants still needs to be proven. If the corrosion resistance is inadequate, then a complete corrosion, mechanical properties, and irradiation performance database will need to be developed for alternate candidates. For both F/M and austenitic materials, an option would be to coat a material in such a manner that corrosion protection is afforded without loss of mechanical properties or irradiation stability.

\subsubsection{Reactor Vessel Materials Selection and Issues}

The reactor vessel for an LFR must contain the lead coolant at primary inlet temperature. It also must be seismically qualified to hold the volume of lead during operation and shipping. Finally, it must have acceptable mechanical properties over the vessel lifetime (15-20 years). The LFR operates at atmospheric pressure.

For LFR vessels, if the neutron exposure is low enough to avoid swelling, austenitic stainless steels such as 316 or 304 are primary candidates. The Experimental Breeder Reactor No.2 (EBR-II) vessel, which operated in a similar temperature and pressure regime, was built of 304 stainless steel. For pool type designs, the vessel will be in contact with the coolant at the primary inlet temperature and corrosion resistance in low flow or stagnant lead alloy must be verified. HT9 and other F/M steels could also be considered. 
The ASME codes have complete cases for only four alloys, 304, 316, 2 1/4 Cr-1 Mo steels, and Alloy $800 \mathrm{H}$. The 304,316 , and Alloy $800 \mathrm{H}$ have maximum approved temperatures in the range of $760-816^{\circ} \mathrm{C}$. Any other vessel materials or other temperatures will require additional data.

The materials selection, development, and qualification requirements for the vessel are very similar to that for cladding and core internals. Corrosion resistance must be confirmed for 304, 316 , and possibly Alloy $800 \mathrm{H}$. If these are inadequate, alternate materials or approaches must be established.

\section{Potential SSTAR Reactor Vessel Material}

The current LFR working design (SSTAR) is considering both HT9 and T91 as potential reactor vessel materials.

\section{Tensile Behavior}

Previous results [3.35] have shown that low temperature radiation hardening is important in F/M steels (T91 and $\mathrm{HT}$ ) up to $400^{\circ} \mathrm{C}$. As temperature increases hardening decreases more and more and disappears at $400-500^{\circ} \mathrm{C}$; e.g. $\mathrm{HT} 9$ and T91 show no hardening at $450^{\circ} \mathrm{C}$.

New tensile testing of HT-9 specimens from FFTF irradiation was reported at the Structural Materials AFCI Semi-Annual Meeting, September 22, 2005. The HT9 alloy composition (11.95 $\mathrm{Cr}, 0.2 \mathrm{Si}, 1.0 \mathrm{Mo}, 0.6 \mathrm{Ni}, 0.6 \mathrm{Mn}, 0.3 \mathrm{~V}, 0.2 \mathrm{C}$ ) shows a low Si content. Samples were irradiated at high temperatures in the range $373-427^{\circ} \mathrm{C}$ and to doses up to $67.5 \mathrm{dpa}$, see Table 26 below. Tensile tests were conducted at two test temperatures (room temperature and $400^{\circ} \mathrm{C}$ ). Note that the authors report no effect of test temperature on the percent increase in yield stress.

Table 26. Recent Tensile Test Results on FFTF Specimens

$\begin{array}{llcccl}\text { Alloy } & \text { FFTF MOTA/location } & \begin{array}{l}\text { Irr. Temp } \\ {\left[{ }^{\circ} \mathrm{C}\right]}\end{array} & \begin{array}{l}\text { incremental } \\ \text { dose }[\mathrm{dpa}]\end{array} & \begin{array}{c}\text { Test } \\ \text { tolal dose }\end{array} & \begin{array}{l}\text { Temperature } \\ {\left[{ }^{\circ} \mathrm{C}\right]}\end{array} \\ \text { HT9 } & \text { 2A/BCE1 } & 373 & 9.8 & 9.8 & 20,400 \mathrm{C} \\ \text { HT9 } & \text { 2A/1A3 } & 390 & 22.2 & 22.2 & 20,400 \mathrm{C} \\ \text { HT9 } & \text { 2A/3D3 } & 427 & 44 & 44 & 20,400 \mathrm{C} \\ \text { HT9 } & \text { 2A/BCE4, 2B/BCE1 } & 373,373 & 5.82,6.99 & 12.8 & 20,400 \mathrm{C} \\ \text { HT9 } & \text { 2A/1A3, 2B/1A4 } & 390,387 & 22.2,13.1 & 35.3 & 20,400 \mathrm{C} \\ \text { HT9 } & \text { 2A/3D3, 2B/2E2 } & 427,408 & 44,23.5 & 67.5 & 20,400 \mathrm{C}\end{array}$

The HT9 alloy shows very little hardening for irradiations performed at $427^{\circ} \mathrm{C}$ and very little increase in yield stress with increasing dose, see Figure 34. These preliminary results confirm that yield stress is strongly controlled by the irradiation temperature, and increases with decreasing irradiation temperature. 


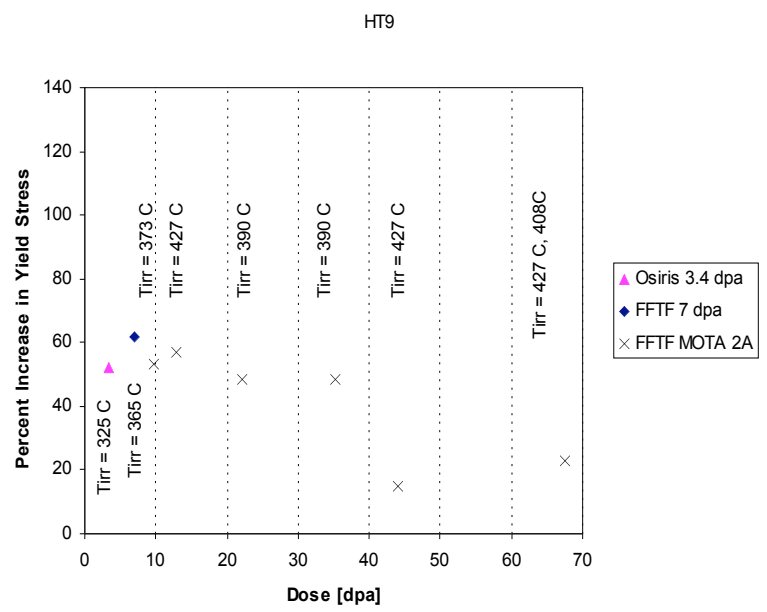

Fig. 34. Percent increase in yield stress [3.35] reported in AFCI Semi-annual Meeting for HT9 specimens irradiated in FFTF MOTA 2A experiment (cross) as compared to those obtained from previously reported results of HT9 specimens irradiated in Osiris (3.4 dpa) and Sandvik HT9 (12Cr-1MoVW) irradiated in FFTF (7dpa).

No published data exists relative to the tensile properties of HT9 irradiated with neutrons to doses higher than $10 \mathrm{dpa}$ and at temperatures in the range $300-450^{\circ} \mathrm{C}$. Most of the irradiation effects on tensile behavior were obtained from irradiation in fast reactors, where irradiation temperatures are restricted to $>360^{\circ} \mathrm{C}$. In Figure 34, we report the results of previous findings for HT9 (12Cr-1Mo-0.5WNbV) irradiated in 1998 in Osiris (3.4 dpa) and Sandvik HT9 irradiated in 1995 in FFTF (7 dpa). In the first case, HT9 (12Cr-1Mo-0.5WNbV) specimens were irradiated in Osiris Reactor (Saclay) at $325^{\circ} \mathrm{C}$ to a dose of $3.4 \mathrm{dpa}$. The yield stress in the unirradiated (485 $\mathrm{MPa})$ and irradiated condition (932 MPa) was reported by Alamo et al. [3.36] for the normalized-tempered condition (N\&T). Klueh et al. [3.37] investigated the tensile properties of Sandvik HT9 specimens with alloy composition: $12.1 \mathrm{Cr}, 0.17 \mathrm{Si}, 1.04 \mathrm{Mo}, 0.51 \mathrm{Ni}, 0.57 \mathrm{Mn}$, $0.29 \mathrm{~V}$, and $0.2 \mathrm{C}$. A yield stress value of $901 \mathrm{MPA}$ was obtained after irradiation up to a dose of $7 \mathrm{dpa}$ in FFTF at $365^{\circ} \mathrm{C}$. The yield stress reported for the unirradiated condition is $556 \mathrm{MPa}$. Both samples were tested at $0^{\circ} \mathrm{C}$. The percent increase in yield stress obtained from these results appears in Figure 34 (solid triangle and blue diamond).

HT9 Tensile

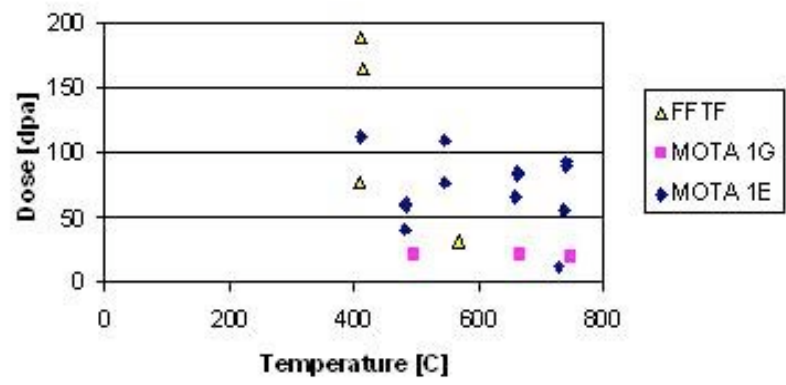

Fig. 35. Range of temperatures and doses covered by the FFTF LMR tensile database. Note the high dose (up to $200 \mathrm{dpa}$ ) achieved by the FFTF samples irradiated at $400^{\circ} \mathrm{C}$ (triangles). 
Other specimens of HT9 steel that belong to the FFTF Liquid Metal Reactor (LMR) materials irradiation database are waiting to be tested [3.38]. Figure 35 shows that HT9 tensile is well represented in the database at temperatures above $400^{\circ} \mathrm{C}$ for doses in the range 20-100 dpa and even for severe doses up to $200 \mathrm{dpa}$.

\section{Impact and Fracture Toughness Behavior}

Martensitic steels with high content of chromium are considered for the liquid metal containers of spallation targets. The main reasons are that they have high strength at elevated temperatures, low thermal stress and anticipated low liquid metal corrosion rates [3.39]. 7-9Cr martensitic steels are considered better than those with higher (10-13 wt.\%) chromium contents because of their lower DBTT shifts after irradiation. Irradiations of $9 \mathrm{Cr}-1 \mathrm{MoVNb}$, and $12 \mathrm{Cr}$ $1 \mathrm{MoW}$ steels were carried out at the FFTF [3.40].

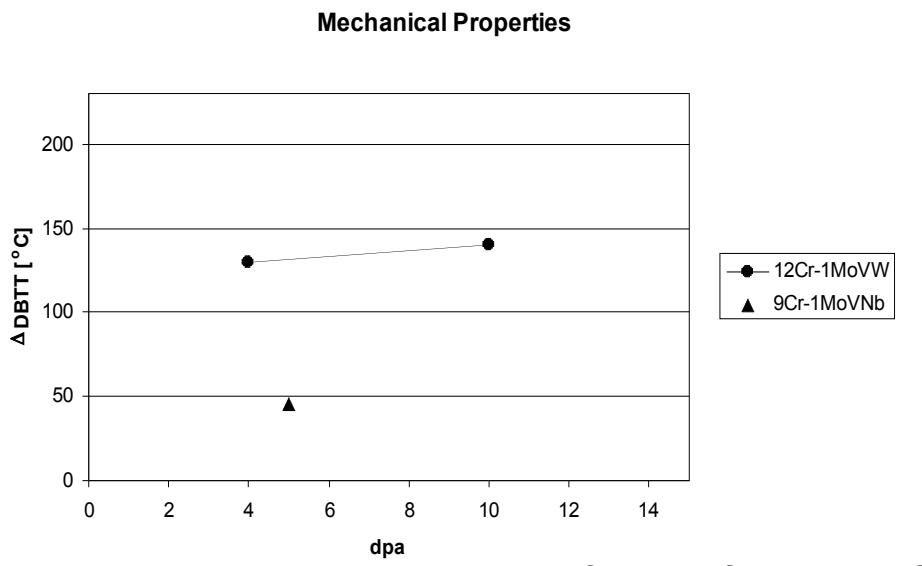

Fig. 36. Ductile-to-brittle transition temperature shift as a function of neutron dose for $12 \mathrm{Cr}-1 \mathrm{MoW}$ (circle) and $9 \mathrm{Cr}-1 \mathrm{MoVNb}$ (triangle) steels. Irradiations carried out at FFTF at $\mathrm{T}_{\text {irr }}=365^{\circ} \mathrm{C}$.

Results are reported for an irradiation temperature $\mathrm{T}_{\text {irr }}=365^{\circ} \mathrm{C}$ and neutron dose up to $10 \mathrm{dpa}$. $9 \mathrm{Cr}-1 \mathrm{MoVNb}$ (triangle) shows better embrittlement properties than 12Cr-MoVW (circle), i.e. $\triangle \mathrm{DBTT} \sim 45^{\circ} \mathrm{C}$ at $\sim 5 \mathrm{dpa}$, (Figure 36 ). DBTT decreases as irradiation temperatures increases as is illustrated in Figure 37 for T91 and HT9 steels irradiated at Phenix up to similar values of neutron dose [3.41].

T91 and HT9

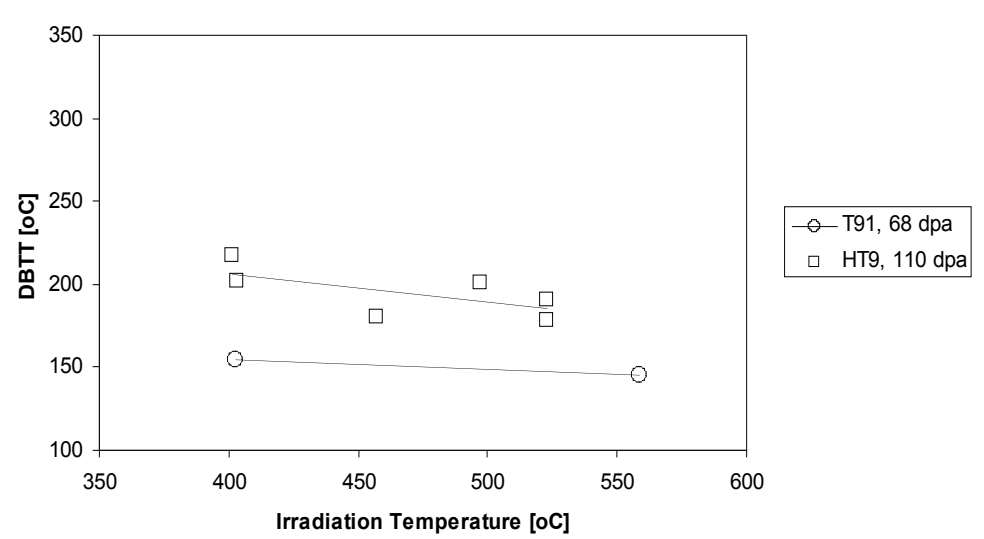

Fig. 37. Embrittlement decreases as irradiation temperature increases for both HT9 (square) and T91 (circle) steels irradiated to 68 and $110 \mathrm{dpa}$ at Phenix. 
F/M steels based on $9 \mathrm{Cr}-1 \mathrm{Mo}$ alloys have greatly improved resistance to radiation affected DBTT shifts, and are candidates to be used in reactor core regions at moderately elevated temperatures.

\section{T91 Master Curve}

Charpy impact and drop weight testing are usually utilized to assess fracture toughness of materials. Recently, fracture toughness evaluation using the Master Curve procedure has recently been accepted by ASTM and is a recommended standard since 2003 (ASTM E 192103 "Standard Test Method for Determination of Reference Temperature, $T_{0}$, for Ferritic Steels in the Transition Range").

The benefit of the Master Curve is that it gives a direct measure of the fracture toughness of the steel. This is of great value compared to Charpy tests. The ductile-to-brittle transition temperature obtained from Charpy tests depends on the initial un-irradiated condition. This is not the case for the Master Curve method.

This recently developed methodology is already being implemented to describe the fracture behavior of reactor pressure vessels of existing LWRs. This success indicates that evaluation of the Master Curve for HT9 and T91 is needed. Limited studies conducted within the crosscutting R\&D program (see Section 4.1) on materials for radiation service have indicated the behavior of T91 steel is consistent with the master curve in ASTM 1921. This also prompts the need of more fundamental understanding of the mechanisms that lie behind DBTT in F/M steels. Advances in the state-of-the-art of the field of multi-scale modeling at the atomistic and mesoscale levels (ab-initio simulations, many-body interatomic potential development, dislocation dynamics models, finite kinematics, linear elasticity, etc) will provide this understanding.

\subsubsection{Heat Exchangers Materials Selection and Issues}

Heat exchanger materials must have good corrosion resistance in lead alloy coolant, particularly given the thin sections typically employed for such applications. Corrosion test requirements are similar to those for other core components, but without the requirement for radiation resistance. The EBR-II intermediate sodium-to-secondary heat exchangers were a tube and shell type that was constructed from $21 / 4 \mathrm{Cr}-1$ Mo steel. For a Rankine cycle, the principle candidate for the primary to secondary side heat exchanger would be $21 / 4 \mathrm{Cr}-1 \mathrm{Mo}$. Like many alloys, the corrosion resistance in lead alloy coolants of $21 / 4 \mathrm{Cr}-1 \mathrm{Mo}$ is unknown and will need to be demonstrated. Higher $\mathrm{Cr}$ alloys like T91 or HT9 are potentially higher performance materials, and preferred alternatives for components that must withstand higher fast neutron fluences.

For longer-term process heat applications associated with higher temperature LFRs, an intermediate heat transport loop is probably needed to isolate the reactor from the energy converter for both safety assurance and product purity. For interfacing with thermochemical water cracking, the chemical plant fluid is $\mathrm{HBr}$ plus steam at $750^{\circ} \mathrm{C}$ and low pressure. For interfacing with turbomachinery, the working fluid options are $\mathrm{S}-\mathrm{CO}_{2}$ or superheated or supercritical steam. 


\subsubsection{Balance-of-plant Materials Selection and Issues}

For lower temperature LFRs, the energy production side is likely to be either a Rankine cycle or a Brayton cycle using $\mathrm{S}-\mathrm{CO}_{2}$ as the working fluid. No development is needed for the Rankine cycle, as this is commonly used in commercial energy production. For the Brayton cycle, an extensive development program would be necessary, as none of the turbines or recuperators have ever been built. Additionally, there is not a corrosion database for material compatibility in high temperature $\left(\sim 550^{\circ} \mathrm{C}\right)$ supercritical carbon dioxide, though this may be a common concern for the GFR. Data exists for high temperature $\mathrm{CO}_{2}$ vapor and for low temperature $\left(\sim 100^{\circ} \mathrm{C}\right)$ supercritical carbon dioxide, but nothing at higher temperatures.

\subsubsection{Expected Research, Testing, and Qualification Needs for LFR Materials}

\subsubsection{Survey and Selection of Candidate Cladding, Duct, and Structural Materials- Mechanical and Corrosion Performance}

The objectives of this area include:

- Identification of materials of construction that make the LFR concept feasible

- Early indication of materials behavior or characteristics that limit in-service conditions for LFR components

Candidate materials have been and will be continue to be selected based on literature survey and investigation of materials usage in industrial application. Materials will be screened for adequate mechanical performance, corrosion resistance, and fabricability. Testing will take place over the range of temperatures, flows, and stresses expected in the LFR system. The materials of interest will be different for the lower temperature $\left(550^{\circ} \mathrm{C}\right)$ and higher temperature $\left(800^{\circ} \mathrm{C}\right)$ versions. For long-life cores, there is a strong need for accelerated materials testing coupled with benchmarked materials performance modeling to reliably predict lifetime performance. For cladding, compatibility with lead/LBE on the coolant side and metal or nitride fuel on the fuel side is required. Weight loss under typical temperature, coolant chemistry, and coolant velocity conditions must be ascertained, as must general corrosion. Weight loss as a function of exposure time in lead alloy is required for all candidates. Stress corrosion cracking and liquid metal embrittlement resistance must be demonstrated.

\subsubsection{Lead/LBE Corrosion Testing of Candidate Cladding, Duct, and Structural Materials}

The objectives of this area include:

- Acquire corrosion performance and properties data for candidate materials of construction for support of conceptual and preliminary design efforts

- Determine corrosion-based limiting conditions of operation for selected materials

Lead/LBE corrosion properties of candidate materials will be investigated under LFR-relevant coolant conditions of chemistry, flow, and temperature. These tests will be conducted using various techniques and facilities, but most notably by using the DELTA loop at Los Alamos National Laboratory (LANL). Therefore, the testing will coordinated in a long-term experimental program that includes development of Lead/LBE technology using the loop facility. 


\subsubsection{Irradiation Testing of Candidate Cladding, Duct, and Structural Materials}

The objectives of this area include:

- Acquire irradiation performance and properties data for candidate materials of construction for support of conceptual and preliminary design efforts

- Determine irradiation properties-based limiting conditions of operation for selected materials

Candidate materials will be irradiated under fast spectrum conditions at LFR relevant temperatures and stresses. Following irradiation, materials will be evaluated to determine mechanical properties, microstructural evolution, and corrosion resistance. These efforts will be performed as part of a larger materials development and assessment activity within the Gen IV program. As part of the LFR-specific workscope, screening studies may be performed using high-energy ion beams to induce irradiation-damage microstructures in samples that can be characterized and tested for corrosion properties.

\subsubsection{High-Temperature Design Methods}

Design methods will be evaluated and extended to cover the temperature and stress regime of the LFR. Developing high temperature design methods is expected to be addressed within Crosscutting Materials R\&D.

\subsubsection{Materials Modeling}

The objectives of this area include:

- Develop mechanistic models of phenomena that control materials behavior in LFR environments

- Use mechanistic materials behavior models to better understand the phenomena that control materials behavior in LFR environments, for the purpose of informing design efforts

Advanced, mechanistically-based models for irradiation performance and corrosion of materials in Lead/LBE will be developed. These developments will need to be coordinated with related activities to be addressed in Crosscutting Materials R\&D.

\subsubsection{Experimental LFR R\&D Plans}

A brief summary of major R\&D activities for the LFR material's program is provided below.

The schedule for these tasks is not well defined because it is highly contingent upon funding availability, which is not fully known at this time. It is, however, laid out as though the required funding would be available to meet the earliest logical schedule of the tasks identified and it will be subject to revision, based on actual funding availability.

\section{Milestones}

FY 2006

- Continue LBE flow loop and bench-scale Pb/LBE corrosion testing as appropriate 
- Establish controllable range of coolant chemistry

- Continue studies of potential alloy modification, surface treatments and amorphous metals for LFR environments

- Begin corrosion and coolant chemistry testing in high temperature $\mathrm{Pb}$ flow system

FY 2007

- Develop detailed integrated LFR materials corrosion testing, evaluation and model development plan

- Complete initial assessment of mechanical and corrosion properties of primary candidate LFR materials in as-received condition

- Complete preliminary selection of primary candidate materials for LFR system

FY 2008

- Intitiate aging and irradiation assessment of primary candidate LFR materials

- Establish reference cladding design and material specifications

- Establish reference coolant chemistry and flow measurement methods

FY 2009

- Complete initial phase of aging and irradiation resistance assessment of primary candidate LFR materials

- Complete initial phase of material corrosion testing and modeling

FY 2010

- Establish Initial design database for short-term mechanical and corrosion properties of primary candidate LFR materials in as-received condition

- Issue initial LFR Materials Handbook

- Issue initial Pb/LBE Coolant Handbook

FY 2011

- Report mechanistic material modeling for LFR conditions

- Report irradiation performance for LFR conditions

FY 2012

- Report qualification testing and modeling status

FY 2013

- Report status of LFR materials qualification for prototype

- Issue revised LFR Materials Handbook

- Issue revised Coolant Handbook 


\subsection{Potential Candidate Materials Selections and Research Plans for GFR}

\subsubsection{Nonmetallic GFR Core and Reactor Internals Materials Selection and Issues}

For the purpose of this discussion, it is convenient to categorize the ceramics considered for GFR core applications as described in Table 27. These classifications are helpful when discussing materials requirements in the absence of solid design data needs such as stress levels and types of loading. The motivation for this classification is driven by the lack of robustness of the current GFR designs. It is anticipated that a palette of different high temperature materials, each having unique performance requirements, will be needed.

Table 27. Maturity of ceramics for GFR applications.

\begin{tabular}{llcc}
\hline \multicolumn{1}{c}{ Ceramics Class } & \multicolumn{1}{c}{$\begin{array}{c}\text { Performance/Data } \\
\text { Requirement }\end{array}$} & $\begin{array}{c}\text { Maturity } \\
\text { Level }\end{array}$ & $\begin{array}{c}\text { Lead-Time for } \\
\text { Preliminary Selection }\end{array}$ \\
\hline Insulating Ceramics & Low/intermediate & Mature & $3-5$ years \\
Structural Ceramics & Intermediate & Adolescent & $6-10$ years \\
Structural Composites & High & Immature & $10-15$ years \\
\hline
\end{tabular}

Another metric for discussing these materials classes, and choosing among them for GFR applications, is the required fracture toughness for the material. Most engineering alloys such as steel have extraordinary ability to resist unstable crack propagation under load, with fracture toughness values in excess of $200 \mathrm{Mpa} \cdot \mathrm{m}^{1 / 2}$. Following neutron irradiation, the fracture toughness for steels, as with most engineering alloys can significantly drop, though this is not of great concern unless the fracture toughness drops to values below about $30-50 \mathrm{MPa} \cdot \mathrm{m}^{1 / 2}$. Contrast these numbers with the fracture toughness of monolithic insulating ceramics, which have fracture toughness value on the order of $3 \mathrm{MPa} \cdot \mathrm{m}^{1 / 2}$ and its clear that special considerations in design are required. However, it is possible through incorporation of platelets, transformable phases $\left(\sim 7 \mathrm{MPa} \cdot \mathrm{m}^{1 / 2}\right)$, chopped fibers $\left(\sim 10 \mathrm{MPa} \bullet \mathrm{m}^{1 / 2}\right)$, or continuous fibers $(\sim 25-$ $30 \mathrm{MPa} \cdot \mathrm{m}^{1 / 2}$ ) to increase the fracture toughness of ceramics. In these cases, the incorporation of continuous fibers is what is being referred to as a "structural composite," with the balance of the second-phase toughened materials falling into the "structural ceramic" category. In summary, when considering the thermophysical requirements for GFR ceramics, the response of the material and choice of material may be driven by the material toughness, which will drive the timescale and cost of materials R\&D.

Insulating ceramics: This class of ceramics has a good knowledge-base for application with low mechanical performance requirements (e.g., tensile stress below $\sim 1 \mathrm{MPa}$ ) and would require the least time for qualification testing. These nonstructural ceramics might be used as spacers, electrical insulators, and/or thermal insulators in the reactor. Common commercial ceramics such as $\mathrm{CaO}$ and $\mathrm{MgO}$ are hygroscopic and therefore are not good candidates for applications which may be exposed to water vapor impurities during maintenance operations. Many of the alkali halide ceramics are highly susceptible to radiolysis from ionizing radiation with accompanying high swelling. Since residual gamma radiation would be present during cooling and heating operations, these radiolysis-sensitive ceramics would tend to crack and spall easily during service and/or maintenance operations. Radiolysis-sensitive ceramics therefore should be dismissed from consideration. Candidate monolithic ceramics with moderate radiation resistance include $\mathrm{Al}_{2} \mathrm{O}_{3}, \mathrm{MgAl}_{2} \mathrm{O}_{3}, \mathrm{Si}_{3} \mathrm{~N}_{4}, \mathrm{AIN}, \mathrm{SiC}$, and $\mathrm{ZrC}$. Required testing for GFR applications would focus on filling gaps in the existing database for thermal conductivity degradation and dimensional stability under irradiation of off-the-shelf materials. 
As will be noted in the irradiation effects section, properties will need to be generated on specific trade-named materials as there can be considerable difference in as-irradiated property changes for nominally the same materials.

Insulating ceramics may cover a wide range of application from local duct insulation to block insulation at the periphery of the active core. Insulating ceramics can be broken down into separate functional classes fibrous and monolithic insulators. For example, there are many ways to achieve insulation in a reactor vessel such as a meter of graphite $\left(\mathrm{K}_{\mathrm{th}}>10 \mathrm{~W} / \mathrm{m}-\mathrm{K}\right)$ thickness plus 0.2 meter of carbon-carbon composite blocks is sufficient to insulate the lower metallic core support structure from the core outlet gas in a HTGR. However, where room is limited to a few inches of insulation thickness to do the same job, a more efficient form of insulation may be needed. Insulation design studies have determined that the best insulation system for high temperature gas-cooled reactor application is the use of $\mathrm{Al}_{2} \mathrm{O}_{3}$ and $\mathrm{SiO}_{2}$ mixed ceramic fiber mats. These fibrous mats and the materials of construction are described for NGNP applications in Section 3.1.3.2.

Typically, monolithic thermal insulators can have very low ( $<10 \mathrm{MPa}$ ) tensile and $(<50 \mathrm{MPa})$ compressive strengths, thus their mechanical performance is quite limited. However, in contrast to fibrous thermal insulation, they will be capable of withstanding much greater loading (e.g. gravity) without significant deformation. Following the example of the previous paragraph, it would not be possible to use fibrous matting to replace thermally insulating floor blocks due to the significant compression which would occur. These monolithic ceramics typically have fracture toughness values of 1 to $5 \mathrm{MPa}-\mathrm{m}^{1 / 2}$.

Structural Ceramics: For many applications in gas-cooled reactor cores, the primary stress of concern is compressive in nature. In this case structural ceramics, or toughened monolithic ceramics, would be appropriate. Given that performance requirements for a structural ceramic are more challenging than those of insulating ceramics, and given the limited data on irradiation performance of this class of materials, irradiation performance testing for GFR applications will be longer and more extensive. This is indicated by the 6 - to 10-year lead-time associated with a fully funded development program that is suggested in Table 27 , at the end of which the material would be ready to move into a qualification program. There may be offthe-shelf materials appropriate for these applications. Candidate monolithic structural ceramics include $\mathrm{Si}_{3} \mathrm{~N}_{4}$, AIN, SiC, and ZrC. Additional candidates include whisker-, platelet-, or transformation-toughened ceramics, such as whisker or platelet-toughened $\mathrm{Al}_{2} \mathrm{O}_{3}$, $\mathrm{Si}_{3} \mathrm{~N}_{4}$, or AIN, and yttria-stabilized $\mathrm{ZrO}_{2}$. Typical fracture toughness values are 5 to $10 \mathrm{MPa}-\mathrm{m}^{1 / 2}$.

Structural Composites: For application where compressive stresses are extreme (>100 $\mathrm{MPa})$, or where tensile stresses are large $(>50 \mathrm{MPa})$ the use of structural composites consisting of woven ceramic fibers and a ceramic matrix will be required. Currently, only $\mathrm{SiC}_{f} / \mathrm{SiC}$ and $\mathrm{C}_{f} / \mathrm{C}$ composites are of sufficient maturity to be considered for application in the GFR timeframe. An example GFR application would be a control rod sleeve or perhaps the core barrel. One essential difference between this class of materials and the structural ceramics is that structural composites would be uniquely engineered for their application and are therefore not off-the-shelf products. Structural ceramic composites typically have fracture

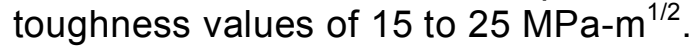

To date, $\mathrm{C}_{f} / \mathrm{C}$ 's have found only specialized use as structural materials, and $\mathrm{SiC}_{\mathrm{f}} / \mathrm{SiC}$ composites have never been used as a high-stress structural component. The limited application of these materials is due primarily to their relative immaturity, lack of design structural codes governing non-metallic materials, and a conservative approach to structural design. However, one key to improving thermal efficiency of power reactors is increasing operating temperatures above the softening point of both standard alloys and superalloys. At 
these temperatures $\left(>>900^{\circ} \mathrm{C}\right.$, ) the only materials that can be considered are refractory alloys and ceramic composites [3.42].

A primary benefit to the use of composites is the inherent ability to design the properties of the systems and their more predictable failure mechanics. For structural applications, the architecture for both $\mathrm{SiC}_{f} / \mathrm{SiC}$ and $\mathrm{C}_{\mathrm{f}} / \mathrm{C}$ will need to be three dimensional to avoid the very low inter-laminar shear stresses inherent in 2-D architecture [3.43]. However, the actual 3-D architecture can vary widely depending on the applications optimizing for strength, stiffness, or thermal conductivity in the most critical orientation. For example, control rod sleeves would likely use a spiral-weave as compared to a balanced or orthogonal weave in shroud or coreblock application. It is important to note that due to the limited understanding of the mechanical performance, irradiation behavior, and design rules, each material and architectural variant will be treated on a proof basis. In other words, each material will undergo a complete series of irradiation and performance tests to prove itself, rather than relying on limited testing in support of standard modeling.

Up to the maximum off-normal temperature assumed for the GFR $\left(\sim 1500^{\circ} \mathrm{C}\right)$, neither $\mathrm{SiC}$ or graphite fiber composites exhibit significant degradation in mechanical properties (excluding oxidation effects.) Both materials have similar decreases in thermal conductivity with temperature, though graphite composites have significantly higher absolute thermal conductivity. The main differences between the systems is the relative maturity of manufacture of the $\mathrm{C}_{f} / \mathrm{C}$ system, allowing more design flexibility and lower cost, and the relative insensitivity to irradiation of the $\mathrm{SiC}_{f} / \mathrm{SiC}$ system at temperatures $300-1000^{\circ} \mathrm{C}$. Because $\mathrm{SiC}$ composite manufacture is less mature than $\mathrm{C}_{f} / \mathrm{C}$, the determining factor in selecting the system is essentially economic, related to the up-front cost on deploying $\mathrm{SiC}_{\mathrm{f}} / \mathrm{SiC}$ balanced with the potential benefit of a longer-lived or lifetime component.

\subsubsection{Expected Research, Testing, and Qualification Needs for Nonmetallic GFR Core and Reactor Internals Applications}

Insulating Ceramics-The primary work in this area will be the determination of the dimensional stability of select commercially available insulating ceramics under GFR appropriate fission neutron irradiation conditions. It is not expected that there will be a spectrum effect on the swelling of these materials except for nitride ceramics, which have enhanced gas production in mixed-spectrum reactors due to a high thermal neutron cross section for gas production by ${ }^{14} \mathrm{~N}$. Therefore, any materials test reactor capable of high-temperature irradiation could be employed for initial scoping studies of non-nitride ceramics.

Structural Ceramics-In association with reactor design specialists, a program to accurately determine the mechanical properties of select structural ceramics with particular emphasis on the statistical nature of failure should be carried out. In addition, an irradiation program will be required to determine the effect of high temperature neutron irradiation on standard thermophysical properties as well as non-standard tests such as creep and fracture toughness. Depending on the coolant system selected, an environmental effects program will be required to study corrosion and grain boundary effects leading to mechanical property degradation.

Structural Composites-A comprehensive program including processing of structural composites of appropriate architecture and composition for GFR application will be required. In parallel, a high-dose irradiation campaign must be carried out to determine not only the mechanical property changes under irradiation but also the swelling and thermal conductivity of 
structural composites under irradiation. In parallel, a committed ASTM standards development activity will be required to appropriately set standards for testing.

Carbon-Carbon Composites $-\mathrm{C}_{f} / \mathrm{C}$ composites will be heavily evaluated for use as structural materials for the NGNP. The primary difference between the $\mathrm{C}_{f} / \mathrm{C}$ composites applications in the GFR and the NGNP is that the GFR $C_{f} / C$ components will be limited to usage well outside to core to minimize excessive moderation, but even so, they will see significantly higher fluences. Hence, the only additional scoping research required for the GFR must address limits of neutron exposure applicable to $\mathrm{C}_{f} / \mathrm{Cs}$ at the temperature of operation and limited studies to ensure the radiation in a fast spectrum is not significantly different than existing data base developed primarily in a thermal reactor spectrum.

Regulatory and Codification Requirements-An ASME code for composites used under GFR core conditions has not been developed. However, it is not clear that any codes will be required. General requirements for regulatory and codification requirements that may be needed for the GFR will be developed under the NGNP program. These may need to be extended to the more extreme conditions of the GFR, but not during the scoping phase of research.

Manufacturing Infrastructure Required-A mature manufacturing infrastructure for the advanced radiation-resistant $\mathrm{SiC}_{\mathrm{f}} / \mathrm{SiC}$ composites that will likely be used for the GFR does not exist at this time. Exploration of the path to developing this infrastructure will need to be examined during the scoping phase of GFR materials research.

\subsubsection{Experimental Ceramics Core and Internals R\&D Plans}

The development tasks for this area of R\&D are contained in Table 28. These are tasks necessary to prove the viability of a few materials in each class. The schedule for these tasks is not well defined because it is highly contingent upon funding availability, which is not fully known at this time. It is, however, laid out as though the required funding would be available to meet the earliest logical schedule of the tasks identified and it will be subject to revision, based on actual funding availability. Once this proof of principal is completed, a set of candidate ceramics materials can be recommended with a high degree of confidence for a follow-on development phase.

Specifically, assessments of the materials compatibility of insulating and structural ceramics as well as ceramic and carbon composites will be made with helium and $\mathrm{S}-\mathrm{CO}_{2}$ environments. Mechanical and thermophysical properties screening studies as a function of irradiation will be performed, including standards formulations for testing of the structural composites. This work will begin as soon as adequate funding is available with the evaluation of irradiation on core ceramic materials using ion irradiations. In FY05, a set of specimens prepared from numerous candidate materials was prepared for inclusion in the Futurix-Ml high-dose, fast-spectrum neutron irradiations to be performed in the Phenix reactor. Their irradiation to $\sim 40 \mathrm{dpa}$ at $1000^{\circ} \mathrm{C}$ will be complete before the Phenix reactor shuts down in 2009.

\subsubsection{Metallic GFR Core and Reactor Internals Materials Selection and Issues}

Because the core operates at such high temperatures in normal conditions, and significantly higher temperatures during thermal excursions in accidents, ceramics are the prime candidates for core internals. However, based on their high temperature capabilities, refractory alloys could also be considered as alternates, but only if the oxygen content in the system can be 
maintained well below $\sim 1 \mathrm{ppm}$. In general, currently available refractory alloys are extremely susceptible to oxidation even at that level [3.44,3.45]; it is understood that the technology is not currently available to maintain oxygen to such low levels in such a system as the GFR. Cermets or intermetallic structures have also been suggested. It may be possible to eventually develop very high temperature versions of more conventional alloys based on Fe-Cr-Ni systems with greatly improved microstructural stability under severe temperature excursions. For example, ODS F/M alloys have shown very good creep resistance at temperatures above $800^{\circ} \mathrm{C}$, and good structural stability up to $1300^{\circ} \mathrm{C}[3.46,3.47]$.

The normal operating temperatures for the three primary out-of core internals components range from $490^{\circ} \mathrm{C}$ to $850^{\circ} \mathrm{C}$ for the reference design. For the lower support plate, the lowswelling austenitic stainless steels and advanced versions of the $8-9 \mathrm{Cr} \mathrm{F} / \mathrm{M}$ steels are viable classes of candidate materials, depending upon design loading conditions. However the higher maximum temperatures for the upper support plate and core barrel $\left(850^{\circ} \mathrm{C}\right)$ are beyond the operating capabilities of these materials, and for these applications it will be necessary to turn to the Ni-base alloys for the required high temperature strength and dimensional stability or to ODS versions of the ferritic and F/M steels produced by mechanical alloying. For alternate designs 1 and 2, where the outlet temperatures are $300 \mathrm{~K}$ and $200-250 \mathrm{~K}$, respectively, below the outlet for the reference design, the normal operating temperatures for all three out-of-core components range from $300^{\circ} \mathrm{C}$ to $650^{\circ} \mathrm{C}$. In all three cases, the advanced austenitic stainless steels, designed for swelling resistance, and the advanced version of the $8-9 \mathrm{Cr} F / \mathrm{M}$ steels provide a group of viable candidate materials.

The preliminary estimates for off-normal transient conditions are of concern and the possible frequency and duration of various off-normal scenarios will require further evaluation since these parameters could strongly affect material selection. For the F/M steels, significant excursions above $\sim 900^{\circ} \mathrm{C}$ could lead to serious embrittlement through an austenite to martensite transformation. Similar temperature excursions for the austenitic steels could lead to the destruction of the steady-state swelling-resistant microstructure and subsequent rapid swelling. The Ni-based superalloys are potentially better able to withstand high temperature excursions and therefore should also be considered for each of these applications. However even these alloys may undergo incipient melting at temperatures as low as $\sim 1200^{\circ} \mathrm{C}$, and there are significant concerns about radiation-induced grain boundary embrittlement of $\mathrm{Ni}$-base superalloys at temperatures above $500^{\circ} \mathrm{C}$ for damage levels above a few dpa. More detailed information on the austenitic stainless steels and F/M steels for reactor applications may be found in a recent report on the survey of materials requirements for the SCWR [3.2]. The application of Ni-base alloys for out-of-core components has recently been discussed in detail in the materials selection and qualification report for the NGNP [3.1]. 
Table 28. Schedule and summary costs for GFR core and internals ceramics research.

\begin{tabular}{|c|c|c|c|c|c|c|}
\hline Task & FY06 & FY07 & FY08 & FY09 & FY10 & FY11 \\
\hline \multicolumn{7}{|l|}{ Insulating Ceramics } \\
\hline Dimensional Stability Under Irradiation & & & $X X X$ & $X X X$ & $X X X$ & $X X X$ \\
\hline Environmental Effects & & $X X X$ & $X X X$ & $X X X$ & $X X X$ & $X X X$ \\
\hline \multicolumn{7}{|l|}{ Structural Ceramics } \\
\hline Mechanical \& Physical Properties Tests & & $X X X$ & $X X X$ & $X X X$ & $X X X$ & $X X X$ \\
\hline $\begin{array}{l}\text { Thermal/Dimensional Properties Under } \\
\text { Irradiation }\end{array}$ & $X X X$ & $X X X$ & $X X X$ & $X X X$ & $X X X$ & $X X X$ \\
\hline Environmental Effects & & $X X X$ & $X X X$ & $X X X$ & $X X X$ & $X X X$ \\
\hline \multicolumn{7}{|l|}{ Ceramic Composites } \\
\hline $\begin{array}{l}\text { High Dose Thermomechanical and } \\
\text { Dimensional Properties }\end{array}$ & $X X X$ & $X X X$ & $X X X$ & $X X X$ & $X X X$ & $X X X$ \\
\hline Processing and Properties & & $X X X$ & $X X X$ & $X X X$ & $X X X$ & $X X X$ \\
\hline Environmental Effects & & $X X X$ & $X X X$ & $X X X$ & $X X X$ & $X X X$ \\
\hline ASTM Standards Development & & $X X X$ & $X X X$ & $X X X$ & $X X X$ & $X X X$ \\
\hline \multicolumn{7}{|l|}{ Carbon Composites } \\
\hline $\begin{array}{l}\text { Baseline Materials Testing and } \\
\text { Characterization }\end{array}$ & & $X X X$ & $X X X$ & & & \\
\hline Full Scale Testing and Verification & & & & $X X X$ & $X X X$ & \\
\hline Irradiated Materials Evaluations & $X X X$ & & $X X X$ & $X X X$ & $X X X$ & $X X X$ \\
\hline Environmental Effects & & $X X X$ & $X X X$ & $X X X$ & $X X X$ & $X X X$ \\
\hline ASTM Standards Development & & $X X X$ & $X X X$ & $X X X$ & $X X X$ & $X X X$ \\
\hline
\end{tabular}

\subsubsection{Expected Research, Testing, and Qualification Needs for Metallic GFR Core and Reactor Internals Applications}

Although the initial approach to the reference design for in-core structures will be based upon the application of ceramic materials, a review of the current status of selected refractory metal alloys will be carried out with emphasis on mechanical and oxidation behavior and radiation effects. It will then be possible to evaluate possible R\&D approaches to developing refractory metal alloys for applications in the reference GFR environment. 
Metallic materials for the reactor internals will be reviewed comprehensively. This review will build heavily on a similar review for the NGNP. The existing database for those alloys will be assembled, analyzed, and evaluated with respect to the design and operating requirements presented above. Of particular importance is the review of the irradiation performance data for each of the three main alloy classes. Based upon this review, a limited set of candidate advanced austenitic steels and F/M steels will be defined. Additional property measurement and testing will be carried out on these materials to cover specific aspects of the GFR environment for which the existing database may be inadequate. Examples of this are: determination of (1) the effects of long-term exposure to $\mathrm{S}-\mathrm{CO}_{2}$ on mechanical behavior, (2) long-term structural stability at GFR temperatures, and (3) the impact of off-normal temperature excursions on structure and properties. Irradiation experiments will be designed and carried out to complement and expand the existing database to cover the projected GFR conditions.

The Ni-base alloys present a different situation since every known set of irradiation data has indicated the potential for high-temperature grain boundary embrittlement. Additional mechanical property assessment for Ni-base alloys, beyond what is already planned for the NGNP, is unwarranted until feasible approaches to solving the grain-boundary embrittlement problem have been demonstrated. Following an in-depth review of the available data and the possible mechanisms involved, low-dose irradiation experiments will be conducted on a series of modified and exploratory alloys to investigate compositional/microstructural strategies to mitigate high temperature embrittlement.

The development of nano-structured alloys fabricated by mechanical alloying presents a promising approach to expanding the high-temperature capability in terms of both creep and swelling resistance and oxidation behavior. It is proposed to evaluate existing ODS materials and, if warranted, initiate R\&D on the design and fabrication of exploratory new materials, both $\mathrm{Fe}$ and Ni-based, specifically designed to meet the more challenging aspects of the GFR environment primarily through a collaborative program with on-going research efforts in this area.

Another promising technique for improving high-temperature metallic materials performance is grain boundary engineering, specifically restructuring the grain boundary character distribution to limit high temperature creep. The application of this technique to austenitic, F/M, and Ni-base alloys may prove useful in improving the ability of metallic materials for use in the GFR.

Materials deemed appropriate for use at temperatures and radiation doses of the GFR will be exposed in $\mathrm{S}-\mathrm{CO}_{2}$ in the temperature range 350 to $1250^{\circ} \mathrm{C}$ for times of up to $10,000 \mathrm{~h}$. These tests will establish reaction kinetics, corrosion allowance, and effect on mechanical properties. It is anticipated that even in the absence of graphite in the core, a helium environment can be established that is within the range of previous test environments. If this cannot be achieved, testing in the proposed helium similar to that stated for $\mathrm{S}-\mathrm{CO}_{2}$ will be required. In addition, the stability of the proposed helium environment will need to be established.

\subsubsection{Experimental Metallic Core and Internals R\&D Plans}

A comprehensive assessment of the current status of advanced austenitic stainless steels and F/M steels will be carried out focusing on materials with proven potential for swelling resistance and satisfactory high temperature mechanical behavior. A limited set of selected materials will form the basis of a program to evaluate mechanical behavior, long-term microstructural stability and radiation resistance, focusing on pertinent GFR conditions. Following an evaluation of the radiation effects data base on $\mathrm{Ni}$ alloys, low dose neutron irradiation experiments will be carried 
out to assess various strategies for reducing the susceptibility to grain boundary embrittlement. The potential application of refractory metal alloys will be assessed and work carried out to investigate the potential for current and improved nano-structured $\mathrm{Fe}$ - and Ni-base alloys with properties specifically tailored to GFR conditions. Table 29 provides a summary of the required research tasks to evaluate GFR metallic internals.

The schedule for these tasks is not well defined because it is highly contingent upon funding availability, which is not fully known at this time. It is, however, laid out as though the required funding would be available to meet the earliest logical schedule of the tasks identified and it will be subject to revision, based on actual funding availability.

Table 29. Schedule and Tasks for GFR metallic internals research.

\begin{tabular}{|l|c|c|c|c|c|c|}
\hline \multicolumn{1}{|c|}{ Task } & FY06 & FY07 & FY08 & FY09 & FY10 & FY11 \\
\hline Refractory metal alloys assessment & & $X X X$ & $X X X$ & & & \\
\hline $\begin{array}{l}\text { Assess advanced austenitic and F-M steels } \\
\text { and Ni alloys; select candidate alloys }\end{array}$ & & $X X X$ & $X X X$ & & & \\
\hline $\begin{array}{l}\text { Determine baseline mechanical properties } \\
\text { and long term microstructural stability }\end{array}$ & & $X X X$ & $X X X$ & $X X X$ & & \\
\hline $\begin{array}{l}\text { Assess environmental effects on mechanical } \\
\text { properties of candidate alloys }\end{array}$ & & & $X X X$ & $X X X$ & $X X X$ & $X X X$ \\
\hline $\begin{array}{l}\text { Assess irradiation effects on candidate } \\
\text { advanced austenitic and F/M steels }\end{array}$ & & $X X X$ & $X X X$ & $X X X$ & $X X X$ & $X X X$ \\
\hline $\begin{array}{l}\text { Assess irradiation effects on candidate } \\
\text { radiation-resistant nickel-based materials }\end{array}$ & & $X X X$ & $X X X$ & $X X X$ & $X X X$ & $X X X$ \\
\hline $\begin{array}{l}\text { Assesement and development of Fe, Ni and } \\
\text { RM base nano-structured materials }\end{array}$ & & $X X X$ & $X X X$ & $X X X$ & $X X X$ & $X X X$ \\
\hline
\end{tabular}

\subsubsection{RPV Materials Selection and Issues}

Based on the currently estimated operating temperatures, $9 \mathrm{Cr}-1 \mathrm{Mo}$ steel would be the most likely candidate pressure vessel material for the GFR, if design and construction were to begin today. However, given the lead time available before material selection is anticipated for the GFR system, materials research and development efforts with other ferritic materials should be a definitive part of the GFR program. Even for the NGNP, for which the lead time is very short, it is anticipated that further developments with variations in the modified $9 \mathrm{Cr}-1 \mathrm{Mo}$ class of F/M steels will provide a material with superior high-temperature creep strength than currently available. In the case of the GFR system, the research and development program should incorporate more advanced materials in the overall class of F/M steels, some of which are currently in progress. For example, advances in dispersion strengthened alloys and ongoing research with nitrogen modified steels are indicating significant promise for extension of adequate creep strength to temperatures of about $800^{\circ} \mathrm{C}$. Alternate pressure vessel materials such as Fe-3Cr-3WV steel should also be considered and some of these materials are discussed in more detail in a later section.

\subsubsection{Expected Research, Testing, and Qualification Needs for GFR RPV}

A comprehensive and detailed review of the potential candidate materials for the RPV system will be performed. This review will build heavily on a similar review for the NGNP but will 
examine the materials with respect to the different operating temperatures and much higher radiation doses associated with the GFR RPV. The existing database for those alloys will be assembled, analyzed, and evaluated with respect to the design and operating requirements presented above that are different that the NGNP. Use of other advanced materials will be evaluated.

A baseline materials test program will be conducted that augments the evaluation of all the basic mechanical and physical properties, and microstructural characterization anticipated for the NGNP program. The properties needed for all the various materials are essentially the same for all three GFR design concepts, with the exception of the $\mathrm{S}-\mathrm{CO}_{2}$ direct design which requires additional considerations. As mentioned earlier, this design is of much higher pressure and will require a significantly thicker vessel with the concomitant issues of fabricability, both with respect to through-thickness properties and welding. Moreover, this design presents a more aggressive environmental situation with regard to corrosion/oxidation of materials and additional creep testing in the anticipated environment will be required. Thus, especially in this case, the environmental issues will require substantial evaluation.

Because of the $60 \mathrm{y}$ design life, thermal aging is a significant issue for the GFR, as it is with the NGNP. Thus, as with the NGNP research plan, thermal aging experiments will be required to obtain data not currently available. Although there is some temperature overlap with the NGNP, it is not comprehensive and additional experiments will be required specifically for the GFR.

The anticipated radiation exposure for the GFR RPV is significantly higher than that for the NGNP. Most of the F/M steels discussed earlier have good radiation resistance to embrittlement and swelling in the anticipated temperature regime and to the anticipated radiation dose. However, specific radiation experiments will be required at the specific design conditions to validate that information for the designers and for the regulatory authority. As a first step, a detailed review will be conducted of irradiation effects on all the potential candidate alloys mentioned above. An experimental program will be designed based on the results of the review and irradiations of preliminary candidate materials will begin once an irradiation facility is identified. In addition to irradiation of the currently identified materials, selected advanced materials will be included. For purposes of this plan, specimens to be irradiated will include those for tensile, creep, and stress rupture, Charpy impact, and fracture toughness. In the case of an RPV without heavy shielding against radiation, irradiations would be conducted in a highflux facility to attain the necessary dose $(\sim 15 \mathrm{dpa})$ in a reasonable time. For the use of standard $21 / 4 \mathrm{Cr}-1$ Mo steel, some shielding (e.g., tungsten) would be required to decrease the dose to below about $0.1 \mathrm{dpa}$, and a low flux irradiation facility would be more appropriate to obtain the necessary data.

\subsubsection{Experimental Reactor Pressure Vessel Materials R\&D Plans}

Although many of the research needs for the GFR RPV will be undertaken within the research scope of the NGNP, there are some differences between the operating conditions that will require GFR-specific research. Moreover, there are significant uncertainties regarding those conditions for the three different GFR designs, primarily related to the greater radiation exposure of the vessel materials. Most of the F/M steels being considered have good radiation resistance in the anticipated temperature regime and to the anticipated radiation dose. However, specific radiation experiments will be required at the specific design conditions to ensure that the potential candidate materials will perform adequately under GFR conditions. Table 30 provides a summary of the required research tasks to evaluate GFR RPV internals. 
The schedule for these tasks is not well defined because it is highly contingent upon funding availability, which is not fully known at this time. It is, however, laid out as though the required funding would be available to meet the earliest logical schedule of the tasks identified and it will be subject to revision, based on actual funding availability.

\subsubsection{High Temperature Metallic Components Materials Selection and Issues}

Based on the operating conditions of GFR and ongoing efforts made in NGNP materials selection, two groups of metallic materials are recommended as primary and secondary candidates, respectively, for high temperature metallic GFR components.

The primary potential candidate materials for high-temperature balance of plant components other than the power conversion system are listed in Table 31 with brief status information. Among these materials, Inconel 617 is considered as a leading candidate. The material was developed in the earlier gas-cooled reactor projects, and could be applied. Alloy $800 \mathrm{H}$ is in Subsection $\mathrm{NH}$, and would be the leading candidate for the intermediate temperature range of $600-760^{\circ} \mathrm{C}$. The $316 \mathrm{FR}$ stainless steel has not has the significant advantage in the United States

Table 30. Schedule and tasks for GFR RPV research.

\begin{tabular}{|l|l|l|l|l|l|l|}
\hline \multicolumn{1}{|c|}{ Task } & FY06 & FY07 & FY08 & FY09 & FY10 & FY11 \\
\hline Baseline Materials & & $X X X$ & $X X X$ & $X X X$ & & \\
\hline Aging & & $X X X$ & $X X X$ & $X X X$ & $X X X$ & $X X X$ \\
\hline Irradiation Effects & & $X X X$ & $X X X$ & $X X X$ & $X X X$ & $X X X$ \\
\hline
\end{tabular}

of having gone through ASME Code deliberations that culminated in the draft Code case, and the body of experts that developed the case simultaneously identified what must be done before the Code case in Subsection $\mathrm{NH}$, but the database is adequate to incorporate the steel should the need arise. The Gr91 and Gr22 (Class 1) steels are currently in Subsection NH.

Table 31. Primary potential candidate materials for high-temperature metallic GFR components.

\begin{tabular}{llllllll}
\hline $\begin{array}{l}\text { Primary } \\
\text { Candidates }\end{array}$ & $\begin{array}{l}\text { Nominal } \\
\text { Composition }\end{array}$ & $\begin{array}{l}\text { UNS } \\
\text { Number }\end{array}$ & $\begin{array}{l}\text { Existing } \\
\text { Data } \\
\text { Max } \\
\text { Temp. }{ }^{\circ} \mathrm{C}\end{array}$ & $\begin{array}{l}\text { Helium } \\
\text { Experience }\end{array}$ & $\begin{array}{l}\text { Aging } \\
\text { Experience }\end{array}$ & $\begin{array}{l}\text { Section II } \\
\text { Physical } \\
\text { Props }\end{array}$ & $\begin{array}{l}\text { Design } \\
\text { Codes }\end{array}$ \\
\hline Inconel 617 & $\begin{array}{l}\text { 45Ni-22Cr- } \\
\text { 12Co-9Mo }\end{array}$ & N06617 & 1100 & Yes & Yes & No & Yes \\
Incoloy $800 \mathrm{H}$ & $33 \mathrm{Ni}-42 \mathrm{Fe}-21 \mathrm{Cr}$ & & 1100 & Yes & Yes & Yes & Yes \\
$316 \mathrm{FR}$ & 16Cr-12Ni-2Mo & 700 & No & Yes & No & No \\
Gr91 & 9Cr-1Mo-V & 650 & No & Yes & Yes & Yes \\
Gr22 & $21 / 4 \mathrm{Cr}-1 \mathrm{Mo}$ & 650 & Yes & Yes & Yes & Yes \\
\hline
\end{tabular}

The secondary potential candidate materials for GFR are listed in Table 32. These materials are considered as secondary candidates mainly because their databases have not been 
developed for inclusion into the high-temperature nuclear code (ASME BVP Sect. III, Subsect. $\mathrm{NH}$ ). All of these materials, with the exception of CCA617, have extensive databases.

Table 32. Secondary potential candidate materials for high-temperature metallic GFR components.

\begin{tabular}{|c|c|c|c|c|c|c|c|}
\hline $\begin{array}{l}\text { Secondary } \\
\text { Candidates }\end{array}$ & $\begin{array}{l}\text { Nominal } \\
\text { Composition }\end{array}$ & $\begin{array}{l}\text { UNS } \\
\text { Number }\end{array}$ & $\begin{array}{l}\text { Existing } \\
\text { Data } \\
\text { Max } \\
\text { Temp. }{ }^{\circ} \mathrm{C}\end{array}$ & $\begin{array}{l}\text { Helium } \\
\text { Experience }\end{array}$ & $\begin{array}{l}\text { Aging } \\
\text { Experience }\end{array}$ & $\begin{array}{l}\text { Section II } \\
\text { Physical } \\
\text { Props }\end{array}$ & $\begin{array}{l}\text { Design } \\
\text { Codes }\end{array}$ \\
\hline Hastelloy X & $\begin{array}{l}\mathrm{Ni}-22 \mathrm{Cr}- \\
9 \mathrm{Mo}-18 \mathrm{Fe}\end{array}$ & N06002 & 1000 & Yes & Yes & Yes & No \\
\hline Hastelloy XR & $\begin{array}{l}\mathrm{Ni}-22 \mathrm{Cr}-9 \mathrm{Mo}- \\
18 \mathrm{Fe}\end{array}$ & & 1000 & Yes & Yes & No & Yes \\
\hline $\begin{array}{l}\text { CCA Inconel } \\
617\end{array}$ & $\begin{array}{l}45 \mathrm{Ni}-22 \mathrm{Cr}-12 \mathrm{Co}- \\
9 \mathrm{Mo}\end{array}$ & N06617 & 1100 & No & No & No & No \\
\hline Alloy 230 & $\begin{array}{l}53 \mathrm{Ni}-22 \mathrm{Cr}-14 \mathrm{~W}- \\
\text { Co-Fe-Mo }\end{array}$ & & 900 & No & No & Yes & Yes \\
\hline Gr92 & $\begin{array}{l}9 \mathrm{Cr}-1.5 \mathrm{~W}-\mathrm{Mo}-\mathrm{V}- \\
\mathrm{Nb}\end{array}$ & & 650 & No & No & Yes & Yes \\
\hline Gr23 & $\begin{array}{l}21 / 4 \mathrm{Cr}-1.5 \mathrm{~W}-\mathrm{V}- \\
\mathrm{Nb}\end{array}$ & & 650 & No & No & Yes & Yes \\
\hline
\end{tabular}

There are a number of outstanding potential candidates that have not been included in Tables 31 and 32. Their inclusion depends to a large extent on which option is under consideration. Clearly, for any option, the Co-bearing alloys are to be avoided where radiation fields may be present. Thus, alloys 617 and CCA617 may not be first choices for components located in the immediate vicinity of the reactor vessel. Alloy 230 is a good alternative to alloys 617 . Hastelloy $\mathrm{XR}$ is low in Co, which provides an advantage over Hastelloy $\mathrm{X}$. These alloys may be adequate for the helium option.

For high-temperature heat exchanger and piping for helium service materials, new alloys, such as SAVE 25, 602CA, HR120, and Sanicro29, could be considered. Generally, these alloys are far from being qualified for Sect III construction, but have good promise.

Although the service temperatures are lower, the $\mathrm{CO}_{2}$ service environment presents a major consideration in the selection of alloys. To avoid carburization or metal dusting, it is preferable to have alloys that are high in nickel and chromium. Nickel cladding of the structural materials could be an option. Also, alloys that are alumina-formers could be considered, if they could be heat-treated to form the needed protective coating prior to service. Lacking these options, the austenitic and ferritic steels listed in Tables 31 and 32 remain the primary and secondary candidates for all three options.

\subsubsection{Expected Research, Testing, and Qualification Needs for High Temperature Metallic Components}

The research and development plan for the high-temperature GFR materials assumes that the efforts on the NGNP will be directly applicable. At this point, it is recognized that the materials listed in Tables 31 and 32 are also in the NGNP plan. The emphasis should be placed on the elements that are different in the two systems. Specifically, it will be the environment that will 
differ between the GFR and the NGNP. The GFR plan should include both helium and $\mathrm{CO}_{2}$ effects on the mechanical properties. Here, it is assumed that corrosive characteristics of the helium and $\mathrm{CO}_{2}$ environments will be established as another part of the GFR material research plan. The specific temperatures and times for the different materials should be linked to the components for which the materials are candidates. For example, testing of the nickel base alloys in helium should be extended to $850^{\circ} \mathrm{C}$. The proposed testing temperatures for candidate GFR materials are listed in Table 33.

Having established materials and conditions, the first logical step is to assess the experience with the alloys or similar alloys. This information then forms a foundation on which to develop an exploratory testing program to gather the data needed to determine feasibility of the GFR concept. Typically, the kind of exploratory mechanical testing includes creep-rupture, fatigue, crack growth, and combinations of the three. The experimental activities for the scoping phase should not be extensive, but rather sufficient to identify significant trends and assess any unexpected viability issues.

Table 33. Testing temperatures $\left({ }^{\circ} \mathrm{C}\right)$ and environments for GFR potential candidate hightemperature alloys.

\begin{tabular}{lcc}
\hline Alloy group & Helium Environment & $\mathbf{C O}_{\mathbf{2}}$ Environment \\
\hline Nickel base & 850 & 600 \\
High alloy & 760 & 600 \\
Stainless steel & & 600 \\
Martensitic steel & 600 & 550 \\
Low alloy steel & & 500 \\
\hline
\end{tabular}

\subsubsection{Experimental High-Temperature Metallic Materials R\&D Plans}

Since the operating temperature conditions for the GFR metallic high-temperature structural materials are expected to be within the limits of existing ASME construction codes, the needs for viability research will largely focus on environmental testing to assist in the estimation of corrosion allowances and the assessment of the impact of corrosion on component performance. To these ends, static and dynamic testing in representative environments will be required. It is expected that the research effort on helium contamination effects in the NGNP program will be adequate to assess the viability of the GFR concepts. The $\mathrm{CO}_{2}$ effects are unique to the He-S-CO 2 indirect and all-S- $\mathrm{CO}_{2}$ options, however, so some exploratory creeprupture, creep crack growth, fatigue, and creep-fatigue testing in $\mathrm{CO}_{2}$ will be needed. Table 34 provides a summary of the required research tasks to evaluate GFR high-temperature metallic materials.

The schedule for these tasks is not well defined because it is highly contingent upon funding availability, which is not fully known at this time. It is, however, laid out as though the required funding would be available to meet the earliest logical schedule of the tasks identified and it will be subject to revision, based on actual funding availability. 
Table 34. Schedule and tasks for GFR high-temperature metallic components research.

\begin{tabular}{|l|c|c|c|c|c|c|}
\hline \multicolumn{1}{|c|}{ Task } & FY06 & FY07 & FY08 & FY09 & FY10 & FY11 \\
\hline $\begin{array}{l}\text { Assess } \mathrm{CO}_{2} \text { effects on creep-rupture and creep } \\
\text { crack growth }\end{array}$ & & $\mathrm{XXX}$ & $\mathrm{XXX}$ & $\mathrm{XXX}$ & $\mathrm{XXX}$ & $\mathrm{XXX}$ \\
\hline $\begin{array}{l}\text { Assess } \mathrm{CO}_{2} \text { effects on fatigue and fatigue crack } \\
\text { growth }\end{array}$ & & $\mathrm{XXX}$ & $\mathrm{XXX}$ & $\mathrm{XXX}$ & $\mathrm{XXX}$ & $\mathrm{XXX}$ \\
\hline
\end{tabular}

\subsubsection{Power Conversion Components Materials Selection and Issues}

The candidate materials for the various components of the $850^{\circ} \mathrm{C}$ GFR reference design power conversion system should be essentially identical to those proposed for the higher temperature NGNP. For example, the turbine inlet shroud, which sees the full normal operating temperature in the system, can certainly use the wrought Ni-base alloys (Alloy 617 and Hastelloy X) proposed for the NGNP. In fact, given the lower temperature in the GFR, Fe/Ni-base Alloy $800 \mathrm{H}$ might also well be acceptable for this application.

The other highest temperatures in the GFR reference design power conversion system will be experienced in the first-stage turbine blades and disks. Typically, the disks of the first three stages are cooled to $<650^{\circ} \mathrm{C}$; the blades are not cooled and maximum metal temperature is in the range $800-850^{\circ} \mathrm{C}$. Wrought Nimonic alloys (Ni with about $20 \mathrm{wt} \% \mathrm{Cr}$ with additions of $\mathrm{Ti}$ and $\mathrm{Al}$ and sometimes $\mathrm{Mo}$ ) are prime candidate alloys for the disks. An example is Nimonic $80 \mathrm{~A}$ which was developed for service up to $750^{\circ} \mathrm{C}$. A large number of similar alloys with comparable properties are also commercially available. The blade material will almost certainly be a cast Ni-base alloy such as Alloy $713 \mathrm{LC}$ or IN-100. It should be noted here, however, that the exact materials selected for the disks and blades will likely be highly dependent on the turbine manufacturer selected as each manufacturer has its own favorite materials based on experience and turbine conditions. Further, the materials R\&D plan for the NGNP delegated material choice and qualification of the materials chosen to the turbine manufacturer eventually selected.

The recuperator for the $850^{\circ} \mathrm{C}$ GT-MHR is currently a modular counter-flow He-to-He heat exchanger with corrugated-plate heat exchange surfaces; that for the $850^{\circ} \mathrm{C}$ GFR reference design will likely be similar. Both would operate with helium inlet from the turbine at $\sim 500^{\circ} \mathrm{C}$. Austenitic 300 series stainless steels are the prime candidates for all portions of the recuperator. Examples are $316 \mathrm{~L}$ and stabilized steels such as 321 and 347.

The blades and disks in the GT-MHR power conversion system high- and low-pressure compressors operate at about $110^{\circ} \mathrm{C}$ and a $\mathrm{Ti}$ alloy with $6 \% \mathrm{Al}$ and $4 \% \mathrm{~V}$ is the primary candidate alloy. This should also be acceptable for the GFR reference design system. Finally, the precoolers and intercoolers (He-to-water heat exchangers) of both the GT-MHR and GFR reference would operate with maximum He temperatures of $150^{\circ} \mathrm{C}$ and water temperatures of $60^{\circ} \mathrm{C}$. A titanium-stabilized 300 series stainless steel, 321 , is the primary candidate alloy for the GT-MHR design.

The materials for the power conversion system components in the two alternate designs should be identical as the projected operating conditions for both are essentially identical. It would be expected that use of the candidate materials for the reference design would be conservative 
because of the much lower inlet temperatures in the turbine $\left(550^{\circ} \mathrm{C}\right)$ and the recuperator $\left(400^{\circ} \mathrm{C}\right)$.

\subsubsection{Expected Research, Testing, and Qualification Needs for Power Conversion Components}

Only the issue of compatibility of materials with $\mathrm{S}-\mathrm{CO}_{2}$ is critical to establishing the viability of existing materials for candidate GFR power conversion systems. To this end, potential materials for the alternate concept power conversion system turbine and recuperator should be exposed in $\mathrm{S}-\mathrm{CO}_{2}$ at appropriate temperatures ranging from $350-650^{\circ} \mathrm{C}$ for times to $\sim 10,000 \mathrm{~h}$. These tests should be performed to establish reaction kinetics, set corrosion allowances, and to determine effects of reactions with $\mathrm{S}-\mathrm{CO}_{2}$ on mechanical and physical properties. The results obtained will be important in the materials down-select process.

To this end, three turbine inlet shroud materials, two turbine blade materials, two turbine disk materials, and two recuperator materials should be selected from the preliminary candidate materials discussed earlier and exposed to $\mathrm{S}-\mathrm{CO}_{2}$ as indicated in Table 35 . The materials tested for the turbine inlet shroud will likely overlap those for the indirect cycle IHX and for the direct cycle high-temperature metallic components. Recuperator materials may also overlap with those for latter alternate cycle.

Table 35. Power conversion system materials compatibility test matrix for alternate GFR designs.

\begin{tabular}{|c|c|c|c|c|c|}
\hline \multirow{2}{*}{$\begin{array}{l}\text { Test Temp. } \\
{ }^{\circ} \mathrm{C}\end{array}$} & \multicolumn{5}{|c|}{ Power Conversion System Component } \\
\hline & $\begin{array}{l}\text { Turbine } \\
\text { Shroud }\end{array}$ & Inlet & $\begin{array}{l}\text { Turbine } \\
\text { Blades }\end{array}$ & $\begin{array}{l}\text { Turbine } \\
\text { Disks }\end{array}$ & Recuperator \\
\hline 350 & & & & & $\bar{X}$ \\
\hline 400 & & & & & $x$ \\
\hline 450 & & & & $\mathrm{X}$ & $\mathrm{X}$ \\
\hline 500 & $\mathrm{X}$ & & $\mathrm{X}$ & $\mathrm{X}$ & $\mathrm{X}$ \\
\hline 550 & $\mathrm{X}$ & & $\mathrm{X}$ & $\mathrm{X}$ & \\
\hline 600 & $\mathrm{X}$ & & $\mathrm{X}$ & $\mathrm{X}$ & \\
\hline 650 & $\mathrm{X}$ & & $\mathrm{x}$ & & \\
\hline
\end{tabular}

\subsubsection{Experimental Conversion System Materials R\&D Plans}

Potential materials for the alternate concept power conversion systems' turbines and recuperators should be exposed in $\mathrm{S}-\mathrm{CO}_{2}$ at appropriate temperatures ranging from $350-650^{\circ} \mathrm{C}$ for times to $\sim 10,000 \mathrm{~h}$. These tests should be performed to establish reaction kinetics, set corrosion allowances, and to determine effects of reactions with $\mathrm{S}-\mathrm{CO}_{2}$ on mechanical and physical properties. The results obtained will be important in the materials down-select process. Table 36 provides a summary of the required research tasks to evaluate GFR power system components for compatibility in supercritical carbon dioxide.

The schedule for these tasks is not well defined because it is highly contingent upon funding availability, which is not fully known at this time. It is, however, laid out as though the required funding would be available to meet the earliest logical schedule of the tasks identified and it will be subject to revision, based on actual funding availability. 
Table 36. Schedule and tasks for GFR power conversion materials research.

\begin{tabular}{|l|l|l|l|l|l|l|}
\hline \multicolumn{1}{|c|}{ Task } & FY06 & FY07 & FY08 & FY09 & FY10 & FY11 \\
\hline Baseline Materials Assessment & & $X X X$ & $X X X$ & $X X X$ & $X X X$ & \\
\hline Environmental Exposure in $\mathrm{CO}_{2}$ & & $X X X$ & $X X X$ & $X X X$ & $X X X$ & \\
\hline Post Exposure Materials Assessment & & $X X X$ & $X X X$ & $X X X$ & $X X X$ & $X X X$ \\
\hline
\end{tabular}

\subsubsection{Materials Compatibility Considerations to Establish Feasibility of GFR}

Helium - It is expected that the materials performance needs for the GFR in helium will be largely covered by the work needed for the NGNP and data generated in previous heliumcooled reactor work. The major exception is the demonstration of feasibility of gas cleanup for the reactor with little or no graphite internals. Tests are needed to demonstrate that under the appropriate helium flow rate and atmospheric ingress, the composition of the helium can be maintained within the compositional range of previous testing range. These tests will require an appropriately sized, pumped loop with associated chemistry measurement and side stream gas cleanup equipment.

Supercritical $\mathrm{CO}_{2}$ - Because of the dearth of materials performance data in $\mathrm{S}-\mathrm{CO}_{2}$ at the pressures and temperatures of interest, an exploratory database must be developed to establish feasibility of the concept. The materials proposed for various components of the $\mathrm{S}-\mathrm{CO}_{2}$ cooled reactor will be evaluated over the expected temperature range. As a minimum, the corrosion performance and mechanical properties of proposed materials in $\mathrm{S}-\mathrm{CO}_{2}$, and the lift-off and plating characteristics of the corrosion products must be determined.

Test Program-The tests proposed in this section are in addition to environmental mechanical properties and thermal-physical properties testing proposed in other sections of this feasibility study.

The helium side-stream cleanup studies are needed to establish feasibility of this approach to maintaining control of the helium environment and to determine whether the existing data can support validity of the GFR helium concept or the need for a more extensive test program. It is envisioned that a small number of the materials chosen for their ability to withstand the higher radiation exposure of the GFR, as compared to the previous HTGRs, will need to be evaluated for corrosion performance. These tests will be performed at temperatures up to $50^{\circ} \mathrm{C}$ above the expected exposure temperatures.

A much more extensive array of specimens will need be evaluated for the $\mathrm{S}-\mathrm{CO}_{2}$ environment. It is envisioned that these tests will be performed in a $\mathrm{S}-\mathrm{CO}_{2}$ loop for varying times up to 10,000 hours. These tests will provide for a down-select of materials capable of surviving in the $\mathrm{S}-\mathrm{CO}_{2}$. This smaller subset of materials will then be evaluated in a in-reactor $\mathrm{S}-\mathrm{CO}_{2}$ loop. This will allow for exposure of the chosen materials to the radiolytic products of the $\mathrm{S}-\mathrm{CO}_{2}$ coolant. In addition, the chemistry of the $\mathrm{S}-\mathrm{CO}_{2}$ will be ascertained so as to allow for an understanding of the effects of radiolysis on the coolant and to correlate materials performance with environmental exposure. 
Because choices of materials are still to be modified, the proposed test matrix contained in Table 37 will be identified by materials application rather than specific materials.

Table 37. Environmental materials test matrix.

\begin{tabular}{ll}
\hline Materials application & Environment \\
\hline High dose tolerant metals & Helium \\
Ceramic internal & Supercritical $\mathrm{CO}_{2}$ \\
Inert fuel matrix ceramics & Supercritical $\mathrm{CO}_{2}$ \\
Metallic internal & Supercritical $\mathrm{CO}_{2}$ \\
Pressure vessel cladding & Supercritical $\mathrm{CO}_{2}$ \\
Lift-off/plating experiments & Supercritical $\mathrm{CO}_{2}$ \\
Ceramic internal & In-reactor supercritical $\mathrm{CO}_{2}$ \\
Metallic internal & In-reactor supercritical $\mathrm{CO}_{2}$ \\
Pressure vessel cladding & In-reactor supercritical $\mathrm{CO}_{2}$ \\
\hline
\end{tabular}

\subsubsection{Experimental Materials Compatibility R\&D Plans}

Tests are needed to establish the viability of materials performance in the proposed GFR environments, both helium without graphite and $\mathrm{S}-\mathrm{CO}_{2}$. Test will be performed to determine the possibility of helium gas cleanup. If cleanup is possible, the helium environment, most likely, will be similar to the previous test environments and hence, data from the previous test programs can be used to support viability determinations. In addition, compatibility tests are needed to ascertain the performance of materials that were not previously evaluated. Because of the lack of information, a larger suite of tests are needed for the $\mathrm{S}-\mathrm{CO}_{2}$ environment. Besides materials compatibility information, lift-off/plating studies of corrosion products are required. The latter studies require the use of loop that can attain the appropriate velocities of $\mathrm{S}-\mathrm{CO}_{2}$ at test temperatures. The tests proposed in this section are in addition to mechanical or physical properties testing in the specific gaseous environments already included in other sections of this feasibility study. Additionally, tests of both the chemistry produced in the $\mathrm{S}-\mathrm{CO}_{2}$ by in-core radiolysis and assessment of its effects on candidate materials will be required. Table 38 provides a summary of the required research tasks to evaluate GFR materials compatibility.

The schedule for these tasks is not well defined because it is highly contingent upon funding availability, which is not fully known at this time. It is, however, laid out as though the required funding would be available to meet the earliest logical schedule of the tasks identified and it will be subject to revision, based on actual funding availability. 
Table 38. Schedule and tasks for GFR materials compatibility research.

\begin{tabular}{|l|l|l|l|l|l|l|}
\hline \multicolumn{1}{|c|}{ Task } & FY06 & $\mathrm{FY} 07$ & $\mathrm{FY} 08$ & $\mathrm{FY} 09$ & $\mathrm{FY} 10$ & $\mathrm{FY} 11$ \\
\hline Helium loop (recirculating, low velocity) & & & & & & \\
\hline Helium side stream cleanup studies & & & $\mathrm{XXX}$ & $\mathrm{XXX}$ & & \\
\hline Helium corrosion studies & & & & $\mathrm{XXX}$ & $\mathrm{XXX}$ & $\mathrm{XXX}$ \\
\hline \multicolumn{1}{|c|}{ Supercritical CO} & & & \\
\hline Supercritical $\mathrm{CO}_{2}$ corrosion test loop (low velocity) & & $\mathrm{XXX}$ & $\mathrm{XXX}$ & & & \\
\hline Corrosion performance of proposed materials & & & $\mathrm{XXX}$ & $\mathrm{XXX}$ & $\mathrm{XXX}$ & $\mathrm{XXX}$ \\
\hline Supercritical $\mathrm{CO}_{2}$ lift-off test loop (high velocity) & & $\mathrm{XXX}$ & $\mathrm{XXX}$ & $\mathrm{XXX}$ & $\mathrm{XXX}$ & \\
\hline Lift-off and plating performance of materials & & & & $\mathrm{XXX}$ & $\mathrm{XXX}$ & $\mathrm{XXX}$ \\
\hline Supercritical $\mathrm{CO}_{2}$ in-reactor loop (low velocity) & & $\mathrm{XXX}$ & $\mathrm{XXX}$ & $\mathrm{XXX}$ & & \\
\hline Supercritical $\mathrm{CO}_{2}$ in-reactor loop corrosion studies & & & $\mathrm{XXX}$ & $\mathrm{XXX}$ & $\mathrm{XXX}$ & $\mathrm{XXX}$ \\
\hline $\begin{array}{l}\text { Supercritical } \mathrm{CO}_{2} \text { in-reactor loop chemistry } \\
\text { studies }\end{array}$ & & & $\mathrm{XXX}$ & $\mathrm{XXX}$ & $\mathrm{XXX}$ & $\mathrm{XXX}$ \\
\hline
\end{tabular}

\subsubsection{Required HTDM Experimental and Analytical Activities for GFR}

Assuming that the bulk of HTDM needs for GFR will be covered by activities already planned for the NGNP, the following tasks will remain to establish viability.

- Evaluate methods, existing data, and assist in planned test activities of pressure vessel materials and metallic core internals and reactor internals specific to GFR to gain material (creep, fatigue, creep-fatigue) properties required for HTDM.

- Evaluate the results of testing for GFR, and propose a method to address variation in material properties of pressure vessel material with thickness for high temperature design (section $\mathrm{NH}$ ).

- Evaluate the need and assess the available damage models and life prediction approaches (creep, creep-fatigue) to address 60 year design service life (aging effects) with available data, and extrapolation of data for such long periods, for both base and weld metals (pressure vessel, core and reactor internal materials). Develop or propose appropriate models for high temperature design.

- Analyze and simulate component-like parts under representative loadings, irradiation exposure and times for high temperature service. Determine if issues arise regarding ratcheting, multiaxial effects, creep, and creep-fatigue; develop high temperature design methods and rules to avoid deleterious issues.

- Participate in required ASME Code meetings to guide and implement GFR-related HTDM activities. 
The GFR HTDM and codification requirements for pressure vessel, piping, and heat exchangers are included in the NGNP plans. However, the metallic pressure vessel will experience higher dose levels than the NGNP design, as will the reactor vessel internals, core, and core internals. Further, HTDM for NGNP did not include any efforts for core internals or core supports. Hence, the following research must be conducted to assess the viability of materials for the GFR.

\subsubsection{Experimental HTDM R\&D Plans}

Detailed inelastic analysis must be conducted. This will help designers assess the limitations of the vessel internals materials with respect to time-independent, time-dependent, ratcheting limits, accelerated creep damage, creep-fatigue, creep buckling, flaw sensitivity (fracture toughness) and multiaxial effects. Further, the same issues must be examined for possible deleterious effects due to the high radiation levels. Scoping tests will be conducted and compared with analytical and numerical predictions or irradiated vs. unirradiated material. These efforts will apply to $21 / 4 \mathrm{Cr}$, the modified $9 \mathrm{Cr}$ alloys, and may be extended to one of the best candidates the class $12 \mathrm{Cr}$ or $3 \mathrm{Cr}$ alloys. Similar efforts will be needed to asses the viability of ODS, intermetallics and the F/M alloys for core components and reactor internals. Table 39 provides a summary of the required research tasks to establish GFR high temperature design methodology.

The schedule for these tasks is not well defined because it is highly contingent upon funding availability, which is not fully known at this time. It is, however, laid out as though the required funding would be available to meet the earliest logical schedule of the tasks identified and it will be subject to revision, based on actual funding availability.

Table 39. Schedule and tasks for GFR high temperature design methodology research.

\begin{tabular}{|l|c|c|c|c|c|c|}
\hline \multicolumn{1}{|c|}{ Task } & FY06 & FY07 & FY08 & FY09 & FY10 & FY11 \\
\hline Supplemental Testing & & XXX & XXX & XXX & XXX & XXX \\
\hline Analytical Methods Development & & XXX & XXX & XXX & XXX & XXX \\
\hline Codes and Standards Interactions & & XXX & XXX & XXX & XXX & XXX \\
\hline
\end{tabular}

\subsection{POTENTIAL CANDIDATE MATERIALS SELECTIONS AND RESEARCH PLANS FOR NUCLEAR HYDROGEN SYSTEMS}

Examining the conditions under which the components of the three nuclear hydrogen generation systems will operate has allowed the areas of needed materials research areas to be identified that must be addressed before the systems can be deployed. While this research covers issues of materials compatibility, high-temperature strength and stability of materials, and fabrication technologies, the near-term focus will be primarily on materials compatibility. 


\subsubsection{Potential Candidate Materials and Research Needs for SI System Components}

\subsubsection{Operating Conditions and Candidate Materials for SI System Components}

The SI process can be readily broken down into the three sections listed above, but to investigate the issues associated with materials selection and qualification it is necessary to examine the conditions that exist for the components within each section of the process. Since the number and type of components within the individual sections are quite varied and are still being refined with regard to their exact operating conditions, it is useful to group the components into categories in which a set of conditions can be established that are expected to envelop their operation. These bounding conditions can then be used to examine the materials issues of greatest concern to the SI process.

The bounding operational conditions for the three sections of the SI system that are expected to provide the greatest materials challenges are listed by section along with candidate materials identified for them in Table 40. Materials challenges and prioritized materials research topics associated with the different sections are provided below.

\subsubsection{Prioritized Research Needs for SI System Components}

\section{Section 1 - Sulfuric Acid and Hydriodic Acid Generation}

The major components in this section of the SI system are faced primarily with issues of corrosion, in as much as they all operate at very modest temperatures where long-term strength and stability of the materials is of little concern. It is useful to consider the vessels that contain the corrosive reactants separately from the internal components where heat transfer is a significant issue. Since the vessels operate at low temperatures, it is anticipated that they can be constructed of low-alloy steels and protected with fluorocarbon coatings or liners, such as Teflon, Kynar, or even polyethylene or polypropylene in the less aggressive environments. While the effectiveness of these protective coatings will need to be evaluated, this area of materials research is considered to be of relatively low priority. For the internal components in section 1, including the numerous types of heat exchangers required, the challenge is greater since the environments described in Table 40a are quite aggressive. Screening of highly corrosion resistant metals and alloys including $\mathrm{Ta}, \mathrm{Zr}$, B2, 242, and Hastelloy C-276, as well as monolithic ceramics, such as $\mathrm{Si}_{3} \mathrm{Ni}_{4}, \mathrm{SiO}_{2}, \mathrm{Al}_{2} \mathrm{O}_{3}$, and $\mathrm{Nb}-1 \mathrm{Zr}$ - coatings is recommended. As historical work has indicated that the corrosion challenges in this section can likely be met, the initial corrosion screening of these materials are considered to be a medium priority.

\section{Section 2 - Sulfuric Acid Concentration and Decomposition}

Even though the SI system Section 2 lists only the two areas of concentration and decomposition explicitly, the materials challenges can be best examined over three ranges of temperature and corresponding reactant chemistries as summarized in Table $40 \mathrm{~b}$. In this section of the system, sulfuric acid is heated from low temperature to the point at which it decomposes. Throughout the section, process heat from the nuclear island will be supplied to the reactants via integral heat exchangers in the chemical reaction vessels. The heat transfer medium for the nuclear island is expected to be either high-pressure helium or molten salt. While the majority of corrosion concerns for the process components will be those related to the reactant stream, there are also concerns that arise on the primary side of the heat exchangers associated with the process fluids at very high temperatures. Selection of candidate materials and their screening includes considerations of interactions on both the primary side with heat transfer fluids and on the secondary side with chemical reactants. 
Table 40. Operating conditions and materials candidates for major sections of an SI nuclear hydrogen generation plant.

\section{a. Section 1 - Sulfuric Acid and Hydriodic Acid Generation}

\begin{tabular}{|c|c|c|c|c|}
\hline & \begin{tabular}{|c} 
Temperature \\
$\left({ }^{\circ} \mathrm{C}\right)$
\end{tabular} & \begin{tabular}{|c|} 
Pressure \\
$(\mathrm{MPa})^{*}$
\end{tabular} & $\begin{array}{c}\text { Chemical } \\
\text { Environment }\end{array}$ & Material Candidates \\
\hline \multicolumn{5}{|l|}{ S-I Bunsen Reaction } \\
\hline Main Reactor HX & $120-130$ & $0.1-0.3$ & $\begin{array}{c}8 w \mathrm{wt} \% \mathrm{H}_{2} \mathrm{O} \\
2 \mathrm{wt} \% \mathrm{H}_{2} \mathrm{SO}_{4} \\
80 \mathrm{wt} \% \mathrm{I}_{2} \\
7 \mathrm{wt} \% \mathrm{HI} \\
0.5 \mathrm{wt} \% \mathrm{O}_{2} \\
1.7 \mathrm{wt} \% \mathrm{SO}_{2}\end{array}$ & \multirow{3}{*}{$\begin{array}{c}\mathrm{Ta}, \mathrm{Zr}, \mathrm{Si}_{3} \mathrm{Ni}_{4}, \mathrm{SiO}_{2} \text {, } \\
\mathrm{Al}_{2} \mathrm{O}_{3}, \mathrm{~B} 2,242, \\
\mathrm{Hastelloy} \mathrm{C} \mathrm{C}-276, \\
\text { and } \mathrm{Nb}-1 \mathrm{Zr} \text { - coating }\end{array}$} \\
\hline $\mathrm{H}_{2} \mathrm{SO}_{4}$ Boost Reactor & $120-130$ & $0.1-0.3$ & $\begin{array}{c}57 \mathrm{wt} \% \mathrm{H}_{2} \mathrm{SO}_{4} \\
43 \mathrm{wt} \% \mathrm{H}_{2} \mathrm{O} \\
0.1 \mathrm{wt} \% \mathrm{SO}_{2} \\
\text { trace } \mathrm{I}_{2}\end{array}$ & \\
\hline $\mathrm{HI}$ Phase $\mathrm{SO}_{2}$ Stripper $\mathrm{HX}$ & $120-130$ & $0.1-0.3$ & $\begin{array}{c}\text { Trace } \mathrm{H}_{2} \mathrm{SO}_{4} \\
6 \mathrm{wt} \% \mathrm{H}_{2} \mathrm{O} \\
0.2 \% \mathrm{wt} \% \mathrm{SO}_{2} \\
87 \mathrm{wt} \% \mathrm{I}_{2} \\
7 \mathrm{wt} \% \mathrm{HI}\end{array}$ & \\
\hline $\begin{array}{l}\text { Vessels for Bunsen Reaction } \\
\text { HXs }\end{array}$ & $120-130$ & $0.1-0.3$ & Ranges listed above & $\begin{array}{c}\text { Florocarbon-lined } \\
\text { (Teflon, Kynar, etc.) } \\
\text { low-alloy steels }\end{array}$ \\
\hline
\end{tabular}

*to obtain pressure in bar, multiply by 10

\section{b. Section 2 - Sulfuric Acid Concentration and Decomposition}

\begin{tabular}{|c|c|c|c|c|}
\hline & $\begin{array}{c}\text { Temperature } \\
\left.\text { ( }{ }^{\circ} \mathrm{C}\right)\end{array}$ & $\begin{array}{c}\text { Pressure } \\
\text { (MPa)* }^{*}\end{array}$ & $\begin{array}{c}\text { Chemical } \\
\text { Environment }\end{array}$ & Material Candidates \\
\hline \multicolumn{5}{|c|}{$\mathrm{S}$-I $\mathrm{H}_{2} \mathrm{SO}_{4}$ Concentrator } \\
\hline Primary Side & $<450$ & $0.1-6.8$ & $\mathrm{He} /$ molten salt & \multirow{2}{*}{$\begin{array}{l}\text { Hastelloy B2 \& N, SiC, } \\
\text { C-C composites, } \\
\text { C276, 800/800H, Hi-Si } \\
\text { steel (Duriclor } 51 \mathrm{M} \text { ), } \\
\text { glass-lined steel, Nb } \\
\text { coatings }\end{array}$} \\
\hline Secondary Side & $<400$ & 0.1 & $\begin{array}{c}0-0.1 \mathrm{wt} \% \mathrm{SO}_{2} \\
57-98 \mathrm{wt} \% \mathrm{H}_{2} \mathrm{SO}_{4} \\
2-42 \mathrm{wt} \% \mathrm{H}_{2} \mathrm{O} \\
\text { trace } \mathrm{I}_{2}\end{array}$ & \\
\hline \multicolumn{5}{|l|}{$\mathrm{S}-\mathrm{I} \mathrm{H}_{2} \mathrm{SO}_{4}$ Vaporizer } \\
\hline Primary Side & 580 to 380 & $0.1-6.8$ & $\mathrm{He} /$ molten salt & \multirow{2}{*}{$\begin{array}{c}\text { Hastelloy B2, G, \& N, } \\
\mathrm{SiC}, \mathrm{C}-\mathrm{C} \text { composites, } \\
\mathrm{Si}_{3} \mathrm{Ni}_{4}, \mathrm{C} 276,800 / 800 \mathrm{H}, \\
\mathrm{Hi}-\mathrm{Si} \text { steel (Duriclor } \\
51 \mathrm{M} \text { ), glass-lined steel, } \\
\text { Nb coatings }\end{array}$} \\
\hline Secondary Side & 330 to 530 & 0.7 & $\begin{array}{c}\text { Liquid - Vapor } \\
98-71 \text { wt } \% \mathrm{H}_{2} \mathrm{SO}_{4} \\
0-22 \mathrm{wt} \% \mathrm{SO}_{3} \\
2-7 \mathrm{wt} \% \mathrm{H}_{2} \mathrm{O}\end{array}$ & \\
\hline \multicolumn{5}{|c|}{$\mathrm{S}-\mathrm{I} \mathrm{H}_{2} \mathrm{SO}_{4}$ Decomposer } \\
\hline Primary Side & 950 to 800 & $0.1-6.8$ & $\mathrm{He} /$ molten salt & \multirow{2}{*}{$\begin{array}{c}\text { Hastelloy } \mathrm{B} 2, \mathrm{SiC}, \mathrm{C}-\mathrm{C} \\
\text { composites, } \\
\mathrm{Si}_{3} \mathrm{Ni}_{4}, 242,214,800 \mathrm{HT}, \\
\mathrm{Nb}-1 \mathrm{Zr}, \\
\mathrm{Au} \text {-, } \mathrm{Pt}-, \mathrm{Fe}_{3} \mathrm{Al}-\& \\
\text { glass-coatings, } \\
\mathrm{Pt}-, \mathrm{Cu}-, \text { \& } \\
\mathrm{Fe}_{2} \mathrm{O}_{3} \text {-catalysts }\end{array}$} \\
\hline Secondary Side & 530 to 900 & 0.7 & $\begin{array}{c}\text { Inlet - Outlet } \\
71-20-w t \% \mathrm{H}_{2} \mathrm{SO}_{4} \\
22-13 w t \% \mathrm{SO}_{3} \\
7-16 w t \% \mathrm{H}_{2} \mathrm{O} \\
0-40 w t \% \mathrm{SO}_{2} \\
0-10 w t \% \mathrm{O}_{2}\end{array}$ & \\
\hline
\end{tabular}

*to obtain pressure in bar, multiply by 10 
Table 40. Operating conditions and materials candidates for major sections of an SI nuclear hydrogen Generation plant. (cont)

c. Section 3 - Hydrogen lodide Decomposition

\begin{tabular}{|c|c|c|c|c|}
\hline & $\begin{array}{c}\text { Temperature } \\
\left({ }^{\circ} \mathrm{C}\right)\end{array}$ & \begin{tabular}{|c|} 
Pressure \\
(MPa)* $^{*}$
\end{tabular} & $\begin{array}{c}\text { Chemical } \\
\text { Environment }\end{array}$ & Material Candidates \\
\hline \multicolumn{5}{|l|}{ S-I HIx Reactive Distillation } \\
\hline Inlet feed stream & 262 & 2.2 & $\begin{array}{c}11 \mathrm{wt} \% \mathrm{HI} \\
81 \mathrm{wt} \% \mathrm{I}_{2} \\
8 \mathrm{wt} \% \mathrm{H}_{2} \mathrm{O} \\
\end{array}$ & \multirow{3}{*}{$\begin{array}{c}\text { Ta, Ta-10W, Mo, Nb, } \\
\text { Nb-1Zr, Zircaloy } 702, \\
\text { SiC, Vitreous carbon, C- } \\
\text { C composites, Bulk } \\
\text { metallic glasses }\end{array}$} \\
\hline Outlet column bottom & 310 & 2.2 & $\begin{array}{c}1 \mathrm{wt} \% \mathrm{HI} \\
98 \mathrm{wt} \% \mathrm{I}_{2}, \\
1 \mathrm{wt} \% \mathrm{H}_{2} \mathrm{O}\end{array}$ & \\
\hline $\mathrm{H}_{2}$ Scrubber/Condenser & 221 to 25 & 2.2 & $\begin{array}{c}66 \text { wt } \% \mathrm{HI} \\
32 \mathrm{wt} \% \mathrm{H}_{2} \mathrm{O} \\
2 \mathrm{wt} \% \mathrm{H}_{2}\end{array}$ & \\
\hline \multicolumn{5}{|l|}{ S-I HIx Phosphoric Acid Reactor } \\
\hline Concentrated $\mathrm{H}_{3} \mathrm{PO}_{4}$ & $132-211$ & 0.1 & $\begin{array}{c}96 \mathrm{wt} \% \mathrm{H}_{3} \mathrm{PO}_{4} \\
4 \mathrm{wt} \% \mathrm{H}_{2} \mathrm{O}\end{array}$ & \multirow{4}{*}{$\begin{array}{l}\text { TBD based on relevant } \\
\text { industrial experience }\end{array}$} \\
\hline Column feed & $120-241$ & $0.3-0.9$ & $\begin{array}{c}74 \mathrm{wt} \% \mathrm{H}_{3} \mathrm{PO}_{4} \\
11 \mathrm{wt} \% \mathrm{HI} \\
10 \mathrm{wt} \% \mathrm{H}_{2} \mathrm{O} \\
4 \mathrm{wt} \% \mathrm{I}_{2}\end{array}$ & \\
\hline Dilute $\mathrm{H}_{3} \mathrm{PO}_{4}$ & 250 & 0.95 & $\begin{array}{c}87 w t \% \mathrm{H}_{3} \mathrm{PO}_{4} \\
13 w t \% \mathrm{H}_{2} \mathrm{O}\end{array}$ & \\
\hline lodine outlet & 120 & $0.2-0.7$ & $\begin{array}{l}0.1 \mathrm{wt} \% \mathrm{H}_{2} \mathrm{O} \\
99.9 w t \% \mathrm{I}_{2}\end{array}$ & \\
\hline
\end{tabular}

*to obtain pressure in bar, multiply by 10

In the coolest portion of Section 2, sulfuric acid is heated to about $380^{\circ} \mathrm{C}$ while its concentration increases to about $90 \mathrm{wt} \%$. Since the corrosive effects of the sulfuric acid change markedly over this temperature and concentration range, it is recommended that corrosion screening of candidate materials be performed in the temperature range of $25-175^{\circ} \mathrm{C}$ at concentrations of $50-75 \%$ sulfuric acid, as well as between $175-380^{\circ} \mathrm{C}$ at sulfuric acid concentrations of $75-$ $90 \%$. At the lower temperatures, materials to be screened include Hastelloy B2 and N, C-276, $\mathrm{C}_{\mathrm{f}} / \mathrm{C}$ composites, and glass-lined steel. At the higher temperatures, $\mathrm{C}_{\mathrm{f}} / \mathrm{C}$ composites, Hastelloy $\mathrm{N}$, and glass-lined steel should also be screened along with $800 \mathrm{H}$, high-Si steels, and coatings or claddings of $\mathrm{Au}, \mathrm{Pt}$, and $\mathrm{Nb}$. Since this is a critical step for which material performance has not been demonstrated, this area of research is a very high priority in the overall program. If the high-Si steels perform acceptably, it will also be necessary to investigate their fabricability and weldability, since these issues are known to be problems in this class of materials. It will also be necessary to explore the technologies available for cladding or coating structural components reliably and with adequate long-term retention of properties with the materials identified.

The intermediate temperature range in this section includes the components in which the sulfuric acid is vaporized, from about $330-550^{\circ} \mathrm{C}$ and is the most aggressive with regard to environmental attack on structural materials. Hastelloy B2, G, and N, C-276, Alloy 800/800H, $\mathrm{SiC}, \mathrm{Si}_{3} \mathrm{~N}_{4}, \mathrm{C}_{\mathrm{f}} / \mathrm{C}$ composites, glass-lined steel, and coatings or claddings of $\mathrm{Au}, \mathrm{Pt}$, and $\mathrm{Nb}$ are 
considered to have the highest probability of surviving in this environment and will need to be screened. This is considered a very high priority materials issue.

The highest temperature range for components in this section is that portion where the sulfuric acid is decomposed prior to its introduction into the Bunsen section. Temperatures of the reactants range from about $550^{\circ} \mathrm{C}$ to as high as $900^{\circ} \mathrm{C}$ with temperatures of the heat transfer media in the $800-950^{\circ} \mathrm{C}$ range. High-temperature strength and creep resistance are significant issues at these temperatures, as well as the corrosion behavior of the components.

At these temperatures, corrosion on the primary side of the heat exchanger structures must be considered an important variable in selecting and evaluating the behavior of materials candidates. If the process heat media is helium, Hastelloy B2, 242, 214, Nb-1Zr, Alloy $800 \mathrm{HT}$, $\mathrm{SiC}, \mathrm{Si}_{3} \mathrm{~N}_{4}, \mathrm{C}_{\mathrm{f}} / \mathrm{C}$ composites, glass-lined steel, and coatings or claddings of $\mathrm{Au}, \mathrm{Pt}$, and $\mathrm{Nb}$ are potential candidates for joint service with the sulfuric acid. If the process-heat transfer media is molten salt, only $214, \mathrm{Nb}-1 \mathrm{Zr}$, and $\mathrm{C}_{f} / \mathrm{C}$ composites are still considered as viable. All these materials will needed to be screened for corrosion resistance. Additionally, the creep strength of the metals must be assessed at the service conditions, as will be the fabricability of the 214 . The resolution of all these issues, while important to the operation of the systems, are considered as a medium priority to materials R\&D, since existing information is moderately encouraging about performance under these conditions.

Since many of the challenges associated with the decomposition of sulfuric acid are driven by the very high temperatures needed to adequately drive the required chemical reactions forward to completion, it would be very useful to utilize other approaches that could provide the same result at lower temperatures [3.48]. An approach that has the strong potential to reduce the temperatures required for this process, and the associated materials challenges, is the use of selectively permeable, high-temperature, inorganic membranes for separation and concentration of the desirable reactant species. Such membranes have been developed and very successfully used under other DOE programs but have not been evaluated for service under the conditions of interest for the SI process. However, membrane fabrication technology has already been demonstrated for both metallic and ceramic materials that would be candidates for SI service conditions. Particular issues that need to be addressed for potential membrane use in Section 2 of the SI process include: 1) appropriateness of materials of construction with regard to high-temperature strength, corrosion resistance, and durability; 2) identification of processing parameters and resultant membrane structures most appropriate for separation of the particular chemical species of concern; and 3) assessment of separation performance under operating conditions. Considering that the successful use of inorganic membrane technology has the potential to not only reduce the substantial materials challenges in the high-temperature section of the SI process, but, even more significantly, to reduce the temperature requirements of the nuclear reactors that would supply the process heat to the process, this area of material research is a very high priority.

\section{Section 3 - Hydrogen lodide Decomposition}

Materials considerations for both the reference design for hydrogen iodide decomposition by reactive distillation and for the phosphoric acid reactor are described below and summarized in Table 40c.

In the reactive distillation column, the input stream reacts to form a liquid output stream containing the majority of the iodine dissolved in water, and a gaseous output stream of hydrogen, steam, and $\mathrm{HI}$ that is scrubbed and cooled to remove the $\mathrm{HI}$ and water from the hydrogen. The hydriodic acid in the three process streams is extremely corrosive, so 
construction materials will be severely challenged. Candidate materials have been identified but will need to be evaluated for their corrosion resistance as a very high priority task in the materials program.

As an alternative process, phosphoric acid can be added to the water, iodine, $\mathrm{HI}$ solution from the Bunsen reaction to produce two immiscible solutions-one containing iodine and the other containing phosphoric acid, water and $\mathrm{HI}$. The $\mathrm{HI}$ can then be separated from solution by distillation and broken down into hydrogen and iodine by either liquid- or gaseous-phase decomposition. A range of phosphoric acid concentrations are used in the process, some in combination with the other components, but based on industrial experience, there are fairly well established ways to deal with the corrosion of the expected process streams. Surveying industrial approaches to handling these process streams is a medium priority to ensure that commercial approaches and materials are appropriate.

\subsubsection{Potential Candidate Materials and Research Needs for Ca-Br System Components}

\subsubsection{Operating Conditions and Candidate Materials for $\mathrm{Ca}-\mathrm{Br}$ System Components}

Description of the functions of the major $\mathrm{Ca}-\mathrm{Br}$ system components is provided below. Their operation conditions and the candidate materials identified for them are listed in Table 41.

\section{Steam Superheater}

High-temperature steam to be supplied to the reaction beds in the $\mathrm{Ca}-\mathrm{Br}$ hydrogen production process is heated in a superheater using process heat from the nuclear island. It is anticipated that either compressed helium or molten salt will be the operative heat transfer fluid for delivery of nuclear heat.

\section{Ca-Br Reaction Bed}

Virtually all the chemical reactions in the Ca-Br-based hydrogen production system, except the $\mathrm{HBr}$ dissociation step will take place in the reaction beds. These will include the reactions described in previous sections for the production of $\mathrm{HBr}$ in the reactant stream and $\mathrm{CaO}$ in the bed itself during the forward reaction, and the production of $\mathrm{O}_{2}$ in the reactant stream and $\mathrm{CaBr}_{2}$ in the bed itself during bed regeneration. Since the reaction bed hardware must function and survive in both production and regeneration modes, the materials of construction will have a range of challenges.

The major components within the reaction bed are envisioned to be 1) a reaction vessel, which may or may not be thermally insulated, to contain the bed; 2) an integral heat exchanger within the bed itself to provide or remove the heat required for the endothermic or exothermic reactions for the forward and regenerative modes of operation; 3 ) the solid reactant materials comprising the beds themselves; and 4) the bed supports, which may include catalytic materials.

\section{$\mathrm{Ca}-\mathrm{Br} \mathrm{HBr}$ Heat Exchanger}

Since the operative temperature of the plasmatron is significantly cooler than the discharge temperature of the $\mathrm{HBr}$ from the reaction bed, it will necessary to cool the reactant stream before it reaches the plasmatron in an intermediate heat exchangers.

\section{Ca-Br Plasmatron}

The decomposition of $\mathrm{HBr}$ to $\mathrm{H}_{2}$ and $\mathrm{Br}_{2}$ using plasma-chemistry dissociation takes place at modest process conditions $\left(\sim 100^{\circ} \mathrm{C}\right.$ and atmospheric pressure or below) in the plasmatron. 
Table 41. Operating conditions and materials candidates in a $\mathrm{Ca}-\mathrm{Br}$ plant.

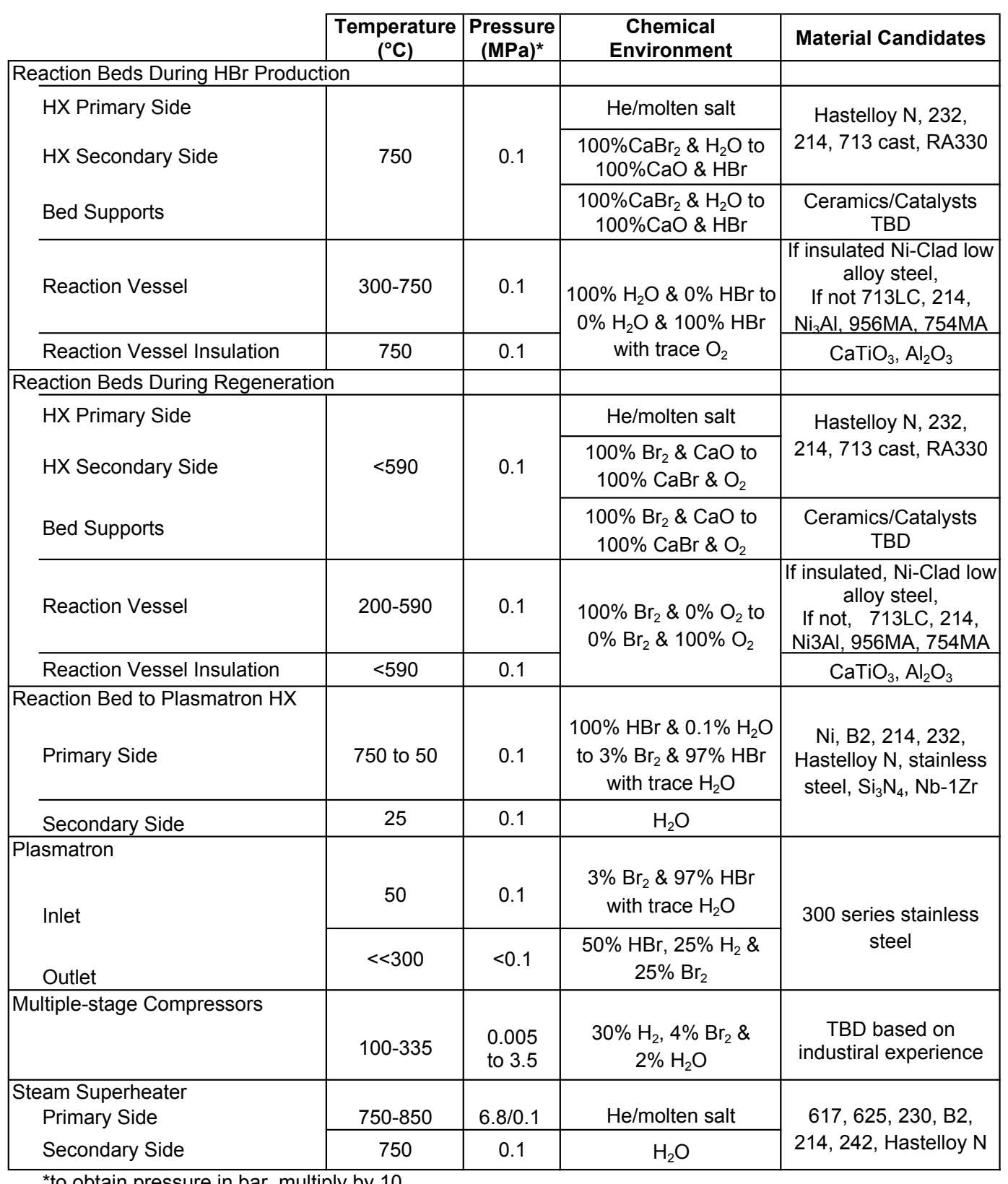

While important from a process perspective, there are no significant materials challenges envisioned for the construction or operation of the plasmatron.

\section{Ca-Br Compressors}

Following the production of $\mathrm{H}_{2}$ and $\mathrm{Br}_{2}$ in the plasmatron, a series of compressors is required to achieve the pressure required for pressure swing absorption separation of the bromine from the hydrogen process stream and eventual transmission or storage of the hydrogen. At this point in time, it is not clear whether the compressors will be centrifugal or reciprocating pumps. In any case, the anticipated conditions for these components appear to be within existing industrial 
experience, so a survey of industrial practices is expected to provide significant guidance on materials selection and screening. Fairly minor materials issues are expected for these components.

\subsubsection{Prioritized Materials Research Needs for Ca-Br System Components}

\section{Steam Superheater}

Whether the high-temperature process heat for the Ca-Br steam superheater will be supplied using high-pressure helium or molten salt will be the major parameter in selecting and qualifying a material for service in this component, since the material compatibility issues are so different. While materials screening for corrosion on the steam side will be required for all the materials candidates, molten salt service will limit these candidates and require appropriate corrosion screening for Hastelloy $\mathrm{N}$ (for temperatures up to $750^{\circ} \mathrm{C}$ ), $\mathrm{B} 2,242$, and 214 . Candidates for helium service would include $617,625,230$, B2, and 214 . Additionally, given the relatively low fabricability and weldability of alloy 214 , an assessment of it would be required. Since it is anticipated that some of the alloys being considered would function under the conditions envisioned for the superheater, and the major question is service life, not viability, this area is given a medium priority.

\section{Ca-Br Reaction Bed}

Insulated reaction vessel-If the reaction vessel is thermally insulated, it is anticipated that a nickel-clad low-alloy pressure vessel material would meet the needs of the component. However, the nickel cladding would need to be evaluated for corrosion resistance at the temperatures and fairly wide range of chemical compositions associated with the forward and regeneration modes of operation of the bed. This research is given a medium priority.

Uninsulated reaction vessel-If the vessel is not insulated, the materials challenges become much more significant. The high-temperature and aggressive environments of both modes of operation dramatically limit the candidate materials to classes of materials that have both very good high temperature strength and form very stable surface layers for corrosion resistance. Fabricability of these materials is an issue, particularly for the castable 713LC that should be investigated at a medium priority level. Evaluating the corrosion resistance of the materials would be a high priority if the decision is made to use an uninsulated vessel.

Integral reaction bed heat exchanger-No significant high-temperature strength or corrosion issues are expected for this component with respect to the molten salt or helium environment on the primary side. However, the corrosion resistance of the candidate materials over the temperatures and fairly wide range of chemical compositions associated with the forward and regeneration modes of operation of the bed must be ascertained to see which, if any, candidate materials will offer acceptable service. This is a high materials R\&D priority.

Bed reactant materials and supports-The composition of the reactant and catalytic materials in the beds are defined by the chemical reactions in which they are involved as described in the preceding sections. The unknowns at this point primarily involve the detailed form in which the reactants will fabricated and how they will be supported. Until additional information becomes available to better describe the geometries and material forms to be utilized, the required experimental program to assess these materials cannot be defined.

\section{$\mathrm{Ca}-\mathrm{Br} \mathrm{HBr}$ Heat Exchanger}

The compositions under which the primary side of this heat exchanger will operate in cooling the process gas from the reaction beds before its introduction to the plasmatron are quite novel by 
industrial experience. Obtaining the corrosion resistance needed with adequate strength at the higher temperatures of operation that will exist in this device or series of devices is anticipated to be very challenging. As suite of high temperature alloys and structural ceramics has been identified as candidate materials, and a very high priority for the $\mathrm{NHI}$ materials program will be to evaluate their corrosion resistance in the 500 to $750^{\circ} \mathrm{C}$ temperature range. Additionally, if either 214 or silicon nitride are identified as particularly promising, an assessment of their fabricability will be required, as well.

Ca-Br Plasmatron

The modest operating conditions of this device will not present any significant materials challenges that cannot be readily addressed with traditional construction materials.

Ca-Br Compressors

Once the decision is made whether the compressors will be centrifugal or reciprocating, screening of materials suggested by industrial use may need to be done in the temperature and environments of interest. This decision will be made at a later date.

\subsubsection{Potential Candidate Materials and Research Needs for HTE System Components}

\subsubsection{Operating Conditions and Candidate Materials for HTE System Components}

The anticipated operating conditions and materials candidates for the major HTE components are shown in Table 42.

\section{Electrolytic Cell Materials}

Interconnect Plate-The interconnect plate between adjacent planar cells represents one of the key materials challenges in the development of high-temperature electrolysis. Operation of SOFCs or solid oxide electrolytic cells above about $800^{\circ} \mathrm{C}$ will require the use of ceramic bipolar plates, with attendant cost and fabrication challenges. Below $800^{\circ} \mathrm{C}$, it would be desirable to use metallic interconnection plates to minimize fabrication challenges and costs of the cells. However, the combination of requirements for structural stability and corrosion resistance of the interconnects in the anticipated ranges of process stream components, in conjunction with their need for adequate electrical conductivity, severely limits metallic candidate materials. As with other components, the conditions for the interconnect plate are quite severe in the SOFCs being developed by the DOE-FE programs. Therefore, the FE program will be an important source of research for potential HTE materials. However, the effects of the unique chemical environment, containing the virtually pure oxygen that exists in the HTE system cell, on materials for service as interconnects will require assessment within the $\mathrm{NHI}$ program.

Other Electrolytic Cell Components-The other major components within the electrolytic cell include the ceramic electrolyte, anode, and cathodes, as well as the seals at the edges of the cells. Materials R\&D within the DOE-FE program is expected to adequately address these components, hence they are not included in the $\mathrm{NHI}$ materials studies. 
Table 42. Operating conditions and materials candidates in a HTE plant.

\begin{tabular}{|c|c|c|c|c|}
\hline & $\begin{array}{c}\text { Temperature } \\
\left({ }^{\circ} \mathrm{C}\right)\end{array}$ & $\begin{array}{c}\text { Pressure } \\
(\mathrm{MPa})\end{array}$ & $\begin{array}{c}\text { Chemical } \\
\text { Environment }\end{array}$ & Material Candidates \\
\hline $\begin{array}{l}\text { HTE Electrolytic Cell Components } \\
\text { Cathode Inlet }\end{array}$ & $800-900$ & 2.5 & 90 v/o $\mathrm{H}_{2} \mathrm{O}, 10$ v/o $\mathrm{H}_{2}$ & $\mathrm{Ni}-\mathrm{ZrO}_{2}$ \\
\hline Cathode Outlet & $800-900$ & 2.5 & $10 \mathrm{v} / \mathrm{o} \mathrm{H}_{2} \mathrm{O}, 90 \mathrm{v} / \mathrm{o} \mathrm{H}_{2}$ & $\mathrm{Ni}-\mathrm{ZrO}_{2}$ \\
\hline Electrolyte & $800-900$ & 2.5 & $\mathrm{n} / \mathrm{a}$ & YSZ, LSGM \\
\hline Anode & $800-900$ & 2.5 & $\mathrm{O}_{2}$ (+diluent?) & LSM \\
\hline Bipolar plate & $800-900$ & 2.5 & $\begin{array}{c}\mathrm{H}_{2} \mathrm{O} / \mathrm{O}_{2} \text { on one side, } \\
\mathrm{O}_{2} \text { (+ diluent?) on other }\end{array}$ & $\mathrm{La}(\mathrm{Ca}) \mathrm{CrO}_{3}$ \\
\hline Interconnects & $600-850$ & 2.5 & $\mathrm{H}_{2} \mathrm{O}, \mathrm{O}_{2}, \mathrm{H}_{2}$ & $\begin{array}{l}\text { Low volatility chromia } \\
\text { formers or reduced } \\
\text { reaction-rate alumina } \\
\text { formers } \\
\end{array}$ \\
\hline $\begin{array}{l}\text { Balance of Plant Components } \\
\text { Steam-Hydrogen Separator/Recuperator } \\
\text { Primary Side } \\
\text { Secondary Side } \\
\end{array}$ & $\begin{array}{l}700-850 \\
25 \text { to } 450 \\
\end{array}$ & $\begin{array}{l}2.5 \\
2.5\end{array}$ & $\begin{array}{c}\text { variable } \mathrm{H}_{2} \mathrm{O}-\mathrm{H}_{2} \\
\mathrm{H}_{2} \mathrm{O}\end{array}$ & 214, MA956, MA75 \\
\hline $\begin{array}{l}\text { Steam-Hydrogen Separator/Membrane } \\
\text { Primary Side } \\
\text { Secondary Side } \\
\end{array}$ & $\begin{array}{l}800-900 \\
800-900\end{array}$ & $\begin{array}{l}2.5 \\
2.5\end{array}$ & $\begin{array}{c}90 \text { v/o } \mathrm{H}_{2} \mathrm{O}, 10 \text { v/o } \mathrm{H}_{2} \\
\mathrm{H}_{2},<1 \text { v/o } \mathrm{H}_{2} \mathrm{O}\end{array}$ & $\mathrm{Al}_{2} \mathrm{O}_{3}, \mathrm{Cr}_{2} \mathrm{O}_{3}$ \\
\hline $\begin{array}{l}\text { Hydrogen Cooler/Recuperator } \\
\text { Primary Side } \\
\text { Secondary Side } \\
\end{array}$ & $\begin{array}{l}850 \text { to } 25 \\
25 \text { to } 450\end{array}$ & $\begin{array}{l}2.5 \\
2.5\end{array}$ & $\begin{array}{c}\mathrm{H}_{2},<10 \text { v/o } \mathrm{H}_{2} \mathrm{O} \\
\mathrm{H}_{2} \mathrm{O}\end{array}$ & 214, MA956, MA754 \\
\hline $\begin{array}{l}\text { Oxygen Cooler/Recuperator } \\
\text { Primary Side } \\
\text { Secondary Side }\end{array}$ & $\begin{array}{l}850 \text { to } 25 \\
25 \text { to } 450\end{array}$ & $\begin{array}{l}2.0-3.5 \\
2.5\end{array}$ & $\begin{array}{c}\mathrm{O}_{2}(+ \text { diluent? }) \\
\mathrm{H}_{2} \mathrm{O}\end{array}$ & $\begin{array}{l}617,230, \mathrm{~B} 2,214 \\
\text { ceramic oxides }\end{array}$ \\
\hline $\begin{array}{l}\text { Steam Superheater } \\
\text { Primary Side } \\
\text { Secondary Side }\end{array}$ & $\begin{array}{l}900-950 \\
750-850\end{array}$ & $\begin{array}{c}6.8 / 0.1 \\
5\end{array}$ & $\begin{array}{l}\mathrm{He} / \text { molten salt } \\
\mathrm{H}_{2} \mathrm{O}\end{array}$ & $\begin{array}{c}617,625,230, \mathrm{~B} 2 \\
214,242\end{array}$ \\
\hline
\end{tabular}

\section{Steam-Hydrogen Separator}

Separation of the hydrogen-steam mixture exiting from the HTE cells can be done either through condensation of the steam or through the use of a high-temperature, selectively permeable membrane. Condensation requires heat exchangers for cooling the mixture and reheating of the condensed water, lowering the overall efficiency of the process. The use of an inorganic, hydrogen permeable membrane would allow nearly isothermal and constant pressure operation of the electrolytic plant. The durability and performance of such a membrane in the reducing environment of the $800^{\circ} \mathrm{C}$ steam-hydrogen mixture will have to be investigated. Following the separation of the process stream, the hydrogen product will be cooled and collected for use and the water will be recycled back into the feed stream for the HTE cells.

\section{Hydrogen-Cooling Heat Exchanger}

If membranes are successfully used for high-temperature separation of hydrogen from the HTE cell, it will necessary to cool the hydrogen, prior to its collection for storage or transmission. If possible, this will be done with a recuperative heat exchanger to provide heating of the HTE-cell feed stream. If materials or system constraints do not permit the cooling from the very high temperatures typical of cell output conditions, it may be necessary to cool the hydrogen via adiabatic expansion to the point that it can be reasonably handled. Because of the reducing conditions, the use of metal heat exchangers for cooling the hydrogen flow should be feasible.

\section{Oxygen-Cooling Heat Exchanger}

If the waste heat from the high-temperature oxygen stream is to be recovered for feed water heating, significant materials challenges are anticipated for the heat exchanger and associated piping that will comprise the recuperator utilized to cool the exiting oxygen stream. If no diluent 
(e.g. nitrogen or air) is used, the piping and heat exchangers needed will be exposed to extremely oxidizing conditions. If the primary surfaces of the oxygen cooler cannot be adequately protected, possibly with a noble metal or ceramic layer, it may be also be necessary to cool the oxygen via adiabatic expansion to the point that it can be reasonably handled.

\section{Steam Superheater}

The steam feed to the HTE cell must be heated to the desired process temperature in the steam superheater. The steam input to the superheater will come from some combination of the output of the steam-hydrogen separator, the hydrogen and oxygen heat exchangers, and an auxiliary make-up source. The high-temperature process heat for the superheater will be supplied by the nuclear island and likely consist of either high-pressure helium or molten salt.

\subsubsection{Prioritized Materials Research Needs for HTE System Components}

\section{HTE Cell Interconnect Plate}

Ascertaining whether or not it will be possible to use metallic interconnects in the HTE cell will primarily be determined by the response of the material in high-oxygen content at temperatures up to $850^{\circ} \mathrm{C}$. No existing metallic materials have been identified that are known to adequately function in these conditions. While alumina-scale forming metals would likely have the corrosion resistance for such service, they are very difficult to form and would likely develop a surface layer that is too electrically insulating to be acceptable. The only other class of alloys that might perform adequately are the chromia-scale forming materials but the high inherent volatility of chromium at such service conditions would likely make these alloys unstable in thin sections.

Since there is the alternative of using ceramic interconnects or running the cell at lower temperatures to meet the early needs of demonstrating nuclear HTE technology, even at an elevated system cost, the priority of this research was judged to be medium.

\section{Steam-Hydrogen Separator}

The class of materials most likely to operate at the high temperatures and hydrogen contents required for a steam-hydrogen separation condenser is that of alumina-scale forming alloys. These materials are inherently hard to form and very challenging to weld. Corrosion, fabrication, and welding screening of these materials will need to be evaluated. Considering that dropping the required operating temperatures for this component may be possible by adiabatic expansion, these materials issues are given a medium priority.

If the separation of the hydrogen-steam mixture exiting from the HTE cells could be done through the use of a high-temperature, selectively permeable membrane, the overall efficiency and economy of the process could be significantly improved. The existing technology for producing inorganic selectively permeable membranes that are appropriate for hydrogen is already well established. The questions relate to the selection of materials that are stable in the service environment and offer high separation efficiencies. The ceramic materials listed in Table 42 are likely candidates. Considering that there are technologies and materials likely to provide steam-hydrogen separation, this work could be addressed at a medium priority in the near term while the program focuses on viability issues. However, given the likelihood of success and strong potential impact on efficiency and economics, it should be addressed at a higher priority as the program proceeds [3.49]. 


\section{Hydrogen-Cooling Heat Exchanger}

The class of materials most likely to operate at the high temperatures and hydrogen contents of this component are alumina-scale forming alloys. The same materials issues and approaches to addressing the steam-hydrogen separation by condensation are also applicable to this component. Considering that dropping the service temperature for this component may be possible by adiabatic expansion, even though less energy will be recovered, this is not a significant viability issue, hence it is given a medium priority.

\section{Oxygen-Cooling Heat Exchanger}

The anticipated service conditions of very high temperature and oxygen contents on the primary circuit side of this component provide a particular challenge for materials. No existing material candidates have been identified that meet all service requirements. The alloys identified in Table 42 might be useable, but corrosion testing will be required to ascertain if lifetimes are long enough to be considered. It may also be possible to consider the class of ceramic oxides if fabrication issues and the relatively low thermal conductivity of these materials do not preclude them. Considering that dropping the service temperature for this component may be possible by adiabatic expansion, even though less energy will be recovered, this is not a significant viability issue. Moreover, since the likelihood of success is not considered high, this area is given a low priority.

\section{Steam Superheater}

Whether the high-temperature process heat for the superheater will be supplied using highpressure helium or molten salt will be the major parameter in selecting and qualifying a material for service in this component, since the material compatibility issues are so different. While materials screening for corrosion on the steam side will be required for all the materials candidates, molten salt service will limit these candidates and require appropriate corrosion screening for B2, 242, and 214. Candidates for helium service would include 617, 625, 230, B2, and 214. Additionally, given the relatively low fabricability and weldability of alloy 214 , an assessment of it would be required. Since it anticipated that some of the alloys being considered would function in the superheater, and the major question is service life, not viability, this area is given a medium priority.

\subsubsection{Summary of High Priority Materials Research Areas for Nuclear Hydrogen Production}

A wide range of materials research areas have been identified that will need to be addressed before the three systems proposed for nuclear hydrogen production can be deployed. This research covers issues of materials compatibility, high-temperature strength and stability of materials, and fabrication technologies. However, a number of key areas were identified as particularly high priority items that must be addressed early in the program. These areas are summarized below and included in Table 43. Obtaining the candidate materials identified and evaluating them under the environmental conditions that will envelop their service will comprise the next steps for the $\mathrm{NHI}$ materials program. 
Table 43. Summary of high priority materials research issues for the NHI program.

\begin{tabular}{|c|c|c|c|}
\hline System & Component & Research Focus & Comment \\
\hline \multirow[t]{4}{*}{ SI } & $\mathrm{H}_{2} \mathrm{SO}_{4}$ Concentrator & Corrosion screening & $\begin{array}{c}\text { Technical viability } \\
\text { issue }\end{array}$ \\
\hline & $\mathrm{H}_{2} \mathrm{SO}_{4}$ Vaporizer & Corrosion screening & $\begin{array}{c}\text { Technical viability } \\
\text { issue }\end{array}$ \\
\hline & HI Reactive Distillation Column & Corrosion screening & $\begin{array}{c}\text { Technical viability } \\
\text { issue }\end{array}$ \\
\hline & Inorganic Membranes & $\begin{array}{l}\text { Performance and } \\
\text { corrosion screening }\end{array}$ & $\begin{array}{c}\text { Technical viability } \\
\text { issue }\end{array}$ \\
\hline \multirow[t]{3}{*}{$\mathrm{Ca}-\mathrm{Br}$} & Reaction Bed HX & Corrosion screening & $\begin{array}{c}\text { Technical viability } \\
\text { issue }\end{array}$ \\
\hline & $\mathrm{Ca}-\mathrm{Br} / \mathrm{HBr} \mathrm{Hx}$ & Corrosion screening & $\begin{array}{c}\text { Technical viability } \\
\text { issue }\end{array}$ \\
\hline & Reaction Bed Vessel & Corrosion screening & $\begin{array}{c}\text { Technical viability, } \\
\text { if not internally } \\
\text { insulated }\end{array}$ \\
\hline \multirow[t]{5}{*}{ HTE. } & Metallic Inteconnects & $\begin{array}{l}\text { Protective surface layer } \\
\text { modifications } \\
\end{array}$ & $\begin{array}{c}\text { Economic viability } \\
\text { issue }\end{array}$ \\
\hline & Steam-Hydrogen Separator & Corrosion screening & $\begin{array}{c}\text { Economic viability } \\
\text { issue }\end{array}$ \\
\hline & Oxygen HX & Corrosion screening & $\begin{array}{c}\text { Economic viability } \\
\text { issue }\end{array}$ \\
\hline & Hydrogen HX & Corrosion screening & $\begin{array}{c}\text { Economic viability } \\
\text { issue }\end{array}$ \\
\hline & Inorganic Membranes & $\begin{array}{l}\text { Performance and } \\
\text { corrosion screening }\end{array}$ & $\begin{array}{c}\text { Economic viability } \\
\text { issue }\end{array}$ \\
\hline
\end{tabular}

\subsubsection{High-Priority Materials R\&D for the SI System}

Three areas of materials compatibility research were identified for the SI system as very high priority issues. These include the screening of materials for service in both the concentrator and vaporizer portions of the sulfuric acid concentration and decomposition section and those used in the reactive distillation column of the hydrogen iodide decomposition section. At the present time, candidate materials have been identified for these service conditions, but the environments are known to be extremely aggressive and performance of even the most promising materials is not adequately established to ensure system viability.

The one additional area of high priority research identified for the SI system was the assessment of high-temperature inorganic membranes for separation of decomposition products of sulfuric acid to potentially reduce peak required temperatures, and associated structural materials requirements, in the hydrogen generation plant and the nuclear reactor providing the process heat.

\subsubsection{High-Priority Materials R\&D for the Ca-Br System}

One area of materials research judged to be of high priority for the $\mathrm{Ca}-\mathrm{Br}$ systems is that of corrosion screening of the materials for the internal heat exchanger within the reaction beds. The wide range of high operating temperatures and widely varying reactants in which these heat exchangers will operate as the beds change from modes of production, where $\mathrm{HBr}$ is replaced by steam, to regeneration, where bromine is replaced by pure oxygen, will create a significant challenge for the heat exchanger materials. 
Investigation of the corrosion resistance of materials for the heat exchanger that will cool the process stream from the reaction beds prior to its introduction into the plasmatron, where the combination of the $\mathrm{HBr}$, bromine, and water must be accommodated is also a very high priority.

The final area that may or may not be a high priority for the $\mathrm{Ca}-\mathrm{Br}$ system is that of the vessel materials that will enclose the reaction beds. If the decision is made to internally insulate this vessel, the reduction in temperature will allow the use of nickel-clad, low-alloy steel. However, if the vessel is not insulated from the operating temperatures required for the bed, the corrosion resistance of the limited materials identified as possible candidates for that application will need to be screened as a high priority task.

\subsubsection{High-Priority Materials R\&D for the HTE System}

Several areas of research were identified for the HTE system that will need to be addressed to assess if materials are available to enable higher efficiency operation and improved economic viability. These include materials for metallic interconnects in the electrolytic cell, as well as materials to enable higher temperature operation of the steam-hydrogen separator and the recuperators for hydrogen and oxygen cooling. Since alternate approaches are available, such as ceramic interconnects or partial adiabatic cooling, these issues should not affect the operational viability of the system and, hence, were not judged to be a high technical priority. If the economic consequences of using the more expensive or less efficient alternate approaches are later judged to affect the overall viability of the system, these issues should be given a high priority in the $\mathrm{NHI}$ materials program.

The only other issue that might also be raised to a high priority on economic grounds is the investigation of the use of organic membranes to enable nearly isothermal (and hence much more economical) separation of hydrogen from steam in the output stream from the cell.

\subsubsection{Schedule and Funding Requirements for Nuclear Hydrogen Production Materials}

The overall schedule and associated funding requirements for the materials R\&D needed for the $\mathrm{NHI}$ program are driven by the need to deploy redundant hydrogen generation technology demonstration facilities in conjunction with the deployment of the NGNP, now expected before 2020. To deploy demonstration-scale hydrogen generation capacity ( $\approx 50 \mathrm{MW})$ as part of the NGNP, will require intermediate technology scale-up demonstrations. It is currently expected this be done in three phases by demonstrating hydrogen generation capability at the lab scale $(\approx 1 \mathrm{~kW})$ by about 2007 and the pilot-plant scale $(500 \mathrm{~kW}-1 \mathrm{MW})$ by about 2011 , prior to the final demonstration scale by about 2020.

Given the unknowns of both the design details of the nuclear hydrogen generation systems and the materials needed for their construction, this is a very aggressive schedule. A high level summary of R\&D plans and schedules for materials research needed to meet the stated deployment time schedule is provided below. The schedule assumes that the required funding will be available.

\section{Milestones}

FY 2006

- Perform initial evaluation of high temperature inorganic membranes for $\mathrm{H}_{2} \mathrm{SO}_{4}$ decomposition 
- Perform evaluation of materials for various components for use in the sulfur-iodine cycle

- Perform evaluation of novel oxygen and hydrogen electrodes for high temperature steam electrolysis

- Perform evaluation of high temperature inorganic membrane for separation of hydrogen and steam for the high temperature steam electrolysis process

FY 2007

- Perform evaluation of high temperature inorganic membranes for $\mathrm{H}_{2} \mathrm{SO}_{4}$ decomposition

- Perform evaluation of materials for various components for use in the sulfur-iodine cycle

- Perform evaluation of novel oxygen and hydrogen electrodes for high temperature steam electrolysis

- Perform evaluation of high temperature inorganic membrane for separation of hydrogen and steam for the high temperature steam electrolysis process

FY 2008-2009

- Down select materials for various process

- Initiate long-term evaluation of down-selected materials

FY 2010-2015

- Complete evaluation of down selected materials

\section{References}

[3.1] G. O. Hayner, et al., September, 2005, Next Generation Nuclear Plant Materials Research and Development Program Plan. INEEL/EXT-05-00758

[3.2] J. Buongiorno, P. MacDonald, W. R. Corwin, L. K. Mansur, R. K. Nanstad, R. W. Swindeman, A. F. Rowcliff, D. F. Wilson, I. G. Wright, and G. Was, September 2003, Supercritical Water Reactor (SCWR) Survey of Materials Experience and R\&D Needs to Assess Viability. INEEL/EXT-03-00693 (Rev. 1)

[3.3] W. R. Corwin, et al., The Gas Fast Reactor (GFR) Survey of Materials Experience and R\&D Needs to Assess Viability, ORNL/TM-2004/99, April 30, 2004 (Draft)

[3.4] Generation IV Nuclear Energy Systems Ten-Year Program Plan, Fiscal Year 2005 Appendix 4: Lead-cooled Fast Reactor, Office of Advanced Nuclear Research, DOE Office of Nuclear Energy, Science and Technology, March 2005.

[3.5] The Gas-Cooled Fast Reactor (GFR) Material Requirements for the Material Selection and Qualification Program, INEEL/EXT-04-01606 (Rev 0), August 2004 
[3.6] Materials Requirements for Nuclear Hydrogen Generation Systems, W. R. Corwin, et al., (Draft) September 21, 2004.

[3.7] V. N. Shah, S. Majumdar, and K. Natesan, Review and Assessment of Codes and Procedures for HTGR Components, NUREG/CR-6816 (ANL-02/36), Argonne National Laboratory, June 2003.

[3.8] 2001 ASME Boiler and Pressure Vessel Code, Sect. III, Subsect. NH, Rules for Construction of Nuclear Facility Components, Class I Components in Elevated Temperature Service, Am. Soc. of Mechanical Engineers.

[3.9] J. M. Corum and T. E. McGreevy, R\&D Plan for Development of High-Temperature Structural Design Technology for Generation IV Reactor Systems, ORNL/TM-2004/309, Oak Ridge National Laboratory, December 2004.

[3.10] D. S. Griffin, "Elevated-Temperature Structural Design Evaluation Issues in LMFBR Licensing," Proceedings of Eighth International Conference on Structural Mechanics in Reactor Technology, Vol. L, Paper L9/1, Brussels, August 1985.

[3.11] K. Tsukimori, et al., "Development of FBR Piping Bellows Joints in Japan," Nuclear Engineering and Design, 155, 571-589, May 1995.

[3.12] J. M. Corum and J. J. Blass, "Rules for Design of Alloy 617 Nuclear Components to Very High Temperatures," Fatigue, Fracture, and Risk, PVP-Vol. 215, 147-153, Am. Soc. of Mechanical Engineers, 1991.

[3.13] R. I. Jetter and T. E. McGreevy, Jetter, Simplified Design Criteria for Very High Temperature Applications in Generation IV Reactor," ORNL/TM-2004/308, December 6, 2004.

[3.14] T. E. McGreevy, D. M. Marriott, P. Carter, High-Temperature Design Methods Development Advances for 617: Status \& Plans, ORNL/TM-2005/515, July 28, 2005.

[3.15] R5, The R5 Procedures, UK, 2003.

[3.16] R6, The R6 Procedures, UK, 2003.

[3.17] RCC-MR, Design and Construction Rules for Mechanical Components of FBR Nuclear Islands, AFCEN, 2002.

[3.18] J. C. H. Henager and R. G. Hoagland, Acta Mat 49 (2001) 3739.

[3.19] J. C. H. Henager, C. A. Lewinsohn and R. H. Jones, Acta Mat 49 (2001) 3727

[3.20] R. L. Klueh and D. R. Harries, "High-chromium Ferritic and Martensitic Steels for Nuclear Applications", ASTM stock number: MONO3, (2001), American Society for Testing and Materials, West Conshohocken, PA.

[3.21] D. S. Gelles, "Microstructural Examination of Commercial Ferritic Alloys at 200 dpa", JNM 233-237 (1996) 293-298. 
[3.22] D. S. Gelles "Void swelling in binary Fe-Cr alloys at 200 dpa”, JNM 225 (1995) 163-174.

[3.23] F. A. Garner, M. B. Toloczko, and B. H. Sencer, "Comparison of swelling and irradiation creep behavior of fcc-austenitic and bcc-ferritic/martensitic alloys at high neutron exposure", JNM 276 (2000) 123-142.

[3.24] M. B. Toloczko, F. A. Garner, and C. R. Eiholzer, "Irradiation creep and swelling of the US fusion heats of HT9 and 9Cr-IMo to 208 dpa at 400 ${ }^{\circ}$ “", JNM 212 (1994) 604.

[3.25] L. K. Mansur, Theory and experimental background on dimensional changes in irradiated alloys", JNM 216 (1994) 97.

[3.26] P. Olsson, I. A. Abrikosov, L. Vitos, and J. Wallenius, "Ab initio formation energies of FeCr alloys", JNM 321 (2003) 84-90.

[3.27] R. L. Klueh, P. J. Maziasz, I. S. Kim, L. Heatherly, D. T. Hoelzer, N. Hashimoto, E. A. Kenik, and K. Miyahara, "Tensile and creep properties of an oxide dispersionstrengthened ferritic steel”, JNM 307-311 (2002) 773-777.

[3.28] J. J. Sienicki, A. V. Moisseytsev, P. A. Pfeiffer, W. S. Yang, M. A. Smith, S. J. Kim, Y. D. Bodnar, D. C. Wade, and L. L. Leibowitz, "SSTAR Lead-cooled, Small Modular Fast Reactor with Nitride Fuel", Workshop on Advanced Reactors with Innovative Fuels, ARWIF-2005, Oak Ridge, February 16-18, 2005.

[3.29] R. L. Klueh, N. Hashimoto, R. F. Buck, and M. A. Sokolov, "A potential new ferritic/martensitic steel for fusion applications", JNM 283-287 (2000) 697-701.

[3.30] S. Ukai, T. Narita, A. Alamo, and P. Parmentier, "Tube manufacturing trials by different routes in 9CrW-ODS martensitic steels", JNM 329-333 (2004) 356-361.

[3.31] D. T. Hoelzer, G. R. Odette, M. J. Alinger, D. S. Gelles, A. F. Rowcliffe, R. L Klueh, B. A. Pint, and P. J. Maziasz, "Advanced Alloy Systems", Fusion Materials Science peer review, August 27-28, 2001, University of California-Santa Barbara UCSB.

[3.32] M. B. Toloczko, D. S. Gelles, F. A. Garner, R. J. Kurtz, and K. Abe, "Irradiation creep and swelling from 400 to $600^{\circ} \mathrm{C}$ of the oxide dispersion strengthened ferritic alloy MA957", JNM 329-333 (2004) 352-355.

[3.33] S. Yamashita, N. Akasaka, and S. Ohnuki, "Nano-oxide particle stability of 9-12Cr grain morphology modified ODS steels under neutron irradiation", JNM 329-333 (2004) 377381.

[3.34] I.-S.Kim, J. D. Hunn, N. Hashimoto, D. L. Larson, P. J. Maziasz, K. Miyahara, and E. H. Lee, "Defect and void evolution in oxide dispersion strengthened ferritic steels under 3.2 MeV Fe+ ion irradiation with simultaneous helium injection", JNM 280 (2000) 264-274.

[3.35] PPT semiannual, "Unpublished results from William G. Halsey"

[3.36] A. Alamo, M. Horsten, X. Averty, E. I. Materna-Morris, M. Rieth, and J. C. Brachet, "Mechanical behavior of reduced-activation and conventional martensitic steels after neutron irradiation in the range $250-450^{\circ} \mathrm{C}$ ", JNM 283-287 (2000) 353-357. 
[3.37] Klueh [JNM 225(1995)]

[3.38] PIE FFTF, "Unpublished results from William G. Halsey"

[3.39] Y. Dai, X. J. Jia, and K. Farrell, "Mechanical properties of modified 9Cr-1Mo (T91) irradiated at $<300^{\circ} \mathrm{C}$ in SINQ Target-3", JNM 318 (2003) 192-199.

[3.40] R. L. Klueh, Ji-Jung Kai, and D. J. Alexander, "Microstructure-mechanical properties correlation of irradiated conventional and reduced-activation martensitic steels", JNM 225 (1995) 175-186.

[3.41] J. L. Seran, A. Alamo, A. Maillard, H. Touron, J. C. Brachet, P. Dubuisson, and O. Rabouille, "Pre- and post-irradiation mechanical properties of ferritic-martensitic steels for fusion applications: EM10 base metal and EM10/EM10 welds", JNM 212-215 (1994) 588-593.

[3.42] S. J. Zinkle and N. M. Ghoniem, Fus. Eng. Des. 51-52 (2000) 55.

[3.43] E. Lara-Curzio, in Comprehensive Composites Encyclopedia vol. 4-21, 2000) p. 533.

[3.44] S. J. Zinkle and N. M. Ghoniem, Operating temperature windows for fusion reactor structural materials, Fusion Eng. Design 49-50 (2000) 709-717.

[3.45] S. J. Zinkle, L. J. Ott, D. T. Ingersoll, R. J. Ellis and M. L. Grossbeck, Overview of materials technologies for space nuclear power and propulsion, in M.S. El-Genk (ed.) Space Technology and Applications International Forum-STAIF 2002 (AIP Conf. Proc. vol. 608), American Institute of Physics, 2002, pp. 1063-1074.

[3.46] R. L. Klueh et al., Tensile and creep properties of an oxide dispersion-strengthened ferritic steel, J. Nucl. Mater. 307-311 (2002) 773-777.

[3.47] M. K. Miller, E. A. Kenik, K. F. Russell, L. Heatherly, D. T. Hoelzer and P. J. Maziasz, Atom probe tomography of nanoscale particles in ODS ferritic alloys, Mater. Sci. Eng. A 353 (2003) 140-145.

[3.48] D. F. Wilson and B. L. Bischoff, Membrances for Application to High Temperature $\mathrm{H}_{2} \mathrm{SO}_{4}$ Decomposition, ORNL/TM-2005/521, September 1, 2005 (Draft)

[3.49] B. L. Bischoff, Roddie R. Judkins, and Lawrence E. Powell, Application of Inorganic Membrances to High Temperature Electrolysis, ORNL/TM-2005/521, September 1, 2005 (Draft)

\subsection{CROSSCUTTING MATERIALS RESEARCH PROGRAM}

Four interrelated technical areas of materials R\&D are included within the Gen IV Crosscutting Materials Research Program: 
(1) qualification of materials for service within the vessel and core of the reactors that must withstand radiation-induced challenges;

(2) qualification of materials for service in the balance of plant that must withstand hightemperature challenges;

(3) the development of physically based validated models for predicting long-term, microstructure-property relationships for the high-temperatures, extended-operation periods, and high irradiation doses that will exist in Gen IV reactors; and

(4) the development of an updated high-temperature structural design methodology to provide a basis for design, use, and codification of materials under combined timeindependent and time-dependent loadings.

Additionally, the overall program management function for the Gen IV Integrated Materials Program is maintained within Crosscutting Materials Research. This includes the development and management of the technical crosscutting research areas, the materials research activities that address reactor-specific and energy-conversion system requirements, and the coordination of U.S. Gen IV materials research with the external domestic programs and international partners.

During the initial years of the Crosscutting Materials Research Program, the primary activity was the assessment of materials needs for the Gen IV reactor and NHI system concepts being actively pursued within the U.S. program. The largest aspect of that planning was working with the SIMS and PMs and their staffs to understand the system and component requirements for each reactor system and, based on those requirements, developing the initial materials R\&D programs needed to address the reactor systems. Additionally, the insight gained by understanding those system needs and developing plans to address them has been used to formulate the detailed plans for the four crosscutting materials areas listed above.

Detailed assessment of needs, status, and development of the research plans in the technical crosscutting areas, microstructural analysis and modeling and high-temperature structural design methodology, are described in reports on those subjects. [4.1-4.11]. Summaries of the issues, needs, and resulting research thrusts for the four crosscutting technical areas are provided in the sections that follow.

\subsection{QUALIFICATION OF MATERIALS FOR RADIATION SERVICE}

Many materials challenges of the service environments within specific reactor concepts of the Gen IV Initiative will be common across the different platforms. Of these common aspects, service temperature and neutron exposure will have the greatest influence on material performance and component lifetime. Therefore, combining the evaluation of materials performance as a function of irradiation exposure offers a unique opportunity for addressing the materials development and qualification needs for multiple concepts with a coordinated set of experiments designed to determine properties and irradiation behavior under relevant service conditions. Evaluation of candidate materials that can be used for multiple platforms under coordinated irradiation exposure conditions offers both an improved overall database for predicting materials behavior under operating conditions and significant potential cost savings when compared to conducting separate irradiation evaluations for each reactor concept.

Several factors define the allowable dose for structural and cladding materials at a particular operating temperature in a nuclear reactor. Key structural performance issues for most irradiated metallic alloys are embrittlement and irradiation creep at low temperatures and cracking, swelling, and deformation at high temperatures 
At low temperatures of $300-600^{\circ} \mathrm{C}$, applicable for lower temperature reactor vessels and internals, the evolution of non-equilibrium structures and chemistries promote a hardened matrix and lower grain-boundary cohesive strengths, thereby reducing the tensile stress required for cleavage or intergranular fracture in metals. Candidate metallic materials will require fatigue resistance, adequate strength, and resistance to diffusion-driven processes such as radiationinduced segregation and precipitation, void formation and growth, dislocation-loop growth, creep, and high-temperature corrosion and stress-induced corrosion cracking processes. In ceramics, lower operating temperatures result in amorphization or thermal-conductivity degradation. The materials needs studies for the different reactor concepts completed this year identified a range of existing and advanced alloys that are potential candidate materials in this temperature range, include austenitic iron- and nickel-base alloys, F/M alloys (including advanced $9 \mathrm{Cr}-1 \mathrm{Mo}$ and $12 \mathrm{Cr}-1 \mathrm{Mo}$ materials and the low-nickel, reduced-activation alloys developed for the U.S. Fusion Materials Program), and ODS alloys. Most austenitic and nickelbased materials, with the exception of low-swelling austenitic stainless steels, are unlikely to be viable at higher temperatures and doses within this range $\left(>5-10 \mathrm{dpa}\right.$ and $\left.550^{\circ} \mathrm{C}\right)$ due to swelling.

At higher operating temperatures between $600^{\circ}$ and $800^{\circ} \mathrm{C}$, needed for some core-internal applications, materials degradation mechanisms include dimensional instability caused by thermal creep, He embrittlement of grain boundaries, and cavity swelling or anisotropic growth. All these effects become more pronounced with increasing exposure and result in degradation of macroscopic properties that limit safe or useful operation of affected components. Conventional F/M steels cannot be used above $600^{\circ} \mathrm{C}$ with any significant level of applied stress. The materials needs studies conducted this year identified traditional and modified austenitic stainless steels, ODS F/M steels, precipitate-strengthened iron- or nickel-based superalloys, or refractory alloys of molybdenum, niobium, and tantalum as potential candidates within this temperature range. Nickel-based alloys are not likely to be used in core in this temperature range due to embrittlement, phase instability issues, and swelling at high doses $(>5-10 \mathrm{dpa})$.

For still higher temperatures, exceeding $800^{\circ} \mathrm{C}$, candidate materials become more limited. Only very high-temperature nickel-based alloys such as alloy 617 or Hastalloy X or XR and high-alloy high-nickel alloys, such as Incoloy 800 or $800 \mathrm{HT}$, remain among the typically available commercial materials, and their approved applications are still limited to maximum temperatures below the needs of the NGNP. Of the potential metal-based systems, only advanced ODS and refractory-metal based systems (e.g. tungsten, niobium, molybdenum, vanadium, etc.) are believed to have the potential to operate in this temperature range. Insufficient information is known about the radiation performance of these materials at these temperatures. This lack of irradiation information, coupled with the uncertainties associated with the long-term strength and stability of these metallic alloys at very-high temperatures, has lead to the inclusion of ceramics (primarily silicon carbide composites), graphite, and carbon-carbon composites as the primary near-term candidates for these very high-temperature reactor components in radiation service.

\subsection{QUALIFICATION OF MATERIALS FOR HIGH-TEMPERATURE SERVICE}

Although the operating conditions vary significantly from one reactor system to the next in the Generation IV Initiative, significant commonality exists with regard to the selection of materials for their high-temperature structural components. This commonality reflects the fact that materials for Class I nuclear components for service above the temperature limits of ASME Section III will be limited to those materials incorporated into Section III, Subsection $\mathrm{NH}$. Currently, this subsection permits construction with a very few alloys, namely type $304 \mathrm{H}$ and 
type $316 \mathrm{H}$ stainless steels, alloy $800 \mathrm{H}$, and $21 / 4 \mathrm{Cr}-1 \mathrm{Mo}$ steel (class 1 ). The incorporation of Gr91 (modified $9 \mathrm{Cr}-1 \mathrm{Mo}-\mathrm{V}$ ) steel is in progress. To take full advantage of the potential of the reactor concepts in the Generation IV Initiative, it will be necessary to utilize the advances made in the structural materials technology, select the most promising candidate materials for higher temperature service, and move forward toward acceptance of these materials into the appropriate construction codes.

Even though many of the materials that will be required for construction of high-temperature, out-of-core components will be the same as those used for some in-core applications, the focus of this crosscutting technology development task will be on their unirradiated high-temperature qualification. While short-term tensile and fatigue properties will need to be evaluated for these materials, it is time-dependent creep and creep-fatigue, which are the primary limitations for materials use, that will be most strongly limiting and, hence, principally addressed. The crosscutting technology development associated with high-temperature use of these materials in the presence of neutron irradiation will be addressed in the task on Qualification of Materials for Radiation Service described in Section 4.1.

For the high-temperature materials to be evaluated for out-of-core applications for the Gen IV initiative, the destination of this crosscutting materials research thrust will be their eventual incorporation into ASME Section III, Subsection $\mathrm{NH}$. The materials for such high-temperature service may be separated into several categories by approximate upper-use temperatures. While there is some overlap, and more advanced materials within a class will somewhat extend the temperature limits of current materials, these classes roughly correspond to: (a) ferritic steels including bainitic and martensitic steels up to $12 \%$ chromium for use up to about 650 $700^{\circ} \mathrm{C}$, (b) austenitic stainless steels for use up to about $800-850^{\circ} \mathrm{C}$, (c) high alloys, in which iron content is greater than any other element, and nickel-base alloys for use up to about 900$950^{\circ} \mathrm{C}$, and (d) special materials such as ODS alloys for possible use up to about $1000-1050^{\circ} \mathrm{C}$.

The two primary technical thrusts within this crosscutting activity for the next several years will be to: (1) evaluate the current commercial or near-commercial materials for adequacy of data and properties to incorporate into Subsection NH of the ASME Section III for high-temperature service and begin the codification of those appropriate materials, including required generation of incremental additions to existing data, and (2) perform evaluation and screening of promising advanced materials for higher temperature service, resulting in the selection of candidate materials for further development and eventual inclusion into the Section III Subsection $\mathrm{NH}$. These evaluation and development activities will include all appropriate product forms and section thicknesses needed for required reactor components, including weldments and their constituents (weldmetal, HAZ, and basemetal). Given the accelerated materials qualification activities mandated by the early deployment of the NGNP, it will be necessary to rely almost completely on current commercial materials for the demonstration plant. However, to help optimize performance and minimize costs of follow-on NGNPs, as well as the remaining Gen IV reactors with later anticipated deployment dates, evaluation of advanced materials will be included in the crosscutting research on materials for high-temperature service from the onset of the program. For example, limited and tentative efforts will initially be made on joining of ODS alloys and other hard-to-weld advanced materials.

A particularly important activity that is included within this task is the establishment, population and maintenance of the overall Gen IV materials database. In FY04, an assessment was made of the needs of the Gen IV stakeholders for a database, including SIMs, reactor vendors, regulators, codes and standards bodies, and DOE staff. The need for an integrated database that could be used as a basis for research, design, evaluation, and regulation of Gen IV reactors was strongly endorsed by all stakeholders. In FY05, an implementation plan was established for the development of a web-accessible Gen IV Materials Handbook [4.3], and a system 
including hardware and software that provides the basic functionalities required for the Handbook was assembled in the initial development phase of the plan. Starting in FY06, the plan will be further implemented and the development and maintenance of the database will proceed as a major activity, initially evaluating the basic system, incorporating historical data and then enhancing the functionalities to provide an advanced repository for new data generated within the Gen IV Program. In addition to regular updating with new data generated, functionality enhancements will be continued as new user requirements and new information technologies emerge throughout the life of the Handbook.

\subsection{MICROSTRUCTURAL ANALYSIS AND MODEL DEVELOPMENT}

The fundamental driving force for supporting a theory and modeling task in the Gen IV materials development activity is the inability of experimental programs to cover the breadth of materials and irradiation conditions required for even one of the proposed Gen IV reactor designs. It is a trivial observation that reactor components with lifetimes of up to $\sim 60$ years cannot reach endof-life fluence under prototypic exposure conditions in Gen IV experiments. In some cases, irradiation at higher neutron fluxes in materials test reactors can provide data at the desired fluence, but the effect of accelerated irradiation may alter the material response. More significantly, a range of structural materials will be exposed in environments characterized by temporal and spatial gradients in neutron flux (and hence fluence), temperature, mechanical loading, and chemically-active (corrosive) coolants. As a result, material selection will have to be based on an incomplete experimental database with considerable judgment required to carry out the necessary interpolation and extrapolation.

One of the prominent roles for modeling and microstructural analysis is to provide the basis for making these judgments. The development and application of physically-based models can help interpret the results of experiments that can be carried out only at discrete points within the complete domain of expected exposure conditions, and also provide information for conditions that may be too costly or impossible to reach experimentally. At the same time, the microstructural models can only be reliably developed if an adequate experimental database exists. Uncertainties in material parameters, and the fact that the models are necessarily approximate with respect to the complete set of physical mechanisms that can come into play, mean that experimental data are required for validation and calibration. The required experimental information includes data from engineering experiments (e.g. on dimensional and mechanical property changes, and microstructural measurements from irradiation of candidate materials), and fundamental experiments to verify our understanding of specific mechanisms. Data from these latter experiments, in which specific variables are carefully controlled, are crucial for making confident, model-based extrapolations.

A major aspect of this task is to develop and maintain an integrated link between the modeling and experimental components of the Gen IV materials program. Close interactions with the crosscutting tasks on Materials for Radiation Service and Materials for High-Temperature Service, and related activities for specific reactor concepts are particularly important during the time that the experimental database to support material selection is being generated. These interactions will promote the development of the scientific basis needed to support material choices in the Gen IV program. Although the Gen IV schedule will not likely permit the development of completely new materials, a science-based, integrated program of modeling and key experiments can provide the opportunity to "push the envelope" on materials that are currently in a developmental state by providing an understanding of material behavior in the various reactor environments. Such a program can identify limiting properties and suggest approaches for improving the performance of promising materials, e.g. by changes in alloy chemistry or thermo-mechanical processing. Additionally, the program can provide a much 
improved basis for extrapolating the performance of selected materials to greater neutron exposures and longer times than can be obtained experimentally.

In summary, the overall strategy of this task is to develop physically-based models of microstructural evolution and correlations describing the relationship between microstructure and mechanical properties in order to address the materials challenges associated with the Gen IV program. The goal is to develop the ability to make accurate predictions of radiation-induced dimensional changes and mechanical property changes for Gen IV reactor materials and to describe how these properties evolve in service in the target irradiation environments. Although other tasks for crosscutting and reactor-specific materials are primarily responsible for generating experimental data, this task will help support fundamental experiments and microstructural characterization needed for model development.

\subsubsection{Fundamental Materials Issues in the Fission Reactor Environment}

The response of materials to the in-service environment is determined by a large number of inter-related variables. These include: factors that determine the radiation damage rate (neutron flux level and the neutron energy spectrum), the total damage dose (neutron fluence), temperature, stress level and stress state, and the chemical environment. Moreover, predicting material response is complicated by well-known synergistic interactions among this set of variables; the most common example being the interaction between dose rate and irradiation temperature. The influence of reactor duty cycle and operating history further confound the issue of predicting material response.

As a reasonable and necessary expedient, this task will initially work with relatively simple models for individual processes and properties. This work will build on the foundation of previous modeling work funded by the LMFBR, OFES, and OBES programs. Ongoing development will lead to more robust and comprehensive models as the relevant experience and knowledge base grows. As mentioned above, the integrated modeling program will maintain close links with researchers involved in the experimental and high temperature design tasks during this process. For example, the success of the recently developed "master curve" method of describing fracture behavior in ferritic steels (see ASTM Standard E1921) indicates that it may be possible to obtain a more fundamental understanding of the micromechanical mechanisms that control the ductile-to-brittle transition in these materials. Improved modeling of atomic scale processes and dislocation interactions that are responsible for this embrittlement phenomena are expected to provide this understanding. A second example of the modelingexperimental interface is provided by the development of mechanical performance maps (similar to Ashby maps) that can be used to systematically condense and describe the results obtained from modeling studies and data analysis.

The underlying physical basis of the models that will be developed is microstructural. The models will include the mechanisms that lead to the production, transport and fate of defects and key alloy constituents as a function of the material and irradiation-service variables. The microstructural evolution models will track dimensional changes such as void swelling and irradiation creep and the microstructure will be linked to basic structure-sensitive properties, such as the yield stress. These basic mechanical properties must in turn be linked to other engineering properties, e.g. flow properties and fracture toughness. Microstructural information and mechanical property data developed within the experimental component of the Gen IV program, as well as relevant data generated by other programs such as OFES and OBES, the $\mathrm{NRC}$, and the wider materials science community, will provide the basic information needed for model development and verification. This implies developing and applying:

- individual mechanistic models describing key phenomena

- integrated multiscale models of microstructural evolution and material properties 
- an appropriate mix of dimensional measurements and mechanical property testing

- thorough application of modern microstructural characterization tools

- fundamental experiments to investigate specific mechanisms and provide necessary physical parameters for the models

- verification of model predictions using the results of integral database experiments

- physically-based, engineering correlation models from evolving databases

Near-term needs include the development of kinetic models, including both reaction rate theory and Monte Carlo simulations, that can be used to predict radiation-induced microstructural evolution for critical materials, including advanced oxide-dispersion strengthened steels. A significant investment in first principles calculations is required to support this model development in order to obtain values for critical parameters such as defect formation, migration, and binding energies. Based on the expected Gen IV funding profile, it is likely that the $a b$ initio results will have to be obtained in the context of multi-program collaborations.

\subsubsection{Accelerating Progress in Materials Research}

It is clear that timely resolution of the multiple materials challenges posed by the needs of the Gen IV program will require resources beyond those which are expected to be available. A costeffective approach to accelerating progress in all of the required research areas involves taking advantage of opportunities for collaboration with scientists carrying out relevant work that is funded by other programs. This includes materials research supported by the U.S. NRC, DOE OBES and OFES, as well as research carried out in other countries. A successful example of multi-program, international collaboration is the International Group on Radiation Damage Mechanisms (IGRDM). This consortium of researchers, each of which is funded by their respective institutions, has substantially advanced our understanding of embrittlement mechanisms in light water reactor pressure vessels.

In addition, there are two European examples of well-coordinated, broad-based materials research projects on modeling and simulation of radiation effects that could serve as models for a larger domestic effort. These projects also provide a significant opportunity for collaboration and leveraging of research not funded by the U.S. DOE. The larger of these two projects, which involves 12 European research laboratories and 16 universities, is called PERFECT and is funded by the European Union (http://www.fp6perfect.net). A smaller, but still challenging research effort on developing predictive models for fusion reactor materials is funded within the United Kingdom by their Engineering and Physical Sciences Research Council (http://users.ox.ac.uk/ roberts/sgrgroup/fusion/fusion_main.htm). Some U.S. researchers who are partially funded by the Gen IV project are informally collaborating with their European colleagues involved in these two programs. Collaboration and information exchange are on the basis of "in-kind" research contributions by the U.S. participants. Additional funding to increase the level of U.S. participation in these collaborations would be of substantial benefit to the Gen IV program.

The efficient use of domestic resources also requires that the research groups funded by Gen IV collaborate effectively. Thus, efforts are being made to improve the framework for collaboration between those institutions and individuals that are funded by the Gen IV and AFCl programs. This involves the development of partnerships between the national laboratories as well as between the laboratory staff and university researchers. Several components of the modeling task are good candidates for university-funded research projects.

\subsection{Development Of Improved High Temperature Structural Design Technology}

Time-dependent failure modes and time- and rate-dependent deformation response to timevarying thermal and mechanical loadings characterize the design of Gen IV metallic 
components operating at high-temperatures. The threshold defining high-temperature operation is $371^{\circ} \mathrm{C}\left(700^{\circ} \mathrm{F}\right)$ for the ferritic steels currently permitted for construction of Class 1 nuclear components by the ASME Boiler and Pressure Vessel Code, Section III, Subsection NH, and $427^{\circ} \mathrm{C}\left(800^{\circ} \mathrm{F}\right)$ for the permitted austenitic alloys. The primary role of the High Temperature Structural Design (HTSD) Technology task ${ }^{1}$, discussed in section 3.1.2.6, which is an integral and inseparable part of the overall Gen IV materials program, is three-fold. First it will provide the data and models required by ASME Code groups to formulate time-dependent failure criteria that will assure adequate life for components fabricated from the selected Gen IV materials. ${ }^{2}$ Second, it will provide the experimentally-based constitutive models that are the foundation of the inelastic design analyses specifically required by Subsection $\mathrm{NH}$ of Section III of the ASME Boiler and Pressure Vessel Code, which governs design of elevated-temperature Class 1 nuclear components [4.12]. Third, it will provide appropriate simplified design procedures required for the conceptual and preliminary phases of design and will be useful for many lesscritical regions in final design. This task is thus a key part of the codification and utilization of the selected Gen IV structural materials.

A secondary role of the task deals with regulatory acceptance. Safety assessments, required by $\mathrm{NRC}$, will depend on time-dependent flaw growth and the resulting leak rates from postulated pressure-boundary breaks. This requires a flaw assessment procedure capable of reliably predicting crack-induced failures as well as the size and growth of the resulting opening in the pressure boundary. Identification of an overall proven procedure is a part of this task.

The task is focused primarily on four Gen IV reactor concepts. These concepts, their approximate coolant inlet and outlet temperatures, and representative candidate component materials are shown in Table 44. A common feature of all four concepts is that the coolant outlet temperature is above the threshold for time-dependent deformation and failure behavior for the alloys currently covered by Subsection NH. Actually, component materials should have adequate long-term performance at temperatures about $50^{\circ} \mathrm{C}$ higher than the normal operating temperatures given in Table 44. Furthermore, they must withstand abnormal excursions to even higher temperatures without adversely affecting subsequent component design life. The target design life of Gen IV components is generally 60 years $(526,000 \mathrm{~h})$, which significantly exceeds life times currently allowed by Subsection $\mathrm{NH}$.

The candidate structural materials listed in Table 13 fall largely into two classes: medium-hightemperature alloys, characterized by the $\mathrm{Cr}$ - Mo steels and AISI 304 and 316 stainless steels, and very-high-temperature alloys, characterized by nickel-base alloys. The strategy for the crosscutting development effort described herein is to focus initial efforts on representative materials from each class - modified $9 \mathrm{Cr}-1 \mathrm{Mo}$ steel at medium high temperatures and nickelbase Alloys 617 and 230 at very high temperatures. As other key structural materials are identified for the various reactor concepts, they will be factored into the effort, especially for NGNP components and in those cases where an identified material is common to more than one reactor concept. The pace of the main effort will be dictated by the NGNP schedule and funding, since NGNP is accelerated relative to the schedules for the other concepts.

\footnotetext{
${ }^{1}$ The High Temperature Structural Design task and the High Temperature Materials task are highly integral tasks, which jointly provide for structural design criteria \& procedures and design data used to quantify design criteria \& procedures. The term High Temperature Design Methodology (HTDM) is used to refer to the integration of both tasks as an inseparable requirement to achieve ASME Section III, Subsection NH codification and support licensing for design, construction, and operation of reactors.

${ }^{2} \mathrm{~A}$ clear distinction should be made between the development of criteria (e.g., the damage accumulation rule and multiaxial strength criterion needed to guard against creep rupture) and the design data needed to quantify the criteria (e.g., uniaxial creep-rupture data). The former are largely the purview of the High-Temperature Structural Design Technology task; the latter are the responsibility of the design data generation tasks.
} 
The overall challenges and requirements for designing high-temperature Gen IV components, especially when operating temperatures are at the upper end of the usable range for the chosen materials, as will likely be the case for Gen IV components, are explained, as background, in the Section 3.1.2.6 on HTSD for NGNP. The current scope and coverage of Subsection NH of the ASME Code and its associated Code cases are also outlined in Section 3.1.2.6. Identified shortcomings and limitations, as they apply to Gen IV plant components, are described. Against this backdrop, and the projected NGNP schedule, the requirements for codification and design with the selected Gen IV high-temperature metallic materials and the overall scope and schedule for the required High Temperature Structural Design Technology task are presented in Section 3.1.2.6. The task is divided into six subtasks:

- inelastic design analysis methods,

- failure models for design criteria,

- simplified methods and criteria,

- confirmatory structural tests and analyses,

- safety / reliability assessments, and

- resolution of identified shortcomings, issues, and regulatory concerns.

The activities within this crosscutting task and its associated milestones included in Section 4.7. Respectively, will begin to address the High Temperature Design Methodology needs for materials for the GFR, LFR, and SCWR systems. Specialized schedule-driven reactor-specific needs and the development of high-temperature design methodology for NGNP system materials are addressed in section 3.1.2.6 on NGNP materials. Since the HTDM activities for the NGNP will provide the lead in this overall topical area, the crosscutting HTDM activities will supplement the NGNP tasks as needed for the remaining systems. 
Table 44. Generation IV reactor concepts, coolant temperatures, and representative candidate structural materials.

\begin{tabular}{|c|c|c|}
\hline Reactor concept & $\begin{array}{c}\text { Coolant } \\
\text { temperature, } \\
\mathrm{T}_{\text {in }} / \mathrm{T}_{\text {out }}\left({ }^{\circ} \mathrm{C}\right)\end{array}$ & $\begin{array}{l}\text { Representative components and } \\
\text { candidate structural materials }\end{array}$ \\
\hline $\begin{array}{l}\text { Next Generation Nuclear } \\
\text { Plant (NGNP, very-high- } \\
\text { temperature gas-cooled } \\
\text { reactor) }\end{array}$ & $650 / 950$ & $\begin{array}{l}9 \mathrm{Cr} \text { (Mod9Cr-1Mo) steel for } \\
\text { pressure vessel; nickel-base alloys } \\
617 \text { and } 230 \text { for very-high- } \\
\text { temperature hot-gas components, } \\
\text { including IHX }\end{array}$ \\
\hline $\begin{array}{l}\text { Gas-Cooled Fast Reactor } \\
\text { (GFR) }\end{array}$ & $490 / 850$ & $\begin{array}{l}9 \mathrm{Cr} \text { to } 12 \mathrm{Cr} \text { martensitic steel or } 2 \\
1 / 4 \mathrm{Cr}-1 \mathrm{Mo} \text { steel for pressure } \\
\text { vessel (low-alloy steel if cooled); } \\
\text { nickel-base alloys, AISI } 316 \\
\text { stainless steel, or } 9 \mathrm{Cr} \text { ODS for } \\
\text { very-high-temperature hot-gas } \\
\text { components }\end{array}$ \\
\hline $\begin{array}{l}\text { Supercritical Water } \\
\text { Reactor (SCWR) }\end{array}$ & $280 / 500$ & $\begin{array}{l}\text { SA } 508 \text { Grade } 3 \text { steel, or higher- } \\
\text { strength alternative } 508 \mathrm{Grade} 4 \mathrm{~N} \\
\text { or developmental } 3 \mathrm{Cr}-3 \mathrm{WV} \\
\text { steel, for vessel with insulated } \\
\text { outlet nozzle; existing Subsect. } \mathrm{NH} \\
\text { materials ( } 9 \mathrm{Cr}-1 \mathrm{Mo} \text { steel or } \\
\text { three austenitic alloys), or } \\
\text { improvement thereof, for } \\
\text { uninsulated vessel and for high- } \\
\text { temperature steam lines }\end{array}$ \\
\hline \multirow[t]{2}{*}{$\begin{array}{l}\text { Lead-Cooled Fast } \\
\text { Reactor (LFR) }\end{array}$} & $\begin{array}{l}400 / 550 \text { (near- } \\
\text { term, lead or } \\
\text { lead - bismuth } \\
\text { cooled) }\end{array}$ & $\begin{array}{l}\text { AISI } 304 \text { or } 316 \text { stainless steel, or } \\
\text { modification thereof, for core } \\
\text { vessel; } 21 / 4 \mathrm{Cr}-1 \mathrm{Mo} \text { or } 9 \mathrm{Cr}-1 \\
\text { Mo for heat exchangers; advanced } \\
\text { stainless steels or ferritic - } \\
\text { martensitic steel for upper core } \\
\text { internals }\end{array}$ \\
\hline & $\begin{array}{l}500 / 750-800 \\
\text { (long-term, pure } \\
\text { lead cooled) }\end{array}$ & $\begin{array}{l}\text { Higher temperature alloys for } \\
\text { vessel and heat exchangers; } \\
\text { possibly refractories or ceramics } \\
\text { for core components }\end{array}$ \\
\hline
\end{tabular}

\subsection{System-Specific Materials}

The primary areas of system-specific materials research include structural materials compatibility with coolants and heat-transfer media and materials that will be used with a particular system, such as graphite for the NGNP or structural ceramics for the use in GFR core components. Additionally, high-temperature- and radiation-service materials tasks that must be addressed on such an accelerated schedule that it outpaces crosscutting research have been identified for the NGNP. The expert assistance required to formulate and coordinate such research will be provided from within the crosscutting tasks on the same topical areas

In addition to providing coordination for the reactor-specific needs of the Gen IV Program, it is important to consider the various approaches for their energy conversions system that include both electrical generation and use of process heat for hydrogen production. While many of the 
materials issues for electrical generation are similar to those in the fossil fuel industry, the same cannot be said for hydrogen production. Multiple approaches, described in detail in Section 2.5 of this document on $\mathrm{NHI}$ systems, include the use of thermo-chemical separation and thermally assisted electrolysis. Both of these approaches will have significant materials challenges including high-temperature structural stability, stability and effectiveness of special functional materials for catalysis and separation technology, thermal barrier materials, and materials compatibility with a variety of heat-transfer media and process-related chemicals.

Also of particular concern are the very high-temperature heat exchangers envisioned both on the reactor side and the hydrogen production side of the process-heat transfer loops, as well as the lower temperature heat exchangers used within any chemical separation system. The combination of high-temperature operations and simultaneous exposure to multiple process and heat transfer fluids will present significant challenges to maintain the integrity of the thin sections inherent in heat exchangers.

While some of the specialized requirements for materials will be addressed as part of the related crosscutting task, the remaining specialized materials requirements for the particular reactor and energy conversion systems will need to be addressed separately. Therefore, activities within this subtask will focus on working with the reactor SIMs, the energy conversion crosscutting NTD, and the PM for the NHI program to develop and implement an individualized, yet integrated, materials program that addresses their needs for high-temperature materials, materials compatibility, corrosion, and functional materials in a coordinated, prioritized manner. It is important to note that the detailed milestones for the system-system materials concerns will be specified for and associated required funding allocated directly by the affected SIM, NTD or PM.

The system-specific tasks that have been identified to date are described in detail in Sections 3.1 through 3.5 .

\subsection{National Materials Technology Program Integration}

To help ensure that the materials R\&D activities conducted within the overall Gen IV Reactor Initiative form an integrated, efficient program, an additional task is included to coordinate, prioritize, and implement materials cross-cutting research with that needed for each specific reactor concept and the energy-conversion system. Principal activities within this task will be to work with the SIMs, PMs, and other NTDs to:

- Develop a detailed understanding of the conditions that all major components and subsystems in each reactor concept and energy-conversion system must withstand (e.g. temperature, irradiation dose, corrosive media, etc., and their combinations);

- Collect and evaluate existing related data from domestic and foreign sources to determine deficiencies in materials data or capabilities;

- Provide cross-platform guidance to ensure appropriate materials R\&D is performed in support of each reactor concept, with minimum overlap and no technical voids;

- Ensure that the cross-cutting materials research provides needed and useful information that can be applied to support all reactor concepts; and

- Help ensure that an integrated materials research is developed, prioritized, and implemented to address the materials needs of the overall Gen IV Reactor Initiative.

The major products of this task will be to provide regularly updated reports assessing potential materials for use in all Gen IV reactor concepts and providing recommendations for reactorspecific materials screening and evaluations to identify viable candidate materials. 
The high-level objectives of the Integrated Gen IV National Materials Technology Program for the next ten years are to:

- Complete updated assessments of cross-cutting and reactor-specific materials for use in all Gen IV reactor concepts to identify viable candidate materials;

- Complete the development of a comprehensive irradiation-effects materials database for materials needed for radiation service in Gen IV reactors;

- Complete development of a comprehensive high-temperature materials properties database to support the design, use, and codification of materials needed for Gen IV reactors;

- Complete adequate qualification of the materials to be used in the NGNP reactor to enable the design and ordering of all major components and subsystems;

- Complete development of an improved high-temperature design methodology that will support design, use, and codification of materials needed for Gen IV reactors;

- Complete development of an comprehensive model for predicting long-term properties of materials needed for Gen IV reactors as a function of thermal and irradiation exposure;

- Interface with Gen IV International Forum and relevant domestic and foreign materials research programs to optimize the effectiveness of materials R\&D plan

The anticipated deployment of the NGNP by the end of the next decade will require a strong acceleration of materials qualification needed to enable final design and ordering of long-lead components within the next five to seven years. As a result, a major focus of materials research during the next ten years will be on the qualification of commercial and near-commercial materials and the related high-temperature design methodology needed to specify and order those components. Parallel studies on materials for other reactor concepts will both take advantage of the accelerated work for the NGNP and examine additional materials under other conditions where the NGNP materials studies are inadequate or inappropriate for their conditions. To help level required resources to the extent possible, the additional studies on materials for other reactor concepts will generally increase in scope as portions of the NGNPrelated materials studies are completed.

\subsection{Experimental R\&D Plans For Crosscutting Materials}

A high-level summary of R\&D plans and schedules for the materials crosscutting tasks is provided below. The schedule for major deliverables for all crosscutting activities is predicated on adequate funding. Funding for reactor-specific and energy-conversion-system materials needs other than for planning and coordination will be provided by the individual reactor concepts and energy conversion activities.

\section{Milestones}

FY 2006

- Complete initial low-dose scoping irradiations of commercial and near-commercial materials

- Complete technical review and publish the draft detailed survey of metallic materials for irradiated service in Gen IV reactor internals and RPVs including requirements for irradiation temperatures, temperature overlap and irradiation conditions for fast spectrum reactors GFR/LFR, mixed spectrum reactor SCWR and thermal spectrum reactor NGNP 
- Initiate joining and combined-effects screening studies on commercial and nearcommercial alloys.

- Complete on scoping evaluation of friction stir welding of advanced alloys

- Scrub and evaluate initial population of historical data in materials database

- Complete initial population of materials database with available historical data, and initiate additions of available advanced materials data and new data developed in Gen IV Program

- Evaluate the basic software and hardware system for the electronic materials database and initiate customization for the web-accessible Gen IV Materials Handbook

- Complete beta-test version of Gen IV Materials Handbook

- Provide interim report on creep-fatigue testing of Alloy 617 near the upper temperature range of the material $\left(\sim 950^{\circ} \mathrm{C}\right)$.

- Provide initial report on constitutive model development and testing for Alloy 617.

- Upgrade $2^{\text {nd }}$ creep-fatigue machine and initiate testing of Alloy 230.

- Prepare interim report on results of model-based nucleation phase of the significant extended defects produced under irradiation.

- Initiate development of Monte Carlo model of radiation-induced microstructural evolution, make relevant comparisons with reaction rate theory.

- Prepare updated, status report on integrated R\&D plan for assessment and selection of crosscutting candidate materials for high-temperature and radiation service in Gen IV reactor systems.

FY 2007

- Complete PIE for initial low-dose scoping irradiations of commercial and nearcommercial materials.

- Continue low-dose scoping irradiations of commercial and near-commercial materials.

- Initiate initial low-dose scoping irradiations of advanced metallic materials

- Structure an integrated experimental and modeling approach to investigate radiation effects issues that crosscut the four reactor concepts, with emphasis on critical areas

- Continue studies of time-dependent mechanical properties combined-effects on commercial and near-commercial alloys

- Continue detailed studies of high-temperature, time-dependent properties for advanced candidate materials for high-temperature service and required materials modifications

- Continue joining studies on commercial, near-commercial alloys and advanced hightemperature materials

- Complete development of evaluated description of historical data in materials database

- Continue population of materials database on advanced materials and new data developed in the Gen IV Program by U.S. and foreign partners

- Develop initial product requirements for functionality enhancement and advanced customization of web-accessible Gen IV Materials Handbook 
- Provide interim report on results of creep-fatigue testing of Alloy 617 and Alloy 230.

- Provide interim report on constitutive model development for Alloy 617 and initiate testing in support of constitutive modeling for Alloy 230.

- Prepare interim report on mechanisms responsible for the development of radiationenhanced, -induced, and -modified microstructural changes on advanced alloys.

- Prepare updated, status report on integrated R\&D plan for assessment and selection of crosscutting candidate materials for high-temperature and radiation service in Gen IV reactor systems.

FY 2008

- Perform detailed analysis of available reactor facilities that will accommodate irradiation capsules at conditions needed for high flux-high temperature irradiations for SCWR, GFR and LFR, and low flux-high temperature irradiations for NGNP

- Complete initial low-dose scoping irradiations of advanced materials and low-dose scoping irradiations of commercial and near-commercial materials.

- Complete development of evaluated description of initial advanced materials database

- Continue population of materials database on advanced materials and new data developed in the Gen IV Program by U.S. and foreign partners

- Prepare interim report on initial studies of time-dependent mechanical properties, combined-effects, and joining technology for advanced alloys and provide recommendations for further studies.

- Prepare interim report on kinetics and thermodynamics of formation and stability of the very fine oxide clusters in ODS alloys, and make recommendations on use of ODS alloys.

- Complete initial functionality enhancement and advanced customization of webaccessible Gen IV Materials Handbook

- Provide interim report on results of creep-fatigue testing of Alloy 617 and Alloy 230 and initiate creep-fatigue life prediction modeling efforts.

- Initiate constitutive model development for Alloy 230.

- Prepare interim report on kinetics and thermodynamics of formation and stability of the very fine oxide clusters in ODS alloys, and make recommendations on use of ODS alloys.

- Prepare updated, status report on integrated R\&D plan for assessment and selection of crosscutting candidate materials for high-temperature and radiation service in Gen IV reactor systems.

FY 2009

- Complete PIE of low-dose scoping irradiations.

- Based on analysis of neutronic, volumetric and instrumentation characteristics select host reactor facilities for irradiations and initiate designs of irradiation capsules for GFR, LFR, and SCWR

- Initiate high-dose scoping irradiations of advanced materials for reactor internals 
- Initiate qualification testing of advanced materials for high-temperature service for all advanced reactor concepts

- Complete initial qualification studies of advanced materials for high-temperature service and provide recommendations for further studies for all advanced reactor concepts

- Provide interim design basis for existing Gen IV materials in database

- Continue population of materials database on advanced materials and new data developed in the Gen IV Program by U.S. and foreign partners

- Evaluate the web-accessible Gen IV Materials Handbook for new user requirements for functionality enhancement and advanced customization

- Provide interim constitutive equations for Alloy 617.

- $\quad$ Provide initial report on creep-fatigue modeling compared with test results of Alloy 617 and Alloy 230.

- Prepare interim report on atomistic mechanisms in support of advanced micromechanical models for predicting mechanical properties of structural materials.

- Prepare updated, status report on integrated R\&D plan for assessment and selection of crosscutting candidate materials for high-temperature and radiation service in Gen IV reactor systems.

FY 2010

- Complete selection of primary RPV candidate materials based on literature reviews and screening irradiation experiments.

- Complete low-dose irradiation experiments and PIE of advanced materials for reactor internals

- In conjunction with microstructure and modeling task, design special materials experiments to examine effects of high dose rate-high temperature irradiations for SCWR, GFR and LFR conditions

- Continue qualification testing of advanced materials (such as ODS etc.) for hightemperature service for all advanced reactor concepts

- Continue population of materials database on from advanced materials and new data developed in the Gen IV Program by U.S. and foreign partners

- Continue functionality enhancement and advanced customization of web-accessible Gen IV Materials Handbook

- Prepare report on results of comprehensive modeling of radiation-induced microstructural evolution in the primary Gen IV candidate structural materials, identify areas for further model development.

- Provide interim constitutive equations for Alloy 230.

- Refurbish a biaxial test machine for testing and constitutive model development for Alloys 617 and 230, and Mod9Cr-1Mo.

- Initiate creep-fatigue interaction life prediction modeling.

- Prepare updated, status report on integrated R\&D plan for assessment and selection of crosscutting candidate materials for high-temperature and radiation service in Gen IV reactor systems. 
FY 2011

- Prepare report on scoping studies of low-dose irradiations of commercial, nearcommercial, and advanced materials for radiation service

- Complete PIE for low-dose irradiations experiments of advanced materials for reactor internals

- In collaboration with microstructure and modeling task, perform advanced microstructural analysis and property measurements to examine effects of low dose rate-high temperature irradiations

- Continue qualification testing of advanced materials (such as alloy 214) for hightemperature service for all advanced reactor concepts

- Provide revised design basis for Gen IV materials in database

- Continue population of materials database on from advanced materials and new data developed in the Gen IV Program by U.S. and foreign partners

- Evaluate the web-accessible Gen IV Materials Handbook for new user requirements for functionality enhancement and advanced customization

- Prepare detailed interim report on integrated models for assessing radiation-induced and time-dependent, high-temperature changes in Gen IV candidate structural materials.

- Initiate biaxial testing and constitutive model development for Alloys 617 and 230, and Mod9Cr-1Mo.

- Initiate creep-fatigue interaction life prediction modeling.

- Prepare updated, status report on integrated R\&D plan for assessment and selection of crosscutting candidate materials for high-temperature and radiation service in Gen IV reactor systems.

FY 2012

- Complete initial high-dose irradiation experiments of advanced materials for reactor internals

- Complete preliminary assessment of candidate materials for radiation service for high temperature reactors and provide input to remaining reactor concepts regarding establishing detailed plans to meet their needs

- Complete designs of irradiation capsules for GFR, LFR, and SCWR

- Continue population of materials database on from advanced materials and new data developed in the Gen IV Program by U.S. and foreign partners

- Continue assessment mechanical properties of special and advanced materials

- Continue functionality enhancement and advanced customization of web-accessible Gen IV Materials Handbook

- Prepare detailed interim report ranking candidate Gen-IV structural materials based on predictions of comprehensive microstructural models.

- Provide interim and final reports on cree-fatigue modeling compared with test results for Alloy 617 and Alloy 230. 
- Prepare updated, status report on integrated R\&D plan for assessment and selection of crosscutting candidate materials for high-temperature and radiation service in Gen IV reactor systems.

FY 2013

- Prepare reports on scoping irradiations of advanced materials for reactor internals

- In collaboration with microstructure and modeling task, perform advanced microstructural analysis to examine effects of high dose rate-high temperature irradiations for SCWR, GFR and LFR conditions

- Provide final design basis for Gen IV materials in database

- Continue population of materials database on from advanced materials and new data developed in the Gen IV Program by U.S. and foreign partners

- Evaluate the web-accessible Gen IV Materials Handbook for new user requirements for functionality enhancement and advanced customization

- Provide recommendations for further studies for all advanced reactor concepts

- Develop, design, build, conduct, and compare structural features and component testing results to predicted behavior for validation of very high temperature structural design methodology.

- Prepare final report on model-based analysis of formation and stability of radiationinduced or enhanced phase stability in irradiated alloys, including oxide clusters in ODS alloys.

- Prepare updated, status report on integrated R\&D plan for assessment and selection of crosscutting candidate materials for high-temperature and radiation service in Gen IV reactor systems.

FY 2014

- Complete high dose scoping irradiations of advanced materials for reactor internals

- Continue high dose irradiations of candidate advanced materials for internals radiation service and provide recommendations for further studies for all advanced reactor concepts

- Prepare final report on micromechanical models, including their atomistic basis, used to predict relationship between microstructure and mechanical properties in structural materials planned for use in Gen IV reactor program.

- Prepare updated, status report on integrated R\&D plan for assessment and selection of crosscutting candidate materials for high-temperature and radiation service in Gen IV reactor systems.

FY 2015

- Initiate high dose irradiations of candidate advanced materials for internals radiation service

- Prepare final report on integrated models for assessing radiation-induced and timedependent, high-temperature changes in Gen IV candidate structural materials and provide recommendations for any further studies required to refine and validate the models in support of Gen IV reactor operations.

- Provide final constitutive models for Alloys 617 and 230, and Mod9Cr-1Mo. 
- Resolve identified shortcomings, issues, and regulatory concerns in high-temperature structural design methodology.

- Prepare updated, status report on integrated R\&D plan for assessment and selection of crosscutting candidate materials for high-temperature and radiation service in Gen IV reactor systems.

\section{References}

[4.1] R. K. Nanstad, L. K. Mansur, and A. F. Rowcliffe, "Plan for Qualification of Materials for Radiation Service Generation IV Reactor Materials Program," August 2004.

[4.2] L. K. Mansur, R. K. Nanstad, A. F. Rowcliffe, and R. L. Klueh, "Survey of Metallic Materials for Irradiated Service in Generation IV Reactor Internals and Pressure Vessels," ORNL/TM-2005/519, August 2005 (Draft).

[4.3] P. Rittenhouse and W. Ren, "Gen IV Materials Handbook Implementation Plan," ORNL/TM-2005/77, March 2005.

[4.4] P. Rittenhouse and W. Ren, "Initial Development of the Gen IV Materials Handbook," ORNL-GEN4/LTR-05-012, September 2005 (Draft).

[4.5] W. Ren and R. W. Swindeman, "High Temperature Metallic Materials Test Plan for Next Generation Nuclear Plant," Rev. 0, September 2004 (Draft).

[4.6] W. Ren and R. W. Swindeman, "Initiation of Scoping Tests to Provide Time-Dependent Input for HTDM Constitutive Equation Development," ORNL-GEN4/LTR-05-006, August 2005 (Draft).

[4.7] R. E. Stoller and L. K. Mansur, "Modeling and Microstructural Analysis: Needs and Requirements for Generation IV Fission Reactors," ORNL/TM-2003-242, September 2003 (Draft).

[4.8] R. E. Stoller and L. K. Mansur, "An Assessment of Radiation Damage Models and Methods," ORNL/TM-2005/506, May 2005.

[4.9] R. E. Stoller, "Preliminary Assessment of Required Modeling in Oxide Dispersion Strengthened Steels for Gen-IV Applications," ORNL/GEN4/LT-05-015, September 2005.

[4.10] J. M. Corum and T. E. McGreevy, "R\&D Plan for Development of High-Temperature Structural Design Technology for Generation IV Reactor Systems," September 2004, (Draft).

[4.11] T. E. McGreevy, D. L. Marriott, and P. Carter, "High-Temperature Design Methods Development Advances for 617: Status and Plans," ORNL/TM-2005/515, July 2005 (Draft).

[4.12] 2001 ASME Boiler and Pressure Vessel Code, Sect. III, Subsect. NH, Rules for Construction of Nuclear Facility Components, Class I Components in Elevated Temperature Service, Am. Soc. of Mechanical Engineers. 


\subsection{GEN IV MATERIALS FUNDING REQUIREMENTS}

Funding requirements for the Gen IV Materials Program, including reactor-specific and crosscutting activities have been estimated [5.1], but significantly exceed anticipated available long-term resources, which at this time are not well defined. Hence, only funding levels for the various materials activities actually identified for FY06 has been used as a basis for the R\&D activities described in this document. The basis for the FY06 materials R\&D is provided below. Additional information on long-term funding profiles will be included in future revisions of this document.

Table 45. FY06 Funding for Gen IV Reactor Materials R\&D (K\$)

\begin{tabular}{|lr|}
\hline NGNP Materials & \\
Graphite & 2845 \\
High Temperature Design Methodology & 1035 \\
Code \& Standards & 518 \\
Environmental Testing \& Aging & 697 \\
RPV Irradiation Facility & 250 \\
Structural Composites & 1625 \\
Administration & 530 \\
Total & 7500 \\
\hline SCWR Materials & \\
Materials Compatibility & 400 \\
Total & 400 \\
\hline GFR Materials & 300 \\
Irradiation Effects & 130 \\
High Temperature Materials & 430 \\
Total & \\
\hline LFR Materials & 650 \\
Materials Compatibility & 100 \\
Test Loop Design & 750 \\
Total & 320 \\
\hline Crosscutting Materials & 135 \\
Materials for Radiation Service & 525 \\
Materials for High Temperature Service & 2000 \\
Microstructural Analysis and Modeling & \\
High Temperature Design Methodology & 575 \\
System Specific Materials & \\
Materials Program Management & \\
Total & \\
\hline & \\
\hline
\end{tabular}

[5.1] Updated ORNL/TM2003/244/R1 "Generation IV Reactors Integrated Materials Plan," Revision 1, W. R. Corwin, August 31, 2004 